\title{
WestVirginiaUniversity
}

THE RESEARCH REPOSITORY @ WVU

Graduate Theses, Dissertations, and Problem Reports

2004

\section{Load-based energy savings in three-phase squirrel cage induction motors}

Subodh Chaudhari

West Virginia University

Follow this and additional works at: https://researchrepository.wvu.edu/etd

\section{Recommended Citation}

Chaudhari, Subodh, "Load-based energy savings in three-phase squirrel cage induction motors" (2004). Graduate Theses, Dissertations, and Problem Reports. 1530.

https://researchrepository.wvu.edu/etd/1530

This Thesis is protected by copyright and/or related rights. It has been brought to you by the The Research Repository @ WVU with permission from the rights-holder(s). You are free to use this Thesis in any way that is permitted by the copyright and related rights legislation that applies to your use. For other uses you must obtain permission from the rights-holder(s) directly, unless additional rights are indicated by a Creative Commons license in the record and/ or on the work itself. This Thesis has been accepted for inclusion in WVU Graduate Theses, Dissertations, and Problem Reports collection by an authorized administrator of The Research Repository @ WVU. For more information, please contact researchrepository@mail.wvu.edu. 


\title{
Load Based Energy Savings in Three Phase Squirrel Cage Induction Motors
}

\author{
Subodh Chaudhari
}

Thesis submitted to the

College of Engineering and Mineral Resources

At West Virginia University

In partial fulfillment of the requirements

For the degree of

\author{
Master of Science \\ In \\ Industrial Engineering \\ B. Gopalakrishnan, Ph.D., P.E., CEM Chair \\ Ralph Plummer, Ph.D., P.E. \\ Parviz Famouri, Ph.D.
}

Department of Industrial and Management Systems

Engineering

\section{Morgantown, West Virginia \\ 2004}

Keywords: Induction Motors, Load Estimation, Slip Method, Input Power Measurement, Motor Efficiency, Equivalent Circuit Parameters, Energy Savings 


\section{ABSTRACT \\ Load Based Energy Savings in Three Phase Squirrel Cage Induction Motors}

\section{Subodh Chaudhari}

\section{Chair Dr. B. Gopalakrishnan}

Energy is an extremely valuable resource which should be used carefully. After realizing this in the 1990's DOE started various energy efficiency measures in order to reduce the energy consumed by US industry. Motors use almost 50 percent of the electricity in the United States. If motor efficiency could be increased then energy consumption could be reduced. There have been efforts to increase motor efficiency over past decade which lead to development of premium efficiency motors. Designed motor efficiency is normally above 90 percent so motors do not waste energy. However, motor efficiency decreases when load factor is less than 50 percent. Therefore measures need to be taken to make the motor sizes properly fit the application load profile so as to improve operational efficiency. Based on plant assessment experience plant personnel have very limited data on motor loading. The decisions concerning motor sizing are usually based on judgment or the slip method. Accurate load determination methods such as input power measurement involve working around high voltages hence have safety issues. These methods are time consuming and expensive. The purpose of this research was to develop a method of sizing electric motors which is simple to use, economical, safe and accurate. This research collected data during fifteen energy assessments conducted at variety of facilities using the motor load monitoring method as well as by using a stroboscope method. A statistical analysis of the data was conducted to determine if a relationship exists between slip method and input power measurement load factors, so that prediction of accurate load factor can be made based on the load factor obtained by slip method. The model was built and validated based on mathematical and electrical engineering principles. 


\section{AKNOWLEDGEMENT}

I would like to wholeheartedly thank my advisor Dr. B. Gopalakrishnan and Dr. P. Famouri for their continued support, guidance and encouragement during the course of this research work. I also wish to thank Dr. Ralph Plummer for his advice and support.

Above all, I wish to thank god, my parents, my brother and all my friends for their constant support and blessings and enabling my success and happiness in all my pursuits and endeavors in life.

Lastly, I would like to again thank Dr. B. Gopalakrishnan, who encouraged me to

present a paper on part of this work in SPIE (International Society for Optical Engineering) conference. 


\section{Table of Contents}

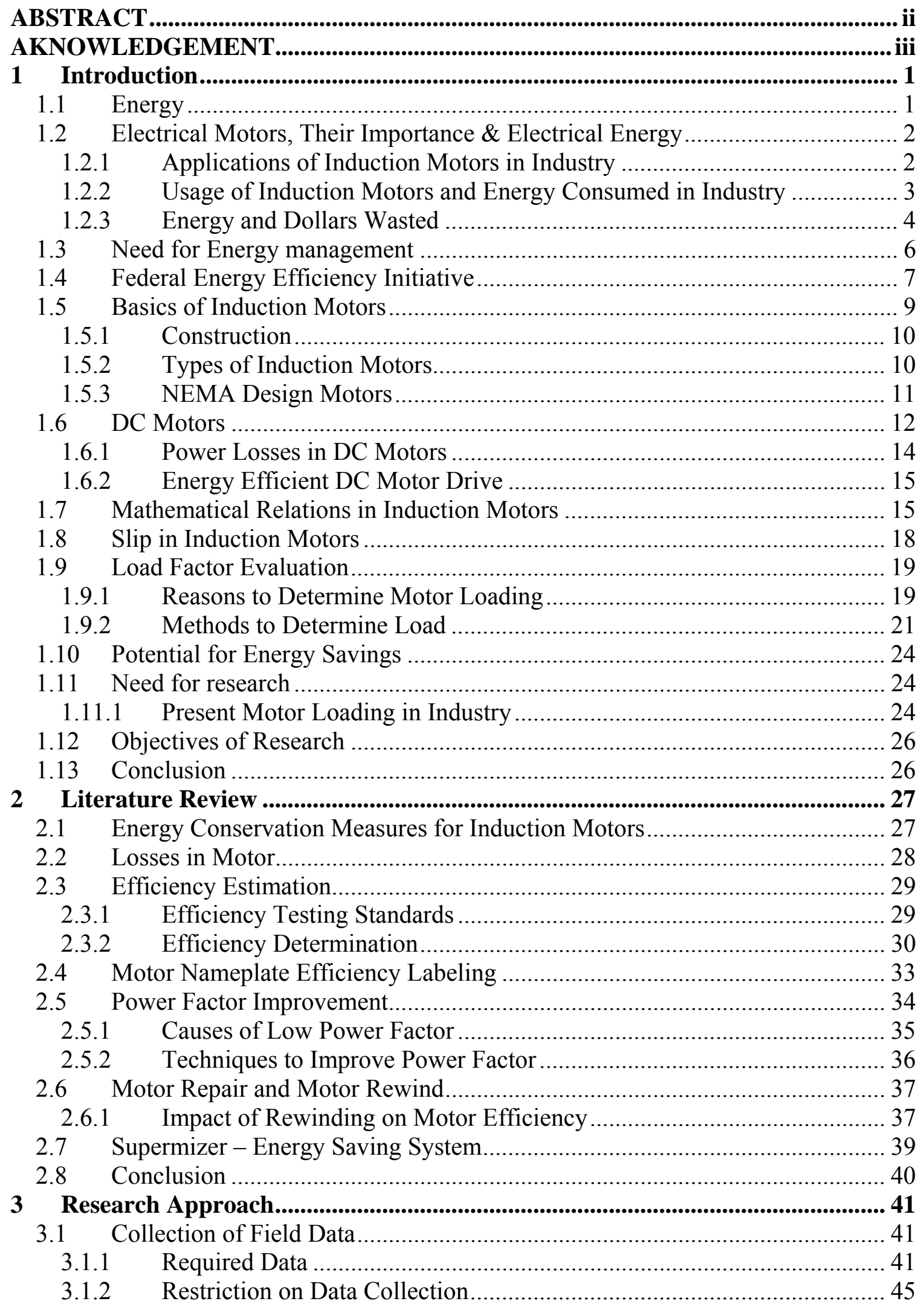


3.1.3 Procedure for Data Collection ………………........................................ 46

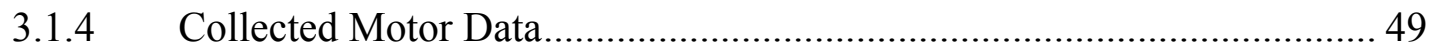

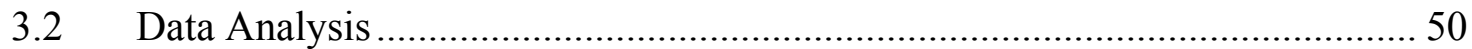

3.2.1 Load Factor Evaluation by Slip Method ..................................................50

3.2.2 Load Factor Evaluation by Voltage Corrected Slip Method ..................... 50

3.2.3 Load Factor Evaluation by Line Current Measurement Method ............... 51

3.2.4 Load Factor Evaluation by Input Power Measurement ............................. 51

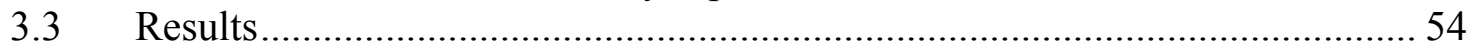

3.3.1 Motor Loading In the Study Carried Out In the Field .............................. 54

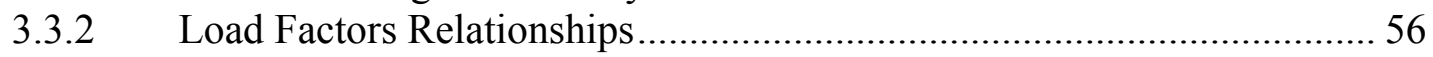

3.3.3 Motor Energy \& Demand Savings................................................................... 60

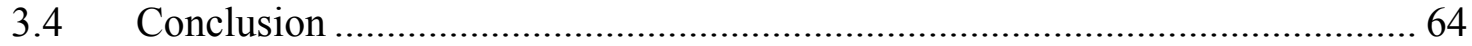

$4 \quad$ Statistical Analysis and Model Development .............................................................. 65

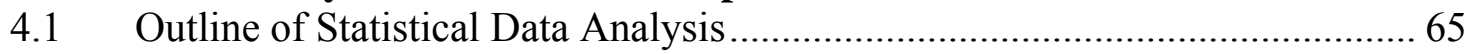

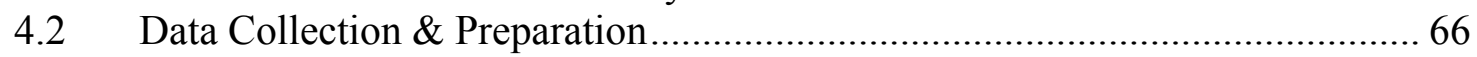

4.2.1 Elimination of Unnecessary Variables...................................................... 66

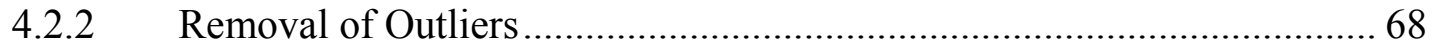

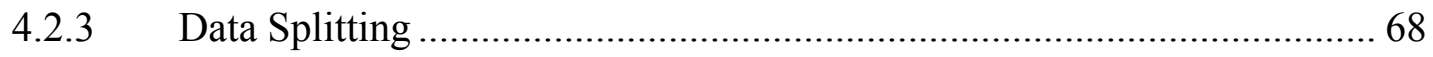

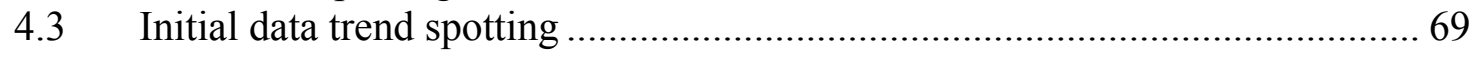

4.4 Model Building ................................................................................... 71

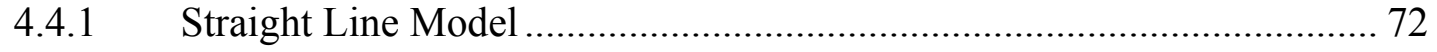

4.4.2 Polynomial Model......................................................................... 75

4.4.3 Multiple Regression Model................................................................. 78

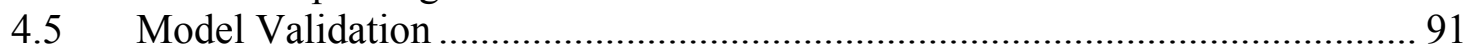

4.6 Summary \& Conclusion................................................................................. 93

5 Load Factor Discrepancies and Other Considerations ........................................... 94

5.1 Reasons for under-loaded motors .............................................................. 94

5.1.1 Application Need .............................................................................. 94

5.1.2 Purchasing practices............................................................................... 94

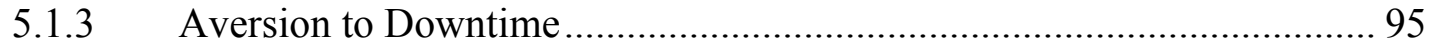

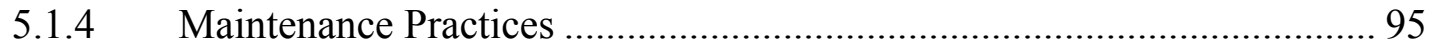

5.1.5 Downsized Production........................................................................... 96

5.1.6 Allowance for load growth .................................................................... 96

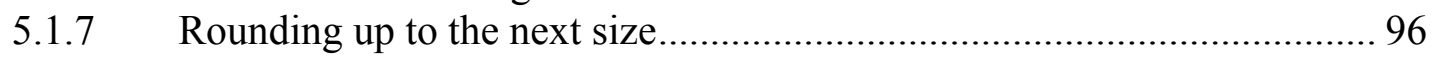

5.2 Adjustable Speed Drives (ASD) …………................................................ 97

5.2.1 Types of Adjustable Speed Drives........................................................... 98

5.2.2 Benefits of Using ASDs................................................................... 99

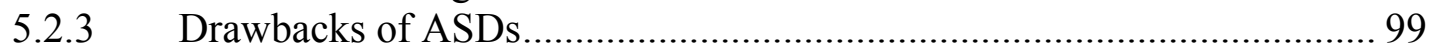

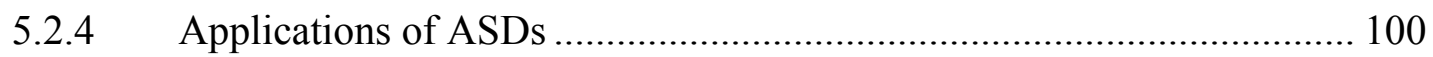

5.3 Discrepancies in Load Factors ...................................................................... 101

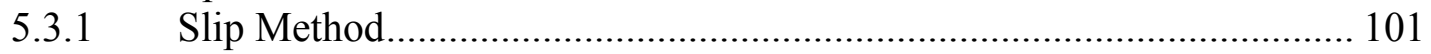

5.3.2 Voltage Corrected Slip Method .............................................................. 102

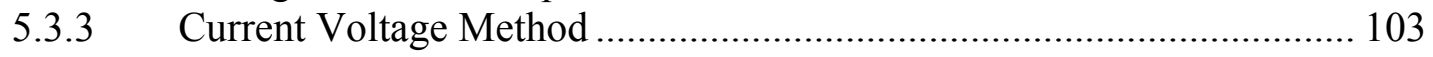

5.4 Reasons for Load Factor Discrepancies.......................................................... 105

5.5 MATLAB GUI for torque-speed curve generation ......................................... 106

5.6 Validation of Statistical Model Built Considering Losses in Motor............... 109 
5.7 Summary \& Conclusion.......................................................................... 113

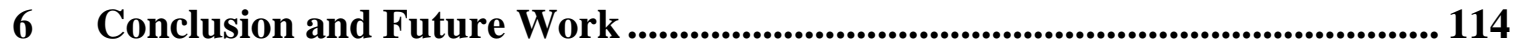

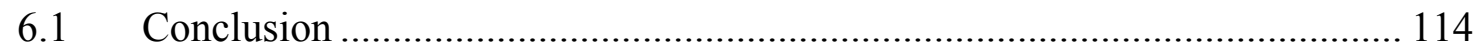

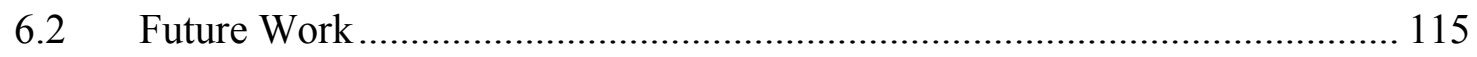

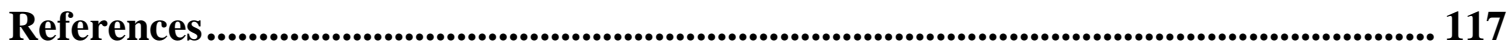

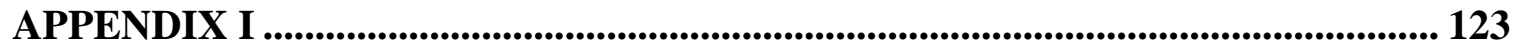

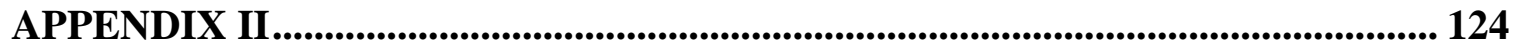

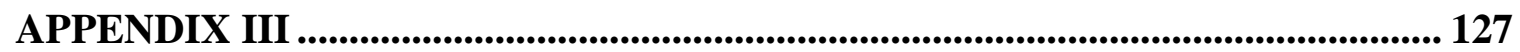

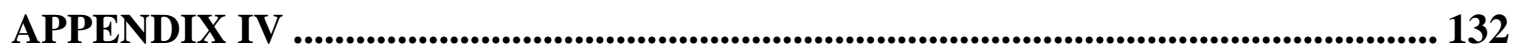

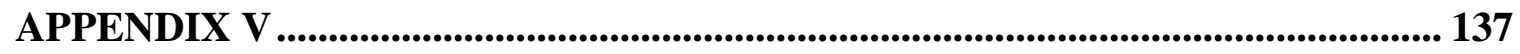




\section{List of Figures}

Figure 1.1 Energy Consumed by Oversized Motor vs. Properly Loaded Motor ................ 5

Figure 1.2 Cost Lost Due to Oversized Motor Over 10 Year Period ................................ 6

Figure 1.3 Relative shares of electrical input used by different motor types .................... 9

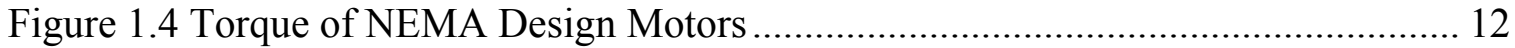

Figure 1.5 Optimal Efficiency Obtained by Controlling Field Current for Different Operating Points ................................................................................. 14

Figure 1.6 Efficiency and Power Factor Variation with Part Load on Motor .................. 20

Figure 1.7 Percentage of Under-Loaded Motors in US industry ................................. 25

Figure 2.1 Distribution of Induction Motor Losses.................................................. 28

Figure 2.2 Six Impedance per Phase Equivalent Circuit of an Induction Motor .............. 32

Figure 2.3 Power Factor Triangle............................................................................... 34

Figure 2.4 Power Factor Variation with Load...................................................... 35

Figure 2.5 Capacitor Principle for Increasing Power Factor...................................... 36

Figure 2.6 Conceptual Configuration Diagram of Supermizer .................................... 39

Figure 3.1 Principle of Stroboscope Speed Measurement ............................................. 47

Figure 3.2 3 Phase 3 wire Delta Connection Arrangement for Amprobe ........................ 48

Figure 3.3 DM II Pro 3 Phase 3 wire (Phase to Phase Measurement) Connections

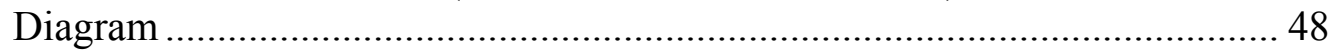

Figure 3.4 Percentage of Motors According to Load Factor.......................................... 54

Figure 3.5 Overall distribution of load factors in the tested motors............................... 55

Figure 3.6 Slip Load Factor Vs Power Measurement Load Factor................................. 57

Figure 3.7 Relationship between voltage corrected slip method LF and I/P power measurement LF .................................................................................. 58

Figure 3.8 Relationship between LF by line current method and LF power measurement

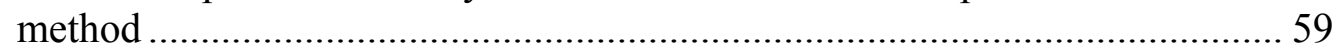

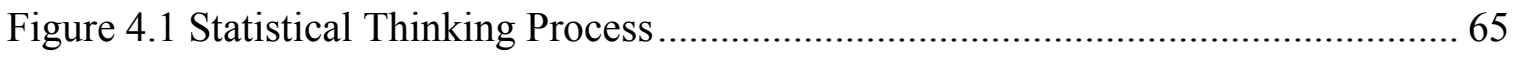

Figure 4.3 Scatter matrix of considered variables for initial trend spotting .................... 69

Figure 4.4 Scatter Matrix of Significant Variables and Interactions.............................. 70

Figure 4.5 SAS Output for Straight Line Model ......................................................... 72

Figure 4.6 Straight Line Fit Model for I/P Power Measurement Load ............................ 73

Figure 4.7 Residual vs Predicted for Straight-Line Fit Model ........................................ 73

Figure 4.8 Residual vs LF_S for Straight Line Fit Model............................................ 74

Figure 4.9 Normal Probability Plot for Straight-line Fit Model.................................... 74

Figure 4.10 Normal Probability Plot of LF_S ...................................................... 75

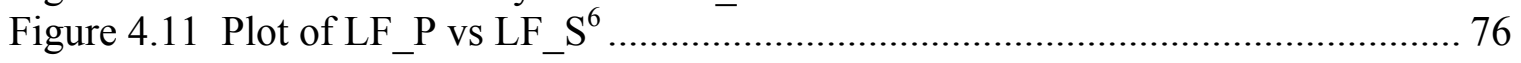

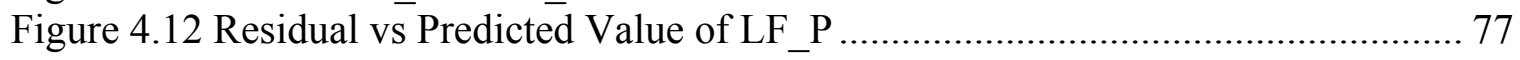

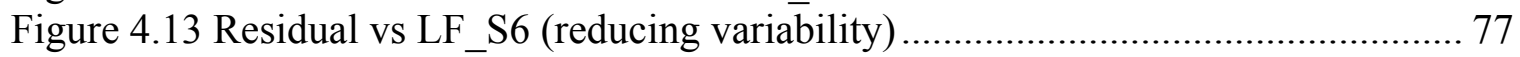

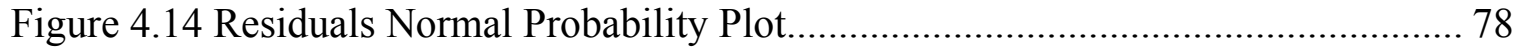

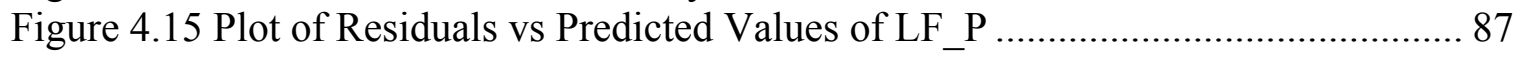

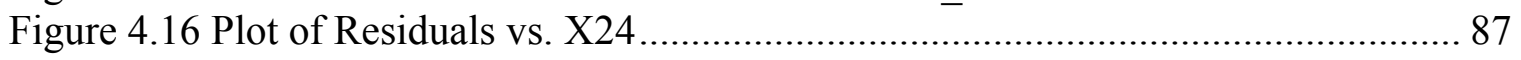

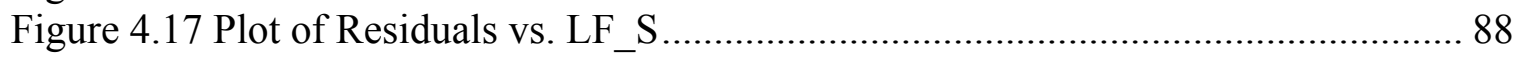

Figure 4.18 Normal Probability Plot for Residuals .................................................... 88

Figure 4.19 Response Surface for Model Fitted to Data................................................. 91

Figure 5.1 Schematic of Adjustable Speed Drive with Feedback Loop .......................... 97

Figure 5.2 ASD, Motor and System Efficiency vs. Partial Load .................................. 100 
Figure 5.3 Discrepancy in Load Factors Obtained by Slip Method and I/P Power measurement Method

Figure 5.4 Load factor discrepancy for slip method vs. Motor HP

Figure 5.5 Discrepancies in Load Factors obtained by Power Measurement and Voltage

Corrected Slip

Figure 5.6 Load factor discrepancy for voltage corrected slip method vs. Motor HP .... 103

Figure 5.7 Discrepancies in Load Factors obtained by Power Measurement and Current

Voltage Method....

Figure 5.8 Load factor Discrepancy for Current Voltage Method vs. Motor HP

Figure 5.9 Load Factor Discrepancies vs. HP of Motors

Figure 5.10 Input Screen for MATLAB GUI to Calculate Performance of Induction Motor

Figure 5.11 Equivalent Circuit Produced by MATLAB GUI.

Figure 5.12 Information Screen - Formulae Used for Calculation of Performance for

Motor 108

Figure 5.13 Output Generated by Designed GUI and Operating Characteristics of Motor

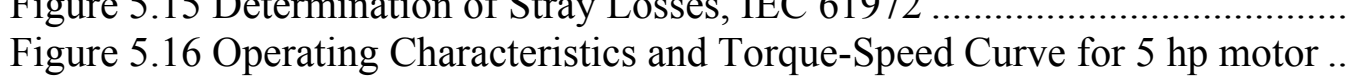

Figure 6.1 Derating Factor Due to Unbalance in Voltage. 


\section{List of Tables}

Table 1.1 Drivepower's share of US electricity use, by end-use....................................... 3

Table 1.2 Sample loading data of a motor tested in field and projected savings................ 4

Table 1.3 Energy consumed by Oversized vs. Properly Loaded Motors and Costs ........... 5

Table 1.4 Characteristics of NEMA Design motors ......................................................... 12

Table 1.5 Synchronous Speeds According to Number of Poles ……………………...... 23

Table 1.6 Motor Loading by Horsepower in US (Source X-energy 1998) ...................... 25

Table 2.1 Different Standards for Efficiency Measurement of Induction Motor ............. 30

Table 2.2 NEMA Allowable Tolerances on Some of Motor Nameplate Parameters....... 34

Table 2.3 Empirical Studies of Efficiency Loss During Motor Repair ............................ 38

Table 2.4 Efficiency Improvement Techniques While Rewinding Motor [13]................ 39

Table 3.1 Parameters Selected for Field Data Collection ................................................. 44

Table 3.2 Fields of the DM II Pro Recorded Data......................................................... 49

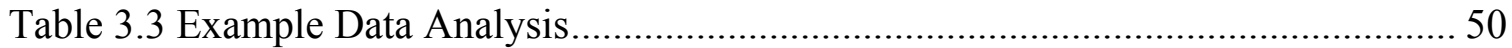

Table 3.4 Load Factors by Different Methods for recorded motors ................................. 52

Table 3.5 Data Found on Motor Loading In Field Energy Assessments.......................... 54

Table 3.6 Load Factors of the Motors Examined ........................................................... 55

Table 3.7 Relationships between load factors and their coefficients of regression .......... 59

Table 3.8 Motor Considered for Energy and Demand Savings Analysis ......................... 61

Table 3.9 Cost Data Used to Calculate Energy Savings .................................................... 61

Table 3.10 Proposed Configuration vs. Original Configuration of Motor and Savings

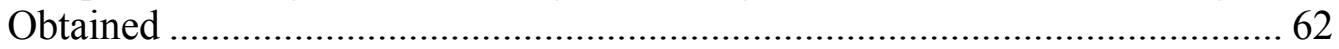

Table 4.1 Outliers removed in data preparation step from collected data .........................6 68

Table 4.2 ANOVA for Polynomial Model Fitted to LF_S vs LF_P Data ........................ 75

Table 4.3 Fit Statistics for Polynomial Model ............................................................. 76

Table 4.4 Parameter Estimated of Polynomial Model fitted............................................. 76

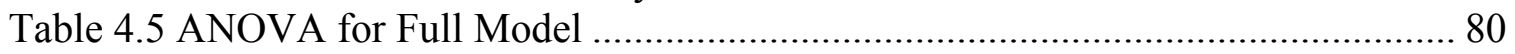

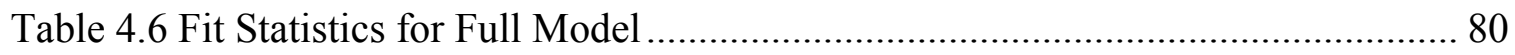

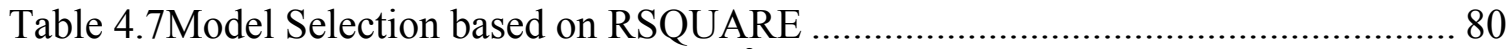

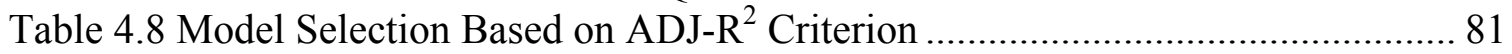

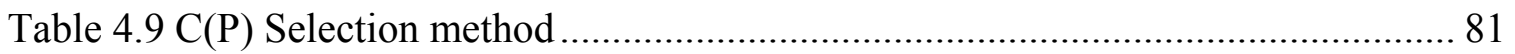

Table 4.10 ANOVA of Final Step of Forward Selection Method ..................................... 82

Table 4.11 Parameter Estimates Obtained with Forward Selection .................................. 82

Table 4.12 Summary of Forward Selection ................................................................. 82

Table 4.13 ANOVA of Final Step of Backward Elimination........................................... 83

Table 4.14 Parameter Estimates for Backward Elimination Method ................................. 83

Table 4.15 Summary of Backward Elimination …………………………………....... 83

Table 4.16 Stepwise ANOVA and Parameter Estimates ................................................. 84

Table 4.17 Summary of Stepwise Selection Method.................................................... 85

Table 4.18 Fit Statistics for Stepwise Model ............................................................... 85

Table 4.19 Covariance and Correlation of Estimates ..................................................... 85

Table 4.20 Consistent Covariance of Estimates ……………....................................... 86

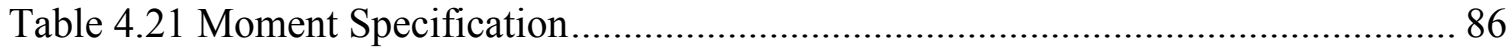

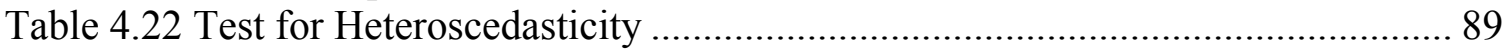

Table 4.23 VIFs of Predictor Variables ....................................................................... 90 
Table 4.24 Summary of Models fitted for input power measurement load and slip method

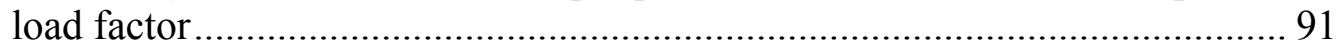

Table 4.25 Validation of Selected Model ……………............................................... 92 


\section{Chapter 1}

\section{Introduction}

\subsection{Energy}

Energy plays a vital role in $21^{\text {st }}$ century day-to-day life. It was in mid 1800 s when Benjamin Franklin demonstrated that lightning was a form of electricity. Since the inception of the first commercial power station in 1879 in San Francisco the use of electricity has continually increased. World energy consumption is expected to increase $40 \%$ to $50 \%$ by the year 2010 , and the global mix of fuels is projected to remain substantially the same as today. Some of the interesting facts about energy are summarized below [31].

- Worldwide, some 2 billion people are currently without electricity.

- In 1997, U.S. residents consumed an average of 12,133 kilowatt-hours of electricity each, almost nine times greater than the average for the rest of the world.

- Though accounting for only 4-5 percent of the world's population, Americans consume almost 30 percent of the world's energy.

- The United States spends about $\$ 440$ billion annually for energy. Energy costs U.S. consumers $\$ 200$ billion and U.S. manufacturers $\$ 100$ billion annually.

Energy has very significant impact on the operation of the industrialized US economy. In recent years, the American consumers have spent almost a half trillion dollars a year on energy which is consumed in four broad sectors, namely residential, commercial, industrial and transportation. Industry is historically the largest consuming sector of the economy with fluctuating trends as compared with the smooth trends in other sectors [24]. Industry ranks highest among the electrical energy consumers as well. Of the electrical energy that is consumed by industry more than $50 \%$ is used to drive electrical motors. Almost $65 \%$ of this energy is used to drive AC induction motors. Accounting for such a high share of energy consumption, motors draw special attention from an energy savings stand point, whether it is on plant level or national level. The 
following sections discuss importance, usage, applications and other aspects of induction motors.

\subsection{Electrical Motors, Their Importance \& Electrical Energy}

\subsubsection{Applications of Induction Motors in Industry}

The typical uses of the squirrel cage induction motors are listed here according to the design type.

\section{Single Phase Motors}

Capacitor Start/Induction Run

The design is a heavy-duty unit, which has approximately $300 \%$ (of full load) starting torque. Common applications include compressors, pumps, conveyors and other "hard-to-start" applications [1]. Capacitor Start/Capacitor Run

This type of design has lower full-load amps as a result of the run capacitor and is consequently used on mostly higher horsepower single-phase motors [1]. Permanent Split Capacitor (PSC)

A permanent Split Capacitor motor has low starting torque and low starting current. PSC motors are generally used on direct-drive fans and blowers. They can also be designed for higher starting torque and intermittent applications, where rapid reversing is desired.

Single phase motors are generally understood to have base performance worse than three phase motors. Another problem with efficiency in traditionally single-phase applications is that the speed of the machine is fixed, or perhaps very coarsely controlled through techniques like pole changing. The resulting efficiency is not optimal.

\section{Three Phase Motors}

NEMA (National Electrical Manufacturers Association) Design A

These motors are used in injection molding machines, where typically very high starting currents are required.

NEMA Design B

Fans, blowers, centrifugal pumps \& compressors, etc., where starting torque requirements are relatively low. 


\section{NEMA Design C}

Conveyors, stirring machines, crushers, agitators, reciprocating pumps etc., where starting under load is required.

\section{NEMA Design D}

These motors are used for high peak loads, loads with flywheels such as shears, elevators, extractors, winches, hoists, cranes oil well pumping \& wire drawing machines. NEMA Design E

These motors are used in low starting torque fans, where low starting torques usually are not a problem.

\subsubsection{Usage of Induction Motors and Energy Consumed in Industry}

Three phase induction motors are the motors most frequently encountered in industry. Their simple, rugged and easy to maintain construction has enabled them to be widely used in industry in almost all applications. These motors are also called workhorses of the industry. The induction motors are used widely in the industry as well as the home appliances.

Table 1.1 Drivepower's share of US electricity use, by end-use

\begin{tabular}{|c|c|c|}
\hline Energy Application & $\begin{array}{c}\text { \% of total US } \\
\text { electricity consumed } \\
\text { by the application }\end{array}$ & $\begin{array}{c}\text { \% consumed by } \\
\text { the motors in the } \\
\text { application }\end{array}$ \\
\hline Stand alone motors & 22.6 & 22.6 \\
\hline Space cooling and air handling & 12 & 11.4 \\
\hline Appliances & 12 & 7.5 \\
\hline Misc. plug loads & 11.5 & 2.3 \\
\hline Utilities' own use, railways, power authorities & 8 & 6.9 \\
\hline Space heating & 7 & 1.8 \\
\hline Lights & 15.5 & - \\
\hline Electrolysis and process heat & 6 & - \\
\hline Water heating & 5 & - \\
\hline Total & $\sim \mathbf{1 0 0} \%$ & $\mathbf{5 2 . 5 \%}$ \\
\hline
\end{tabular}


It is estimated that more than 2 billion electric motors were operating in the United States in 1997 [26]. Out of these 2 billion motors approximately 1.9 billions are fractional horsepower motors, 35 million are DC motors and 65 million are AC induction motors. The motors consume $1,851 \mathrm{TWh}$ of electricity annually out of which $78 \%$ goes for the AC induction motors [26]. The figures give us the idea about vast usage of AC induction motors in the industry. Table 1.1 presents data of electricity consumption of motors for year 1999. In US industrial process operations, over 13.5 million electric motors of $1 \mathrm{HP}$ or greater convert electricity into useful work. Industry spends over $\$ 33$ billion (US) annually for electricity dedicated to electric motor-driven systems [34].

\subsubsection{Energy and Dollars Wasted}

It is evident that a lot of energy and money is wasted due to under-loaded motors. A sample motor is chosen from the assessed motors to depict this fact. Table 1.2 shows the motor details of the current configuration and proposed configuration of the motor. It was $150 \mathrm{hp}$ motor installed on a milling machine, which was operating for 8,160 hours annually. The measured load factor (LF) was found to be $12 \%$. At such a low load factor as expected the efficiency of motor drops considerably. The efficiency was determine from Motor Master $+{ }^{\mathrm{TM}}$ software to be $10 \%$.

Table 1.2 Sample loading data of a motor tested in field and projected savings

\begin{tabular}{|c|c|c|c|c|c|c|c|c|c|c|c|c|}
\hline \multirow[b]{2}{*}{$\mathbf{0}$} & \multirow[b]{2}{*}{ Motor } & \multirow{2}{*}{$\begin{array}{c}\text { Hrs/ } \\
\text { Yr }\end{array}$} & \multicolumn{3}{|c|}{ Original Motor } & \multicolumn{3}{|c|}{ Proposed } & \multirow{2}{*}{$\begin{array}{c}\text { Saved } \\
\text { MMBtu/ } \\
\text { Yr }\end{array}$} & \multirow{2}{*}{$\begin{array}{c}\text { Savings } \\
\mathbf{\$} / \mathbf{Y r}\end{array}$} & \multirow[b]{2}{*}{ Premium } & \multirow{2}{*}{$\begin{array}{l}\text { Imp } \\
\text { Cost }\end{array}$} \\
\hline & & & $\begin{array}{l}\text { Size } \\
\text { (HP) }\end{array}$ & $\mathbf{L F}$ & Eff. & $\begin{array}{l}\begin{array}{l}\text { Size } \\
\text { (HP) }\end{array} \\
\end{array}$ & $\mathbf{L F}$ & Eff & & & & \\
\hline 1 & 60" Mill & 8160 & 150 & 0.12 & $10 \%$ & 25 & 0.72 & & ה & $\$ 78,690$ & $41,7>2$ & $\$ 1,082$ \\
\hline
\end{tabular}

Instead of this $150 \mathrm{hp}$ motor, a $25 \mathrm{hp}$ motor was suggested to be installed to more closely match the load profile. This motor would operate at $72 \%$ load and $80 \%$ efficiency as determined from MotorMaster $+{ }^{\mathrm{TM}}$. This saved 3,307 MMBtu annually for the facility or $\$ 78,690$ at electricity cost of $\$ 23.79 / \mathrm{MMBtu}$. The suggested motor of $25 \mathrm{hp}$ would cost $\$ 1,082$ to install (i.e. price of $25 \mathrm{hp}$ premium efficiency motor less the salvage value of $150 \mathrm{hp}$ motor, including labor to install $25 \mathrm{hp}$ motor). When a motor is under-loaded it tends to consume more energy since its efficiency drops. The $150 \mathrm{hp}$ motor if loaded $12 \%$ 
will consume 32,700 MMBtu more energy over its life of 10 years as shown in Figure 1.1 .

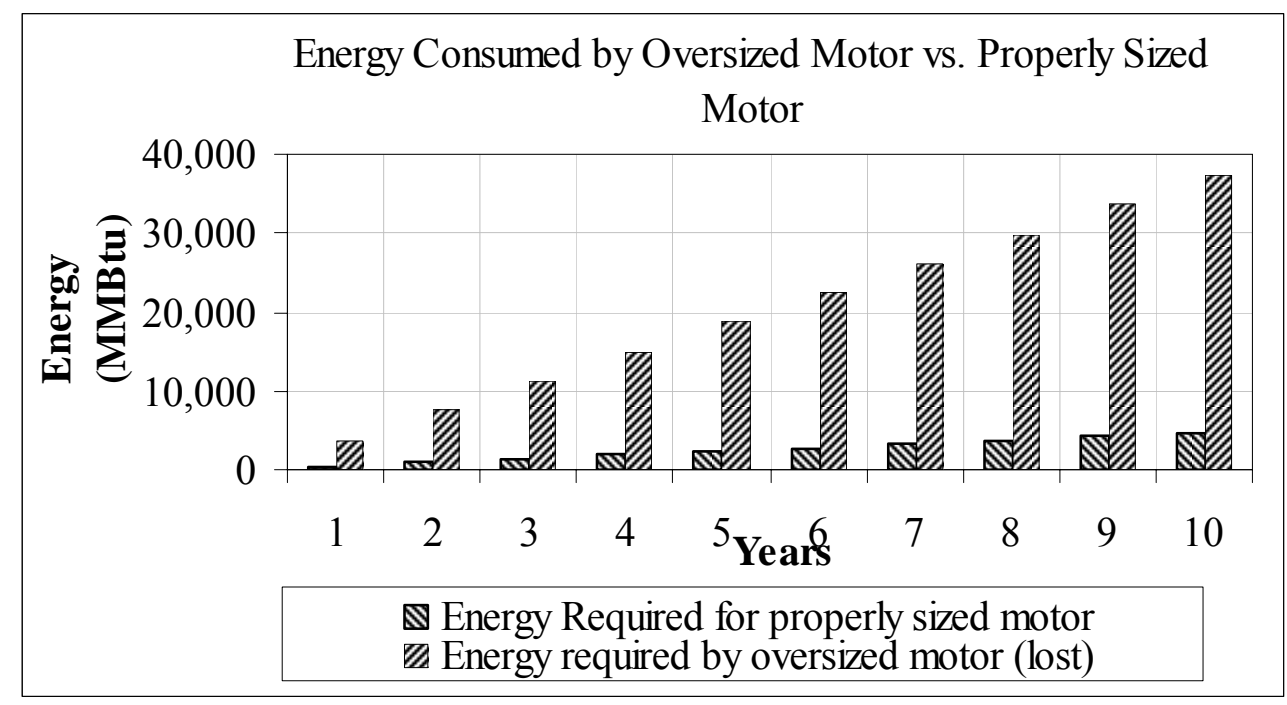

Figure 1.1 Energy Consumed by Oversized Motor vs. Properly Loaded Motor

The energy consumed by the properly loaded motor and the associated costs are presented in Table 1.3. The costs are calculated according to $\$ 23.79 / \mathrm{MMBtu}$ as per the assessed facility rate schedule. This cost comparison assumes the mill will always be loaded at $12 \%$ load factor for $150 \mathrm{hp}$ motor.

Table 1.3 Energy consumed by Oversized vs. Properly Loaded Motors and Costs

\begin{tabular}{|c|c|c|c|c|c|c|}
\hline \multirow[b]{2}{*}{ Year } & \multicolumn{2}{|c|}{ Energy consumed } & \multirow{2}{*}{$\begin{array}{c}\text { Energy } \\
\text { Saved }\end{array}$} & \multicolumn{2}{|c|}{ Cost of operating } & \multirow{2}{*}{ Lost Cost } \\
\hline & $\begin{array}{c}\text { Oversized } \\
\text { Motor }\end{array}$ & $\begin{array}{c}\text { Properly } \\
\text { Loaded } \\
\end{array}$ & & $\begin{array}{c}\text { Oversized } \\
\text { Motor }\end{array}$ & $\begin{array}{c}\text { Properly } \\
\text { Loaded } \\
\end{array}$ & \\
\hline 1 & $3,738.1$ & 467.3 & $3,270.8$ & $\$ 88,929$ & $\$ 11,116$ & $\$ 77,813$ \\
\hline 2 & $7,476.2$ & 934.5 & $6,541.7$ & $\$ 177,859$ & $\$ 22,232$ & $\$ 155,626$ \\
\hline 3 & $11,214.3$ & $1,401.8$ & $9,812.5$ & $\$ 266,788$ & $\$ 33,349$ & $\$ 233,439$ \\
\hline 4 & $14,952.4$ & $1,869.1$ & $13,083.3$ & $\$ 355,718$ & $\$ 44,465$ & $\$ 311,252$ \\
\hline 5 & $18,690.5$ & $2,336.3$ & $16,354.2$ & $\$ 444,647$ & $\$ 55,582$ & $\$ 389,065$ \\
\hline 6 & $22,428.6$ & $2,803.6$ & $19,625.0$ & $\$ 533,576$ & $\$ 66,698$ & $\$ 466,879$ \\
\hline 7 & $26,166.7$ & $3,270.9$ & $22,895.8$ & $\$ 622,506$ & $\$ 77,814$ & $\$ 544,692$ \\
\hline 8 & $29,904.8$ & $3,738.2$ & $26,166.7$ & $\$ 711,435$ & $\$ 88,931$ & $\$ 622,505$ \\
\hline 9 & $33,642.9$ & $4,205.4$ & $29,437.5$ & $\$ 800,365$ & $\$ 100,047$ & $\$ 700,318$ \\
\hline 10 & $37,381.0$ & $4,672.7$ & $32,708.3$ & $\$ 889,294$ & $\$ 111,163$ & $\$ 778,131$ \\
\hline
\end{tabular}


Figure 1.2 shows how dollars are wasted over a 10 year period for the motor considered. It can be seen that almost $\$ 778,131$ are wasted.

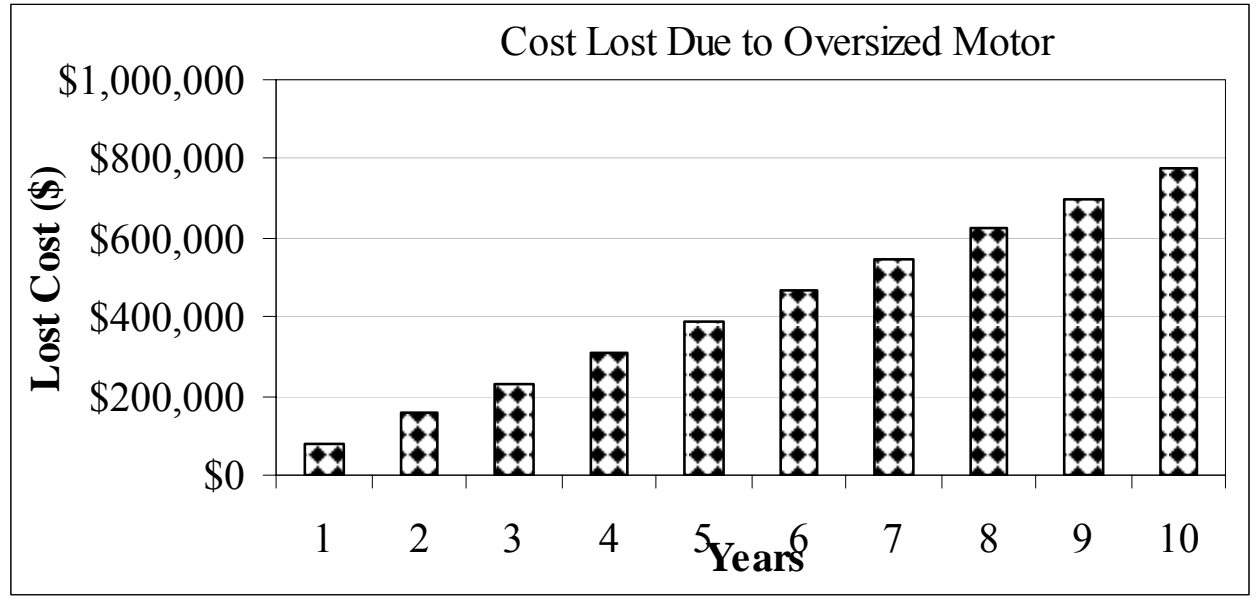

Figure 1.2 Cost Lost Due to Oversized Motor Over 10 Year Period

\subsection{Need for Energy management}

The best route to sustainable development of the energy system is a "low energy path", which means that nations should direct their efforts "to produce the same levels of energy services with as little as half the primary energy currently consumed" [31]. The improvement of energy efficiency is now generally viewed as the most important option to reduce the negative impacts of the use of energy and/or fossil fuels in the near term. Energy efficiency is defined as decreasing the use of energy per energy service without substantially affecting the level of these services [31].

Several interesting energy efficiency facts are presented below:

- A decrease of only $1 \%$ in industrial energy use would save the equivalent of about 55 million barrels of oil per year, worth about $\$ 1$ billion.

- By taking appropriate energy-saving measures, by 2010 the United States can have an energy system that reduces costs by $\$ 530$ per household per year and reduces global warming pollutant emissions to 10 percent below 1990 levels.

Important areas that need to be given consideration in the context of industrial energy usage are [24]-

- Industrial energy usage patterns and future outlook 
- How the energy is used by industries

- Technologies to improve energy efficiency

- Corporate viewpoint on energy and various incentives offered.

Energy could be saved by the industries by adopting many energy efficient technologies and practices, both currently available and under development. A few of the cost effective methods to improve energy efficiency are the following [24].

- General housekeeping and maintenance programs

- Energy management and accounting program

- New and improved methods and procedures of production

- Product changes to save energy

\subsection{Federal Energy Efficiency Initiative}

Since the mid-1990s, manufacturing plants in the United States have undertaken measures to reduce energy consumption. One of the primary methods has been to increase the efficiency of motor systems. Though the saving opportunities for energy savings and cost savings are substantial from optimization and efficiency increase of the motor system, there are barriers to tapping these savings. The US Department of Energy's Office of Energy Efficiency and Renewable Energy (EERE) have encouraged energy saving efforts through its BestPractices program [17]. The utilities, government, non-profit agencies, and private industry commonly offer energy-saving programs, including programs to improve the efficiency of the motor systems. In the past, they have used a broad array of regulatory and voluntary mechanisms to promote energy-saving investments and actions that are in the public interest. These mechanisms include education and technical assistance programs, utility rebates and other demand-side interventions [26]. These initiatives are designed to

1. Stimulate the development and market introduction of new energy efficient models of motors

2. Strategically build the market share of these new products until they attain a niche position in the market and then, 
3. Change consumer purchasing practices in order to further expand the market adoption of these measures so that they reach mass market status and eventually become the common practice [26].

The Motor Challenge program operated by DOE works in almost every area related to motors including motor management and motor systems optimization. DOE's Office of Industrial Technologies created Motor Challenge in 1993 as a voluntary industry-government partnership. The primary goal of the program was to increase market penetration of the efficient motor systems by helping industry adopt systems approach to developing, buying and managing motor systems.

\section{Motor Master}

MotorMaster+4.0, software program is a result of federal initiative that analyzes motor and motor system efficiency. Designed for utility auditors, industrial plant energy coordinators, and consulting engineers, MotorMaster+4.0 is used to identify inefficient or oversized facility motors and compute the energy and demand savings associated with selection of an energy-efficient replacement model. MotorMaster+4.0 has expanded Inventory Management, Maintenance Logging, Lifecycle Costing, Savings Tracking and Trending functions, Conservation Analysis, Savings Evaluation, Energy Accounting, and Environmental Reporting Capabilities. Version 4.0 of MotorMaster+ was released in October 1998, but the program is updated continually. The latest update of the motors database was March 06, 2003. The MotorMaster+ 4.0 software program was developed by the Washington State University Cooperative Extension Energy Program (the Energy Program), and is funded by the U.S. Department of Energy (USDOE) via the Office of Industrial Technologies' Best Practices Program (formerly the Motor Challenge Program).

Other similar program by DOE and CEE is Motor Decisions Matter ${ }^{\mathrm{SM}}$. The goal of the program is to increase the demand for premium motors and quality motor repair services by promoting to decision makers the benefits of implementing the motor management plan. Also there are loan programs, rebate programs and tax credit programs available for promotion of the premium motors. While past and current program efforts have made significant progress, much more needs to be done [26]. Fundamental need is to properly understand the basics of the induction motors. 
Nicola Tesla invented the alternating current induction motor in 1888. From its inception its ease of manufacture and its power dominated the field of electromechanical energy conversion. Considering its universal use and application the power available from a given motor frame construction was increased from 7.5 Hp in 1900 to $100+\mathrm{Hp}$ by 1965 . Electric motors are rugged, reliable, and far more efficient than steam-powered equipment that motors have replaced over the past century [32]. A well designed and well-maintained electric motor can convert over $90 \%$ of its input energy into useful shaft power, 24 hours a day, for decades. The popularity of motors attests to their effectiveness. It is this popularity that makes electric motor systems such an important potential source of energy savings: because more than half of all electricity flows through them, even modest improvements in their design and operation can yield tremendous dividends [9]. A sizable percentage (15-25\%) of U.S. electricity can be saved by optimizing the performance of electric motors and their associated wiring, powerconditioning equipment, controls, and transmission components [6].

\subsection{Basics of Induction Motors}

Three phase induction motors is a "mature technology" [13]. Motors produce useful work by causing the shaft to rotate thus converting electrical energy into mechanical energy. There are three basic types of electric motors: AC induction or asynchronous, synchronous and DC motors. Figure 1.1 shows the relative shares of electrical input used by different motor types.

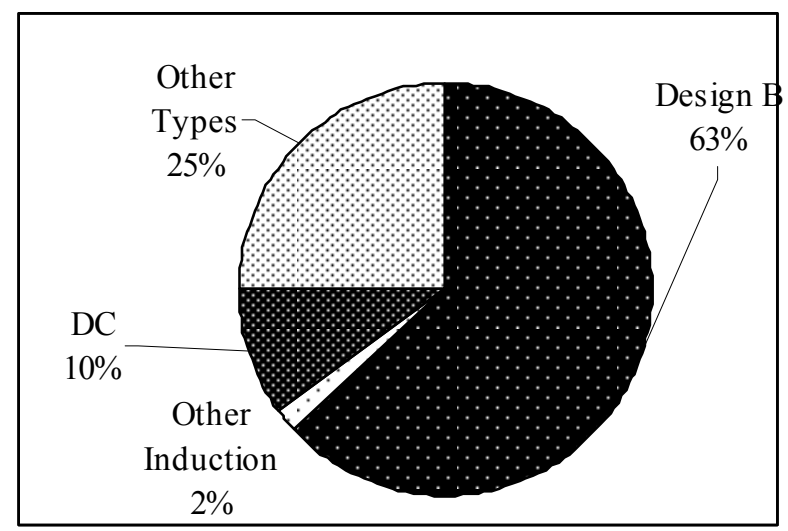

Figure 1.3 Relative shares of electrical input used by different motor types [26] 
In an induction motor the stator poles rotate at synchronous speed and the rotor poles are induced by transformer action and also rotate at synchronous speed. The rotor rotates physically at a speed slightly slower than the synchronous speed and slows down slightly as the load torque and power requirements increase.

\subsubsection{Construction}

Induction motors are the simplest and most rugged of all electric motors. There are only two main components: the stator and the rotor. The rotor is separated from the stator by a small air-gap which ranges from $0.4 \mathrm{~mm}$ to $4 \mathrm{~mm}$ depending on the power of the motor [32]. The rotor is constructed of a number of conducting bars running parallel to the axis of the motor and two conducting rings on the ends. The assembly resembles a squirrel cage, thus this type of motor is often called a squirrel-cage motor. The stator contains a pattern of copper coils arranged in windings. As alternating current is passed through the windings, a moving magnetic field is formed near the stator. This induces a current in the rotor, creating its own magnetic field as explained earlier. The interaction of these fields produces a torque on the rotor. There is no direct electrical connection between the stator and the rotor. There are two types of rotor windings:

a) Conventional three-phase windings made of insulated wire and

b) Squirrel cage windings.

\subsubsection{Types of Induction Motors}

The type of winding gives rise to two main types of motors: squirrel cage induction motors and wound rotor induction motors. Squirrel cage induction motors are most common and are either three phases or single phase.

\subsubsection{Squirrel Cage Induction Motor}

Most induction motors contain a rotor in which the conductors, made of either aluminum or copper are arranged in a cylindrical format resembling a "squirrel cage". Squirrel cage induction motors have no external electrical connections to the rotor, which is made of solid, un-insulated aluminum or copper bars short circuited at both ends of the rotor with solid rings of the same metal. The rotor and stator are connected by magnetic 
field that crosses the air-gap. This simple construction results in relatively low maintenance requirements [28].

The relationship between torque and speed in squirrel cage motors is largely dependent on rotor resistance. As the rotor resistance decreases, the performance speed improves and the starting torque decreases. The smaller the slip for a given load the higher the efficiency because induced currents and their associated rotor losses are also smaller. Three phase squirrel cage induction motors dominate application above $1 \mathrm{hp}$. Single phase squirrel cage induction motors are more common in sizes below $1 \mathrm{hp}$ and large home appliances. Single-phase motors are larger and more expensive, with a lower efficiency than three phase motors that have same power and speed ratings. Additionally three phase induction motors are more reliable since they do not need special starting equipment.

\section{Shaded Pole Motors}

Another type of induction design, the shaded pole motor, is the most commonly used in packaged equipment applications below $0.17(1 / 6) \mathrm{hp}$ such as small fans in portable heaters, small condensing units for air conditioning and refrigeration [28]. Although shaded pole motors are cheaper than single-phase squirrel cage motors, their efficiency is poor (below 20\%) and their use is restricted to low power applications with a limited number of operating hours.

\subsubsection{Wound Rotor Induction Motors}

Unlike the squirrel-cage construction of the NEMA motors, the wound-rotor motor has (as the name implies) windings on the rotor instead of the conducting cage. These windings are connected via slip rings on the rotor shaft to and external resistance control circuit. Varying the resistance of the windings allows adjustment of the behavior of the motor. Note that increasing the resistance effectively lowers the speed of the motor at any given load [1].

\subsubsection{NEMA Design Motors}

The National Electrical Manufacturers Association (NEMA) has assigned a simple letter designation to four of the most common three-phase AC electric motors. These vary in starting torque and speed regulation. They are all of squirrel-cage 
construction, and are available in many sizes. The graph in Figure 1.4 shows the performance curve for each type. Note that Design A gives the highest peak torque and Design $\mathrm{B}$ which is the most common gives the lowest peak torque. Table 1.4 gives typical applications of induction motors according to NEMA designs. Typical characteristics of these designs i.e. starting torque, current and slip are also given.

Table 1.4 Characteristics of NEMA Design motors

\begin{tabular}{|c|c|c|c|l|}
\hline Design & $\begin{array}{c}\text { Starting } \\
\text { Torque }\end{array}$ & $\begin{array}{c}\text { Starting } \\
\text { Current }\end{array}$ & Slip & \multicolumn{1}{|l|}{ Typical Application } \\
\hline Design A & Normal & Relatively high & $\leq 5 \%$ & Injection-molding machines \\
\hline Design B & Normal & Low & $\leq 5 \%$ & M/C Tools, pumps, fans, compressors \\
\hline Design C & High & Low & $\leq 5 \%$ & Applications without great overloads \\
\hline Design D & Highest & Low & $5-13 \%$ & Punch presses, cranes, elevators \\
\hline Design E & Low & High & Low & Low starting torque fans \\
\hline
\end{tabular}

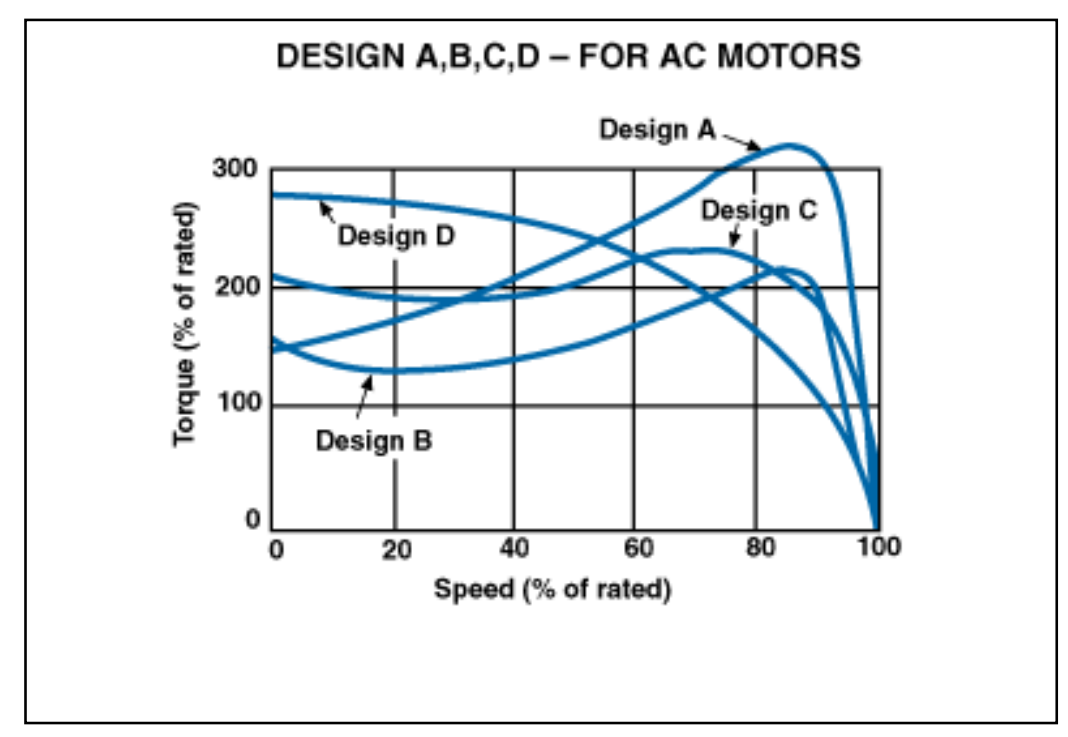

Figure 1.4 Torque of NEMA Design Motors [28]

\subsection{Motors}

Approximately $50 \%$ of all industrial drives are of direct current type. Most of the installed electric machines sometimes work in low efficiency conditions by running at two thirds or less their normal load (Nailen, 1989). For this reason, industrial users are 
turning to high efficiency motors at the time of replacement. The capital invested in DC motor drive systems is high and replacing them solely based on their energy efficiency performance is usually not justifiable (Famouri, 1997). However many existing DC motor drive systems can be improved to increase their overall system efficiency by utilizing electronic control to reduce motor losses [48].

DC motors can provide high torque and speed control can be easily achieved over a wide range. They are being used in various applications in industry such as printing presses, pipe forming mills and many other industrial applications where speed control is important. Due to recent development in power electronics technology more attention has been paid on the efficient drive of DC motors. The early work in loss minimization of DC motors has been reported by Petrov, Slezhanovski, and Cathey in literature.

There are two general methods for loss minimization of DC motors. One method assumes that the loss model is known. The speed and armature current of DC motors should be detected, then the excitation current is found by the direct calculation of the loss minimization condition or checking a pre-calculated lookup table. It is known that the measurement of the loss model parameters is very difficult and time consuming. For some motors that are already installed, such measurements might not be available. Different machines have different parameters, and what is more important that these parameter values vary with temperature and other operating factors [48].

The second method is to sense the changes of incoming power to the motor and seek the optimal field current for the particular operating point. Very few publications refer to this method [48].

It is well known that when a DC machine power demand is less than its rated value, it is not necessary to maintain the excitation at its maximum value. Excessive excitation increases the machine copper and iron losses. Therefore, the excitation can be adjusted according to the load requirements to reduce drive losses in steady state. Figure 1.5 shows, according to experimental results, how the drive efficiency raises when the excitation is adjusted for each steady state operating point, principally for a power demand less than its rated value [49]. 


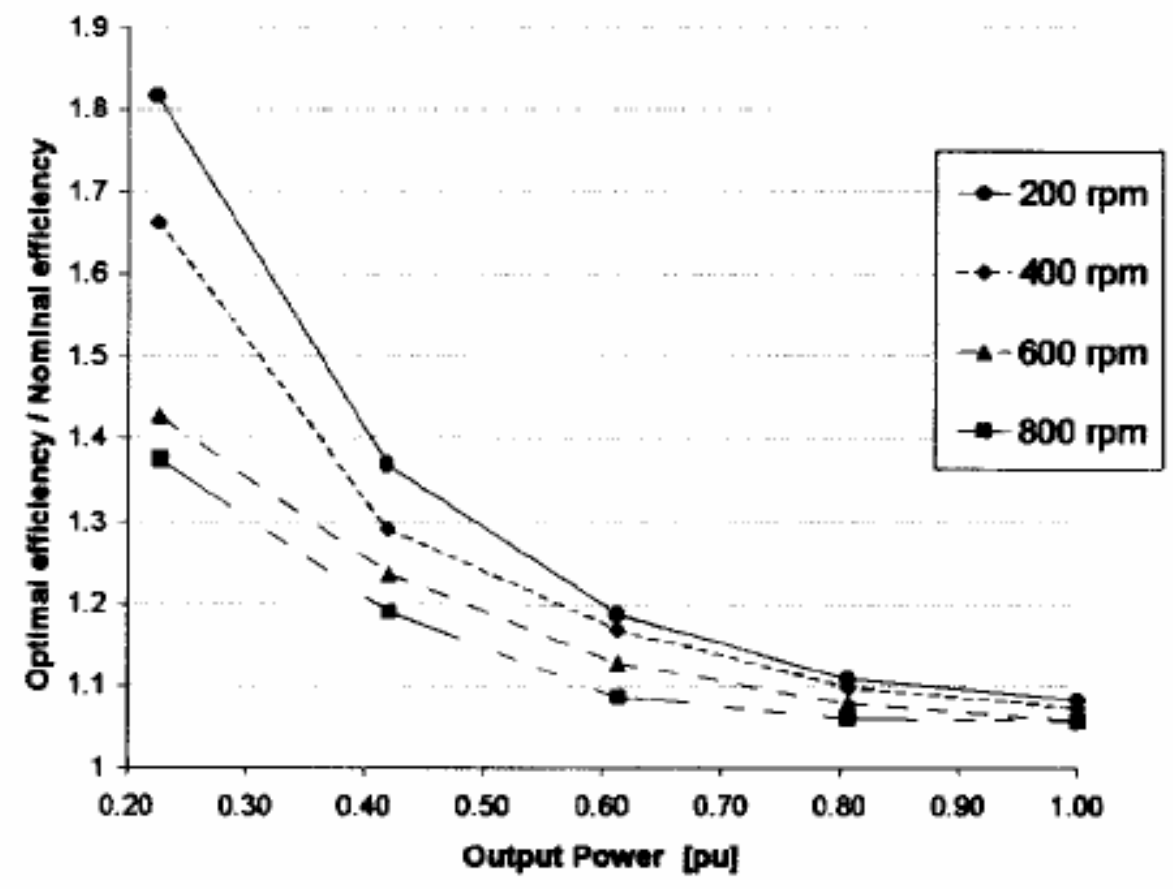

Figure 1.5 Optimal Efficiency Obtained by Controlling Field Current for Different Operating Points

\subsubsection{Power Losses in DC Motors}

When DC motor converts electrical energy into mechanical energy there is always some loss of power which contributes towards loss of efficiency of the DC motor. The study of power losses gives us a clue how they may be reduced for efficient operation of DC motor. There are two types of losses in DC motors [48]:

1. Mechanical Losses: They are due to bearing friction and windage. The friction losses depend upon the speed of the machine, and upon the design of the bearing brushes and commutators. Windage losses depend on the speed and design of the cooling fan, and the turbulence produced by the revolving parts.

2. Electrical Losses: The electrical losses are composed of: a) Conductor $I^{2} R$ (copper) losses, b) Brush losses, c) Iron (core) loss.

Conductor $I^{2} R$ losses are due to the current flowing through stator and rotor windings. These $I^{2} R$ losses show up as heat, causing conductor temperatures to rise above ambient temperature.

The $I^{2} R$ losses in brushes are negligible because the current density is far less than that used in copper. However, voltage contact drop between the brushes and commutator may 
produce significant losses. This is called brush losses that usually included in armature circuit loss.

Iron losses are produced in armature core of a DC machine. They are due to hysterysis and eddy currents. Total power loss in DC motor is the addition of all these losses.

\subsubsection{Energy Efficient DC Motor Drive}

As proposed by Famouri and Jing Wang, in a separately excited DC motor, the field current and armature current are controlled independently. The losses can be reduced by reducing the field current. If so, the armature current should be increased to keep the required torque. The total losses vary with the combination of armature current and field current. For a given speed and a load torque, many sets of $I_{a}$ and $I_{f}$ will meet this condition but only one set corresponds to a minimum power loss. This point can be found by detecting the change in input power.

\subsection{Mathematical Relations in Induction Motors}

It is critical to understand the basic mathematical relationships that govern the operation of the induction motors. Some of the basic relationships that are used for estimation are reviewed below:

\section{Synchronous Speed}

It is the speed at which the magnetic field inside the stator of the induction motor rotates. It is given by, [1]

$n_{s}=\frac{120 \times \mathrm{f}}{\mathrm{P}}$

Where,

$\mathrm{n}_{\mathrm{s}}=$ Synchronous speed of the motor

$\mathrm{f}=$ Frequency of the applied voltage

$\mathrm{P}=$ no. of poles used in the motor construction.

\section{Torque}

The torque generated by the induction motor is given by following equation, $T=\frac{5250 \times \mathrm{HP}}{\mathrm{N}_{\mathrm{rpm}}}$

Where, 
$\mathrm{HP}=$ Horse power rating, $\mathrm{hp}$

$\mathrm{N}_{\mathrm{rpm}}=$ Operating speed, rpm

\section{Slip}

The frequency of the AC current supply determines the speed at which the magnetic field inside the stator rotates. The rotor follows somewhat behind this field, turning at a slower pace. This difference in speed is called slip [1]

$\%$ Slip $=\frac{\mathrm{Ns}-\mathrm{N}}{\mathrm{Ns}}$

Where,

Ns $=$ Synchronous RPM

$\mathrm{N}=$ Measured RPM

\section{Real Power (kW)}

This is the power that is used for doing useful work. It is estimated as, [2]

$k W=\frac{\sqrt{3} \times I \times V \times P F}{1000}$

Where,

$\mathrm{I}=$ Average line current, Amps

$\mathrm{V}=$ Average 3 phase voltage, Volts

$\mathrm{PF}=$ Power factor, no units

\section{Reactive Power (kVAR)}

This is the component of power that is not useful. It is the power that magnetic equipment (transformer, motor and relay) needs to produce the magnetizing flux. It is estimated as,

$k V A R=\sqrt{\mathrm{kVA}^{2}-\mathrm{kW}^{2}}$

Where,

$\mathrm{kVA}=$ Apparent power

$\mathrm{kW}=$ Real power

\section{Apparent Power (kVA)}

It is the "vector summation" of KVAR and KW.

$k V A=\frac{\sqrt{3} \times \mathrm{Ix} \mathrm{V}}{1000}$ 


\section{Power Factor}

Power Factor (P.F.) is the ratio of Working Power to Apparent Power.

$P F=\frac{\mathrm{kW}}{\mathrm{kVA}}=\cos \phi$

\section{Output Power (HP)}

This is mechanical output of the motor used for doing useful work [26].

$k W=\frac{\sqrt{3} \times \mathrm{I} \times \mathrm{V} \times \mathrm{PF} \times \eta}{1000}$

Where,

$\eta=$ Efficiency, no units

\section{Locked Rotor Current}

Locked rotor current can be estimated from the motor nameplate data as given in equation [32],

$I_{L}=\frac{1000 \mathrm{xHP} \times(\mathrm{kVA} / \mathrm{HP})}{\mathrm{Vx} \sqrt{3}}$

Where,

$\mathrm{HP}=$ Horse power rating, hp

$\mathrm{kVA} / \mathrm{HP}=$ rating from standard $\mathrm{kVA} / \mathrm{HP}$ chart.

\section{Operating Efficiency}

If the load has been estimated as described above and we have the input three phase power measured with proper instrumentation, the efficiency can be determined by equation 1.10

$\eta=\frac{0.746 \times \mathrm{HP} \times \mathrm{Load}}{\mathrm{P}_{\mathrm{i}}}$

Where,

$\eta=$ Efficiency as operated in \%

$\mathrm{HP}=$ Nameplate rated horsepower

Load $=$ Output power as a $\%$ of rated power

$\mathrm{P}_{\mathrm{i}}=$ Three-phase power in $\mathrm{kW}$ 
If losses are determined ${ }^{1}$, $\eta=\frac{\text { Output }}{\text { Input }}=1-\frac{\text { Losses }}{\text { Input }}$

\subsection{Slip in Induction Motors}

The stator structure is composed of steel laminations shaped to form poles. Copper wire coils are wound around these poles. These primary windings are connected to a voltage source to produce a rotating magnetic field. Three-phase motors with windings spaced 120 electrical deg apart are standard for industrial, commercial, and residential use. The rotor is another assembly made of laminations over a steel shaft core. The alternating current (AC) is "induced" into the rotor via the rotating magnetic flux produced in the stator. Motor torque is developed from the interaction of currents flowing in the rotor bars and the stators' rotating magnetic field.

In actual operation, rotor speed always lags the magnetic field's speed, allowing the rotor bars to cut magnetic lines of force and produce useful torque. This speed difference is called slip speed. Slip also increases with load, and it is necessary to produce torque. According to the formal definition of slip, it can be obtained as shown in equation 1.3. For small values of motor slip, the slip is proportional to the rotor resistance, stator voltage frequency, and load torque and is in inverse proportion to the second power of supply voltage [26]

$s \propto \frac{\operatorname{Rr} \cdot f \cdot \tau}{V^{2}}$

Where,

$\mathrm{S}=$ Slip (for small values)

$\mathrm{Rr}=$ Resistance of rotor

$f=$ Frequency of voltage of stator

$\tau=$ Load torque

$\mathrm{V}=$ Supply voltage.

\footnotetext{
${ }^{1}$ Losses can be determined with IEEE 112, Method B standard test procedure. The details can be found in NEMA documentation.
} 
The traditional way to control the speed of a wound rotor induction motor is to increase the slip by adding resistance in the rotor circuit. The slip of low-horsepower motors is higher than those of high-horsepower motors because of higher rotor winding resistance in smaller motors. Smaller motors and lower-speed motors typically have higher relative slip. However, high-slip, large motors and low-slip, small motors are available.

Full-load slip varies from less than $1 \%$ (in high-horsepower motors) to more than $5 \%$ (in fractional-horsepower motors). These variations may cause load-sharing problems when motors of different sizes are connected mechanically. At low load, the sharing is about correct, but at full load, the motor with lower slip takes a higher share of the load than the motor with higher slip.

The rotor speed decreases in proportion to the load torque [26]. This means the rotor slip increases in the same proportion. Relatively high rotor impedance is required for good across-the-line (full-voltage) starting performance (meaning high torque against low current), and low rotor impedance is necessary for low full-load speed slip and high operating efficiency. The curves reveal how higher rotor impedance reduces the starting current and increases the starting torque, but it causes a higher slip than in a standard motor.

\subsection{Load Factor Evaluation}

To compare the operating costs of an existing standard motor with an appropriately-sized energy efficient replacement, you need to determine operating hours, efficiency improvement values, and load. Part-load is a term used to describe the actual load served by the motor as compared to the rated full-load capability of the motor. Motor part-loads may be estimated through using input power, amperage, or speed measurements techniques.

\subsubsection{Reasons to Determine Motor Loading}

There are numerous reasons for which determination of the load factor on the motor may be required. Some of these situations are enlisted below [27]: 
- Maximum efficiency of a motor is usually near $75 \%$ of rated load. The efficiency tends to decrease dramatically below 50\% load, as shown in Figure 1.6. However, the range of good efficiency varies with individual motors and tends to extend over a broader range for larger motors. Thus it may be necessary to determine load factor in order to determine the operating efficiency range.

- At low loads the power factor of the motor tends to fall, as shown in Figure 1.6.

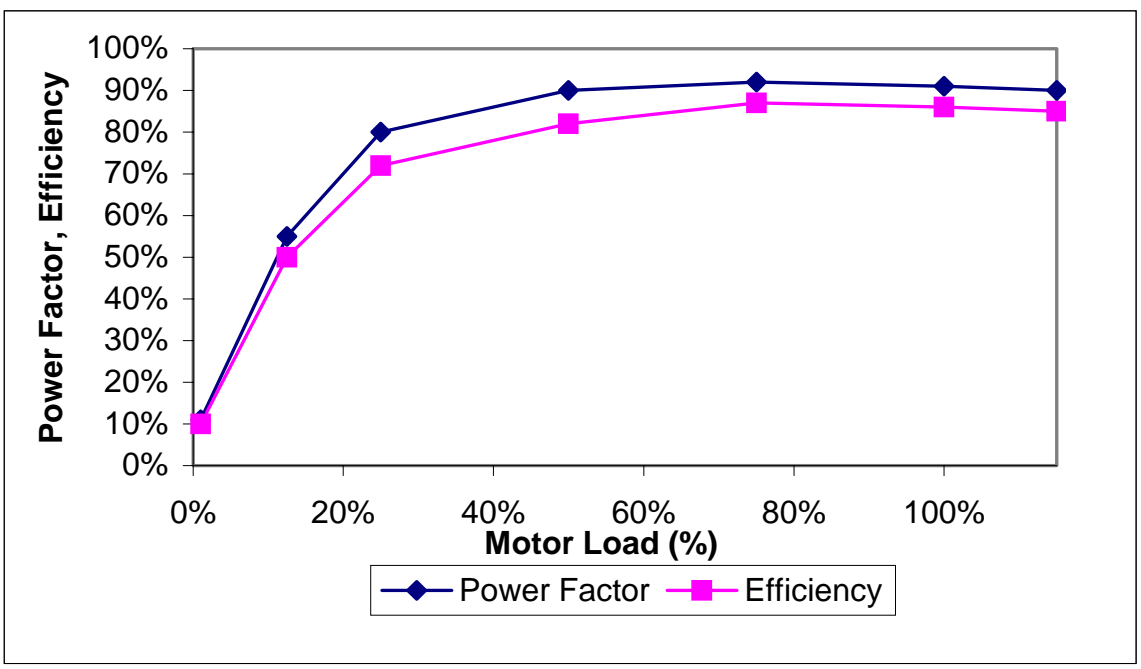

Figure 1.6 Efficiency and Power Factor Variation with Part Load on Motor [5]

- Overloaded motors can overheat and lose efficiency.

- Although many motors have service factors of 1.15 , running the motor continuously above rated load reduces efficiency and motor life.

- A motor should not operate overloaded when voltage is below nominal or when cooling is impaired by altitude, high ambient temperature, or dirty motor surfaces.

- Sometimes motors are oversized because they must accommodate peak conditions, such as when a pumping system must satisfy occasionally high demands. Options available to meet variable loads include two-speed motors, adjustable speed drives. To make this kind of decision load determination may be required [27].

- Load factor profiles can help you determine if (and where) adding adjustable speed drives (ASDs) would be cost effective.

- Load factor determination may be necessary for load management strategies that maintain loads within an acceptable range. 
- Determining if your motors are properly loaded enables you to make informed decisions about when to replace motors and which replacements to choose.

- Perform a motor load and efficiency analysis on all major working motors as part of preventative maintenance and energy conservation program.

\subsubsection{Methods to Determine Load}

The ratio of the actual power being generated by a motor to its rated power is called the motor's load factor, LF. It is usually expressed as a fraction or in per cent.

$$
\operatorname{LF}(\%)=\frac{100 \times \text { Actual Power Out }}{\text { Rated Power Out }}
$$

The LF of a motor depends on actual power delivered by the motor therefore methods to determine load factor revolve around measurement of actual power. There are several methods by which one can estimate actual power output of an induction motor. Several methods are described in following sections.

\subsubsection{Load Estimation by Input Power Measurement}

One of the most accurate methods for load determination is the input power measurement method (watt method). A three-phase wattmeter is attached to the motor input leads, usually at the motor controller disconnect. The motor load is estimated by multiplying the motor input power by an approximate motor efficiency. The nameplate efficiency, manufacturer's data, or data from the MotorMaster+ 4.0 database can be used to find the value for motor efficiency. The watt method works well above $50 \%$ load since the efficiency curve for most motors is relatively flat between $50 \%$ and $100 \%$, and at these loads power measurements are reasonably accurate [26].

Input Power $(\mathrm{kW})$ x Efficiency $(\%)$

$\operatorname{LF}(\%)=$

\section{Rated Horsepower x 0.746}

The method has two main drawbacks, however. First, the results are dependent on the accuracy of the efficiency estimate. Second, they are sensitive to the voltage applied to the motor. Although it is possible to correct for voltage error, correction requires 
knowledge of the effects of voltage variations on the efficiency of any specific motor design [26].

\subsubsection{MotorMaster+ Input Power Measurement Method}

The MotorMaster+ 4.0 software (WSU 2003) uses a variant of the watt method, applying an iterative approach. It starts with an efficiency value and divides it into the wattage to get output power and compute percent load. Then it looks up a new efficiency from a partial load efficiency table and re-computes load. The software requires several iterations to converge on load [19].

\subsubsection{Line Current Measurement Method}

The amperage draw of a motor varies approximately linearly with respect to load down to about $50 \%$ of full load. Below the $50 \%$ load point, due to reactive magnetizing current requirements, power factor degrades, and the amperage curve becomes increasingly non-linear and is no longer a useful indicator of load. The no load or idle amperage for most motors is typically on the order of 25 to 40 percent of the nameplate full load current while the power draw or no load loss is only 4 to $8 \%$ of the name plate horsepower [18].

Advantages of using the current based load estimation technique are that NEMA MG 1-12.47 allows a tolerance of only $10 \%$ when reporting nameplate full load current. In addition, motor terminal voltages only affect current to the first power, while slip varies with the square of the voltage [26]. Finally, a motor's current draw is not directly related to operating temperature. The equation that relates motor load to measured current values is [26]:

$\mathrm{LF}=\frac{\text { Amps measured } \mathrm{X} \text { Volts measured }}{\text { Amps nameplate } \mathrm{X} \text { Volts nameplate }}$

\subsubsection{Slip Method}

One of the simplest methods of load determination is the slip method. This method takes advantage of the nearly linear relationship between motor slip and load. The synchronous speed of an induction motor depends on the frequency of the power supply and on the number of poles for which the motor is wound. The higher the 
frequency, the faster a motor runs. The more poles the motor has, the slower it runs. The synchronous speeds (Ns) for a squirrel cage induction motors are given in Table 1.5.

Table 1.5 Synchronous Speeds According to Number of Poles

\begin{tabular}{|c|c|c|}
\hline & Poles (P) & Synchronous RPM (120x f/P) \\
\hline \multirow{4}{*}{$\begin{array}{c}\text { Voltage Frequency } \\
\mathrm{f}=60 \mathrm{~Hz}\end{array}$} & 2 & 3600 \\
\cline { 2 - 3 } & 4 & 1800 \\
\cline { 2 - 3 } & 6 & 1200 \\
\cline { 2 - 3 } & 8 & 900 \\
\cline { 2 - 3 } & 10 & 720 \\
\hline
\end{tabular}

The actual speed of the motor is less than its synchronous speed with the difference between the synchronous and actual speed being referred as slip. The percentage slip can be calculated as shown in equation 1.3. The motor load can be estimated with slip measurement as follows:

Load $=\frac{\text { Slip }}{\left(\mathrm{S}_{\mathrm{s}}-\mathrm{S}_{\mathrm{r}}\right)}$

Where,

Slip $=\mathrm{S}_{\mathrm{s}}-\mathrm{S}_{\mathrm{m}}$

$\mathrm{Sm}=$ Measured Speed, $\mathrm{S}_{\mathrm{m}}$

$\mathrm{S}_{\mathrm{s}}=$ Synchronous speed, $\mathrm{rpm}$

$\mathrm{S}_{\mathrm{r}}=$ Rated Speed, rpm (at full load)

\subsubsection{Voltage Corrected Slip Method}

Slip also varies with motor voltage, possibly resulting in errors of over 5\% because of voltage variation [26]. Voltage compensation can reduce some of the error occurred in measuring loads by slip method, if the motor is not powered exactly at nameplate voltage. The voltage corrected slip method requires a voltmeter and a tachometer. The method, expressed mathematically, is

$$
\text { Load }=\frac{\text { Slip }}{\left(S_{s}-S_{r}\right) \times\left(\frac{V r}{V}\right)^{2}}
$$


Where,

Slip $=\mathrm{S}_{\mathrm{s}}-\mathrm{S}_{\mathrm{m}}$

$\mathrm{Sm}=$ Measured Speed, $\mathrm{S}_{\mathrm{m}}$

$\mathrm{S}_{\mathrm{s}}=$ Synchronous speed, rpm

$\mathrm{S}_{\mathrm{r}}=$ Rated Speed, rpm (at full load)

$\mathrm{V}_{\mathrm{r}}=$ Rated voltage, Volts

$\mathrm{V}=$ Measured average phase voltage, Volts

\subsection{Potential for Energy Savings}

According to the DOE Industrial Assessment Center database one of the top three energy assessment recommendations is use most efficient type of electric motors. It has been estimated that $28-42 \%$ of all US motor input energy (15-25\% of all US electricity) can be saved by full application of motor saving measures [26]. Of 1,851 TWh that induction motor consume each year only 1,101-1,492 TWh would need to be supplied. Thus 513-780 TWh of electricity could be saved per year [26].

Many other studies that have been carried out for estimating the saving potential of motor systems show similar figures. The most aggressive estimate of $28-60 \%$ was made by $\mathrm{E}$ source ${ }^{2}$. This estimate is for the motor population as a whole, and includes many measures that improve the motor systems energy efficiency. The lowest estimate of 11$18 \%$ was made by X-Energy (1998) in a study for DOE. However, this study was very conservative in that, it estimated savings only from the projects that had a simple payback of three years or less on a retrofit basis. The recent studies show average potential for savings as $23-41 \%$ [26]. However, many of these savings require new installations of existing equipment which would take years to implement.

\subsection{Need for research}

\subsubsection{Present Motor Loading in Industry}

Currently, a large number of induction motor applications that are used in the manufacturing industry are oversized. The calculations that are perfomed by the plant engineers when doing motor installation decisions are usually based on the load

\footnotetext{
2 The E Source is owned by Platts Consulting, a McGraw Hill consulting company.
} 
determination technique of slip method. This is the easiest way of determining the motor load. The load factor is important because it is one of the prime factors that determine the operating efficiency of a motor. As the load factor drops below optimal of $60-80 \%$ loading, the efficiency of the motor starts decreasing. The efficiency drop is considerable below $50 \%$ of the load factor. All the motors that are operating below $50-65 \%$ of loading should be considered for downsizing.

The fact that most of the motors that are used today in the industry are underloaded is evident from the findings summarized in Table 1.6. The findings are compiled from a recent X-Energy national field study [26]. In this field study, instantaneous measurements were taken on a representative sample of hundreds of motors in the field and the results were weighted to represent the motor population at large. From the graph presented in Figure 1.7 it is noted that almost every horsepower category has half of the motors loaded under $40 \%$. Overall, it was found that $44 \%$ of motors are operating at less than $40 \%$ of full load.

Table 1.6 Motor Loading by Horsepower in US (Source X-energy 1998)

\begin{tabular}{|c|c|c|c|c|c|c|}
\hline & \multicolumn{6}{|c|}{ Horse Power } \\
\hline Part Load & $\mathbf{1}-\mathbf{5}$ HP & $\mathbf{6}-\mathbf{2 0}$ HP & $\mathbf{2 1 - 5 0 ~ H P}$ & $\mathbf{5 1 - 1 0 0}$ HP & $\mathbf{1 0 1 - 2 0 0 ~ H P ~}$ & $\mathbf{2 0 0 +}$ HP \\
\hline$<\mathbf{4 0} \%$ & $42 \%$ & $48 \%$ & $39 \%$ & $45 \%$ & $24 \%$ & $40 \%$ \\
\hline $\mathbf{4 0}-\mathbf{1 2 0} \%$ & $54 \%$ & $51 \%$ & $60 \%$ & $54 \%$ & $75 \%$ & $58 \%$ \\
\hline$>\mathbf{1 2 0} \%$ & $4 \%$ & $1 \%$ & $1 \%$ & $0 \%$ & $1 \%$ & $2 \%$ \\
\hline
\end{tabular}

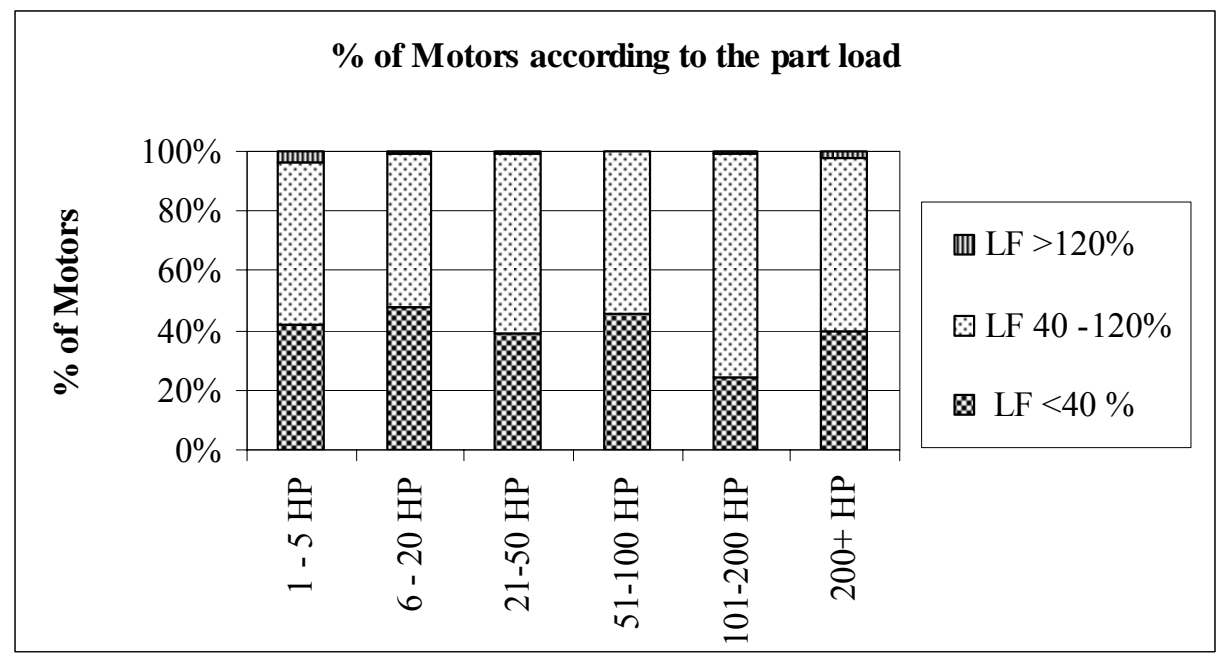

Figure 1.7 Percentage of Under-Loaded Motors in US industry 


\subsection{Objectives of Research}

The main objective of this study is to develop Energy Conservation Opportunity (ECO) for motor systems based on load conditions. Another major aim is to estimate the impact of motor system loading on bottom-line competitiveness as well as energy and demand savings and to provide insights into the mechanisms by which such benefits are delivered to industry. Specifically, the objectives of this research can be summarized as follows:

- Collect field data of motor loading and analyze it using various tools including MotorMaster+TM 4.0.

- Compare load results of electrical load monitoring vs. load results by slip method

- Find out the relationship between the load factor obtained by the stroboscope method and load factor obtained by input power measurement method.

- Develop a model for determining energy savings as well as for economic analysis of properly loaded motor.

- Statistical analysis and model development.

- Validate the systematic approach and model.

The data from fifteen plant assessments is collected, analyzed and presented to provide an estimate of their impact on energy and cost savings, which will allow the results of these assessments to feed back into DOE's strategic planning process.

\subsection{Conclusion}

This chapter reviews importance of electrical induction motors, their applications and fundamental relationships used to estimate load factor. An example has been quoted to get the idea of how energy and dollars are wasted because of improperly loaded motor. Information on percentage of under loaded motors found in industry is presented. This can be used to get an idea about kind of problem the industry is facing. It clearly indicates that lot of energy and money is wasted due to under-loaded motors. 


\section{Chapter 2}

\section{Literature Review}

Since the mid-1990s, manufacturing plants in the United States have undertaken measures to reduce energy consumption. One of the primary types of these measures has been to increase the efficiency of their motor systems. The US Department of Energy's Office of Energy Efficiency and Renewable Energy (EERE) have encouraged these efforts through its Best Practices program.

\subsection{Energy Conservation Measures for Induction Motors}

Most analyses of the potential for improved efficiency in motor systems have focused on only two technologies: high-efficiency motors and adjustable-speed drives. These are indeed very important technologies, but, as part of an overall systems approach for reducing motor energy use, many other measures deserve attention as well. These include [9]:

- Optimal motor sizing

- New and improved types of motors. Better motor repair practices

- Improved controls in addition to ASDs

- More efficient motor-driven equipment including fans, pumps, and compressors

- Motor system design improvements including better selection of equipment and system components matched to the application

- Reduced waste of compressed air and other fluids moved by motor systems

- Electrical tune-ups, including phase balancing, power-factor and voltage correction, and reduction of in-plant distribution losses

- Mechanical design improvements, including optimal selection and sizing of gears, chains, belts, and bearings

- Better maintenance and monitoring practices

Only by paying close attention to all of the above parameters and to the synergism among themselves can designers and users of motor systems truly optimize efficiency and reliability [9]. 


\subsection{Losses in Motor}

The two elements of a motor's losses are the load-related or 'copper' loss, which varies with the square of the load, and a fixed loss that is obviously constant. Although they are very dependent on the individual motor design, they split roughly $60 \%-40 \%$ between the variable and constant components of the full-load loss. The Figure 2.1 below shows the typical source and distribution of the primary losses for a modern induction machine and at full load the fixed losses are $12 \%$ for windage and friction and $28 \%$ for the excitation loss [8].

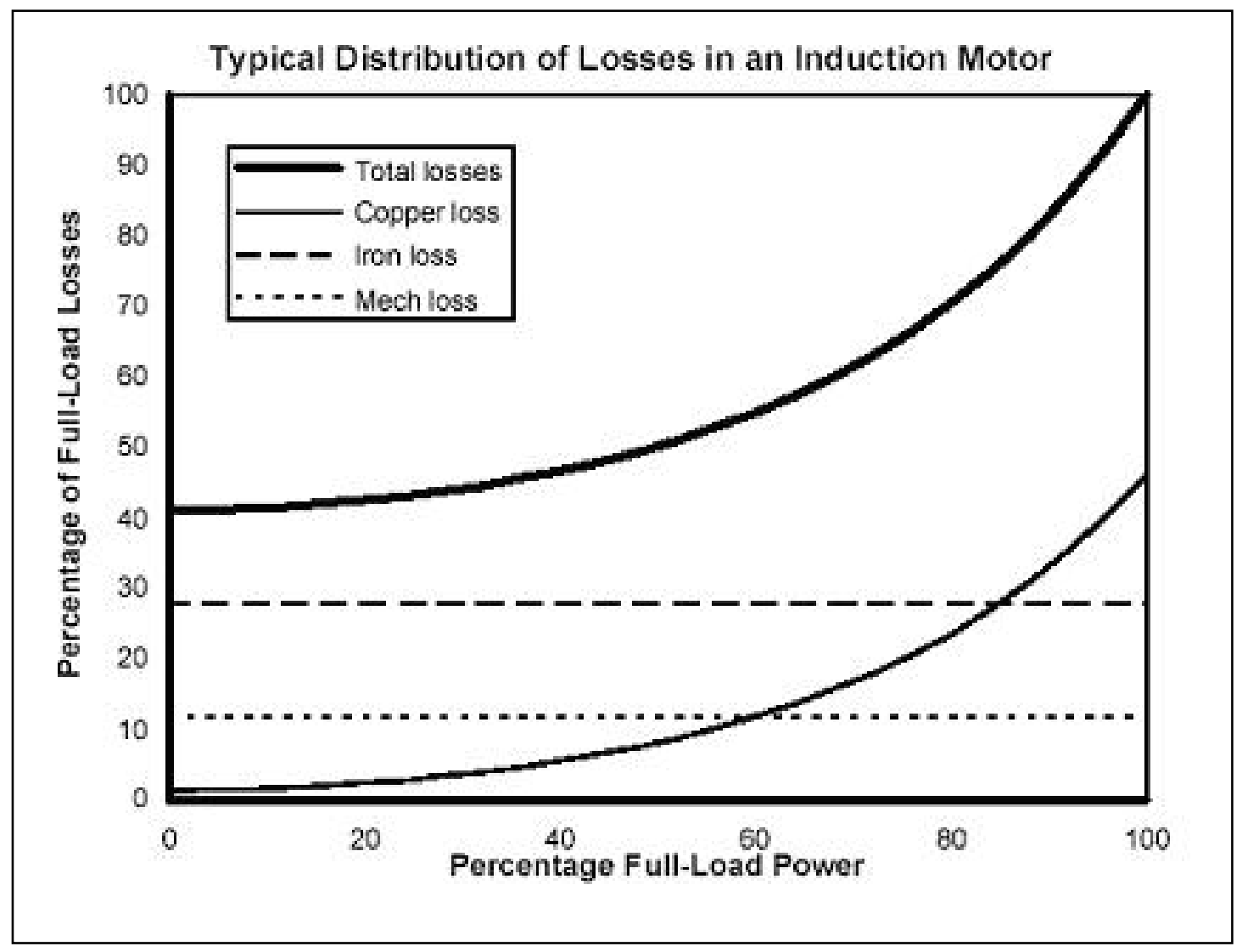

Figure 2.1 Distribution of Induction Motor Losses [8]

There are four basic kinds of loss mechanisms in a motor: electrical; magnetic (core); mechanical (windage and friction); and stray. Whenever current flows through a conductor, power is dissipated. These electrical losses are a function of the square of the current times the resistance, and thus are termed $I^{2} R$ losses, where $I$ is the symbol for current and $\mathrm{R}$ is the symbol for resistance. In a motor, $\mathrm{I}^{2} \mathrm{R}$ losses occur in the stator and rotor. Because they rise with the square of the current, such losses increase rapidly with 
the motor's load. By using more, and sometimes better, lower-resistance materials (switching from aluminum to copper, for instance), manufacturers have reduced the.$I^{2} \mathrm{R}$ losses in efficient motors. Magnetic losses occur in the steel laminations of the stator and rotor and are due to eddy currents and hysteresis [47].

Use of larger cross-sections of iron in the stator and rotor, thinner laminations, and improved magnetic materials can decrease the magnetic losses. Magnetic losses in a given motor decrease slightly as the load increases, though it is not shown in Figure 2.1. Mechanical losses occur in the form of bearing friction and "windage" created by the fans that cool the motor. Windage losses can be decreased through improved fan design. Mechanical losses are relatively small in open, low-speed motors but may be substantial in large high-speed motors or TEFC motors.

Stray losses are miscellaneous losses resulting from leakage flux, non-uniform current distribution, mechanical imperfections in the air gap, and irregularities in the air gap flux density. They typically represent $1-1.5 \%$ of the total input power and increase with the load. Stray losses can also be decreased by optimal design and careful manufacturing [47].

\subsection{Efficiency Estimation}

This is the most important performance parameter of a motor. By definition, efficiency means the percentage of input power supplied that can be obtained as output power to do the useful work.

\subsubsection{Efficiency Testing Standards}

Different standards for testing motors have been developed by various organizations in several countries. Because of these differences, the test results for a given motor may vary depending on the procedure that is carried out. Users need to be aware of these differences so that it is possible to compare motors as much as possible on the basis of uniform test methods. The principal testing methods are given in Table 2.2 along with remarks. Some of the standards assume stray losses. Stray losses represent $1.5-2.25 \%$ of the full, load power, not the $0.5 \%$ as assumed by the IEC, or $0 \%$ as assumed by the JEC. Groups in the IEC have recognized this problem and are currently 
considering the adoption of a new test procedure. The new test procedure would involve direct estimation of the stray losses which is similar to IEEE/CSA standards. It is unclear when the new procedure will come into effect [26].

Table 2.1 Different Standards for Efficiency Measurement of Induction Motor

\begin{tabular}{|l|l|l|}
\hline \multicolumn{1}{|c|}{ Association } & \multicolumn{1}{c|}{ Standard } & \multicolumn{1}{c|}{ Remarks } \\
\hline $\begin{array}{l}\text { Canadian Standards } \\
\text { Association }\end{array}$ & $\begin{array}{l}\text { CSA C-390- } \\
93\end{array}$ & Harmonized with IEEE, accurate \\
\hline $\begin{array}{l}\text { Institute of Electrical and } \\
\text { Electronics Engineers }\end{array}$ & $\begin{array}{l}\text { IEEE 112, } \\
\text { Method B }\end{array}$ & $\begin{array}{l}\text { Most accurate, most time consuming } \\
\text { and expensive }\end{array}$ \\
\hline $\begin{array}{l}\text { International Electro } \\
\text { technical Commission }\end{array}$ & IEC - 34.2 & $\begin{array}{l}\text { Less accurate, allows tolerance on } \\
\text { efficiency, assumes stray losses = } \\
0.5 \% \text { of Total Power }\end{array}$ \\
\hline $\begin{array}{l}\text { Japanese Electro technical } \\
\text { Commission }\end{array}$ & JEC - 37 & $\begin{array}{l}\text { Less accurate, optimistic, assumes } \\
\text { stray losses =0\% }\end{array}$ \\
\hline
\end{tabular}

\subsubsection{Efficiency Determination}

No good methods exist for measuring motor efficiency in situ. All available options have major drawbacks: they tend to be time and labor-intensive, require expensive test devices, or produce estimates of questionable accuracy [27]. However, although these methods are not as accurate as the IEEE 112-B method, which requires a specially equipped laboratory, they can provide some useful estimates of the motor load and efficiency. These estimates can help identify low-efficiency motors, motors damaged in rewinding, and oversized motors.

There are several sophisticated methods for determining motor efficiency. These methods fall into three categories: special devices, software methods, and analytical methods. The special devices package all or most of the required instrumentation in a portable box. Software and analytical methods require generic portable instruments for measuring watts, vars, resistance, volts, amps, and speed. These need to be instruments of premium accuracy, especially the wattmeter that must have a broad range including good accuracy at low power and low power factor. 


\subsubsection{Software and Computerized Methods}

Washington State University Cooperative Extension Energy Program, in partnership with the Oregon State University Motor Systems Resource Facility, conducted lab testing of several efficiency-measuring methods. These included three special devices: the Vogelsang and Benning Motor-Check, the ECNZ Vectron Motor Monitor, and the Niagara Instruments MAS-1000. Their efficiency readings were carefully compared to "true" efficiency, measured by a dynamometer and precision lab instruments per IEEE testing standards. From 25\% load to $150 \%$ load the special devices tended to hold accuracy within 3\%, even in adverse conditions of voltage deviation and unbalance on old, damaged, or rewound motors. In less challenging test conditions, they tended to operate within $2 \%$ accuracy. These instruments require a skilled electrician or other personnel trained in the safe connection of electrical equipment in industrial power systems plus about a day of training and practice. The motors must be temporarily unpowered for a resistance test and temporarily uncoupled for a no-load test, i.e., running at normal voltage unloaded. Uncoupling in-situ is rarely convenient, but the no-load test can be run at times such as receiving inspection or following service at the shop. No-load performance does not tend to change significantly over time in the absence of a failure/repair event [26].

Software and analytical methods were also tested in the lab research described above. When measurement of input data was made with precision lab instruments, the accuracy of methods requiring a no-load test approached that of the special devices' performance. The Oak Ridge National Laboratory has developed ORMEL96 (Oak Ridge Motor Efficiency and Load, 1996), a software program that uses an equivalent circuit method to estimate the load and efficiency of an in-service motor. Only nameplate data and a measurement of rotor speed are required to compute both the motor efficiency and load factor. The program allows the user to enter optional measured data, such as stator resistance, to improve accuracy of the efficiency estimate. Future refinements of ORMEL96 are expected to create a more user-friendly product. Finally, motor load and efficiency values are automatically determined when measured values are entered into MotorMaster+TM 4.0 software's motor inventory module. MotorMaster+TM 4.0 is available at no cost on DOE website. 


\subsubsection{Equivalent Circuit Method}

Efficiency assessed through an equivalent circuit method is based upon impedance values of an equivalent circuit, shown in Figure 2.2. The circuit represents fundamental portion of a complex equivalent circuit of an induction motor. The six impedances are stator resistance $\mathrm{R} 1$, stator leakage reactance $\mathrm{X} 1$, magnetizing reactance $\mathrm{Xm}$, core loss resistance Ro, rotor leakage reactance X2 and rotor resistance R2. The slip affects the load of equivalent circuit. The advantage of equivalent circuit method is that the performance of the motor can be predicted at any load when the impedance values are known. On the other hand the impedance values can change a great deal when the motor speed varies between standstill and no load, due to deep bar effects and magnetic saturation [52]. There are different approaches for obtaining impedance values.

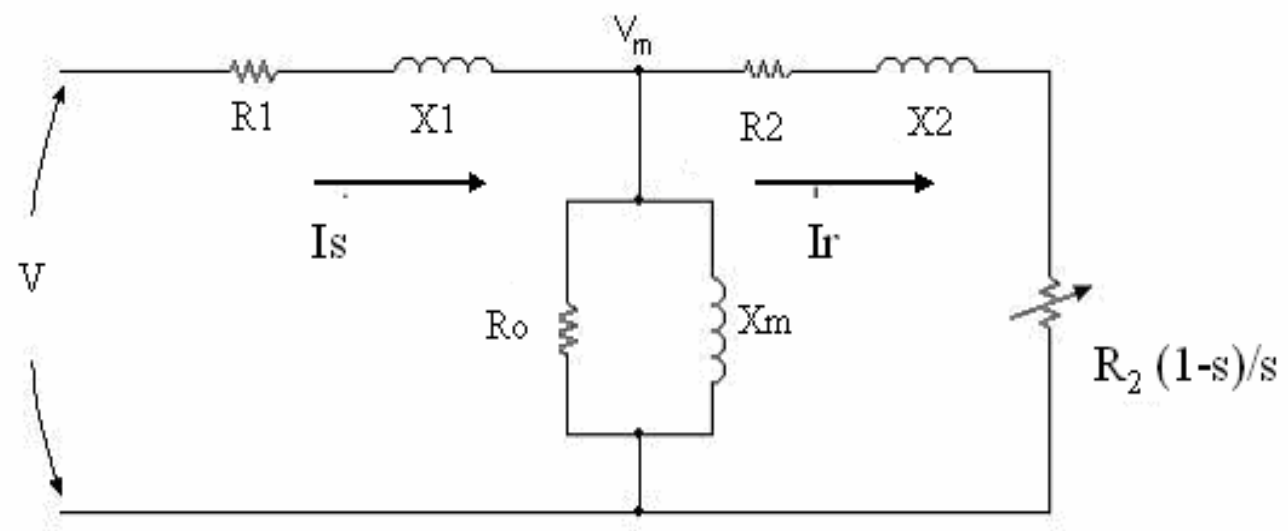

Figure 2.2 Six Impedance per Phase Equivalent Circuit of an Induction Motor [52]

The IEEE Standard 112 Method F is an example of equivalent circuit method. It is not a useful field test for efficiency. Slip is an important parameter for the load calculation. The performance of an electric motor, at least with regard to efficiency, can be calculated from equivalent circuit [52]. Equivalent circuit methods permit one to compute the estimates of efficiency of the motor when it is operating at loads other than those at which measurements were made.

\subsubsection{Segregated Loss Method}

The segregated loss method estimates the magnitudes of the five losses, namely, stator copper loss, rotor copper loss, core loss, stray-load loss and friction and windage 
loss. The shaft output power is the input power minus the losses. Some methods in this category are quite complicated and intrusive, while others rely on empirical factors to estimate the losses [52]. There are quite a number of available methods that are based on evaluations of the five losses. One good example of these methods is IEEE Standard 112 Method E.

Other field methods for evaluation of induction motor efficiency include airgap torque method, shaft torque method, slip method, current method, statistical method and most simple nameplate method. These are found listed in number of references including [52].

\subsection{Motor Nameplate Efficiency Labeling}

It is important to understand the nameplate parameters of the motor and what they mean. In the late 1970s and early 1980s, NEMA established a labeling program for the most common types and sizes of motors ranging from 1 to $125 \mathrm{hp}$. Under this program, the nominal and minimum efficiency ratings for a motor are listed on its nameplate. The nominal efficiency is analogous to the average efficiency of a sample of motors of the same design and minimum efficiency roughly represents the fifth percentile of the sample. Since variations in materials, manufacturing processes, and testing result in motor-to-motor efficiency variations, NEMA specified one standard procedure for labeling efficiencies. The standard assumes that the distribution of efficiencies for a population of a given motor is normal. The motor should be labeled with a value from a table of allowable values that is less than or equal to the nominal value of the sample population (NEMA 1.999). The strength of the labeling program is that it embodies the natural variation in individual motors and provides a standard measure of motor performance that makes comparison between different manufacturers' products easy. The weakness of the program has been that there has been no certification of the manufacturers' reported efficiency values. The Energy Policy Act (EPAct) addresses this problem by establishing an efficiency certification process and requiring that all motors be labeled with the certified value [8].

Besides efficiency, one has to be careful while calculating values that involve rated speed, voltage and current. NEMA allows certain tolerances when these are specified on 
the nameplate. The allowable tolerances on rated speed, rated voltage and full load current are given in Table 2.2.

Table 2.2 NEMA Allowable Tolerances on Some of Motor Nameplate Parameters

\begin{tabular}{|c|c|}
\hline Parameter & NEMA allowable Tolerance \\
\hline Speed & $20 \%$ \\
\hline Voltage & $\pm 10 \%$ \\
\hline Current & $10 \%$ \\
\hline
\end{tabular}

\subsection{Power Factor Improvement}

A lot of research has been done on improvement of power factor for induction motor and its effect on efficiency and on energy savings overall. A lot of work is evident in the area of effect of power factor on energy consumption. Power factor is the ratio of real power to the apparent power. Power Factor $=\operatorname{Cos} \theta=\mathrm{kW} /$ KVA. ss shown in Figure 2.3 .

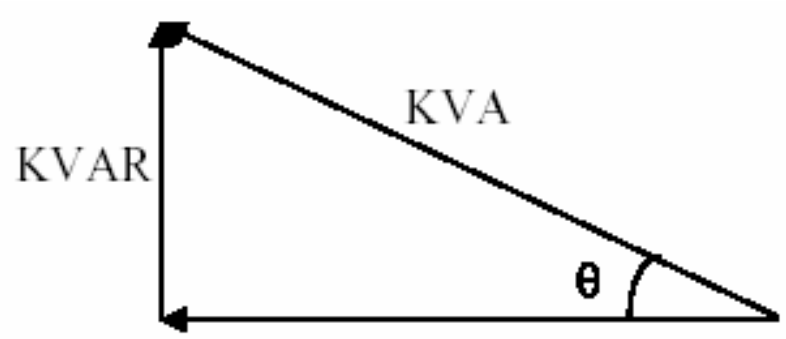

KW

Figure 2.3 Power Factor Triangle [53]

It is known that the power factor also reduces as the motor operates at partial loads. The graph of variation of power factor is flat between 60 to $100 \%$ load and drops off suddenly below 50\% loading. Such a characteristic graph has been shown in Figure 2.4. The induction motor power factor contributes towards overall power factor of the plant so it is generally desirable to keep it near 1 . 


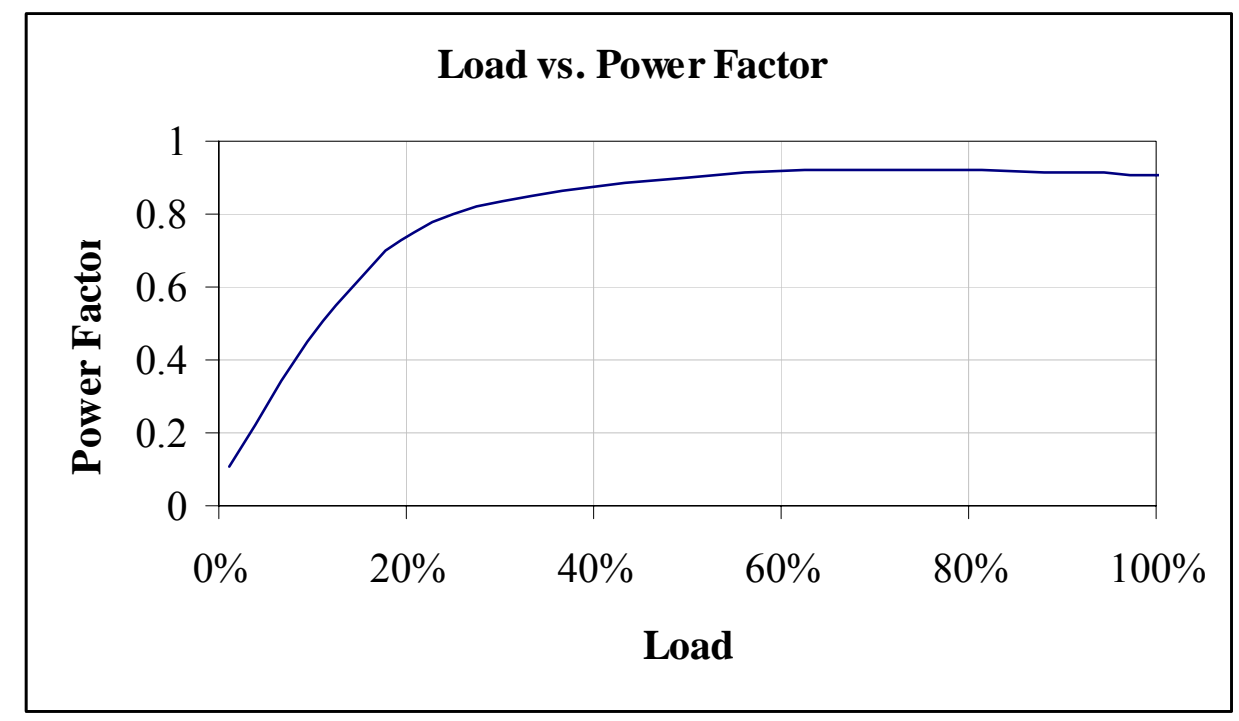

Figure 2.4 Power Factor Variation with Load

\section{Cost Savings Due to Power Factor Improvement}

As seen in Figure 2.3 power factor is ratio of $\mathrm{kW}$ (real power) and kVA (apparent power). $\mathrm{kVAR}$ is the un-used component of power, i.e. reactive power which is introduced because of the inductive loads. This component cannot be eliminated but it is desirable that it should be minimum possible. A little more consideration will show that, as the power factor approaches unity apparent power equals real power, i.e. $\mathrm{kW}$ is saved which otherwise would have been wasted. In other words, power factor improvement demonstrated demand savings, which has been dealt with in Chapter 3, section 3.3.3.2.

\subsubsection{Causes of Low Power Factor}

Low power factor results when $\mathrm{kW}$ is small in relation with KVA i.e. when there are inductive loads in the system. Inductive loads which are sources of reactive power include [53]:

- Transformers

- Induction motors

- Induction generators

- High intensity discharge (HID) lighting

These inductive loads constitute a major portion of the power consumed in industrial complexes. Reactive power required by inductive loads increases the amount of apparent 
power (KVA) in the distribution system thus increasing lag angle $\theta$ between $\mathrm{kW}$ and KVA.

\subsubsection{Techniques to Improve Power Factor}

Sources of reactive power such transformers and induction motors decrease power factor and consumers of reactive power increase the power factor [53]. These consumers of reactive power can be,

- Capacitors

- Synchronous generators

- Synchronous motors

Following techniques are discussed in literature to improve power factor:

- Installing capacitors (KVAR Generators) decreases the magnitude of reactive power (KVAR), thus increasing power factor. The presence of both a capacitor and inductor in the same circuit results in the continuous alternating transfer of energy between the two. Thus, when the circuit is balanced, all the energy released by the inductor is absorbed by the capacitor.

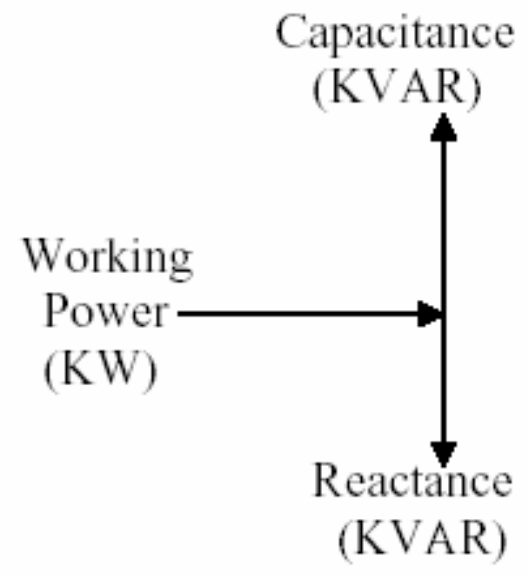

Figure 2.5 Capacitor Principle for Increasing Power Factor [53]

- Minimizing operation of idling or lightly loaded motors.

- Avoiding operation of equipment above its rated voltage.

- Replacing standard motors as they burn out with energy-efficient motors.

Improved power factor can reduce utility bills reducing peak KW demand and eliminating power factor penalty charged by utility company. Power factor improvement 
may lead to increased system capacity and reduced losses. Also motors run cooler and more efficient [53].

Other techniques of power factor improvement for squirrel cage induction motor are terminal voltage reduction and floating winding with static capacitors which, have been discussed in [25].

\subsection{Motor Repair and Motor Rewind}

Each year, more motors are repaired than new motors are sold. For every new motor bought, approximately 2.5 motors are repaired. It is estimated that motors are repaired on the average of every 5-7 years. Since they are frequently operated for 20-30 years, a motor may be repaired three to five times in its serviceable lifetime [8]. Motor repair and motor rewind terms frequently used interchangeably. In reality these two are separate procedures. A rewound motor can use the same rotor, stator iron, and case, leading to considerable savings in raw materials. Rewinding is very common because it is economical in terms of initial cost. Commercial or industrial facilities that purchase motors at the trade price, rewind most models over $10 \mathrm{hp}$. Larger users that receive a volume discount on motor purchases may restrict rewinding to only those larger than 40 hp. It is generally cheaper to replace failed standard motors under $10 \mathrm{hp}$ with efficient motors rather than to rewind them. Severely damaged motors are identified as they fail after repair. Slightly damaged units that look fine but are running, 1-5\% below nameplate efficiency can tally up to thousands of dollars in excess losses over the years. For instance, in the course of severe bearing failure, the rotor may hit the stator and damage the magnetic properties of the iron core. If the bearing is replaced but the magnetic damage is ignored, the repaired motor will appear to be as good as new, while in actuality it will be sustaining excess operating losses. The only way to quantify these losses is to test the motor [8].

\subsubsection{Impact of Rewinding on Motor Efficiency}

No comprehensive studies of the impact of motor repair on efficiency are available. A review of the literature has identified five empirical studies covering 52 motors, all less than $150 \mathrm{hp}$ as shown in Table 2.4. Across these five studies, following 
repairs, the full-load efficiency decreased $0.5-2.5 \%$, with an average of $1 \%$. It is likely that the impact of rewinding is somewhat lower for larger motors because they are usually repaired by larger shops that are more likely to have quality assurance programs in place. Table 2.4 is given here [26].

Table 2.3 Empirical Studies of Efficiency Loss During Motor Repair

\begin{tabular}{|c|c|c|c|}
\hline Study & $\begin{array}{c}\text { Sample } \\
\text { Size }\end{array}$ & $\begin{array}{c}\text { Decrease in Rated } \\
\text { Efficiency }\end{array}$ & Comments \\
\hline McGovern (1984) & 27 & $1.5-2.5 \%$ & $\begin{array}{l}\text { motors ranged 3-150HP,wide } \\
\text { range, age and rewind histories }\end{array}$ \\
\hline $\begin{array}{l}\text { Colby \& Flora } \\
\text { (1990) }\end{array}$ & 4 & $0.5-1.0 \%$ & $\begin{array}{l}\text { Std. and premium efficiency } 5- \\
10 \mathrm{HP} \text { motors }\end{array}$ \\
\hline Zeller (1992) & 10 & $\begin{array}{c}\text { 0.5\%@rated load, } \\
0.7 \% @ \text { load }\end{array}$ & $\begin{array}{l}\text { Controlled test; identical } 20 \mathrm{hp} \\
\text { premium efficiency motor shops }\end{array}$ \\
\hline Dederer (1991) & 9 & $\begin{array}{c}\text { 1.1\%@rated load, } \\
\text { 0.9\%@load }\end{array}$ & $\begin{array}{l}\text { Controlled test; identical } 20 \mathrm{hp} \\
\text { standard efficiency motor shops }\end{array}$ \\
\hline $\begin{array}{l}\text { Ontario Hydro } \\
\text { (1992) }\end{array}$ & 2 & $\begin{array}{c}2.2 \%<=40 \mathrm{HP} \\
0.4 \%>40 \mathrm{HP}\end{array}$ & Motors rewound 4 times each \\
\hline
\end{tabular}

On the contrary to above study as specified in [13] with electrical power costs rising and the cost of operating motor is so expensive, the question of how rewinding affects a motor efficiency has become more important. It is claimed by some that a welldone rewind can have even greater efficiency than the original design. Motor efficiencies from manufacturers have increased since the motors came into existence as the design constraints and materials improved. The distribution of losses will be different for different designs of motors. Difference in speed, design and enclosure will affect the loss distribution. So the factors which are affected during rewind depend on the ability of the repair shop to replace the parts which control the losses such as stator core, windings and the rotor. The improvement possibilities are discussed in Table 2.4[13]. 
Table 2.4 Efficiency Improvement Techniques While Rewinding Motor [13]

\begin{tabular}{|c|l|}
\hline Motor Loss & \multicolumn{1}{|c|}{ Improvement Possibilities } \\
\hline \multirow{2}{*}{ Stator loss } & Increase amount of copper wire in slot \\
\cline { 2 - 2 } & Decrease length of coil endturns \\
\cline { 2 - 2 } & Decrease turns in stator (not recommended) \\
\hline Rotor loss & Decrease turns in stator (not recommended) \\
\hline Core loss & Use better insulation burnout techniques \\
\hline
\end{tabular}

\subsection{Supermizer - Energy Saving System}

The supermizer is an automatic power controller that controls the on/off times of semi-conductors switches by means of a micro computer implemented algorithm in order to feed optimum voltage to a motor at every load [54]. It provides maximum energy savings by monitoring the working load, the applied voltage (V) and the load current (I) of the AC induction motor. The applied voltage and current are inter-related. The supermizer maintains the operating points at minimum current level for a given load factor by detecting the load variations on the motor through its load detection mechanism. With supermizer the motor is always operating at its maximum efficiency irrespective of the degree of loading, with no adverse effect on the delivered torque.

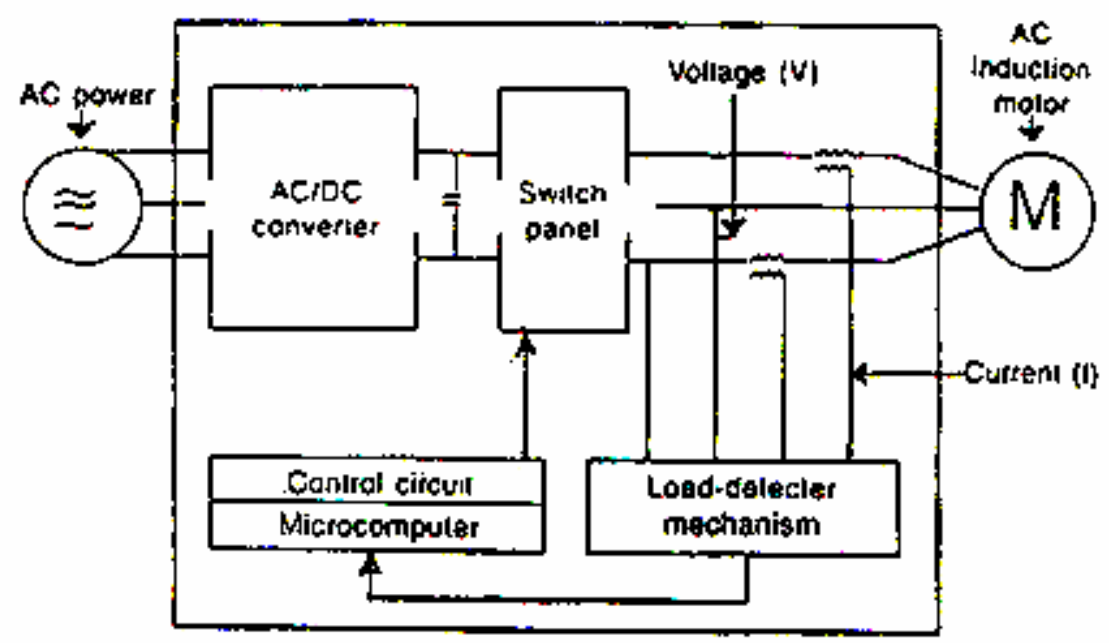

Figure 2.6 Conceptual Configuration Diagram of Supermizer [54]

The conceptual configuration of the supermizer is shown in Figure 2.6. The supermizer has been patented in more than 30 countries. Supermizer delivers [54]: 
- Improvement in power consumption and power factor

- Reduction in amount of waste heat from motor and therefore results in comfortable environment

- Supplies motor with optimum voltage for maximum power output

- Low noise and reduced vibrations

- Soft start

Supermizer is applicable in light loading, fluctuating loads or periodically alternating heavy and light loads. It is not found to be very useful in case of motors operating at near full loads all time where no speed reduction is possible or in case of special energy saving motors [54].

\subsection{Conclusion}

The literature review reveals the work that has already been done in the area of energy conservation of three phase induction motors. A lot of effort has been put into research in order to increase the efficiency of the induction motors and so reduce the energy consumed by them. Also, some of the literature reveals rewinding methods that can be used in order to prevent the efficiency loss that is experienced generally once the motor is rewound. Though relatively less, research efforts are evident in the area of energy conservation of induction motors with help of load management. It is extremely important to be aware of the load profile of the motor in order to make it properly sized. Motors matched to the load profile result in optimum energy usage. Accurate load measurement techniques as studied in the literature are tedious and sometimes inaccurate or unsafe. No simple, quick, economical and safe method which gives fairly accurate estimate of motor load can be found in the literature. The advantage of such a method will be that industry can base its decision about motor sizing and load determination on the method with fair accuracy. This will lead to huge energy savings and demand savings in the long run and help the federal energy efficiency aim as well as the industry to improve their profits and competitiveness. 


\section{Chapter 3}

\section{Research Approach}

\subsection{Collection of Field Data}

Evaluation of current conditions that exist in the industry calls for rigorous data collection of the motors operating in the industry. As has been stated in the previous sections motors alone account for more than $50 \%$ energy consumption in the United States industry and the number of motors that are operating is above 1 billion. This may give an impression that the data can be easily obtainable, which is not the case. The data collection is tedious. Frequently, the motors are inaccessibly fixed, have poor visibility of shaft or rotating part. In some cases the electrical panel is not accessible to make necessary connections of the instruments. Considering this, one has to carefully select the parameters that have to be monitored on which the study will be based.

Generally, it is necessary to answer the following questions,

- What data should be collected or required?

- How much data should be collected?

- How to collect the required data?

With answer to these questions one is equipped to collect the required data. This section answers the listed questions for data collection.

\subsubsection{Required Data}

The methods that have been reviewed in the literature to evaluate the necessary analysis factors viz., load factor, efficiency and energy savings, dictate the requirements of the data. In the present study undertaken, the importance of field data collection can not be overemphasized. Therefore, it is necessary to have understanding of the data that is available and can be collected in addition to the data that has to be collected.

Section MG1-10.40 of the NEMA standard requires that all nameplates of single-phase and poly-phase induction motors carry necessary data. A typical nameplate of a motor carries the following data [1]:

Manufacturer: This is the company that manufactured the motor 
Serial Number: This is the number from the manufacturer unique to the motor given by the manufacturer that would let manufacturer to trace the motor back in manufacturing.

Voltage: The voltage at which the motor is designed to operate is an important parameter.

Frequency: Input frequency is usually $60 \mathrm{~Hz}$ in United States.

Phase: This represents the number of ac power lines supplying the motor. Single and three-phase are the norms.

Current: Rated load current in amps is at nameplate horsepower (HP) with nameplate voltage and frequency.

Code: A letter code defines the locked rotor kVA on a per-hp basis. Codes are defined in MG 1-10.37.2 by a series of letters from $\mathbf{A}$ to $\mathbf{V}$. Generally, the farther the code letter from $\mathbf{A}$, the higher the inrush current per hp.

Type: NEMA MG 1 requires manufacturer's type, but there is no industry standard regarding what this is.

Power factor: Also given on the nameplate as "P.F." or PF, power factor is the ratio of the active power (W) to the apparent power (VA) expressed as a percentage at rated load.

Horsepower: Shaft horsepower is a measure of the motor's mechanical output rating, its ability to deliver the torque required for the rated load at rated speed. It is usually given as "HP" on the nameplate.

Full-load speed: The speed at which rated full-load torque is delivered at rated power output is full-load speed. It is generally given as "RPM" on the nameplate.

Design: NEMA MG 1 (1987), Section MG 1-1.16, defines "design," which defines the torque and current characteristics of the motor. It can be one of DESIGN A, B, C and D.

NEMA Nom. Efficiency: NEMA nominal efficiency on a nameplate represents an average efficiency of a large population of like motors.

Service factor: The service factor (S.F.) is required on a nameplate only if it is higher than 1.0. Industry standard service factor includes 1.15 for open-type motors.

Duty: This block on the nameplate defines the length of time during which the motor can carry its nameplate rating safely. 
Insulation class: Often abbreviated "INSUL CLASS" on nameplates, it is an industry standard classification of the thermal tolerance of the motor winding. Insulation class is a letter designation such as "A," "B," or "F," depending on the winding's ability to survive a given operating temperature for a given life.

Maximum ambient temperature: The nameplate lists the maximum ambient temperature at which the motor can operate and still be within the tolerance of the insulation class at the maximum temperature rise.

Altitude: This indicates the maximum height above sea level at which the motor will remain within its design temperature rise, meeting all other nameplate data.

Enclosure: This designation, often shown as "ENCL" on a nameplate, classifies the motor as to its degree of protection from its environment, and its method of cooling. In MG 1, NEMA describes many variations. The most common are Open Drip-Proof (ODP) and Totally Enclosed Fan Cooled (TEFC).

Frame: This nameplate block can offer a lot of information if the motor is nearly standard. It is important for determining dimensions such as shaft diameter, height and mounting pattern.

Synchronous speed: This is determined by the frequency of the supply voltage and the number of poles in the motor. It is required for calculation of slip load.

Out of this available data, the data that will be required for the analysis of a motor was selected, so as to include on field data collection sheet. Along with this data from the nameplate which is provided at rated i.e. full load conditions, it was necessary to collect data required for analysis at operating conditions. Following data was required.

Application of the motor: This gives the idea of where the installed motor is being used. For example, air compressor, blower, etc.

Operating speed: This is the speed at which the motor actually operates. It is required for the calculation of the slip load.

Operating power factor: It is the power factor at which motor is currently operating. This is required for calculation of input power. 
Three phase voltages: These are the voltages of three phases that are supplying the motor. Though it is not necessary to obtain these separately, average three phase voltage is required for the measurement of input power.

Three phase line currents: These are the currents of three phases that supplying motor. Average line current is used in the measurement of the input power.

Also average line current and voltages are required for the load factor evaluation by line current measurement method as well as voltage corrected slip method.

Operating hours: These are the annual hours for which the motor operates. These are essential to carryout energy saving calculations.

No of Re-windings: As discussed in the literature review, rewinding reduces the operating efficiency of the motor. Therefore, while calculating the output power of the motor this has to be taken into account. Considering these conditions the factors given in Table 3.1 were selected for data collection.

Table 3.1 Parameters Selected for Field Data Collection

\begin{tabular}{|l|l|l|}
\hline \multicolumn{1}{|c|}{ General } & \multicolumn{1}{|c|}{ Mechanical } & \multicolumn{1}{c|}{ Electrical } \\
\hline Manufacturer & Synchronous Speed & Rated Voltage \\
\hline Serial Number & Rated Speed & Phase Voltages (Vab, Vbc,Vac) \\
\hline Application & Measured Speed & Rated Current \\
\hline Size (HP) & & Line Currents (Iab, Ibc, Iac) \\
\hline
\end{tabular}

Due to poor accessibility, age of the motor or other difficulties certain parameters were noted only where available. They are,

- Rated Power Factor

- Nominal Efficiency of Motor

- Enclosure

- No of Re-windings

A field data collection sheet was designed which is given in Appendix I. The data was collected in the facilities using this data collection sheet. 


\subsubsection{Restriction on Data Collection}

The data that is collected for this research is mostly obtained under DOE or West Virginia Development Office (WVDO) funded research projects. The projects are designed to help reduce small to medium manufacturing industries their energy costs and at the same time save overall energy nationwide. The manufacturing operations can range from food processing to steel plant. Under these projects, a team is deployed to the manufacturing plant being assessed. The team reviews the manufacturing process of the plant as well as the equipment used in the process for possible energy saving opportunities. Typically these assessments are one day assessments during which the team focuses on different areas such as HVAC, steam systems, insulation, compressors plant lighting and motors. When assessment begins the team starts off by speaking with associated maintenance and process personnel to get general idea about the process and major energy consuming equipment. After this, there is initial walk-through of the plant during which team spots the opportunities for energy saving. The team collects data of all of the above areas to estimate energy savings and cost savings for the assessed facility. Since it is a one day assessment only, it restricts the time that can be devoted to a particular system.

In the present study, the data collection is restricted by number of factors. Some of them include

- Time

- Cost

- Safety

Also, there are other barriers such as accessibility that put restriction on the data collection. Therefore, to make use of the above mentioned resources efficiently it was necessary to put boundaries on data collection. It has been observed that big motors consume most of the energy while small motors though big in number consume less energy. Therefore, the size (HP) range of the motor was decided to be taken as $20 \mathrm{HP}$ 250 HP. Motors below $20 \mathrm{HP}$ generally account for small percentage of total amount of energy consumption. Also, motors above 250-300 HP are not frequently found in the industry unless it is a very large plant. 
As the assessment of the whole plant has to be done in one day, it limited the time that can be devoted to one particular motor. Therefore it was decided that only 60 data points spaced at an interval of 5 seconds for each motor will be obtained. Wherever needed and as the time permitted more data points for some motors were obtained in order to have adequate understanding of the load variations over the monitored time period. This would give a general idea about the motor load while it is in operation.

\subsubsection{Procedure for Data Collection}

Good data collection always requires systematic data collection procedure. As discussed above the motor data was recorded into a data collection sheet. The speed measurement was done with a digital stroboscope with a controllable frequency. The assessment team goes around the facility during the initial walk through, and spots the convenient motors those can be used for data collection. The data is collected on these motors with the stroboscope and Amprobe ${ }^{\mathrm{TM}}$ DM II Pro.

\subsubsection{Speed Measurement using stroboscope}

Digital stroboscope flashes in unison with the monitored object, and the speed of the object or the motor shaft is equal to the flash rate. The schematic of the motor load test set up can be seen in the Figure 3.1 below. The figure shows the variable frequency source, which is the supply for the unit. A battery pack can also be used to provide the AC supply to the stroboscope. The frequency scalar is used to change the frequency of the flashlight so as to meet the rpm pf the motor shaft. There is also a digital display, which shows the flashes per minute. The flashing unit produces the flashlight through a Xenon flasher, which is directly incident on the rotating shaft of the motor. When the rotating shaft of the motor appears stationary to the eyes of the user then the flash per minute equals the rpm of the motor. The data so recorded from each of the monitored motor was logged into the measured speed field in the data collection sheet. The advantages of using stroboscope include, safety and accurate speed can be obtained within 1 revolution [18]. 


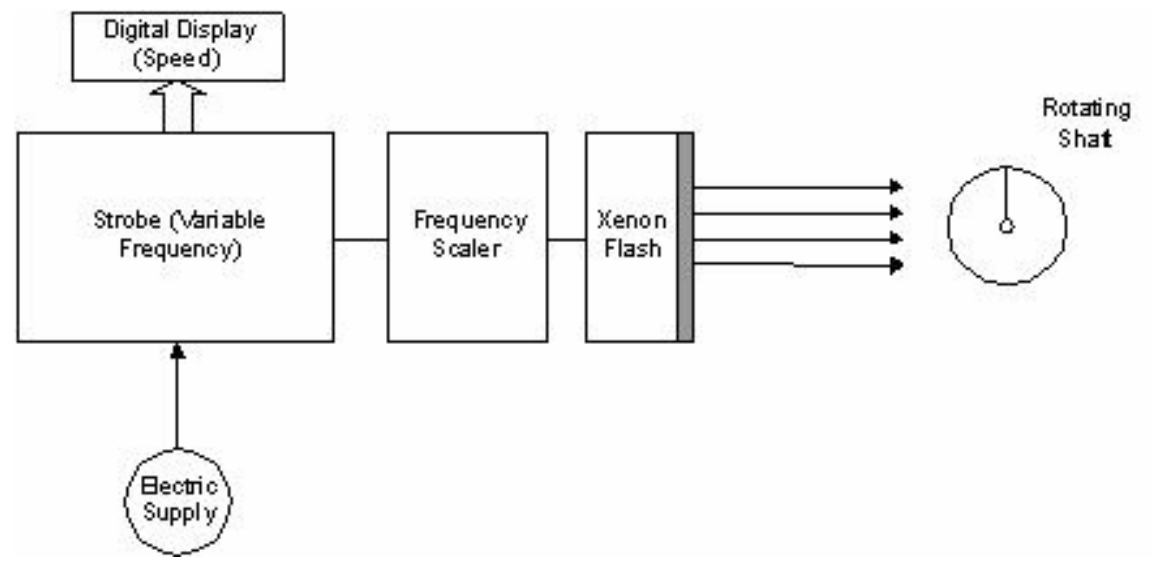

Figure 3.1 Principle of Stroboscope Speed Measurement [18]

\subsubsection{Power Measurement with Amprobe ${ }^{\mathrm{TM}}$ DM II Pro}

For recording the various electrical data that is required, DM II Pro equipment from Amprobe ${ }^{\mathrm{TM}}$ was used. The technical Specifications of the equipment are as given below [12].

AC Voltage:

$0-600 \mathrm{~V}$

AC Current:

1 - 1000A (expandable to 3000A with optional CT's)

Power: Actual (W), Reactive (VAR) and Apparent (VA)

Power Factor:

$0-1$

Energy:

$\mathrm{kWh}$

Peak Demand: $\mathrm{kW}$

Fund. Frequencies: $50 / 60 \mathrm{~Hz}$

Available Recording Time: 1 hour to several months depending on setup

\section{Connections}

Generally, in the manufacturing industry the 3 phase induction motors are connected by three phase three wire arrangements. The arrangement is shown in Figure 3.2

\section{Connections Diagram}

The connection scheme that has been used is shown in the Figure 3.3. The connecting wires that are used are color coded. For the voltage leads 'COM' is connected to by yellow voltage pin to phase II. V1 lead connects with phase III by black voltage pin. And V3 lead connects to phase I by blue voltage pin. The black current probe from 
I1 connects to phase III. The red current probe from I 2 connects to phase II and the blue current probe connects to phase I, as shown in the Figure 3.3

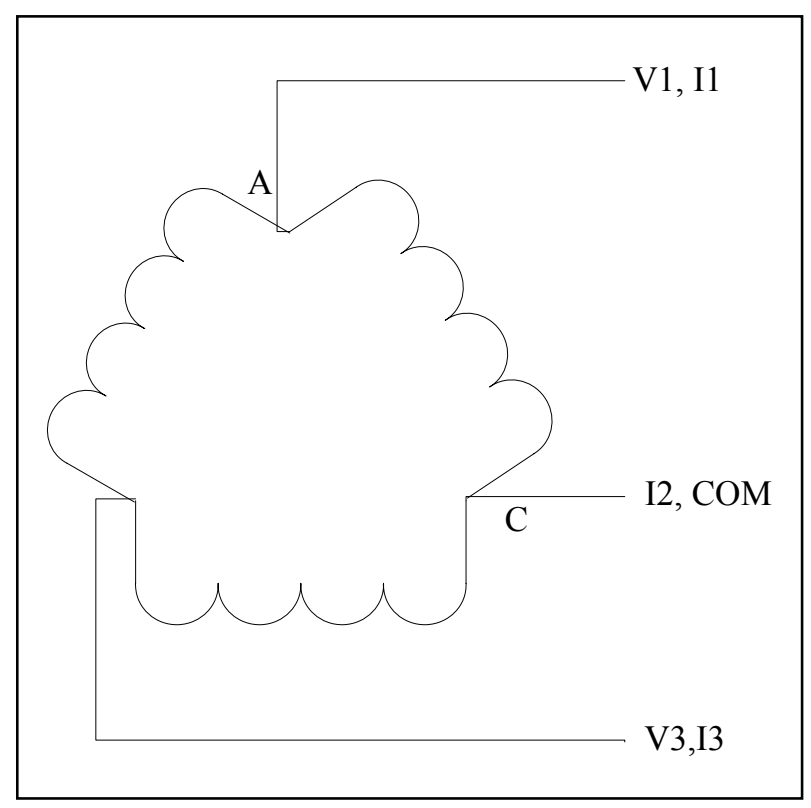

Figure 3.2 3 Phase 3 wire Delta Connection Arrangement for Amprobe

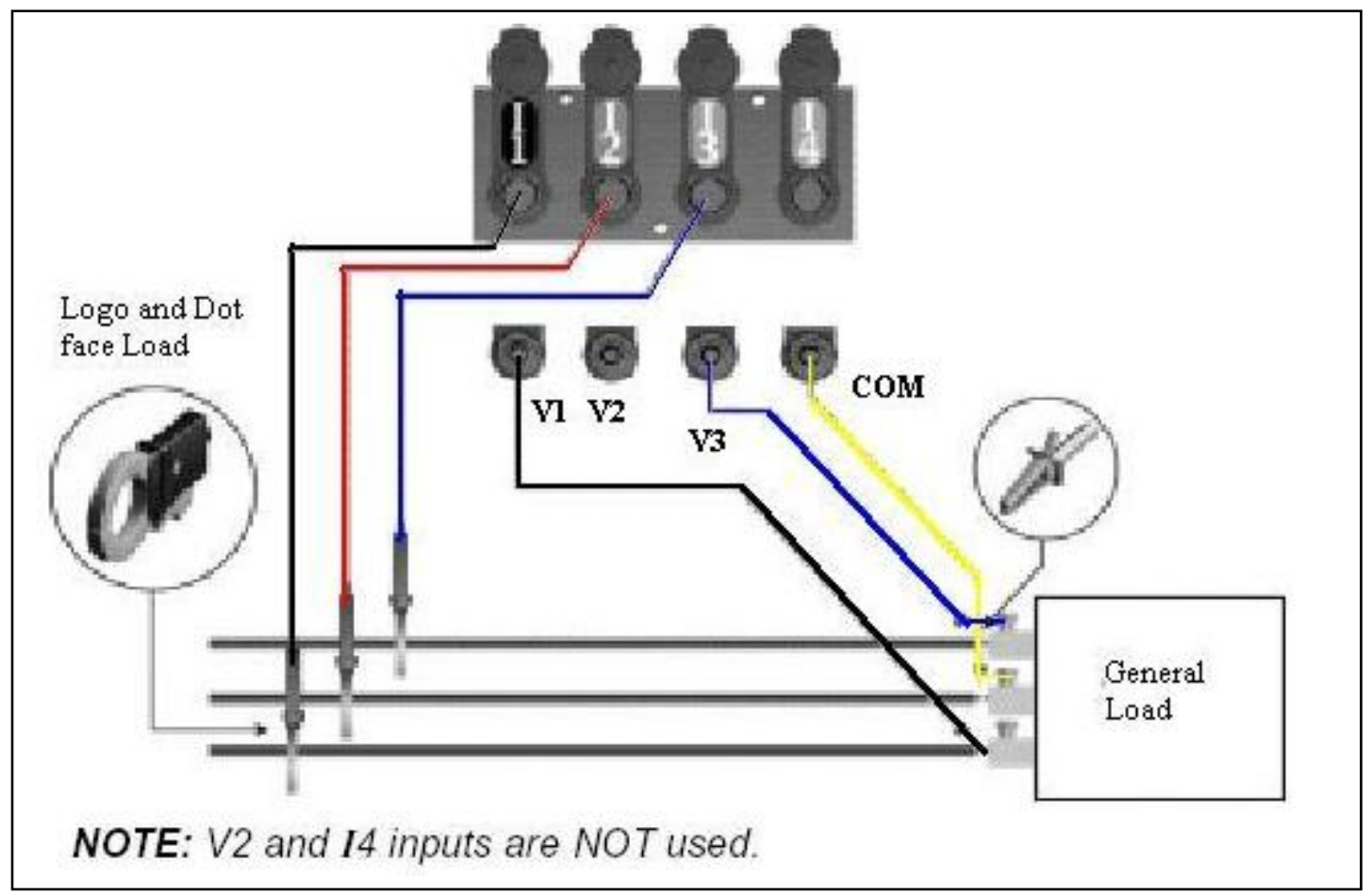

Figure 3.3 DM II Pro 3 Phase 3 wire (Phase to Phase Measurement) Connections Diagram [12] 
After DM II Pro has been hooked in such way, to the electric control box that supplies to the motor, the DM II Pro data is recorded for at least 60 data points to have an idea of the motor loading.

\section{Downloading Data}

After the data is recorded, the connections are removed from the supply and the DMII Pro data is downloaded on a laptop computer using a data transfer cable. This data can be used for analysis. The fields of data recorded by DMII Pro are given in Table 3.2.

\section{RMS Voltages and Current}

The Amprobe ${ }^{\mathrm{TM}}$ DM II Pro records root mean square (RMS) values of voltages of each phase and current. AC current and voltages supplied are in the form of sinusoidal wave so to calculate the effective value of particular current or voltage it is expressed in RMS value. The Amprobe ${ }^{\mathrm{TM}}$ records RMS values of 3 phase voltages $\mathrm{V}_{\mathrm{AB}}, \mathrm{V}_{\mathrm{BC}}$ and $\mathrm{V}_{\mathrm{CA}}$ and line current $\mathrm{I}_{\mathrm{A}}, \mathrm{I}_{\mathrm{B}}$ and $\mathrm{I}_{\mathrm{C}}$.

\section{Real, Reactive and Apparent Power}

These terms are explained earlier in section 1.6. Amprobe $^{\mathrm{TM}}$ directly records the values for the power components.

Table 3.2 Fields of the DM II Pro Recorded Data

\begin{tabular}{|c|c|c|c|c|c|c|c|c|c|}
\hline \multirow{3}{*}{ Time } & RMS & RMS & RMS & RMS & RMS & RMS & \multirow{3}{*}{\begin{tabular}{|c|} 
Real \\
Power \\
$3 \emptyset(W)$
\end{tabular}} & \multirow{3}{*}{$\begin{array}{l}\text { Reactive } \\
\text { Power } \\
\text { (VAR) }\end{array}$} & \multirow{3}{*}{$\begin{array}{c}\text { Apparent } \\
\text { Power } \\
3 \varnothing \text { (VA) }\end{array}$} \\
\hline & Voltage & Curren & Voltage & Curren & t Voltage & Current & & & \\
\hline & $V_{A B}(V)$ & $I_{A}(A)$ & $V_{B C}(V)$ & $\mathrm{I}_{\mathrm{B}}(\mathbf{A})$ & $V_{C A}(V)$ & $\mathrm{I}_{\mathrm{C}}(\mathrm{A})$ & & & \\
\hline & & & & & & & & & \\
\hline
\end{tabular}

\subsubsection{Collected Motor Data}

The data has been collected from 52 different motors so far in the plant assessments as discussed above. The motors ranged from $20 \mathrm{HP}-250 \mathrm{HP}$. The data recorded is too lengthy and tedious to produce here. Summary of the data collected and its analysis has been presented instead in Appendix II. The data collected for slip method analysis was recorded with the help of stroboscope and data collection sheet. Appendix III presents the obtained data. The data was collected and analysis was carried out. 


\subsection{Data Analysis}

The data analysis is carried out in steps of the above data. The steps consisted of the load factor evaluation by the four listed methods, i.e. slip method, voltage corrected slip method, line current measurement method and Input power evaluation method.

\subsubsection{Load Factor Evaluation by Slip Method}

As given in equation 1.14 the load factors were evaluated for each motor. A sample calculation is shown below. Consider motor given in Table 3.3. It is one of the observed motor (no. 11) as shown in Appendix III.

Table 3.3 Example Data Analysis

\begin{tabular}{|l|c|c|c|c|c|c|c|c|}
\hline Sr. & Application & Make & $\begin{array}{c}\text { Size } \\
\text { (HP) }\end{array}$ & $\begin{array}{c}\text { Speed } \\
\text { Rated }\end{array}$ & $\begin{array}{c}\text { Speed } \\
\text { Measured }\end{array}$ & Voltage & $\begin{array}{c}\text { Rated } \\
\text { Current }\end{array}$ & Sr. No \\
\hline 11 & $\begin{array}{c}\text { Air } \\
\text { Compressor }\end{array}$ & $\begin{array}{c}\text { Tatung } \\
\text { Co. }\end{array}$ & 20 & 1745 & 1786.4 & $\begin{array}{c}203- \\
230 / 480\end{array}$ & $\begin{array}{c}57- \\
53 / 26.5\end{array}$ & $\begin{array}{c}\text { U34205044 } \\
\text { (TB0204DBA) }\end{array}$ \\
\hline
\end{tabular}

Load $=\frac{\text { Slip }}{\left(S_{s}-S_{r}\right)}$

Ss $=$ Synchronous Speed

$\mathrm{Sr}=$ Rated Speed

Slip $=$ Synchronous Speed - Measured Speed $=1800-1786=14$

$(\mathrm{Ss}-\mathrm{Sr})=1800-1745=55$

Therefore,

Load Factor $=14 / 55=\mathbf{2 4 . 7} \%$

\subsubsection{Load Factor Evaluation by Voltage Corrected Slip Method}

As given in equation 1.15, one can obtain a better estimate of the load on the motor if knowledge of phase voltage is available. The load factors for this method can be estimated as shown below.

Refer to motor data given in Table 3.3

$$
\text { Load }=\frac{\text { Slip }}{\left(S_{s}-S_{r}\right) \times\left(\frac{V r}{V}\right)^{2}}
$$


Slip $=14$.

$\left(\mathrm{S}_{\mathrm{S}}-\mathrm{S}_{\mathrm{r}}\right)=55$

$\mathrm{V}_{\mathrm{r}}=$ Rated Voltage $=480 \mathrm{~V}$ (i.e the voltage for which the connections are made)

$\mathrm{V}=$ Phase voltage $=469 \mathrm{~V}($ Avg. Phase Voltage from Appendix II)

Therefore,

Load Factor $=14 /\left[55 \times(480 / 469)^{2}\right]=23.6 \%$

\subsubsection{Load Factor Evaluation by Line Current Measurement Method}

This method involves the average line current and phase voltage that is measured using DM II Pro for calculation of the load as shown in equation 1.13.

Refer to the motor data given in Table 3.3,

$\mathrm{LF}=\frac{\text { Amps measured } \mathrm{X} \text { Volts measured }}{\text { Amps nameplate } \mathrm{X} \text { Volts nameplate }}$

Amps ${ }_{\text {measured }}=$ Average line current $=12.9($ from Appendix II $)$

Volts $_{\text {measured }}=$ Average phase voltage $=469$ (from Appendix II)

Amps nameplate $=$ Rated Current $=26.5$ A (from Table 3.3)

Volts nameplate $=$ Rated Voltage $=480 \mathrm{~V}($ From Table 3.3)

Therefore,

Load Factor $=(12.9 \times 469) /(26.5 \times 480)$

Load Factor $=\mathbf{4 7 . 6} \%$

\subsubsection{Load Factor Evaluation by Input Power Measurement}

This method evaluated the input power of the motor for determining the load on the motor. This is most accurate method among the adopted methods for evaluating load factor. The Input power is evaluated from the DM II Pro obtained data, using the following relationship.

$\mathrm{I} / \mathrm{P}$ Power $=\frac{\sqrt{3} \times \mathrm{V} \times \mathrm{I} \times \mathrm{PF}}{1000}$

$\mathrm{V}=$ Average phase voltage $=469 \mathrm{~V}$ (from Appendix II)

$\mathrm{I}=$ Average line current $=12.9$ A (from Appendix II)

$\mathrm{PF}=$ Operating Power Factor $=0.60$ (from Appendix II)

$\mathrm{I} / \mathrm{P}$ Power $=1.732 \times 469 \times 12.9 \times 60 / 1000=6.52 \mathrm{~kW}$ 
The Rated Output power is evaluated by obtaining the efficiency from MotorMaster+TM database.

Rated O/P Power $=\frac{\text { HP } \times 0.746}{\eta_{\text {MotorMaster }}}$

$\eta=0.902$ (from MotorMaster ${ }^{\mathrm{TM}}$ Database)

$\mathrm{HP}=20 \mathrm{hp}($ from Table 3.5)

Therefore, Rated O/P Power $=16.54 \mathrm{~kW}$

Now, load factor can be estimated from the relationship given in equation 1.12.

Load Factor $=6.52 / 16.54=\mathbf{3 9 . 4} \%$

Similarly, the analysis was carried out for 52 other motors. The results of this are shown in Table 3.4 .

Table 3.4 Load Factors by Different Methods for recorded motors

\begin{tabular}{|c|c|c|c|c|c|c|c|}
\hline No & Facility & Motor & HP & $\begin{array}{l}\text { Slip Load } \\
\text { (A) }\end{array}$ & $\begin{array}{c}\text { Voltage } \\
\text { Corrected Slip } \\
\text { (B) }\end{array}$ & $\begin{array}{c}\text { Volt- } \\
\text { current(D) }\end{array}$ & $\begin{array}{l}\text { I/P Power } \\
\text { Measurement } \\
\text { (C) }\end{array}$ \\
\hline 1 & \multirow{3}{*}{ I } & 1 & 60 & 0.135 & 0.141 & 0.358 & 0.339 \\
\hline 2 & & 2 & 25 & 0.250 & 0.280 & 0.583 & 0.695 \\
\hline 3 & & 3 & 125 & 0.115 & 0.059 & 0.369 & 0.310 \\
\hline 4 & \multirow{4}{*}{ II } & 1 & 75 & 1.000 & 0.981 & 0.957 & 0.518 \\
\hline 5 & & 2 & 200 & 0.736 & 0.716 & 0.791 & 0.926 \\
\hline 6 & & 3 & 200 & 1.200 & 1.161 & 0.953 & 0.192 \\
\hline 7 & & 4 & 200 & 0.020 & 0.020 & 0.571 & 0.488 \\
\hline 8 & \multirow{3}{*}{ III } & 1 & 200 & 0.780 & 0.838 & 0.796 & 0.788 \\
\hline 9 & & 2 & 150 & 0.070 & 0.079 & 0.355 & 0.116 \\
\hline 10 & & 3 & 40 & 0.640 & 0.701 & 0.819 & 0.820 \\
\hline 11 & \multirow{3}{*}{ IV } & 1 & 20 & 0.247 & 0.236 & 0.476 & 0.593 \\
\hline 12 & & 2 & 150 & 0.010 & 0.011 & 0.473 & 0.122 \\
\hline 13 & & 3 & 150 & 0.084 & 0.097 & 0.305 & 0.182 \\
\hline 14 & V & 1 & 25 & 0.532 & 0.547 & 0.821 & 0.748 \\
\hline 15 & \multirow{3}{*}{ VI } & 1 & 200 & 0.652 & 0.737 & 0.821 & 0.920 \\
\hline 16 & & 2 & 75 & 0.888 & 1.016 & 1.018 & 1.123 \\
\hline 17 & & 3 & 75 & 0.960 & 1.106 & 1.014 & 1.157 \\
\hline 18 & \multirow{4}{*}{ VII } & 1 & 150 & 0.085 & 0.092 & 0.384 & 0.193 \\
\hline 19 & & 2 & 150 & 0.510 & 0.544 & 0.700 & 0.655 \\
\hline 20 & & 3 & 200 & 0.100 & 0.106 & - & 0.365 \\
\hline 21 & & 4 & 200 & 0.610 & 0.630 & - & 0.619 \\
\hline
\end{tabular}




\begin{tabular}{|c|c|c|c|c|c|c|c|}
\hline No & Facility & Motor & HP & $\begin{array}{c}\text { Slip Load } \\
\text { (A) }\end{array}$ & $\begin{array}{c}\text { Voltage } \\
\text { Corrected Slip } \\
\text { (B) }\end{array}$ & $\begin{array}{c}\text { Volt- } \\
\text { current(D) }\end{array}$ & $\begin{array}{c}\text { I/P Power } \\
\text { Measurement } \\
\text { (C) }\end{array}$ \\
\hline 22 & \multirow{2}{*}{ VII } & 5 & 60 & 0.500 & 0.530 & 0.606 & 0.720 \\
\hline 23 & & 6 & 30 & 0.378 & 0.405 & 1.058 & 0.508 \\
\hline 24 & \multirow{2}{*}{ VIII } & 1 & 20 & 0.047 & 0.051 & 0.388 & 0.138 \\
\hline 25 & & 2 & 20 & 0.511 & 0.554 & 0.841 & 0.841 \\
\hline 26 & \multirow{7}{*}{ IX } & 1 & 30 & 0.525 & 0.521 & 0.599 & 0.640 \\
\hline 27 & & 2 & 25 & 0.343 & 0.353 & 0.618 & 0.593 \\
\hline 28 & & 3 & 25 & 0.406 & 0.419 & 0.644 & 0.634 \\
\hline 29 & & 4 & 75 & 0.446 & 0.470 & 0.665 & 0.662 \\
\hline 30 & & 5 & 75 & 0.560 & 0.592 & 1.111 & 1.110 \\
\hline 31 & & 6 & 100 & 0.443 & 0.471 & 0.448 & 0.386 \\
\hline 32 & & 7 & 40 & 0.914 & 1.141 & 1.466 & 0.743 \\
\hline 33 & \multirow{5}{*}{ X } & 1 & 20 & 0.051 & 0.057 & 0.418 & 0.173 \\
\hline 34 & & 2 & 50 & 0.892 & 0.988 & 0.697 & 0.828 \\
\hline 35 & & 3 & 50 & 0.472 & 0.525 & 0.239 & 0.197 \\
\hline 36 & & 4 & 150 & 0.400 & 0.478 & 0.793 & 0.586 \\
\hline 37 & & 5 & 25 & 0.720 & 0.795 & 0.919 & 0.894 \\
\hline 38 & \multirow{4}{*}{ XI } & 1 & 125 & 0.160 & 0.158 & 0.847 & 0.278 \\
\hline 39 & & 2 & 40 & 0.183 & 0.202 & 0.943 & 0.060 \\
\hline 40 & & 3 & 125 & 0.872 & 0.892 & 1.068 & 1.054 \\
\hline 41 & & 4 & 250 & 0.832 & 0.845 & 1.293 & 1.039 \\
\hline 42 & \multirow{6}{*}{ XII } & 1 & 100 & 0.673 & 0.646 & 0.703 & 0.789 \\
\hline 43 & & 2 & 200 & 0.477 & 0.495 & 0.625 & 0.339 \\
\hline 44 & & 3 & 125 & 0.620 & 0.556 & 0.712 & 0.740 \\
\hline 45 & & 4 & 150 & 1.067 & 1.059 & 0.977 & 0.621 \\
\hline 46 & & 5 & 150 & 0.121 & 0.124 & 0.382 & 0.421 \\
\hline 47 & & 6 & 75 & 0.475 & 0.488 & 0.682 & 0.679 \\
\hline 48 & XIII & 1 & 150 & 0.368 & 0.319 & 0.371 & 0.110 \\
\hline 49 & XIV & 1 & 30 & 0.502 & 0.129 & 0.694 & 0.587 \\
\hline 50 & \multirow{3}{*}{$\mathrm{XV}$} & 1 & 50 & 0.733 & 0.856 & 1.231 & 1.219 \\
\hline 51 & & 2 & 60 & 0.995 & 1.040 & - & 1.126 \\
\hline 52 & & 3 & 30 & 0.068 & 0.065 & - & 0.199 \\
\hline
\end{tabular}




\subsection{Results}

\subsubsection{Motor Loading In the Study Carried Out In the Field}

In this undertaken study 52 motors were tested in the field for the motor loads on the energy assessments for WVDO project in fifteen different plants. The findings were similar to X-energy study in 1998. These findings are summarized in Table 3.5

Table 3.5 Data Found on Motor Loading In Field Energy Assessments

\begin{tabular}{|c|c|c|c|c|}
\hline \multirow{2}{*}{ Part Load } & \multicolumn{4}{|c|}{ Horse Power Category } \\
\cline { 2 - 5 } & $\mathbf{2 0 - 5 0} \mathbf{~ h p}$ & $\mathbf{5 1 - 1 0 0}$ hp & $\mathbf{1 0 1 - 2 0 0}$ hp & $\mathbf{2 0 0 +} \mathbf{~ h p}$ \\
\hline$<\mathbf{4 0} \%$ & $21 \%$ & $18 \%$ & $48 \%$ & $0 \%$ \\
\hline $\mathbf{4 0 - 6 0} \%$ & $21 \%$ & $9 \%$ & $14 \%$ & $0 \%$ \\
\hline $\mathbf{6 0 - 1 2 0} \%$ & $47 \%$ & $73 \%$ & $38 \%$ & $100 \%$ \\
\hline$>\mathbf{1 2 0} \%$ & $11 \%$ & $0 \%$ & $0 \%$ & $0 \%$ \\
\hline Motors Examined & 19 & 11 & 21 & 1 \\
\hline
\end{tabular}

This gives a pretty good idea of how motors are loaded. The graph in Figure 3.4 shows that there is a lot of potential for energy savings in all categories of horsepower. The data should be interpreted carefully for $200+\mathrm{hp}$ motors because only one motor above $200 \mathrm{hp}$ could be tested on the field in the energy assessments that were carried out in 15 plants. Overall it was found that $46 \%$ of motors were operating below $60 \%$ load factor.

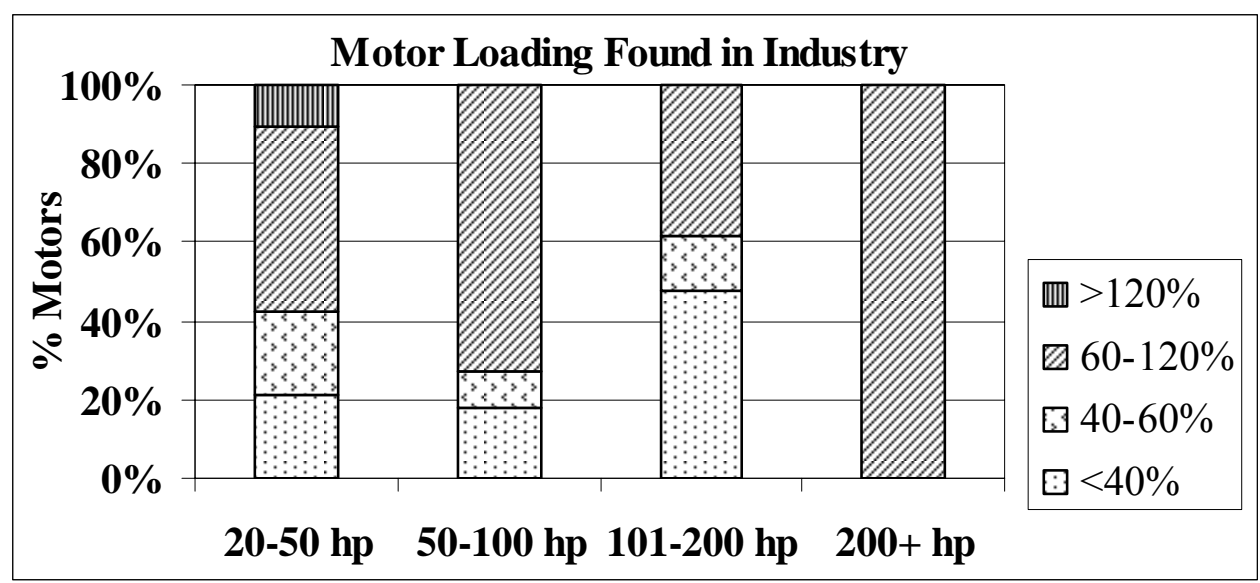

Figure 3.4 Percentage of Motors According to Load Factor 
This agrees fairly with X-energy national field study that was carried out in 1998. All $46 \%$ of these motors could be considered for downsizing ${ }^{3}$. The percentage of motors examined according to load factor is given in Table 3.6. The Figure 3.5 shows the piechart.

Table 3.6 Load Factors of the Motors Examined

\begin{tabular}{|c|c|c|c|c|}
\hline Part Load & $<\mathbf{4 0} \%$ & $\mathbf{4 0 - 6 0} \%$ & $\mathbf{6 0 - 1 2 0} \%$ & $>\mathbf{1 2 0} \%$ \\
\hline \% Examined of Motors & $31 \%$ & $15 \%$ & $50 \%$ & $6 \%$ \\
\hline
\end{tabular}

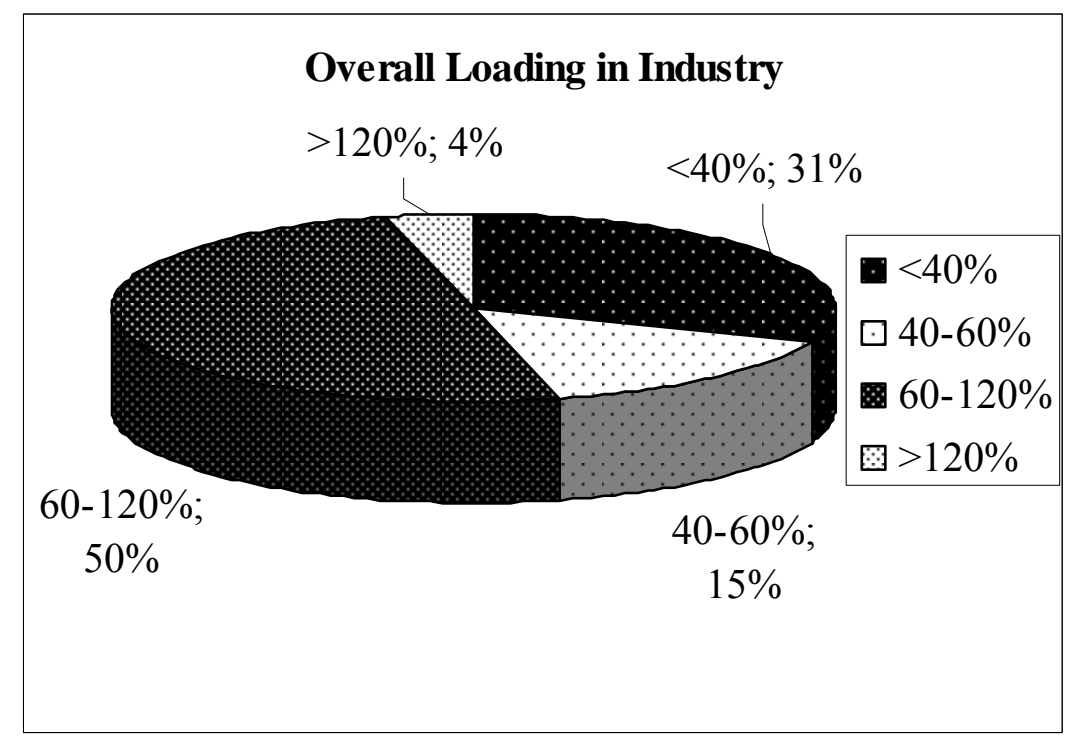

Figure 3.5 Overall distribution of load factors in the tested motors

As discussed above power measurement method gives most accurate results among the considered methods. This is because power measurement is reasonably accurate if motor is operating above $40-50 \%$ load. MotorMaster+ calculates efficiency as described in section 1.8.2.2. This efficiency may slightly differ from the actual operating efficiency but has been found to be reasonably good estimate. The input power measurement load depends on these two values. Better accuracy in these two values leads to better estimate of motor load. A more accurate estimate would involve real efficiency measurement which in turn prompts for loss measurements and subsequent uncoupling of the motor from load to carry out tests which are not feasible for the given scenario. The literature reveals that usually this method is fairly accurate giving estimates within good accuracy.

\footnotetext{
${ }^{3}$ The assessment recommendations have been made to the concerned plants after carrying out economic analysis which shows a reasonable simple payback period of less than 36 months.
} 
Therefore, the load factor measured by this method is regarded as standard to compare with other methods.

If observed closely, it can be noted that the load factor obtained by power measurement technique is always high as compared to slip method and voltage corrected slip method. The load factor calculated from volt-current method gives mixed type of estimates lying on both sides of the load factors obtained by input power measurement method. There are occasions where this does not hold true in observed motors in the undertaken study. The outliers have been removed from the data as discussed in Chapter 4.

Some motors show abnormal deviation from the load factor obtained by the power measurement. These motors form outliers in the collected data. Each motor was closely examined for the non-conforming deviation. It is noted that motors $4,7,32,33,44,46$ and 49 form outliers in the data. It was found that, motor 33 was an irregular type of motor of rated speed $1800 \mathrm{rpm}$ and unspecified synchronous speed, also the frequency and poles were unspecified on the nameplate. The measured speed for this motor was found to be $1851 \mathrm{rpm}$. For other motors there was an indication of error in recording the data due to improper connections of the Amprobe ${ }^{\mathrm{TM}}$. Therefore, these outliers were excluded for analyzing the relationship between load factors obtained by the considered four methods. Therefore, these data points have been excluded and kept intact in the further analysis.

The load results that are obtained with these methods in Table 3.4 are used for following two main purposes

- Establishing relationship between load obtained by 3 methods and input power measurement method

- Approach for analyzing the motor energy savings and perform economic analysis.

The two purposes are elaborated in section 3.3.1 and 3.3.2 respectively.

\subsubsection{Load Factors Relationships}

For examining the relationships, graphs were plotted using Microsoft Excel ${ }^{\circledR}$ as a tool. The graph of load factor obtained by slip and power measurement method vs. the motors was plotted to learn that the load factor obtained by slip method is always less 
than that obtained by input power measurement method. This graph is given in Figure 5.3 and has been discussed in greater detail in Chapter 5. The differences between the loadfactors vary from motor to motor. As found in analysis the difference between the load factors (slip, power measurement) is not a function of motor HP.

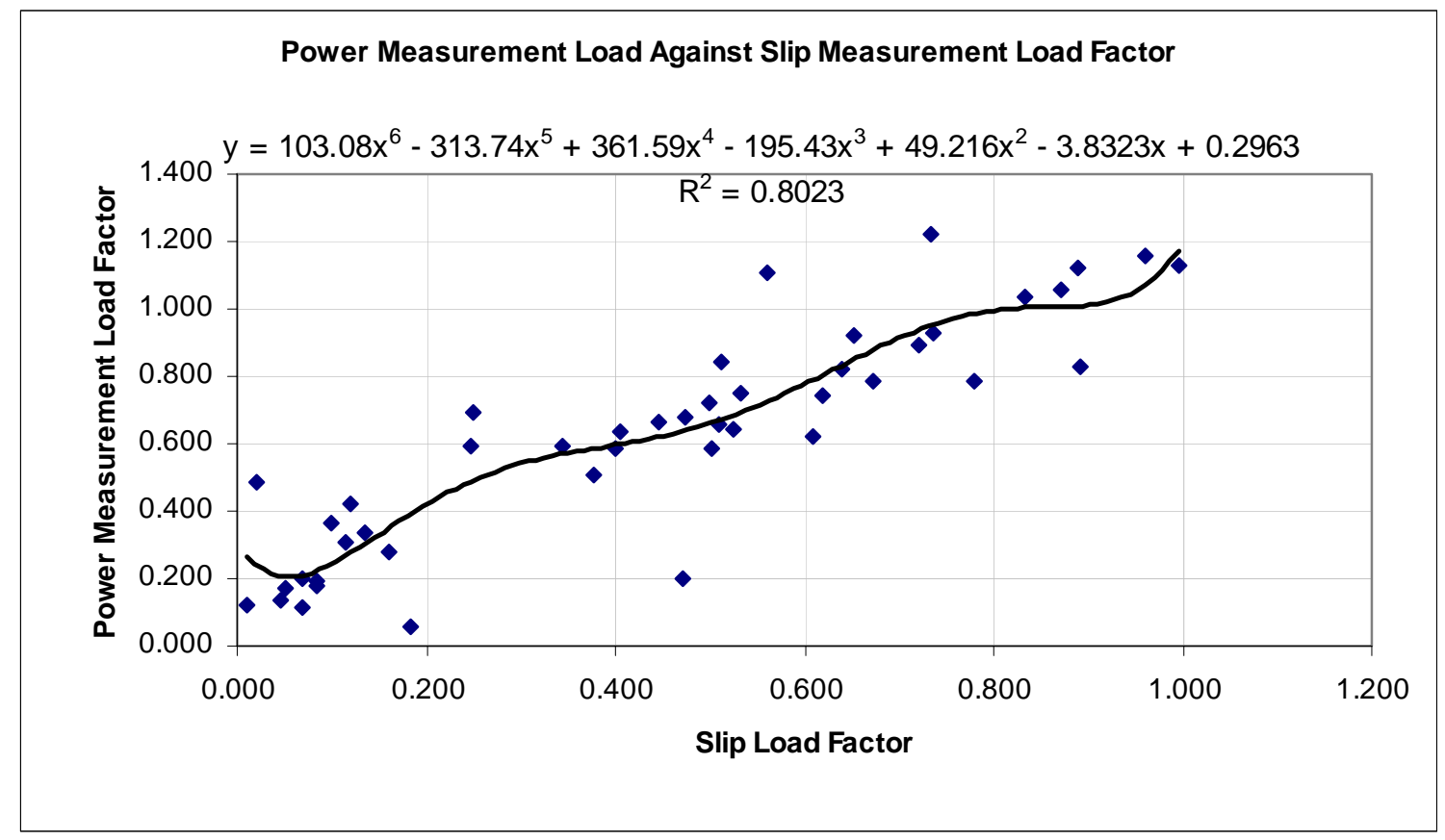

Figure 3.6 Slip Load Factor Vs Power Measurement Load Factor

To find out the relationship between the slip load factor and the power measurement load factor which represents actual load factor with good accuracy, graph with slip load factor on the $\mathrm{x}$ axis and power measurement load factor on $\mathrm{y}$ axis is plotted in Figure 3.6. The $\mathrm{R}^{2}$ value was found to be 0.8023 , which is fairly high for the correlation. The relation between the two was found to be,

$y=103.08 x^{6}-313.74 x^{5}+361.59 x^{4}-195.43 x^{3}+49.216 x^{2}-3.8323 x+0.2963$

Where,

$\mathrm{x}=$ Slip load factor

$\mathrm{y}=$ Power measurement load factor.

Using the above equation, it is possible to predict the power measurement load factor from slip load factor with a $\mathrm{R}^{2}$ value of 0.8023 , which will save the industrial people hurdle of measuring power with expensive instruments in unsafe environment and also give the results in acceptable accuracy. It will also save the time required for the 
process, which is very essential factor in the field evaluations especially short-term assessments as described earlier. The analysis of these two load factors is of major interest in the present work undertaken. It has been discussed and analyzed in much greater detail later in coming Chapters 4 and 5.

The graph of LF obtained by I/P Power against LF by Voltage corrected slip method also shows good correlation as expected. The $\mathrm{R}^{2}$ value obtained is 0.7749 . The graph is shown in Figure 3.7.

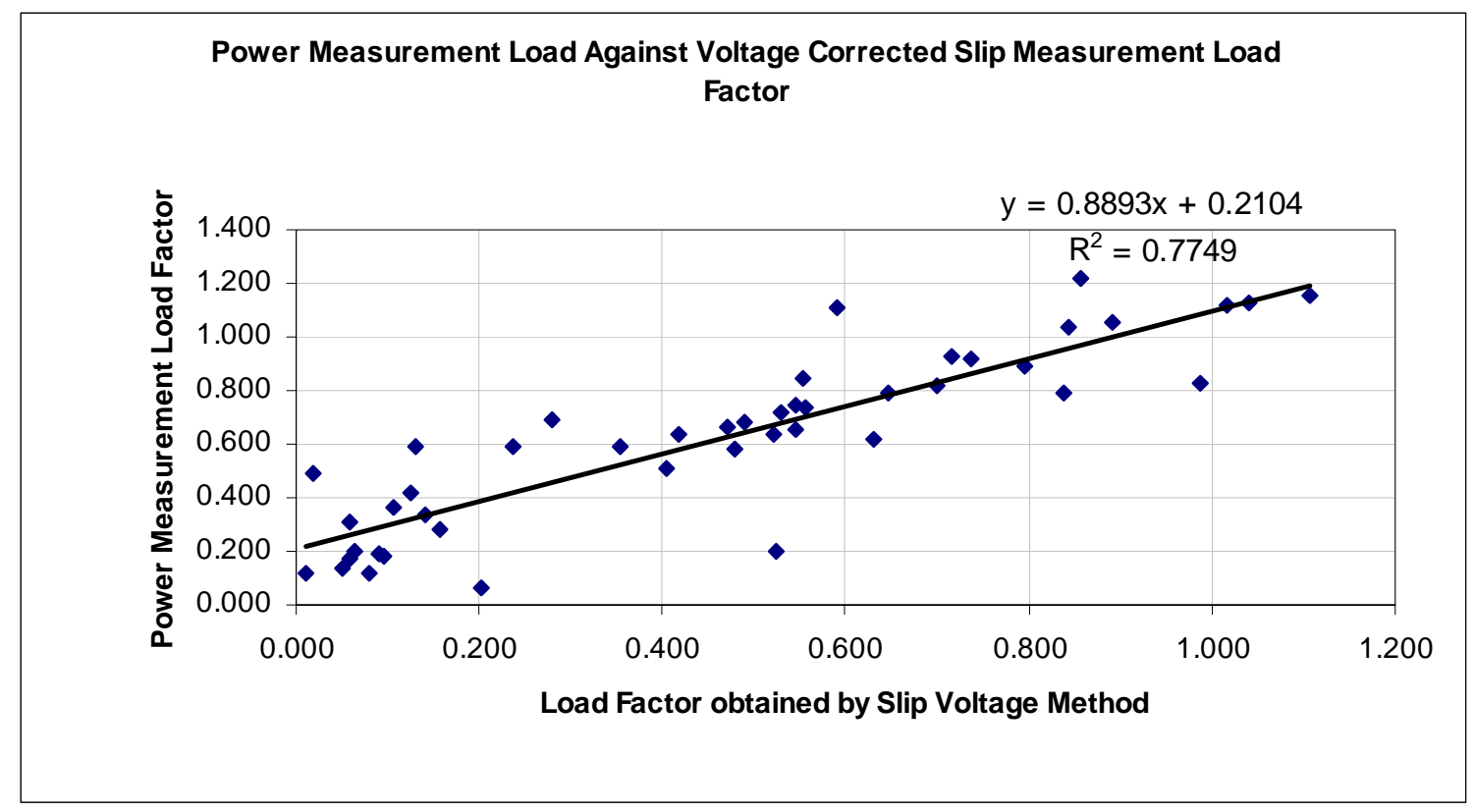

Figure 3.7 Relationship between voltage corrected slip method LF and I/P power measurement LF

The relationship between voltage corrected slip method load factor and input power measurement method load factor was found to be,

$\mathrm{y}=0.8893 \mathrm{x}+0.2104$

Where,

$\mathrm{x}=$ Slip load factor

$\mathrm{y}=$ Power measurement load factor.

The graph of load factor obtained by line current method vs load factor obtained by the power measurement method is shown in Figure 3.8. The scatter of the points is wide. It indicates that there is no relationship between these load factors. 


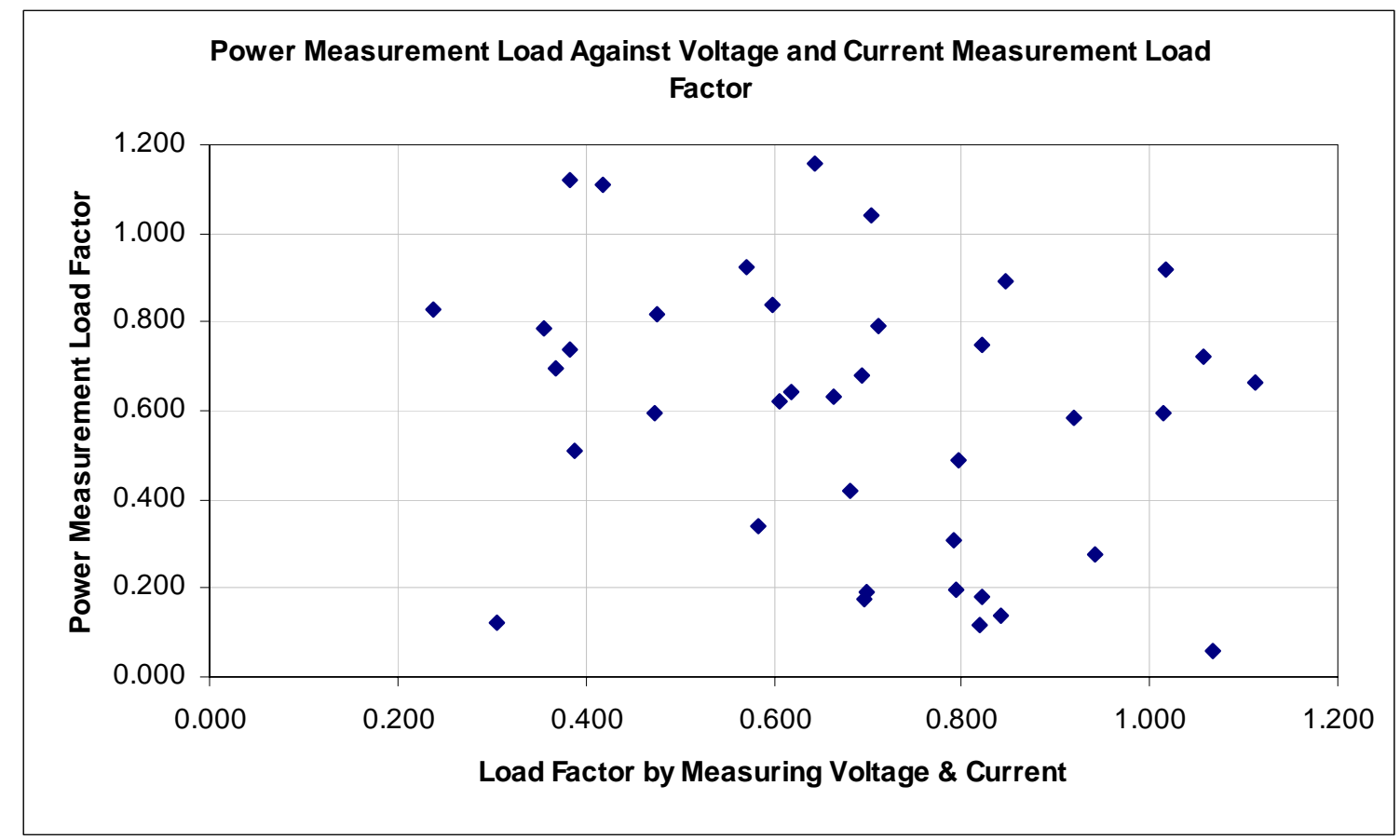

Figure 3.8 Relationship between LF by line current method and LF power measurement method

The summary of the relationships found out has been provided in Table 3.7 along with the coefficients of determination $\left(\mathrm{R}^{2}\right)$ that were obtained. The detailed analysis for $\mathrm{LF}$ (Slip) and \& LF(Power) is given in Chapter 4.

Table 3.7 Relationships between load factors and their coefficients of regression

\begin{tabular}{|l|l|c|}
\hline \multicolumn{1}{|c|}{ Relation Between } & \multicolumn{1}{|c|}{ Equation } & $\mathbf{R}^{2}$ \\
\hline LF(Slip) \& LF(Power) & $\begin{array}{l}\mathrm{y}=103.08 \mathrm{x}^{6}-313.74 \mathrm{x}^{5}+361.59 \mathrm{x}^{4}- \\
195.43 \mathrm{x}^{3}+49.216 \mathrm{x}^{2}-3.8323 \mathrm{x}+0.2963\end{array}$ & 0.8023 \\
\hline $\begin{array}{l}\text { LF(Voltage corrected } \\
\text { slip) \& LF (Power) }\end{array}$ & $\mathrm{y}=0.8893 \mathrm{x}+0.2104$ & 0.7749 \\
\hline $\begin{array}{l}\text { LF(Line Current) \& } \\
\text { LF(Power) }\end{array}$ & Scatter indicates no relationship & - \\
\hline
\end{tabular}

The analysis for voltage corrected slip method and voltage current method were not of major interest, since they do not overcome the issue of safety in measurement. It still involves recording voltage and current and working around high voltage and current areas. Hence these relationships were not investigated further. With the help of equations summarized in Table 3.7 and graphs plotted, it is easy to determine the load factor of the 
motor within reasonable accuracy. This method will be economical and easy to use as only slip load determined with the help of stroboscope is required. Also, as there are high voltages involved in the motor connections it is required to take necessary precautions while measuring load with the input power measurement. It is highly risky as fatal accidents could result in absence of necessary precautions. The slip measurement method with stroboscope is relatively very safe. This gives the devised method added advantage of safety. The load factor thus determined would help plant personnel to make better informed decisions about motor sizing. The electrical savings this would bring are considered below.

\subsubsection{Motor Energy \& Demand Savings}

The results that were obtained for load factor estimation by input power measurement were used to calculate the motor system energy savings that would result if the motor is properly sized according to the load profile measurement. It is assumed that new premium efficiency motor is installed replacing the old one. For our calculation of energy savings due to new installed motor over old motor following equation is suggested:

$$
S(M M B t u)=\frac{N^{*} 2545 B t u / h p}{1,000,000 B t u / M M B t u}\left[\left(\frac{H P^{*} L F}{\eta}\right) \text { op. }-\left(\frac{H P^{*} L F}{\eta}\right) \text { prop. }\right]
$$

Where,

$$
\begin{array}{ll}
\mathrm{S} & =\text { Saving in MMBtu / Year } \\
\mathrm{N} & \text { Yearly hours of operation } \\
\mathrm{HP}_{\mathrm{Op}} & =\text { Existing HP of the motor } \\
\mathrm{LF}_{\mathrm{Op}} & =\text { Existing load factor determined by load monitoring with Amprobe } \\
\eta_{\mathrm{Op}} & \text { Operating Efficiency of the motor, obtained from DOE fact sheet or } \\
& \text { MotorMaster }{ }^{\mathrm{TM}} \text { software. } \\
\mathrm{HP}_{\text {Prop }} & \text { Proposed HP of the motor (estimated as per the load requirement such } \\
& \text { that load factor for new motor will be near } 75 \% \text { ) } \\
\mathrm{LF}_{\text {Prop }} & \text { Load factor on the proposed motor (estimated, near } 75 \% \text { ) } \\
\eta_{\text {Prop }} & \text { Operating Efficiency of the proposed properly sized, premium efficiency } \\
& \text { motor, obtained from DOE fact sheet, or MotorMaster }
\end{array}
$$


The energy savings for each monitored motor can be calculated using the equation given above. The annual savings in $\$ / Y r$ can be calculated for each motor by multiplying S with the energy cost (\$/MMBtu) [20].

Annual savings for an individual motor $=\mathrm{S}(\mathrm{MMBtu}) *$ Energy Cost $(\$ / \mathrm{MMBtu})$

$\mathrm{LF}_{\text {op }}$ is obtained by load monitoring as shown in Table 3.4, and the $\eta_{\text {op }}$ is estimated with the help of MotorMaster ${ }^{\mathrm{TM}}$ software as suggested in the literature review for estimation of motor efficiency by computerized methods. Proposed motor size $\left(\mathrm{HP}_{\text {prop }}\right)$ is obtained by calculating the motor size nearest to the required power. The required power is given by the original motor HP multiplied by the existing load factor that is obtained load monitoring. Motors are manufactured in standard sizes (HP) therefore, the HP that fits best near the required power is proposed. $\mathrm{LF}_{\text {prop }}$ is calculated as per the definition, required power divided by motor size $\left(\mathrm{HP}_{\text {prop }}\right)$. $\mathrm{LF}_{\text {Prop }}$ therefore, is always near $75 \%$. $\eta_{\text {prop }}$ is obtained by interpolation from Motor Master ${ }^{\text {TM }}$ software. Sample calculation for 60 " mill motor that was examined during one of the plant assessment is shown here. Table 3.8 provides data obtained in the plant audit by stroboscope load monitoring.

Table 3.8 Motor Considered for Energy and Demand Savings Analysis

\begin{tabular}{|c|c|c|c|c|c|c|c|c|}
\hline Sr. & Application & Make & $\begin{array}{c}\text { Size } \\
\text { (HP) }\end{array}$ & $\begin{array}{c}\text { Speed } \\
\text { Rated }\end{array}$ & $\begin{array}{c}\text { Speed } \\
\text { Measured }\end{array}$ & Voltage & $\begin{array}{c}\text { Rated } \\
\text { Current }\end{array}$ & Sr. No \\
\hline 12 & $60 "$ Mill & $\begin{array}{c}\text { Continental } \\
\text { Electric }\end{array}$ & 150 & 710 & 719.4 & 440 & 195 & NF806S \\
\hline
\end{tabular}

Table 3.9 provides the plant specific cost data that has been used to calculate the energy as well as demand savings.

Table 3.9 Cost Data Used to Calculate Energy Savings

\begin{tabular}{|l|c|}
\hline Demand Cost $(\$ / \mathrm{kW}-\mathrm{hr})$ & 0.08 \\
\hline Yearly Operating Hours(Hrs) & 8160 \\
\hline Electrical Cost $(\$ / \mathrm{MMBtu})$ & 23.8 \\
\hline Labor Rate $(\$ / \mathrm{Hr})$ & 45 \\
\hline
\end{tabular}




$$
\begin{aligned}
\mathrm{S}= & 8160 \times 10^{-6} \times 2545\left[(150 \times 0.12 / 0.10)_{\mathrm{op}^{-}}\right. \\
& \left.(\text {Motor Size Near }(150 \times 0.12 / 0.75) \times(150 \times 0.12 / \text { Motor Size }) \times 1 / 0.80)_{\mathrm{prop}}\right] \\
= & 8160 \times 10^{-6} \times 2545\left[(150 \times 0.12 / 0.10)_{\mathrm{op}^{-}}\right. \\
& \left.(25 \times(150 \times 0.12 / 75) \times 1 / 0.80)_{\mathrm{prop}}\right] \\
= & 3,308 \mathrm{MMBtu} / \mathrm{Yr}
\end{aligned}
$$

\subsubsection{Cost savings per year}

$\mathrm{EC}=\mathrm{S} \times$ Electricity $\operatorname{Cost}(\$ / \mathrm{MMBtu})$

$\mathrm{EC} \quad=3,308 \times \$ 23.79 / \mathrm{MMBtu}$

$\mathrm{EC}=\$ 78,690 / \mathrm{Yr}$

Table 3.10 shows the summary of operating and proposed motor configuration data along with the energy savings that will be obtained. The load factor for current configuration can be calculated as discussed above. If the values for voltages and currents power factor and real power measured with the help of Amprobe ${ }^{\mathrm{TM}}$ DM II Pro are fed to

\begin{tabular}{|c|c|c|c|c|c|c|c|c|c|c|c|c|}
\hline \multirow[b]{2}{*}{ No } & \multirow{2}{*}{$\begin{array}{c}\text { Motor } \\
\text { Description }\end{array}$} & \multirow[b]{2}{*}{ Hrs/Yr } & \multicolumn{3}{|c|}{$\begin{array}{l}\text { Original Motor } \\
\text { Config. }\end{array}$} & \multicolumn{3}{|c|}{ Proposed Config } & \multirow{2}{*}{$\begin{array}{c}\text { Saved } \\
\text { MMBTU/ } \\
\text { Yr }\end{array}$} & \multirow{2}{*}{$\begin{array}{l}\text { Savings } \\
\text { \$/Yr }\end{array}$} & \multirow{2}{*}{ Premium } & \multirow{2}{*}{$\begin{array}{l}\text { Imp } \\
\text { Cost }\end{array}$} \\
\hline & & & $\begin{array}{l}\text { Size } \\
\text { (HP) }\end{array}$ & LF & Eff\%. & $\begin{array}{l}\text { Size } \\
\text { (HP) }\end{array}$ & LF & Eff\% & & & & \\
\hline 12 & 60" Mill & 8160 & 150 & 0.12 & 10 & 25 & 0.8 & 96.5 & 3307.7 & $\$ 78,690$ & $\$ 1,742$ & $\$ 1,082$ \\
\hline
\end{tabular}
MotorMaster+, it estimates the operating efficiency of motor [19]. The value for this motor was obtained as $10 \%$. The efficiency value of proposed motor is obtained by simple interpolation of the part load efficiencies of the motor in MotorMaster+ database.

Table 3.10 Proposed Configuration vs. Original Configuration of Motor and Savings Obtained

Calculating similarly for others motors tested we get the following savings:

Energy Savings $\quad=3,308 \mathrm{MMBtu} / \mathrm{Yr}$

Energy Cost Savings $=\$ 78,690$

\subsubsection{Demand Savings}

Power saved is estimated as,

$P=\frac{S * 1,000,000 B t u / M M B t u}{N * 3,413} \mathrm{~kW}$ 
$\mathrm{P}=\left(\right.$ Energy saved in MMBtu x $10^{6}$ Btu/MMBtu) / (Annual Operating Hrs x 3413)

$=\left(3,308 \times 10^{6}\right) /(8,160 \mathrm{hrs} / \mathrm{yr} \times 3,413)$

$=118.8 \mathrm{~kW}$

But the rate schedule is such that there is no cost for demand. Therefore, no demand cost savings will be obtained.

$$
\begin{aligned}
\text { Total Cost Savings } & =\mathrm{S}_{\mathrm{cum}}+\mathrm{D} \\
& =\$ 78,690+\$ 0 \\
& =\$ 78,690 / \mathrm{yr}
\end{aligned}
$$

\subsubsection{Economic Analysis}

Premium efficiency motors generally cost more than standard efficiency motors. While considering the individual cost savings that a new motor is anticipated to obtain two more factors should be considered:

1. The operating motor if replaced with new one, has a resale value $(+\mathrm{R})$

2. The labor cost needed to install the new motor (-L)

The resale value of a motor will be obviously proportional to its age. For older motors (usually more than 15-20 years old) resale value of $\$ 5 / \mathrm{HP}$ will give a very conservative estimate [6]. This is generally true for larger motors. For small motors $8-10 \%$ of the purchase price of the motor could be used for obtaining the salvage value. Labor required for installing an individual motor can be assumed as $1.5-2 \mathrm{hrs}$.

By the presented considerations,

$$
\begin{aligned}
\text { Implementation Cost } & =\text { Premium }+ \text { Labor }- \text { Resale Value } \\
& =\$ 1,742+2 *(\$ 45 / \mathrm{hr})-(150 * 5) \\
& =\$ 1,082
\end{aligned}
$$

Motor premiums are added to estimate the total cost of implementation. The simple payback can be calculated as,

Payback (months) $\quad=($ Cost of Implementation / Total Energy Savings) $* 12$ months $/ \mathrm{Yr}$

$=(\$ 9,082 / \$ 78,690) * 12$ months

$=2$ months 
Section 3.3.2 shows the potential for saving from entire motor system of a plant if all the motors are properly loaded and operate efficiently. Also, the economic analysis carried out shows that the simple payback period for this kind of motor replacement projects will be reasonable.

\subsection{Conclusion}

Field data was collected from 15 facilities for 52 motors and successfully analyzed for load by four load estimation methods viz., slip method, voltage-corrected slip method, current-voltage method and input power measurement method. The data was analyzed for examining existing relationships among load factors obtained by different methods. The load factor results of input power measurements were compared with load factor obtained by other methods. The $\mathrm{R}^{2}$ value of 0.8023 was obtained for relationship between slip method load factor and input power measurement method load. Similarly, $\mathrm{R}^{2}$ value of 0.7749 was obtained for relationship between voltage-corrected slip method load and input power measurement method load. Detailed statistical analysis for building relationship will be carried out in Chapter 4. 


\section{Chapter 4}

\section{Statistical Analysis and Model Development}

The importance of statistical analysis for data cannot be overemphasized. Statistics is a science that enables to make decisions under uncertainties (based on some numerical and measurable scales). Decision making process must be based on data neither on personal opinion nor on belief [35]. In the problem at hand, decisions about motor sizing, load and replacement will be based on collected field data in order to have efficient operation of motors and lesser energy consumption. Data are only crude information and not knowledge by themselves. The sequence from data to knowledge is from data to information, from information to facts, and finally, from facts to knowledge. Data becomes information when it becomes relevant to the decision problem. Information becomes fact when the data can support it. Fact becomes knowledge when it is used in the successful completion of decision process [35]. The following Figure 4.1 illustrates the statistical thinking process based on data in constructing statistical models for decision making. This dictates need for statistical data analysis to place knowledge on a systematic evidence base. This required a study of data properties and relationships, and so on.

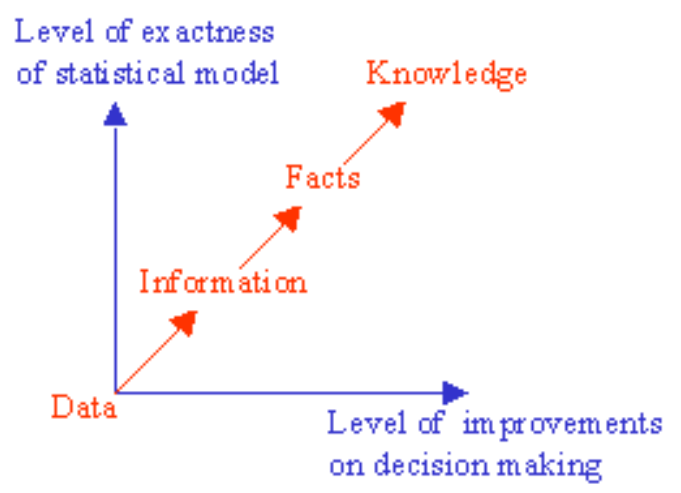

Figure 4.1 Statistical Thinking Process [35]

\subsection{Outline of Statistical Data Analysis}

The objective of statistical data analysis that was carried out was to study the data properties and relationships existing in them. Mainly, it was aimed at obtaining a relationship between load factors calculated from input power measurement method and load factors calculated by slip method considering other data such as rated voltage, rated 
current, rated speed, synchronous speed and full load slip. This can be best done with regression modeling based on the collected data for load factors obtained by input power measurement method, which is response variable. A general overview of model-building process is sighted here. It includes following four phases [36]:

1. Data collection and preparation

2. Reduction of explanatory or predictor variables

3. Model refinement and selection

4. Model validation

The general methodology that has been followed for model building is given in flowchart shown on Figure 4.2. It is important to make meaningful inferences from the model on which, responsible decisions of motor sizing and replacing can be based. Each step shown in the chart has been keenly studied and followed in order to fit a meaningful model.

\subsection{Data Collection \& Preparation}

The data collection for the study at hand has been explained in earlier chapters. The data was collected for 15 facilities for a total of 52 motors. The data is attached in accompanying Appendix I.

\subsubsection{Elimination of Unnecessary Variables}

The assigned names for the variables collected are given here:

No $\quad=$ Observation number assigned to each motor

$\mathrm{HP}=$ Horse power rating of motor

RPM_R = Rated speed of motor in RPM (from nameplate)

RPM_M = Measured speed of motor in RPM (measured with digital stroboscope)

RPM_S = Synchronous speed of motor in RPM (from nameplate)

$\mathrm{S} \quad=$ Full load slip of motor in RPM

Volt $\quad=$ Rated voltage of motor for which it is wired

Curr $\quad=$ Rated current of motor for which it is wired

LF_S $\quad=$ Slip load factor of motor calculated by slip method

LF_P = Load factor of motor calculated from input power measurement 


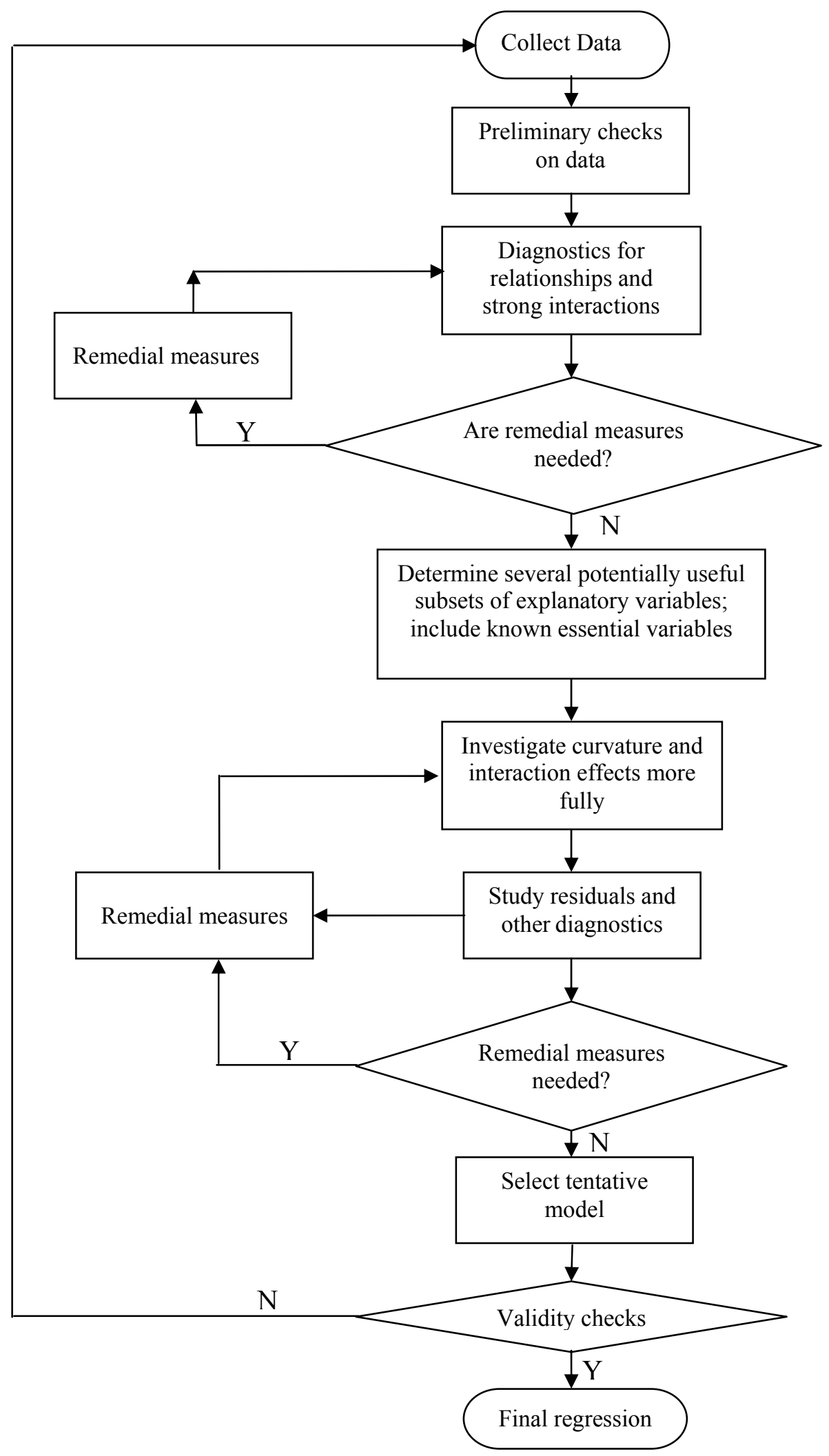

Figure 4.2 Methodology for Building a Regression Model [36] 
These variables were considered for detailed analysis and model building from given data for response variable of LF_P. To come to the given variables for analysis initial screening was done for all collected data variables specified in Table 3.1. Qualitative variables such as make and frame were excluded for ease of analysis.

\subsubsection{Removal of Outliers}

An initial basic pilot model was constructed to see if the data contained any errors of measurement. Also, consideration was given to the motor conditions that prevailed while recording a particular motor. Some motors that carried erroneous readings were eliminated in this step. For example, Motor 7 in facility IX, size 40hp (no. 32 motor) was not a standard type of motor, the nameplate did not carry details about the synchronous speed and rated speed was designated as $1800 \mathrm{rpm}$ which is usually the synchronous speed. Also, it was a very old motor. This type of motors which contributed towards outliers because of personal errors or for other reasons got eliminated in this step. The motors that were removed are given in Table 4.1. Some errors were result of improper equipment setup for data recording. The Amprobe ${ }^{\mathrm{TM}}$ could not be hooked up properly in case of such motors.

Table 4.1 Outliers removed in data preparation step from collected data

\begin{tabular}{|c|c|c|c|c|c|c|c|c|c|}
\hline No & $\begin{array}{c}\text { Size } \\
\text { (HP) }\end{array}$ & $\begin{array}{c}\text { Rated } \\
\text { (RPM) }\end{array}$ & $\begin{array}{c}\text { Measured } \\
\text { (RPM) }\end{array}$ & $\begin{array}{c}\text { Synchro } \\
\text { (RPM) }\end{array}$ & $\begin{array}{c}\text { Slip } \\
\text { (RPM) }\end{array}$ & $\begin{array}{c}\text { Voltage } \\
\text { (V) }\end{array}$ & $\begin{array}{c}\text { Current } \\
\text { (Amp) }\end{array}$ & $\begin{array}{c}\text { Slip } \\
\text { Load }\end{array}$ & $\begin{array}{c}\text { I/P } \\
\text { Power }\end{array}$ \\
\hline 4 & 75 & 1770 & 1770 & 1800 & 30 & 460 & 90 & 1.00 & 0.52 \\
\hline 6 & 200 & 1775 & 1781.6 & 1800 & 18.4 & 460 & 225 & 1.20 & 0.19 \\
\hline 31 & 100 & 1770 & 1786.7 & 1800 & 13.3 & 460 & 120 & 0.44 & 0.39 \\
\hline 32 & 40 & 1800 & 1851.9 & 2400 & 548.1 & 208 & 52 & 1.03 & 0.74 \\
\hline 43 & 200 & 1770 & 1785.7 & 1800 & 14.3 & 460 & 228 & 0.48 & 0.34 \\
\hline 45 & 150 & 1785 & 1784 & 1800 & 16 & 460 & 174 & 1.07 & 0.62 \\
\hline 48 & 150 & 1750 & 1781.6 & 1800 & 18.4 & 460 & 238 & 0.37 & 0.32 \\
\hline
\end{tabular}

\subsubsection{Data Splitting}

To have data later for model validation the collected data is split into two parts model building set and validation or prediction set of data. The second data set has been used to evaluate reasonableness and predictive ability of selected model. Since the data is collected in timely manner it is split into two parts separated at point of time. Motor data collected from last four facilities is made prediction data set. This data set has 10 motors for validation purposes. 


\subsection{Initial data trend spotting}

Once the data has been properly edited and prepared in order to proceed with formal modeling process it is important to identify

1. The functional forms in which explanatory variables should enter the regression model

2. Important interactions that should be included in the model [36].

Scatter plots were prepared to spot data trends that existed in the collected data. The scatter matrix of the specified variables is shown on Figure 4.3.

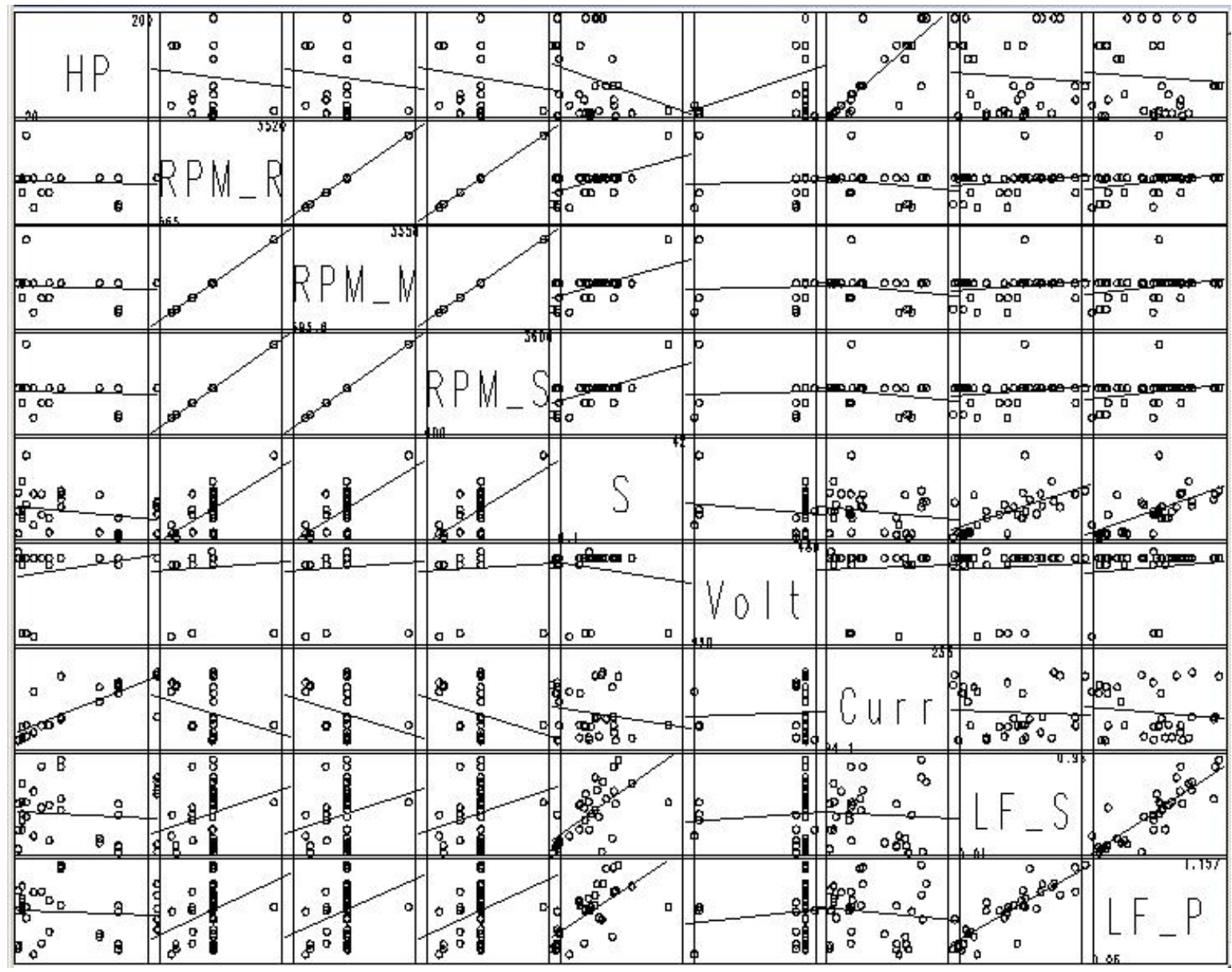

Figure 4.3 Scatter matrix of considered variables for initial trend spotting

Scatter matrix is usually prepared in exploratory studies in order to get an idea about the trends variables have with respect to each other. The scatter matrix is prepared from a SAS macro 'scatmat'. The associated code is given in Appendix IV. The scatter matrix gives scatter plot for variables, i.e. on Figure 4.3 first row of matrix contains scatter plots of HP on Y-axis vs. all other recorded variables one by one on X-axis as one 
proceeds towards the right hand side. For example, last column of first row gives graph of motor HP vs input power measurement load factor. It can be noted that there is no prominent relationship between HP and input power measurement load factor. It can also be clearly seen in above scatter matrix that LF_P and LF_S are linearly proportional. Similarly, other data trends can be spotted. Slip and LF_P also exhibit linear relationship. To know more about which interactions should be included in the model, some of the interactions were added to prepare a scatter plot. The interactions that appeared to be significant from scatter matrix are given below:

$\mathrm{x} 4=\mathrm{HP} * \mathrm{~S}$ (Interaction between horse power and slip)

$\mathrm{x} 7=\mathrm{HP} * \mathrm{LF} \_\mathrm{S}$ (Interaction between horse power and slip load factor)

$\mathrm{x} 24=\mathrm{S} *$ Volt (Interaction between slip and voltage rating of motor)

Only two factor reactions were considered. All higher factor interactions were neglected because such interactions are not normally significant. The scatter matrix with above interactions included is given in Figure 4.4 . It can be seen the interaction between slip and rated voltage has a relationship with LF_P.

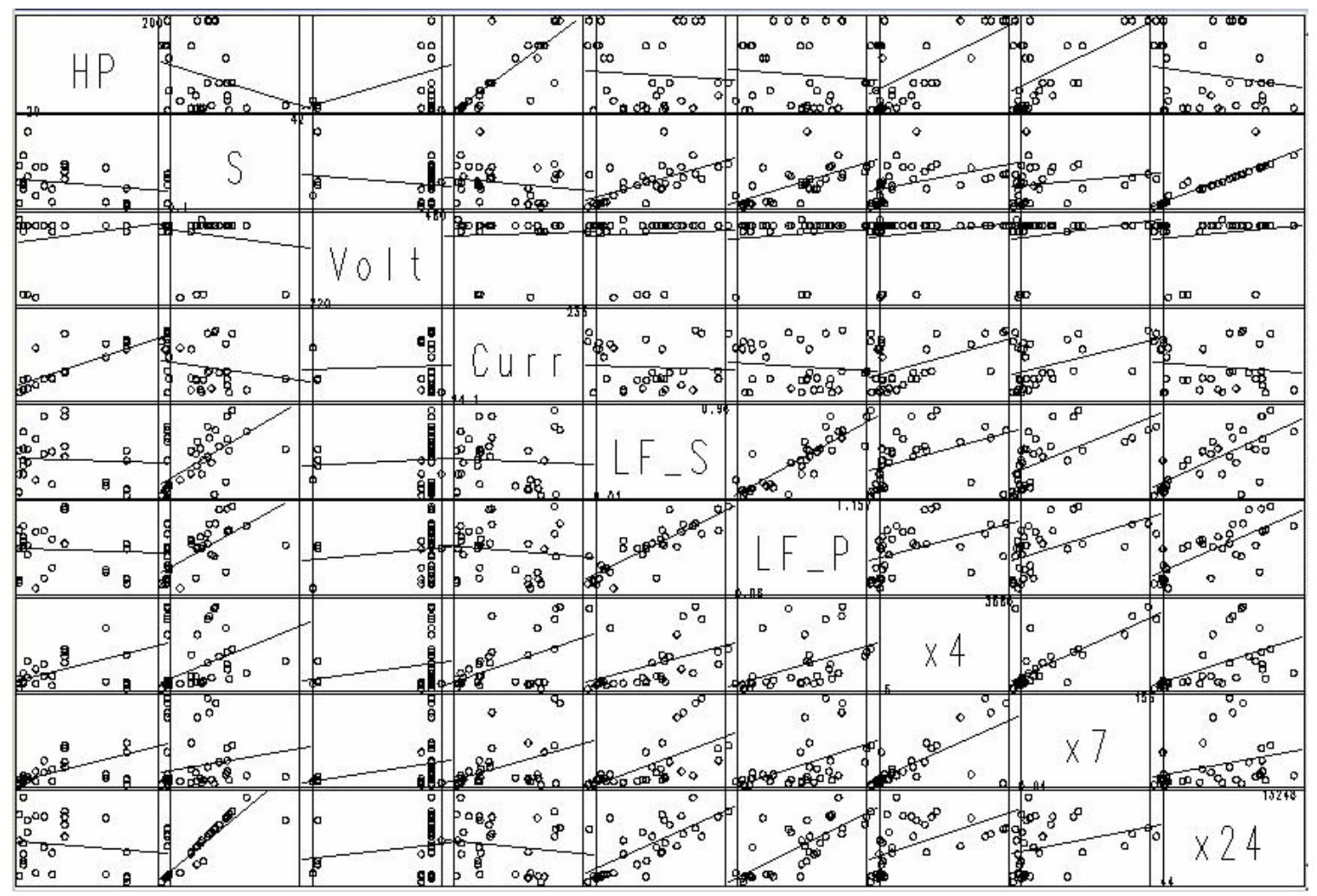

Figure 4.4 Scatter Matrix of Significant Variables and Interactions 
It can be seen from last three columns of scatter matrix that interaction $\mathrm{x} 4$ has little relationship with motor hp and slip load factor. The interaction $\mathrm{x} 7$ has weak relationship with LF_S, LF_P and strong relationship with $\mathrm{x} 4$. The interaction $\mathrm{x} 24$ has strong relationship with slip, LF_S and LF_P. The scatter matrices were prepared in SAS 9.1 Edition, code of which has been given in Appendix IV.

\subsection{Model Building}

Scatter matrices presented initial idea about trends among variables. After this actual procedure for modeling relationship between load factors obtained by input power measurement and load factor obtained by slip method could begin. As described in the previous chapter model has been built only for load factor obtained by power measurement (LF_P) from slip load. The other relationships viz. relationship between LF_P and load factor obtained by voltage corrected slip method, LF_P and load factor obtained by voltage current method were not analyzed in detail as LF_P from LF_S because:

- These methods involve measurement of either voltage or current therefore they do not rule out working around high voltages and current and hence can be dangerous.

- They require costly equipment for measuring voltages and current of in-situ motors.

- They require skilled labor to work with them.

The above reasons rule out the basic objective of this study, which is to derive a simple, inexpensive, quick and safe method of determining load on induction motors. Taking into account above facts only relationship between LF_P and LF_S has been pursued. Different types of model were built for modeling relationship between LF_P and LF_S of which three types of models are:.

1. Straight line model

2. Polynomial model

3. Multiple regression model

Each model is discussed in greater detail in the following sections along with supporting graphs and figures. 


\subsubsection{Straight Line Model}

As has been indicated in scatter matrices, it is clear that there exist a linear relationship between load factor obtained by input power measurement and load factor obtained by slip method. Refer Figures 4.3 and 4.4. Such a model could be easily fitted by SAS 9.1. Detailed analysis of variance table is shown in output of SAS program in Figure 4.5. SAS produces parameter estimates given in Figure 4.5 for straight line fitted to load factor (LF_P) by input power measurement method. The SAS program itself is given in Appendix IV.

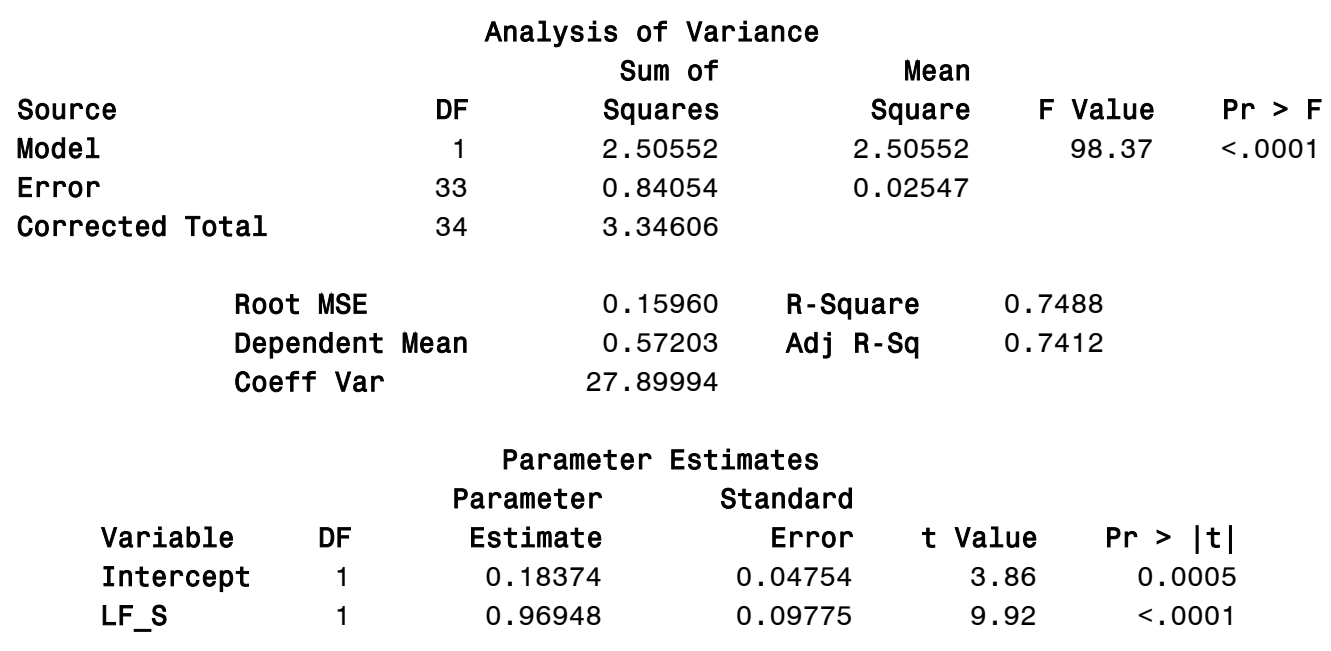

Figure 4.5 SAS Output for Straight Line Model

The straight-line model that is fitted here can be represented as,

$L F{ }_{-} P=0.18374+0.9695 \times L F{ }_{-}$

The graph of this model has been given in Figure 4.6. The graph shows coefficient of determination R2 as 0.7488 and adjusted-R2 as 0.7412 with root mean square error (RMSE) 0.1596. The residual plots of straight-line model are given in Figure 4.7 and Figure 4.8. Each residual plot when observed closely does not show any specific pattern of the variability of the residuals. This satisfied assumption of random variability. It can be said that the error terms are random and normally distributed which is one of the basic assumptions. 


\section{Straight Line Model}

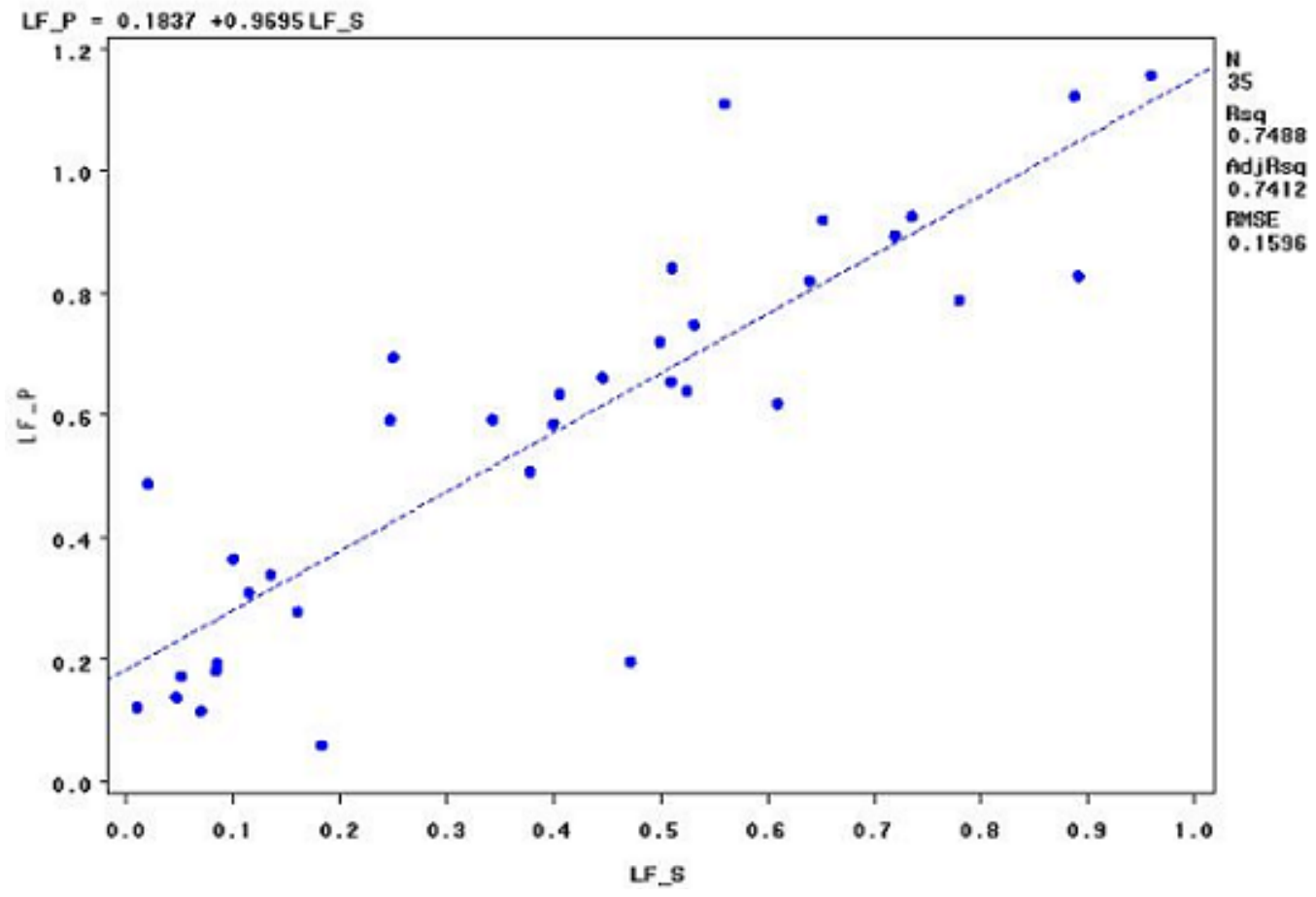

Figure 4.6 Straight Line Fit Model for I/P Power Measurement Load Residual Plot

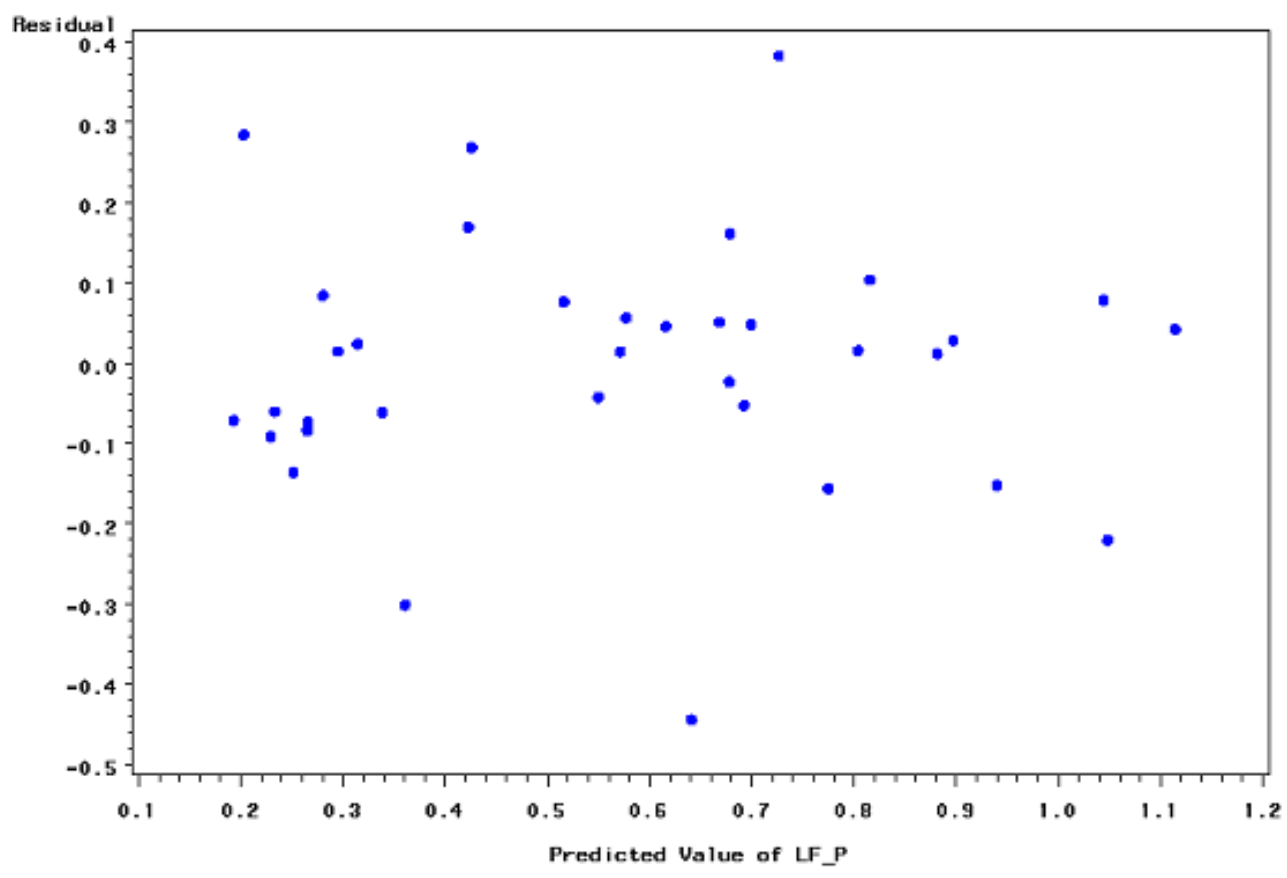

Figure 4.7 Residual vs Predicted for Straight-Line Fit Model 


\section{Residual Plot}

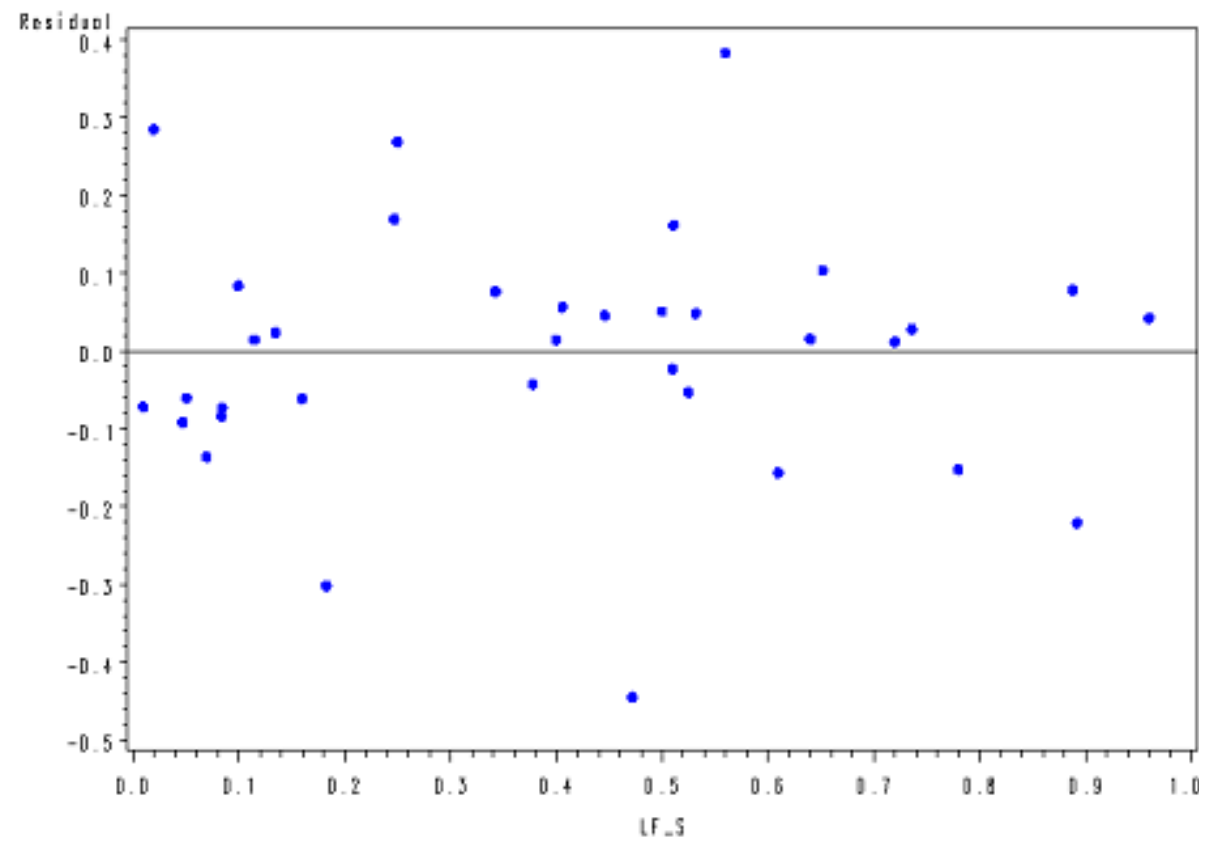

Figure 4.8 Residual vs LF_S for Straight Line Fit Model

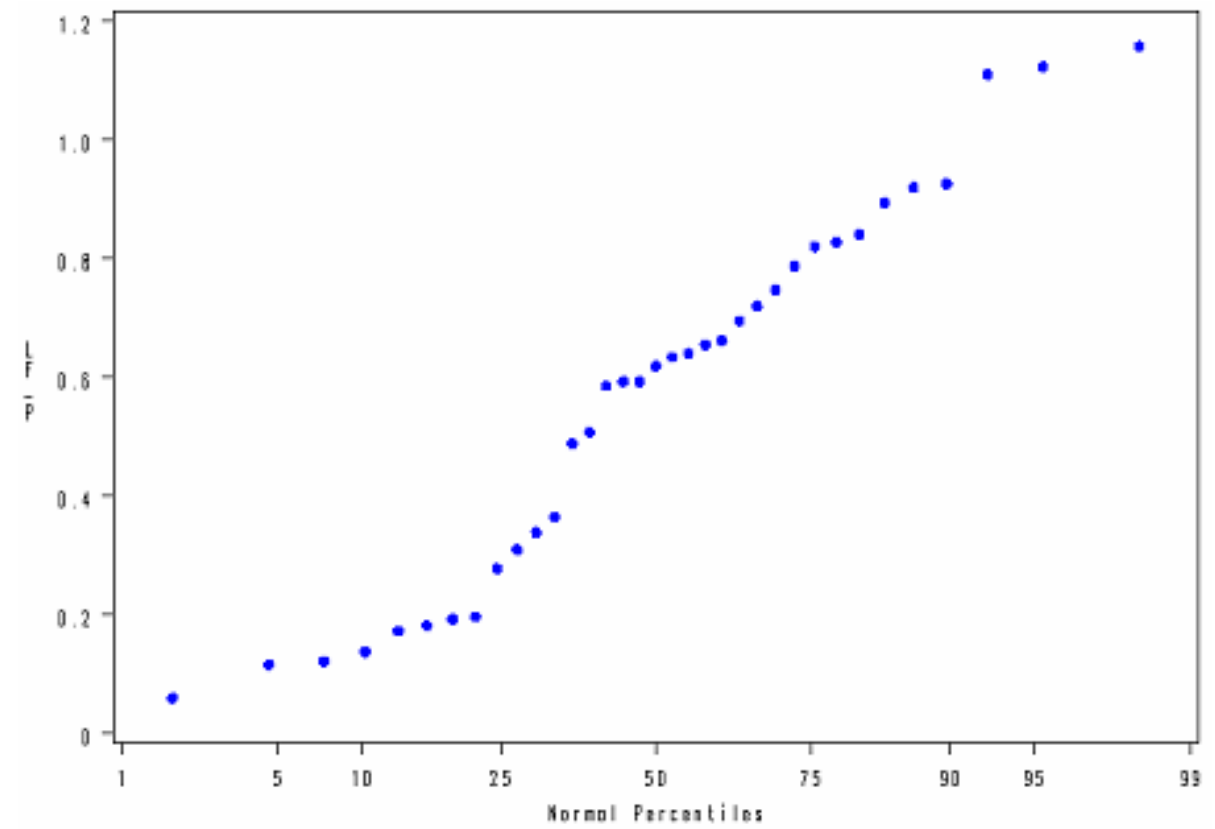

Figure 4.9 Normal Probability Plot for Straight-line Fit Model

The normal probability plot can be plotted for straight-line fit model. The normal probability plot in Figure 4.9 suggests that the assumption of normality is not violated 
and the error distribution is fairly normal. Similarly Figure 4.10 shows normal probability plot for LF_S.

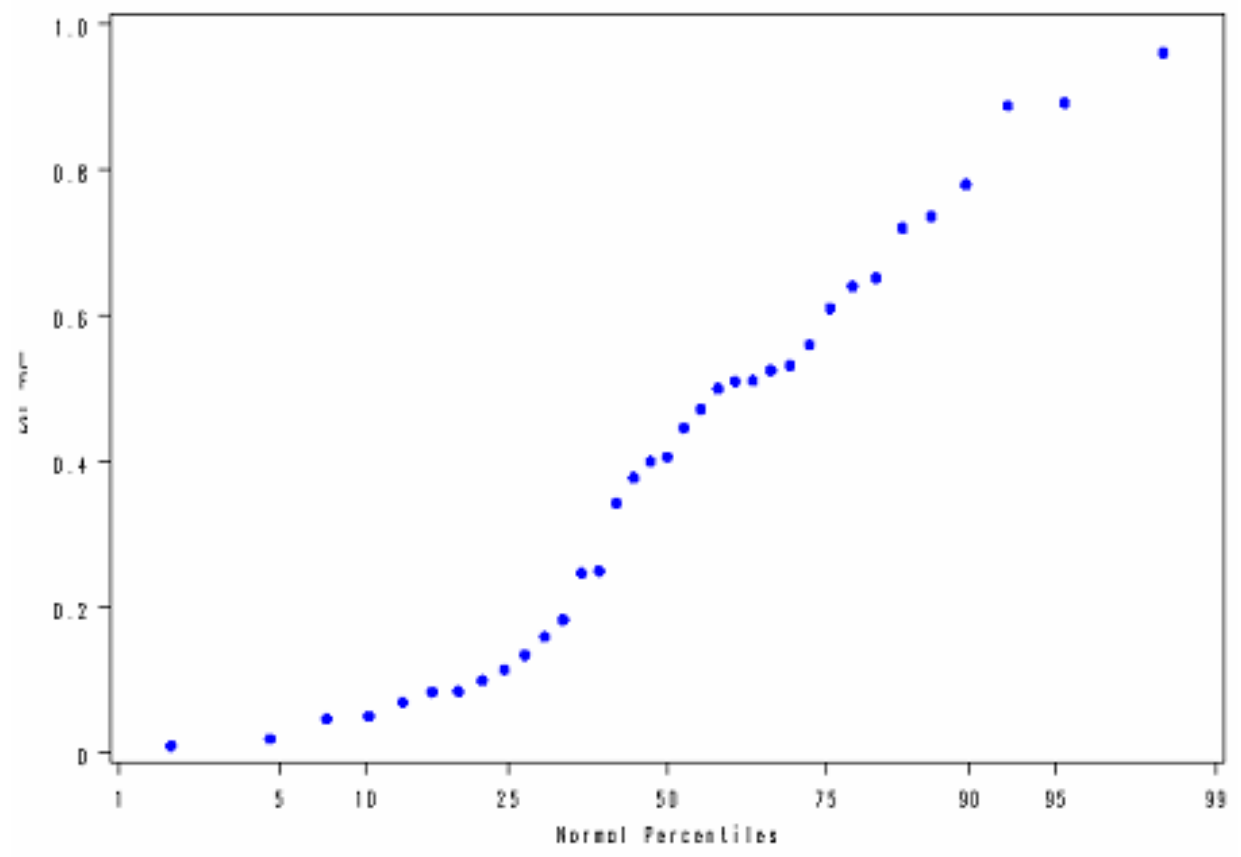

Figure 4.10 Normal Probability Plot of LF_S

\subsubsection{Polynomial Model}

A Polynomial model was fitted to model to the data of LF_P and LF_S. The results are summarized in this section. The SAS code used for fitting this polynomial model has been reproduced in Appendix IV. The ANOVA for polynomial model is given in Table 4.2. A model of power six is shown here. Other models of power from 2 to 5 were also fitted. On the basis of $\mathrm{R}^{2}$ model of power six was selected.

Table 4.2 ANOVA for Polynomial Model Fitted to LF_S vs LF_P Data

\begin{tabular}{|c|c|c|c|c|c|}
\hline Source & DF & Sum of Squares & Mean Square & F-Value & Pr $>$ F \\
\hline Model & 6 & 2.58 & 0.43 & 15.68 & $<.0001$ \\
\hline Error & 28 & 0.77 & 0.03 & & \\
\hline Corrected Total & 34 & 3.35 & & & \\
\hline
\end{tabular}

Table 4.3 gives the fit statistics for the polynomial model. It can be noted that the obtained coefficient of determination, $\mathrm{R}^{2}$ and adjusted- $\mathrm{R}^{2}$ are greater than those obtained for straight line model but with greater root mean square error $(\mathrm{RMSE}=0.16556)$. 
Table 4.3 Fit Statistics for Polynomial Model

\begin{tabular}{|c|c|c|c|}
\hline Root MSE & 0.1655 & R-Square & 0.7706 \\
\hline Dependent Mean & 0.5720 & Adj R-Sq & 0.7215 \\
\hline Coeff Var & 28.9429 & & \\
\hline
\end{tabular}

Table 4.4 Parameter Estimated of Polynomial Model fitted

\begin{tabular}{|c|c|c|c|c|c|}
\hline Variable & DF & $\begin{array}{c}\text { Parameter } \\
\text { Estimate }\end{array}$ & $\begin{array}{c}\text { Standard } \\
\text { Error }\end{array}$ & t Value & Pr $>|\mathbf{t}|$ \\
\hline Intercept & 1 & 0.32 & 0.16 & 2.02 & 0.05 \\
\hline LF_S & 1 & -4.86 & 4.73 & -1.03 & 0.31 \\
\hline LF_S2 & 1 & 59.00 & 44.87 & 1.31 & 0.20 \\
\hline LF_S3 & 1 & -238.15 & 179.85 & -1.32 & 0.20 \\
\hline LF_S4 & 1 & 456.76 & 344.82 & 1.32 & 0.20 \\
\hline LF_S5 & 1 & -415.96 & 313.76 & -1.33 & 0.20 \\
\hline LF_S6 & 1 & 144.45 & 108.87 & 1.33 & 0.20 \\
\hline
\end{tabular}

The parameters estimates are for polynomial fit model are given in Table 4.4. The model appears complex as it involves sixth degree polynomial. The model can be represented as given below,

$\boldsymbol{L F} \_\boldsymbol{P}=0.31887-4.86 L F \_S+59 L F \_S^{2}-238.15 L F \_S^{3}+456.76 L F \_S^{4}-415.96 L F \_S^{5}+$ 144.45LF_S $S^{6}$

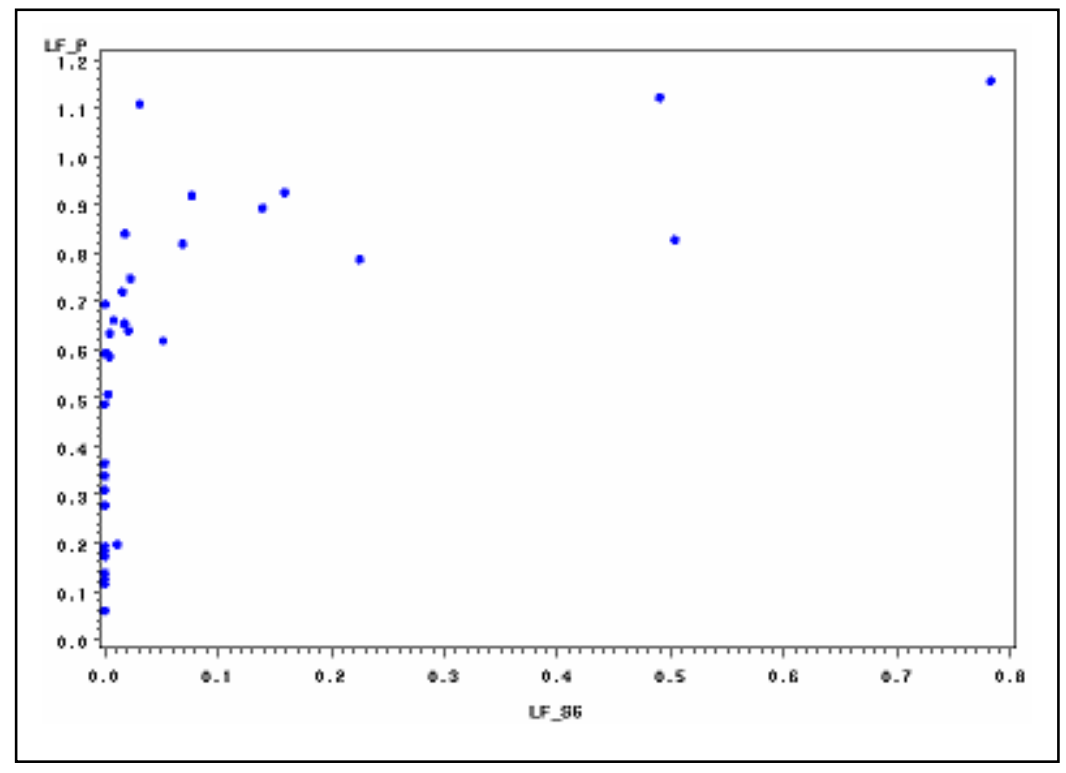

Figure 4.11 Plot of LF_P vs LF_S ${ }^{6}$ 
The residual plots are shown in Figures 4.11, Figure 4.12 and Figure 4.13. The plot of LF_P vs LF_S6 does not show simple linear relationship between them. The residual plot again predicted value of LF_P does not show any specific pattern. Therefore, assumption of random errors and normality is satisfied.

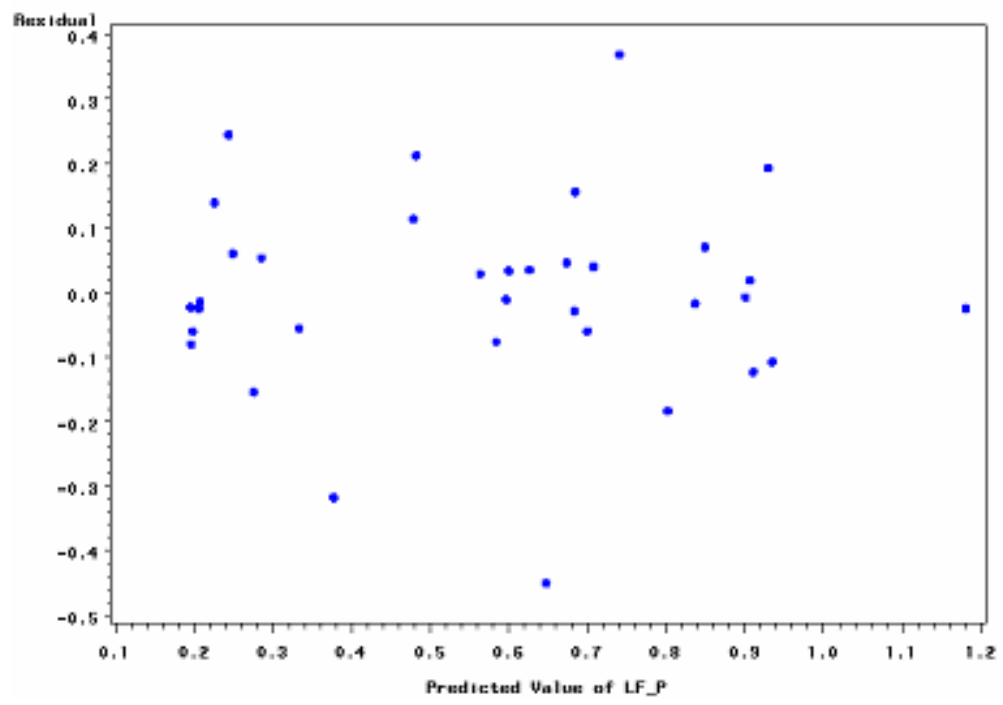

Figure 4.12 Residual vs Predicted Value of LF_P

The residual plot of LF_S6 appears to be exhibiting reducing variability with LF_S6 increasing in Figure 4.13..

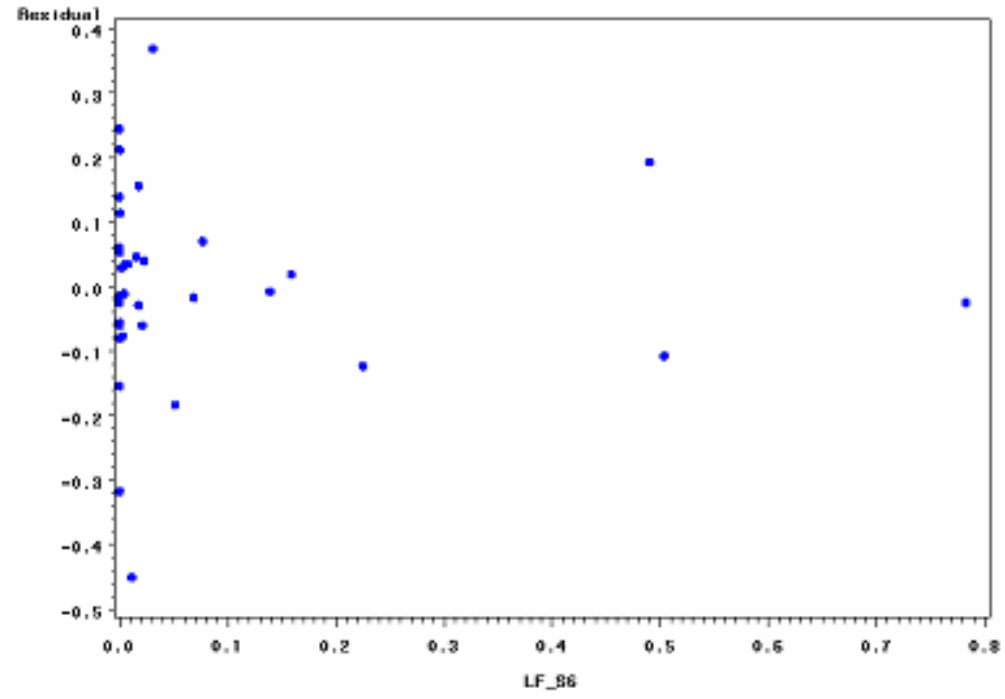

Figure 4.13 Residual vs LF_S6 (reducing variability) 
The normal probability plot of residuals is shown in Figure 4.14. It shows fair agreement with the assumption of normality of error terms.

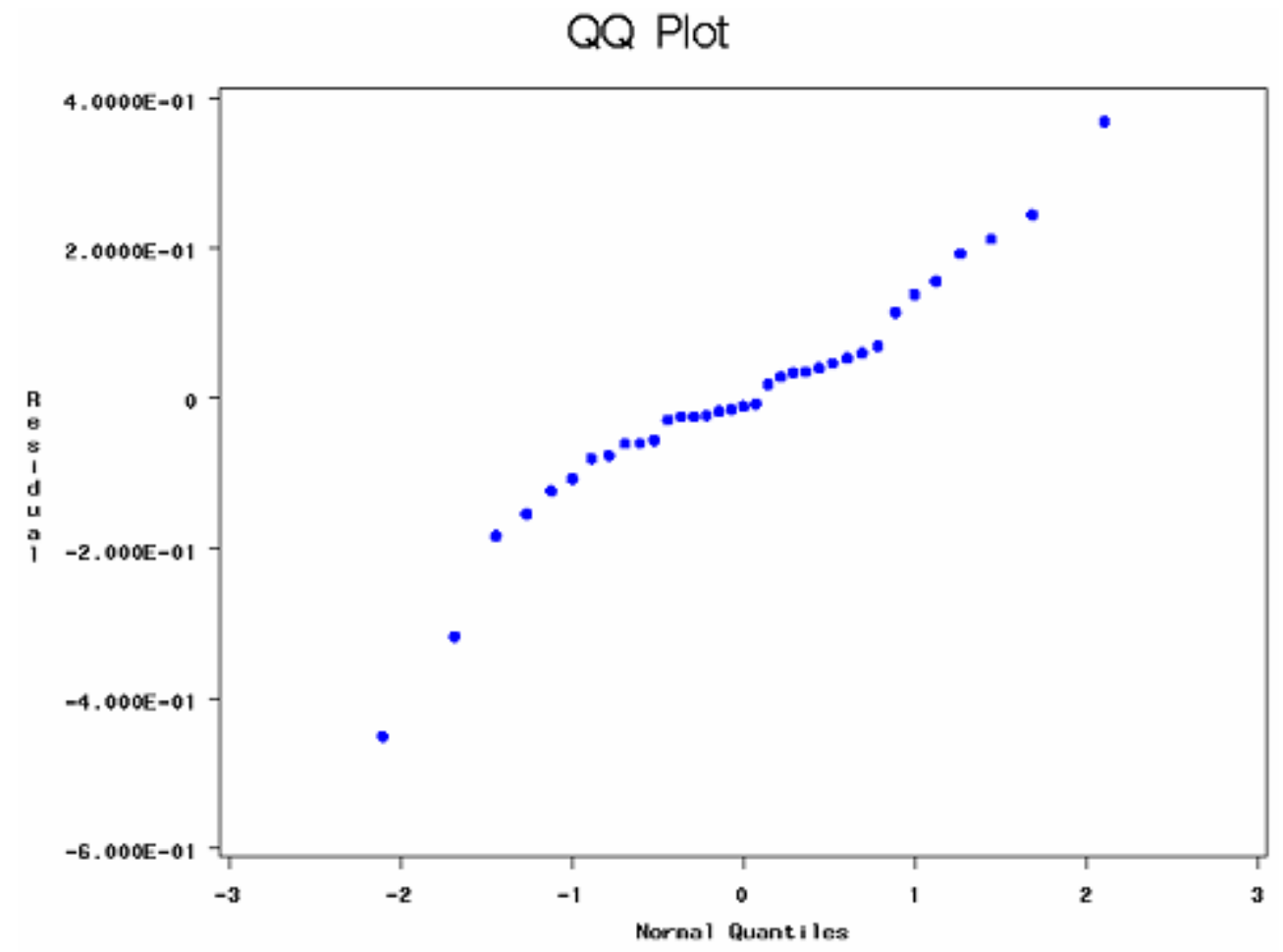

Figure 4.14 Residuals Normal Probability Plot

\subsubsection{Multiple Regression Model}

A multiple regression model was obtained using standard model selection procedure for the considered variables. A model considering all possible two factor interactions was constructed using stepwise selection approach.

\subsubsection{Model Selection and Refinement}

Model selection was done with 8 standard methods in PROC REG of SAS 9.1. These methods are listed here.

- Selection $=$ NONE (to use all variables)

- Selection $=$ RSQUARE

- Selection =ADJRSQ

- Selection $=\mathrm{CP}$

- Selection $=$ MAXR

- Selection $=$ FORWARD 
- Selection $=$ BACKWARD

- Selection $=$ STEPWISE

Though each method did not yield same model, it remained more or less the same for all methods. All two factor interactions were considered while analyzing with stepwise selection procedure. The two factor interactions are given below:

$$
\begin{aligned}
& \mathrm{x} 1=\mathrm{HP} * \mathrm{RPM} \_\mathrm{R} \quad \mathrm{x} 11=\mathrm{RPM} \mathrm{R}^{*} \text { Volt } \quad \mathrm{x} 21=\mathrm{RPM} \_\mathrm{S} * \text { Volt } \\
& \mathrm{x} 2=\text { HP*RPM_M } \quad \mathrm{x} 12=\mathrm{RPM} \mathrm{R}^{*} \text { Curr } \quad \mathrm{x} 22=\mathrm{RPM} \mathrm{S}^{*} \text { Curr } \\
& \text { x3 }=\text { HP*RPM_S } \quad \text { x13 }=\text { RPM_R } * \text { LF_S } \quad \text { x23 }=\text { RPM_S*LF_S } \\
& \text { x4 = HP*S x14 = RPM_M*RPM_S } \quad \text { x24 = S*Volt } \\
& \text { x5 }=\text { HP*Volt } \quad \text { x15 }=\text { RPM_M*S } \quad \text { x25 }=\text { S*Curr } \\
& \text { x6 }=\text { HP*Curr } \quad \mathrm{x} 16=\text { RPM_M } * \text { Volt } \quad \mathrm{x} 26=\mathrm{S} * \text { LF_S } \\
& \text { x7 }=\text { HP*LF_S } \quad \text { x17 }=\text { RPM_M } * \text { Curr } \quad \text { x27 }=\text { Volt*Curr } \\
& \text { x8 }=\text { RPM_R } * \text { RPM_M } \quad \text { x18 }=\text { RPM_M*LF_S } \quad \text { x28 }=\text { Volt*LF_S } \\
& \text { x9 }=\text { RPM_R*RPM_S } \quad \text { x19 }=\text { RPM_S*S } \quad \text { x29 }=\text { Curr*LF_S } \\
& \mathrm{x} 10=\mathrm{RPM} \_\mathrm{R} * \mathrm{~S} \quad \mathrm{x} 20=\mathrm{RPM} \_\mathrm{S} * \mathrm{~S}
\end{aligned}
$$

Higher order interactions were not considered while analyzing as there tend to be very little chances of these interactions being existent. Also, it may add complexity to the model. Each of the model selection criteria as applied to the given data for building a regression model has been discussed here.

\subsection{Full Model}

Full model for the considered variables was constructed using Proc REG in SAS 9.1 with option of 'Selection $=$ NONE'. This is used to include all the recorded significant variables in the model. However, the model obtained is not of full rank. The summary of ANOVA obtained with this method is given in Table 4.5. The fit statistics for full model is produced in Table 4.6. The model produced was not full rank because synchronous and rated speeds of motors were linear multiple of each other. This model was not investigated further. 
Table 4.5 ANOVA for Full Model

\begin{tabular}{|c|c|c|c|c|c|}
\hline Source & DF & $\begin{array}{c}\text { Sum of } \\
\text { Squares }\end{array}$ & $\begin{array}{c}\text { Mean } \\
\text { Square }\end{array}$ & F Value & Pr $>$ F \\
\hline Model & 7 & 2.62255 & 0.37465 & 13.82 & $<.0001$ \\
\hline Error & 25 & 0.67766 & 0.02711 & & \\
\hline Corrected Total & 32 & 3.30021 & & & \\
\hline
\end{tabular}

Table 4.6 Fit Statistics for Full Model

\begin{tabular}{|c|c|c|c|}
\hline Root MSE & 0.16464 & R-Square & 0.7947 \\
\hline Dependent Mean & 0.57688 & Adj R-Sq & 0.7372 \\
\hline Coeff Var & 28.53981 & & \\
\hline
\end{tabular}

\subsection{RSQUARE Model}

This was used to find model including specified number of variables that has maximum $\mathrm{R}^{2}$ with option of 'Selection = RSQUARE' in Proc REG model statement. This investigated each model that was possible for given number of variables. The models were reported to the SAS output. However, the output is too lengthy to produce here; an example of 7 models is produced in Table 4.7. To actually see models produced according to $\mathrm{R}^{2}$, SAS code attached in Appendix IV should be executed.

Table 4.7Model Selection based on RSQUARE

\begin{tabular}{|c|c|c|}
\hline $\begin{array}{c}\text { Number of Variables in } \\
\text { Model }\end{array}$ & R-Square & Variables in Model \\
\hline 1 & 0.7553 & LF_S \\
\hline 2 & 0.7725 & RPM_M, LF_S \\
\hline 2 & 0.7694 & S, LF_S \\
\hline 2 & 0.7602 & Volt, LF_S \\
\hline 2 & 0.7553 & HP, LF_S \\
\hline 2 & 0.5141 & S, Volt \\
\hline 3 & 0.7812 & S, Volt, LF_S \\
\hline
\end{tabular}

\subsection{ADJ-R ${ }^{2}$ Model}

When new variables are introduced in model, regression sum of squares (SSR) of model always increases and SSTO of model remains the same. As a result of this $\mathrm{R}^{2}$ of a regression model always increases as number of variables included in the model are increased. In such cases a modified measure of adjusted $R^{2}$ is used. Adj- $R^{2}$ may actually decrease sometimes due to addition of new variables in the model. Adj- $\mathrm{R}^{2}$ gives more 
accurate idea about which variables should be used in model. Available data was investigated for selection of model for maximum ADJ- $\mathrm{R}^{2}$ using 'Proc REG' and option 'Selection $=$ ADJRSQ'. Example of models yielded is presented in Table 4.8. For detailed analysis actual code included in Appendix IV should be executed.

Table 4.8 Model Selection Based on ADJ- $\mathbf{R}^{2}$ Criterion

\begin{tabular}{|c|c|c|c|}
\hline $\begin{array}{c}\text { Number in } \\
\text { Model }\end{array}$ & Adj-R $^{2}$ & R-Square & Variables in Model \\
\hline 3 & 0.7586 & 0.7812 & S Volt, LF_S \\
\hline 4 & 0.7585 & 0.7887 & RPM_R, RPM_M, Curr LF_S \\
\hline 2 & 0.7577 & 0.7728 & RPM_R, LF_S \\
\hline 2 & 0.7575 & 0.7726 & RPM_S, LF_S \\
\hline 4 & 0.7574 & 0.7877 & HP, S, Curr, LF_S \\
\hline 2 & 0.7573 & 0.7725 & RPM_M, LF_S \\
\hline
\end{tabular}

\subsection{Minimum Cp Model}

All possible models were investigated for minimum $\mathrm{Cp}$ in Proc REG, using option 'Selection $=$ CP' in SAS code. Example of the results produced by this criterion is shown in Table 4.9. For detailed analysis Appendix IV should be referred.

Table 4.9 C(P) Selection method

\begin{tabular}{|c|c|c|c|}
\hline $\begin{array}{c}\text { Number in } \\
\text { Model }\end{array}$ & $\mathbf{C}(\mathbf{p})$ & R-Square & $\begin{array}{c}\text { Variables in } \\
\text { Model }\end{array}$ \\
\hline 2 & 0.6586 & 0.7728 & RPM_R, LF_S \\
\hline 2 & 0.6842 & 0.7726 & RPM_S, LF_S \\
\hline 2 & 0.6992 & 0.7725 & RPM_M, LF_S \\
\hline 1 & 0.7928 & 0.7553 & LF_S \\
\hline 2 & 1.0706 & 0.7694 & S, LF_S \\
\hline
\end{tabular}

\subsection{MAXR Model}

Max $\mathrm{R}$ model selection method was used to investigate model that has maximum $R^{2}$. This method allows step by step entry of other variables into model till $R^{2}$ increases significantly. The model produced by this method included 7 variables till there was no further improvement possible in $\mathrm{R}^{2}$. For ANOVA of each step and parameter estimate SAS code given in Appendix IV should be executed. 


\subsection{Forward Selection}

Forward selection procedure starts with one variable and goes on adding another significant variable. The significance of the variable being added is tested with $\mathrm{F}^{*}$ statistics . Default level of significance of 0.5 is used for entry of a variable into model. The ANOVA of last step of forward selection is presented in Table 4.10. The model that is obtained with forward selection method can be represented as,

LF_P $=-0.07208+3.68 * 10^{-05} \mathrm{RPM} \_\mathrm{R}+0.00494 * \mathrm{~S}+0.000418 *$ Volt $+0.85305 *$ LF_S $\ldots$

The parameter estimates have been reproduced in Table 4.11 along with standard error and Type II sum of squares. The summary of forward selection according to the importance of variables in model is tabulated in Table 4.12.

Table 4.10 ANOVA of Final Step of Forward Selection Method

\begin{tabular}{|c|c|c|c|c|c|}
\hline Source & DF & $\begin{array}{c}\text { Sum of } \\
\text { Squares }\end{array}$ & $\begin{array}{c}\text { Mean } \\
\text { Square }\end{array}$ & F Value & Pr $>$ F \\
\hline Model & 4 & 2.58437 & 0.64609 & 25.27 & $<.0001$ \\
\hline Error & 28 & 0.71585 & 0.02557 & & \\
\hline Corrected Total & 32 & 3.30021 & & & \\
\hline
\end{tabular}

Table 4.11 Parameter Estimates Obtained with Forward Selection

\begin{tabular}{|c|c|c|c|c|c|}
\hline Variable & $\begin{array}{c}\text { Parameter } \\
\text { Estimate }\end{array}$ & $\begin{array}{c}\text { Standard } \\
\text { Error }\end{array}$ & Type II SS & F Value & Pr $>$ F \\
\hline Intercept & -0.07208 & 0.17979 & 0.00411 & 0.16 & 0.6915 \\
\hline RPM_R & $3.68 \mathrm{E}-05$ & $7.49 \mathrm{E}-05$ & 0.00615 & 0.24 & 0.6275 \\
\hline S & 0.00494 & 0.00564 & 0.0196 & 0.77 & 0.3887 \\
\hline Volt & 0.000418 & 0.000404 & 0.02739 & 1.07 & 0.3095 \\
\hline LF_S & 0.85305 & 0.15191 & 0.80624 & 31.54 & $<.0001$ \\
\hline
\end{tabular}

Table 4.12 Summary of Forward Selection

\begin{tabular}{|c|c|c|c|c|c|c|c|}
\hline Step & $\begin{array}{c}\text { Variable } \\
\text { Entered }\end{array}$ & $\begin{array}{c}\text { Number } \\
\text { Vars In }\end{array}$ & $\begin{array}{c}\text { Partial } \\
\text { R-Square }\end{array}$ & $\begin{array}{c}\text { Model } \\
\text { R-Square }\end{array}$ & C(p) & F Value & Pr $>$ F \\
\hline 1 & LF_S & 1 & 0.7553 & 0.7553 & 0.7928 & 95.68 & $<.0001$ \\
\hline 2 & RPM_R & 2 & 0.0175 & 0.7728 & 0.6586 & 2.31 & 0.1386 \\
\hline 3 & Volt & 3 & 0.0043 & 0.7772 & 2.132 & 0.56 & 0.4591 \\
\hline 4 & S & 4 & 0.0059 & 0.7831 & 3.4088 & 0.77 & 0.3887 \\
\hline
\end{tabular}

\subsection{Backward Elimination}

This method starts with a full model and eliminates variables one by one from the model. At each step, the variable with the smallest contribution to the model is deleted. 
ANOVA of backward elimination is produced in Table 4.13. Backward elimination model is fitted for collected data using Proc REG; 'Selection = Backward' option. For details refer Appendix IV.

Table 4.13 ANOVA of Final Step of Backward Elimination

\begin{tabular}{|c|c|c|c|c|c|}
\hline Source & DF & $\begin{array}{c}\text { Sum of } \\
\text { Squares }\end{array}$ & $\begin{array}{c}\text { Mean } \\
\text { Square }\end{array}$ & F Value & Pr $>$ F \\
\hline Model & 1 & 2.49264 & 2.49264 & 95.68 & $<.0001$ \\
\hline Error & 31 & 0.80757 & 0.02605 & & \\
\hline Corrected Total & 32 & 3.30021 & & & \\
\hline
\end{tabular}

The backward elimination method resulted in fitting simple straight line for data. The parameter estimates obtained are given in Table 4.14.

Table 4.14 Parameter Estimates for Backward Elimination Method

\begin{tabular}{|c|c|c|c|c|c|}
\hline Variable & $\begin{array}{c}\text { Parameter } \\
\text { Estimate }\end{array}$ & $\begin{array}{c}\text { Standard } \\
\text { Error }\end{array}$ & Type II SS & F Value & Pr > F \\
\hline Intercept & 0.1767 & 0.04963 & 0.33023 & 12.68 & 0.0012 \\
\hline LF_S & 0.99233 & 0.10145 & 2.49264 & 95.68 & $<.0001$ \\
\hline
\end{tabular}

The backward elimination model is given in Eq. 4.4. The summary of backward elimination is produced in Table 4.15.

$L F_{-} P=0.1767+0.99233 * L F_{-} S$

Table 4.15 Summary of Backward Elimination

\begin{tabular}{|c|c|c|c|c|c|c|c|c|}
\hline Step & $\begin{array}{c}\text { Variable } \\
\text { Entered }\end{array}$ & $\begin{array}{c}\text { Variable } \\
\text { Removed }\end{array}$ & $\begin{array}{c}\text { Number } \\
\text { Vars In }\end{array}$ & $\begin{array}{c}\text { Partial } \\
\text { R-Square }\end{array}$ & $\begin{array}{c}\text { Model } \\
\text { R-Square }\end{array}$ & C(p) & F Value & Pr $>$ F \\
\hline 1 & & Volt & 6 & 0.0008 & 0.7938 & 6.1024 & 0.1 & 0.7516 \\
\hline 2 & & RPM_S & 5 & 0.0029 & 0.7909 & 4.4557 & 0.37 & 0.5505 \\
\hline 3 & S & & 6 & 0.0029 & 0.7938 & 6.1024 & 0.37 & 0.5505 \\
\hline 4 & & S & 5 & 0.0029 & 0.7909 & 4.4557 & 0.37 & 0.5505 \\
\hline 5 & & HP & 4 & 0.0022 & 0.7887 & 2.7273 & 0.29 & 0.5959 \\
\hline 6 & & Curr & 3 & 0.012 & 0.7767 & 2.1872 & 1.59 & 0.2179 \\
\hline 7 & & RPM_M & 2 & 0.0039 & 0.7728 & 0.6586 & 0.5 & 0.4839 \\
\hline 8 & & RPM_R & 1 & 0.0175 & 0.7553 & 0.7928 & 2.31 & 0.1386 \\
\hline
\end{tabular}




\subsection{Stepwise Selection Procedure}

This method is a modification of the forward-selection method in that variables already in the model do not necessarily stay there. Stepwise selection procedure is of major interest and known to be widely accepted. With given data this procedure produced most meaningful results and is discussed in greater detail here. Proc REG with 'Selection $=$ Stepwise' was used in SAS code. Slstay of 0.08 and Slentry of 0.2 were used as significance levels for variable already in the model to stay and variable to enter the model respectively. The ANOVA and parameter estimates of each of there steps are produced in Table 4.16. Summary of stepwise selection method is given Table 4.17.

Table 4.16 Stepwise ANOVA and Parameter Estimates

\begin{tabular}{|c|c|c|c|c|c|c|}
\hline Step 1 & Source & DF & $\begin{array}{c}\text { Sum of } \\
\text { Squares }\end{array}$ & $\begin{array}{c}\text { Mean } \\
\text { Square }\end{array}$ & F Value & $\operatorname{Pr}>\mathbf{F}$ \\
\hline \multirow{3}{*}{ ANOVA } & Model & 1 & 2.49264 & 2.49264 & 95.68 & $<.0001$ \\
\hline & Error & 31 & 0.80757 & 0.02605 & & \\
\hline & Corrected Total & 32 & 3.30021 & & & \\
\hline \multirow{3}{*}{$\begin{array}{l}\text { Parameter } \\
\text { estimates }\end{array}$} & Variable & \begin{tabular}{|c|}
$\begin{array}{c}\text { Parameter } \\
\text { Estimate }\end{array}$ \\
\end{tabular} & \begin{tabular}{|c|}
$\begin{array}{c}\text { Standard } \\
\text { Error }\end{array}$ \\
\end{tabular} & Type II SS & F Value & $\operatorname{Pr}>F$ \\
\hline & Intercept & 0.1767 & 0.04963 & 0.33023 & 12.68 & 0.0012 \\
\hline & LF_S & 0.99233 & 0.10145 & 2.49264 & 95.68 & $<.0001$ \\
\hline Step 2 & Source & DF & $\begin{array}{l}\text { Sum of } \\
\text { Squares }\end{array}$ & $\begin{array}{c}\text { Mean } \\
\text { Square }\end{array}$ & F Value & $\operatorname{Pr}>\mathbf{F}$ \\
\hline \multirow{3}{*}{ ANOVA } & Model & 2 & 2.58851 & 1.29426 & 54.56 & $<.0001$ \\
\hline & Error & 30 & 0.7117 & 0.02372 & & \\
\hline & Corrected Total & 32 & 3.30021 & & & \\
\hline \multirow[t]{4}{*}{$\begin{array}{c}\begin{array}{c}\text { Parameter } \\
\text { estimates }\end{array} \\
\end{array}$} & Variable & \begin{tabular}{c|} 
Parameter \\
Estimate \\
\end{tabular} & \begin{tabular}{|c|}
$\begin{array}{l}\text { Standard } \\
\text { Error }\end{array}$ \\
\end{tabular} & Type II SS & F Value & $\operatorname{Pr}>\mathbf{F}$ \\
\hline & Intercept & 0.14511 & 0.050 & 0.201 & 8.46 & 0.0068 \\
\hline & LF_S & 0.77860 & 0.144 & 0.696 & 29.32 & $<.0001$ \\
\hline & $\mathrm{x} 24$ & 0.00002 & 0.000 & 0.096 & 4.04 & 0.0535 \\
\hline
\end{tabular}


Table 4.17 Summary of Stepwise Selection Method.

\begin{tabular}{|c|c|c|c|c|c|c|c|c|}
\hline Step & $\begin{array}{c}\text { Variable } \\
\text { Entered }\end{array}$ & $\begin{array}{c}\text { Variable } \\
\text { Removed }\end{array}$ & $\begin{array}{c}\text { Number } \\
\text { Vars In }\end{array}$ & $\begin{array}{c}\text { Partial } \\
\text { R-Square }\end{array}$ & $\begin{array}{c}\text { Model } \\
\text { R-Square }\end{array}$ & C(p) & F Value & Pr $>$ F \\
\hline 1 & LF_S & - & 1 & 0.7553 & 0.7553 & 24.4091 & 95.68 & $<.0001$ \\
\hline 2 & x24 & - & 2 & 0.0291 & 0.7843 & 20.0685 & 4.04 & 0.0535 \\
\hline
\end{tabular}

The model obtained is given in equation 4.5.

$$
L F{ }_{-} P=0.14511+0.77860 * L F \_S+0.00002 * \times 24
$$

The model estimated with stepwise selection method is a interaction model containing interaction of voltage rating (V) of motor and recorded slip of motor (S). The equation 4.5 can be represented as,

$$
L F \_P=0.14511+0.77860 * L F \_S+0.00002 * S * \text { Volt }
$$

The fit statistics for above model is given Table 4.18. This model gives us highest $\mathrm{R}^{2}$ as well as highest value for adj- $\mathrm{R}^{2}$. Also, root mean square error (RMSE) for model is relatively lesser. This model was selected for further analysis.

Table 4.18 Fit Statistics for Stepwise Model

\begin{tabular}{|c|c|c|c|}
\hline Root MSE & 0.15402 & R-Square & 0.7843 \\
\hline Dependent Mean & 0.57688 & Adj R-Sq & 0.77 \\
\hline Coeff Var & 26.69954 & & \\
\hline
\end{tabular}

The covariance and correlation of estimates is found and reported in Table 4.19. The covariance of the estimates is found to be very low as expected.

Table 4.19 Covariance and Correlation of Estimates

\begin{tabular}{|c|c|c|c|c|}
\hline & Variable & Intercept & LF_S & x24 \\
\hline \multirow{4}{*}{ Covariance } & Intercept & 0.00249 & -0.002109 & $-1.62 \mathrm{E}-07$ \\
\cline { 2 - 5 } & LF_S & -0.00211 & 0.0206746 & $-1.10 \mathrm{E}-06$ \\
\cline { 2 - 5 } & $\mathbf{x 2 4}$ & $-1.62 \mathrm{E}-07$ & $-1.10 \mathrm{E}-06$ & $1.06 \mathrm{E}-10$ \\
\hline \multirow{5}{*}{ Correlation } & Variable & Intercept & LF_S & x24 \\
\hline & Intercept & 1 & -0.2939 & -0.3149 \\
\cline { 2 - 5 } & LF_S & -0.2939 & 1 & -0.7394 \\
\cline { 2 - 5 } & $\mathbf{x 2 4}$ & -0.3149 & -0.7394 & 1 \\
\hline
\end{tabular}


Consistent covariance of estimates was calculated in order to check the assumption of constancy of error variance, which is a basic assumption in such type of models. The first and second moment specification for model showed that, the assumption of constancy of error variance is not violated in the model. The consistent covariance of estimates is shown in Table 4.20.

Table 4.20 Consistent Covariance of Estimates

\begin{tabular}{|c|c|c|c|}
\hline Variable & Intercept & LF_S & x24 \\
\hline Intercept & 0.001315 & -0.00125 & $-5.17 \mathrm{E}-08$ \\
\hline LF_S & -0.00125 & 0.018808 & $-1.14 \mathrm{E}-06$ \\
\hline x24 & $-5.17 \mathrm{E}-08$ & $-1.14 \mathrm{E}-06$ & $9.56 \mathrm{E}-11$ \\
\hline
\end{tabular}

Table 4.21 Moment Specification

\begin{tabular}{|c|c|c|}
\hline \multicolumn{3}{|c|}{ Test of First and Second } \\
\hline \multicolumn{3}{|c|}{ Moment Specification } \\
\hline DF & Chi-Square & Pr $>$ ChiSq \\
\hline 5 & 5.31 & 0.3791 \\
\hline
\end{tabular}

\subsubsection{Residual Analysis}

Elimination of outliers using following criteria was done.

\section{Hat matrix leverage values}

$0 \leq h_{i i} \leq 1$

$h_{i i} \geq 2 \frac{p}{n}$

Large leverage values indicate $\mathrm{X}$ outliers. Value obtained after calculation is 0.17 .

\section{DFFITS}

The rule of thumb for DFFITS is,

$$
\mid(\text { DFFITS })_{i} \mid>2 * \sqrt{\frac{p}{n}}
$$

Value obtained after calculation is 0.58 .

\section{DFBETAS}

The rule of thumb for DFBETAS is,

$$
(\text { DFBETAS })_{k(i)}>\frac{2}{\sqrt{n}}
$$


Value obtained after calculation is 0.34. After comparing these values with the SAS output, further outliers were investigated in the data. None of the data points were removed as there were no outliers in the data.

\subsubsection{Residual and Normal Probability Plots}

Residual and normal probability plots were prepared for the constructed model in order to check the assumptions of normality and independence of errors. A plot of residuals against predicted values from model is shown in Figure 4.15.

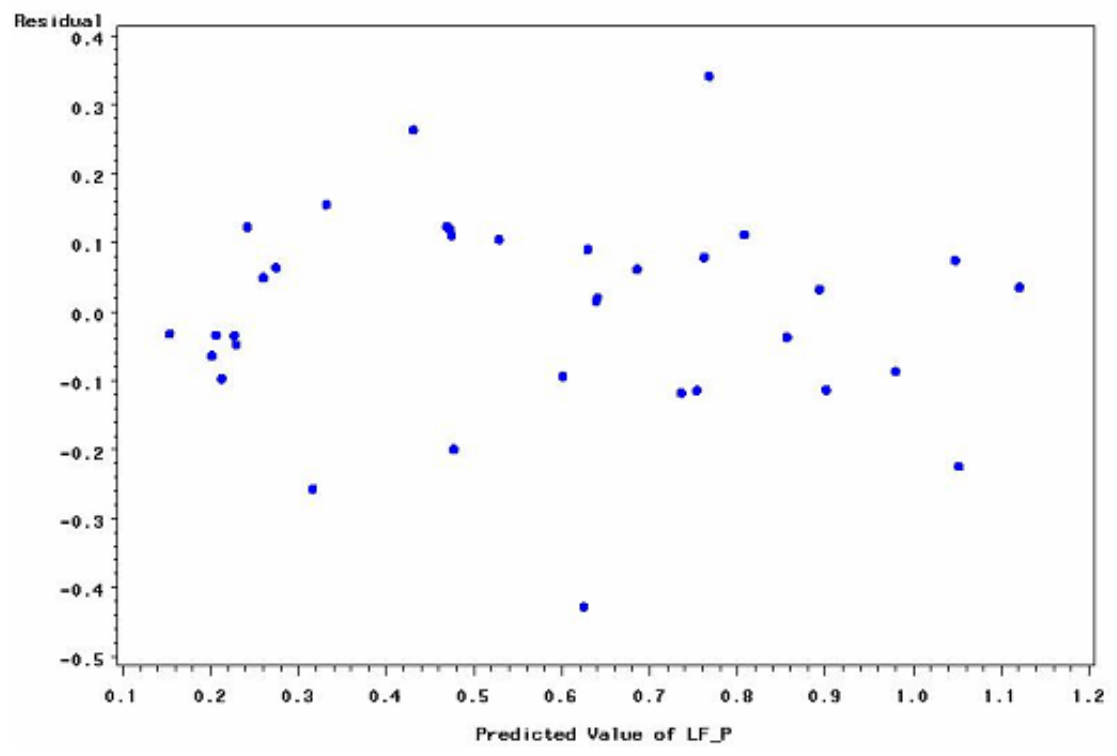

Figure 4.15 Plot of Residuals vs Predicted Values of LF_P

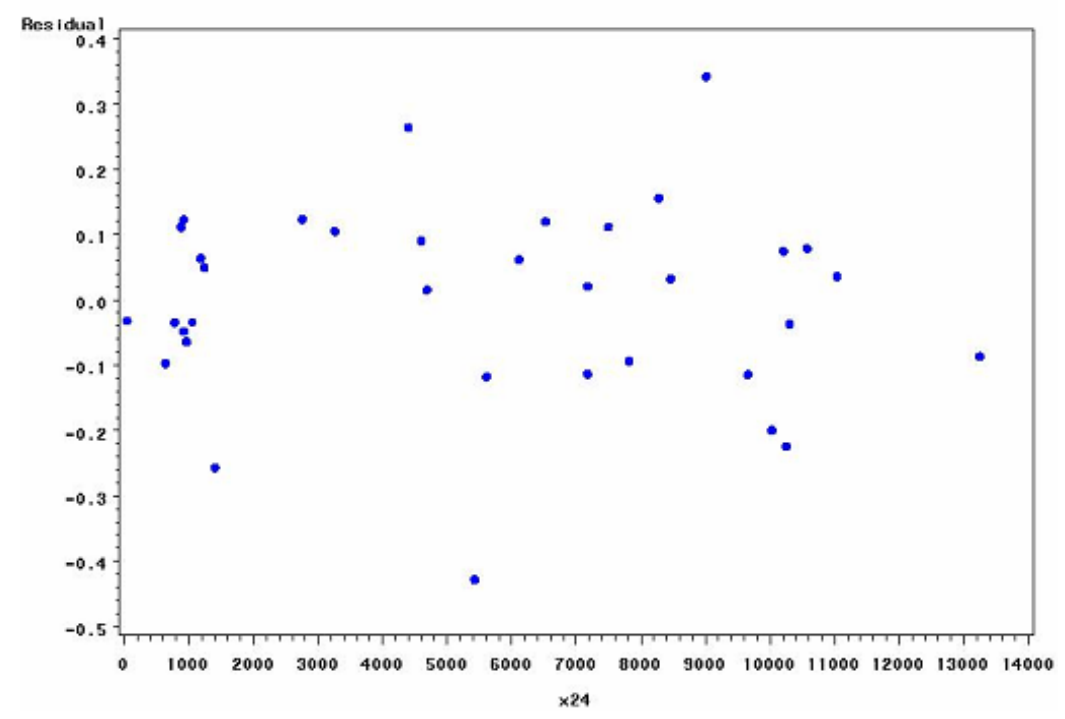

Figure 4.16 Plot of Residuals vs. X24 


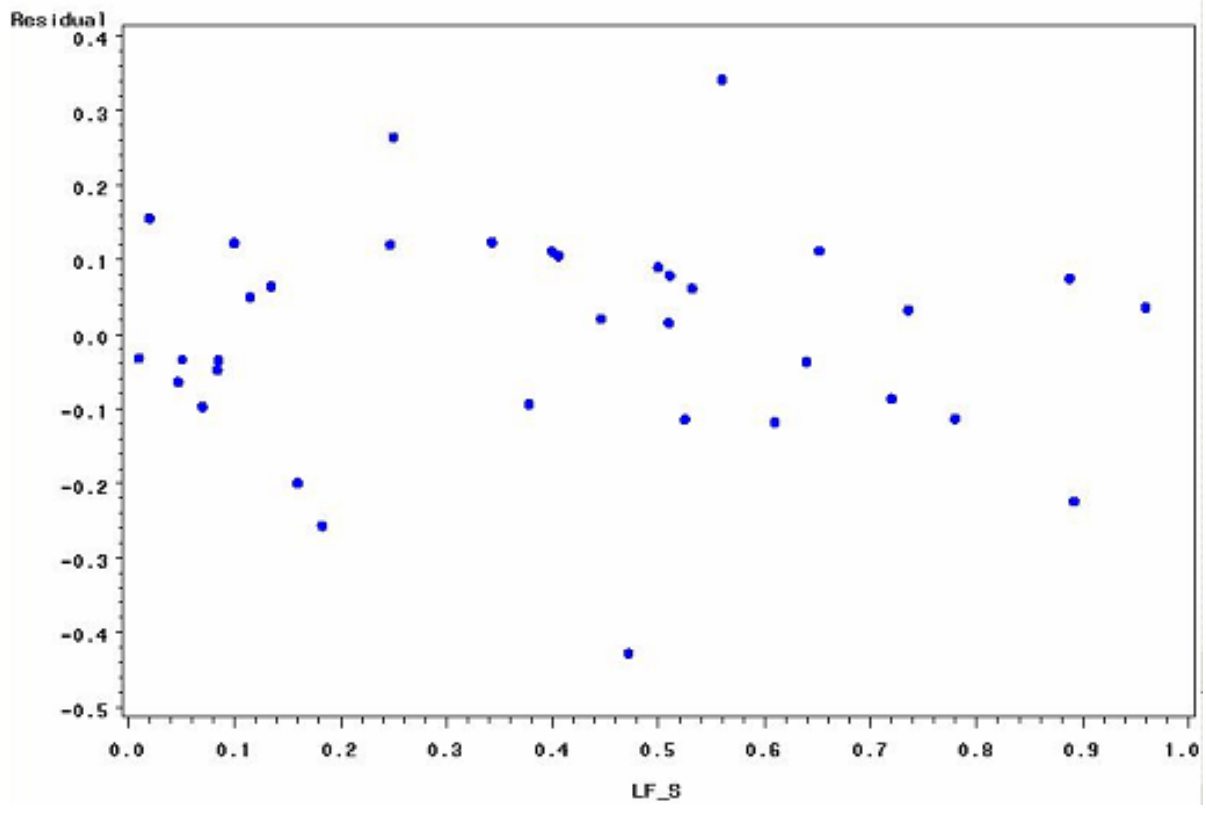

Figure 4.17 Plot of Residuals vs. LF_S

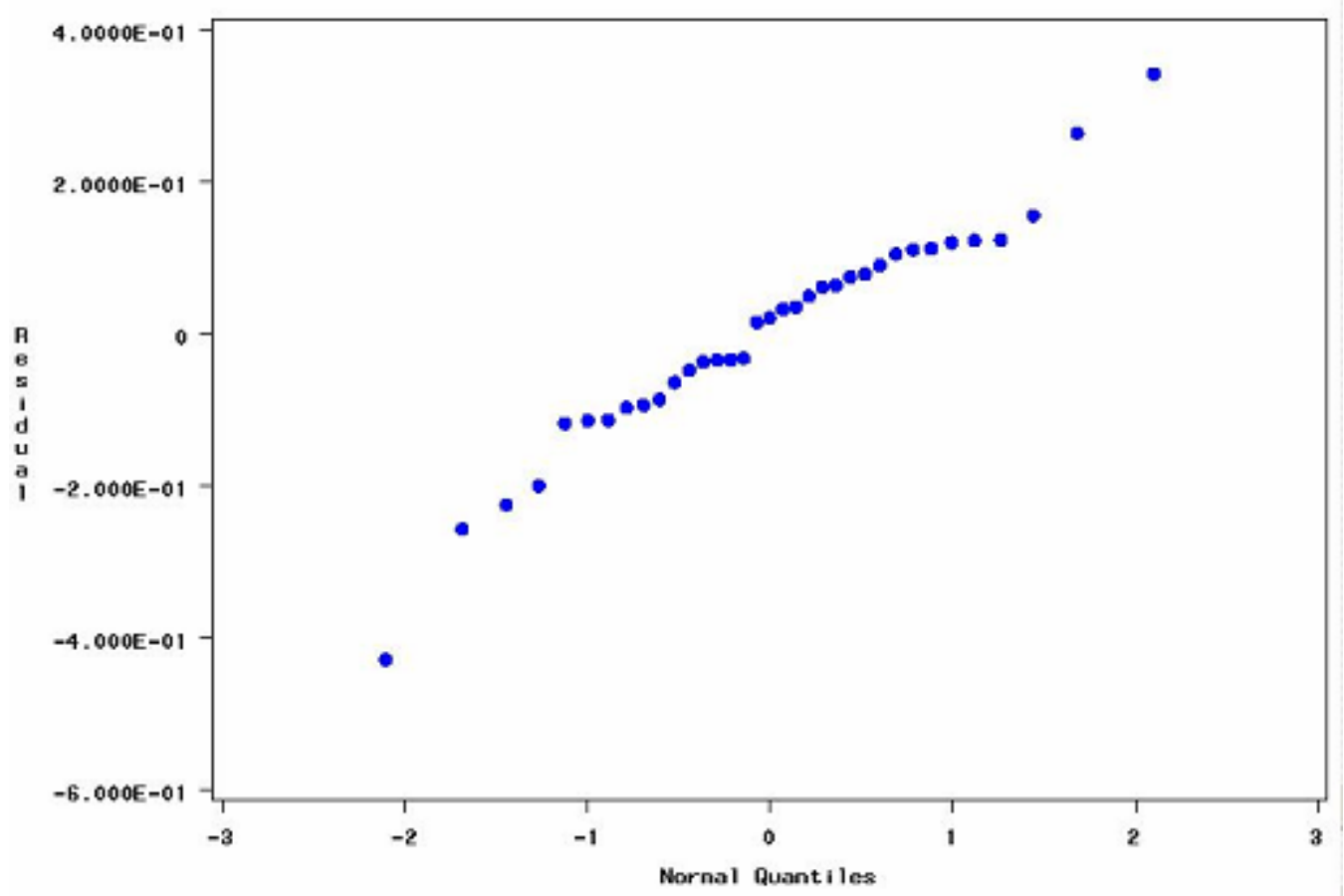

Figure 4.18 Normal Probability Plot for Residuals

The residual plots revealed that the error terms are independent and have constant error variance (Figure 4.16 and Figure 4.17), which is harmonious with the basic underlying assumptions of present regression model under study. It is also important to 
analyze the residuals in order to assess their normality. This was done with the help of normal probability plot shown in Figure 4.18. The normal probability plot does not show departure from normality for the error terms. The tails are more or less straight and all error terms can fall onto a straight line. Also, from these graphs we do not see any indication for the potential outliers. The residual plots do not indicate exclusion of important predictor variables.

\subsubsection{Goodness of fit}

The goodness of the model can be tested with the lack of fit test. However, this test requires at least one replicated observation i.e. an observation with same levels of all predictor variables and different measured value for predicted variable, LF_P for this case. For this reason this test could not be performed.

\subsubsection{Test for Heteroscedasticity}

To test the heteroscedasticity of error terms of model, SPEC option in Proc REG of SAS was used. The first and second moment specification results obtained are shown in Table 4.22. High value of probability shows that the error terms are homoscedastic.

Table 4.22 Test for Heteroscedasticity

\begin{tabular}{|c|c|c|}
\hline DF & Chi-Square & Pr $>$ ChiSq \\
\hline 5 & 4.59 & 0.4677 \\
\hline
\end{tabular}

\subsubsection{Breusch-Pagan Test}

This test was used as second test for checking constancy of error variance. Residuals $\left(\mathrm{e}_{\mathrm{i}}\right)$ obtained were squared $\left(\mathrm{e}_{\mathrm{i}}^{2}\right)$ and regressed against the predictor variables, LF_S and x24 to get SSR* with the help of SAS. The test statistic is obtained as,

$$
\chi_{B P}^{2}=\frac{S S R^{*}}{2} \div\left(\frac{S S E}{n}\right)^{2}
$$

From SAS output we have,

$\mathrm{SSR}^{*}=0.0004\left(\mathrm{e}_{\mathrm{i}}^{2}\right.$ regressed with LF_S and $\left.\mathrm{x} 24\right)$

$\mathrm{SSE}=0.71170($ LF_P regressed with LF_S and x24)

$\mathrm{n}=35$ (observations)

$\chi_{B P}^{2}=0.487$. 
To control a risk at 0.05 , i.e. for $95 \%$ confidence, $\chi^{2}(0.95 ; 3)=7.81$ [36]. Since $\chi_{B P}^{2}=0.487 \leq 7.81 \rightarrow \mathrm{H}_{0}$ is concluded, that error variance is constant. The P-value of this test is $>0.9$ so the data are very consistent with constancy of error variance [36].

\subsubsection{Multi-Collinearity Diagnostics}

The model built was examined for multicollinearity. No informal measures indicated multicollinearity. These informal measures included:

- Large coefficients of simple correlation between pairs of predictor variables.

- Wide confidence intervals for predictor variables.

- Extra sum of squares associated with predictor variable changes when other variables are added to the model.

The variance inflation factors were investigated in order to determine if there existed any multicollinearity. The variance inflation factor for predictor variables are given in Table 4.23.

Table 4.23 VIFs of Predictor Variables

\begin{tabular}{|c|c|c|}
\hline Variable & DF & $\begin{array}{c}\text { Variance } \\
\text { Inflation }\end{array}$ \\
\hline Intercept & 1 & 0 \\
\hline LF_S & 1 & 2.2334 \\
\hline x24 & 1 & 2.2334 \\
\hline
\end{tabular}

The rule of thumb for VIF is $(\mathrm{VIF})_{\mathrm{k}} \leq 10$ and $\overline{V I F}=\frac{\sum(V I F)_{k}}{n-p} \leq 1$ [36]. It was found that all VIF values were less than 10 and also mean value of VIF ( $\overline{V I F})$ was found to be 0.14 which is less than 1 . Therefore, no evidence of multicollinearity is found. After rigorous checking model in equation 4.5 or equation 4.6 was selected as final model as it proves to be a good fit for data. Summary of models fit is given Table 4.24.

Since polynomial models can produce unacceptable results because of their high chances of collinearity problems, it is not recommended to use such models. Such models yield ridiculous results even for small extrapolation and may change readily even if one observation is removed or altered. Therefore, from Table 4.24 on the basis of maximum coefficient of determination and adj- $\mathrm{R}^{2}$ multiple regression model (interaction model) seems to be the best. 
Table 4.24 Summary of Models fitted for input power measurement load and slip method load factor

\begin{tabular}{|c|c|c|c|}
\hline Model & Equation & $\mathbf{R}^{2}$ & $\operatorname{adj} R^{2}$ \\
\hline $\begin{array}{l}\text { Straight } \\
\text { line }\end{array}$ & $L F \_P=0.18374+0.9695 \times L F \_S$ & 0.7488 & 0.7412 \\
\hline Polynomial & $\begin{array}{l}L F \_P=0.31887-4.86^{*} L F \_S+59^{*} L F \_S^{2}- \\
238.15^{*} L F \_S^{3}+456.76^{*} L F \_S^{4}-415.96^{*} L F \_S^{5}+ \\
144.45^{*} L F \_S^{6}\end{array}$ & 0.7706 & 0.7215 \\
\hline $\begin{array}{l}\text { Multiple } \\
\text { regression }\end{array}$ & $\begin{array}{l}L F \_P=0.14511+0.7786 \times L F \_S+2.07 \times 10^{-5} \times \\
S \times \text { Volt }\end{array}$ & 0.7843 & 0.77 \\
\hline
\end{tabular}

To visualize the modeled relationship between load factor obtained by power measurement and slip load factor, a response surface of equation 4.5 is plotted with the help of MATLAB ${ }^{\circledR}$. The LF_S has limits between 0 to 1 and $\times 24$ which is a interaction term is found to have limits between 72 and 198,000 for the collected data. Using these limits a response surface was plotted as shown in Figure 4.19.

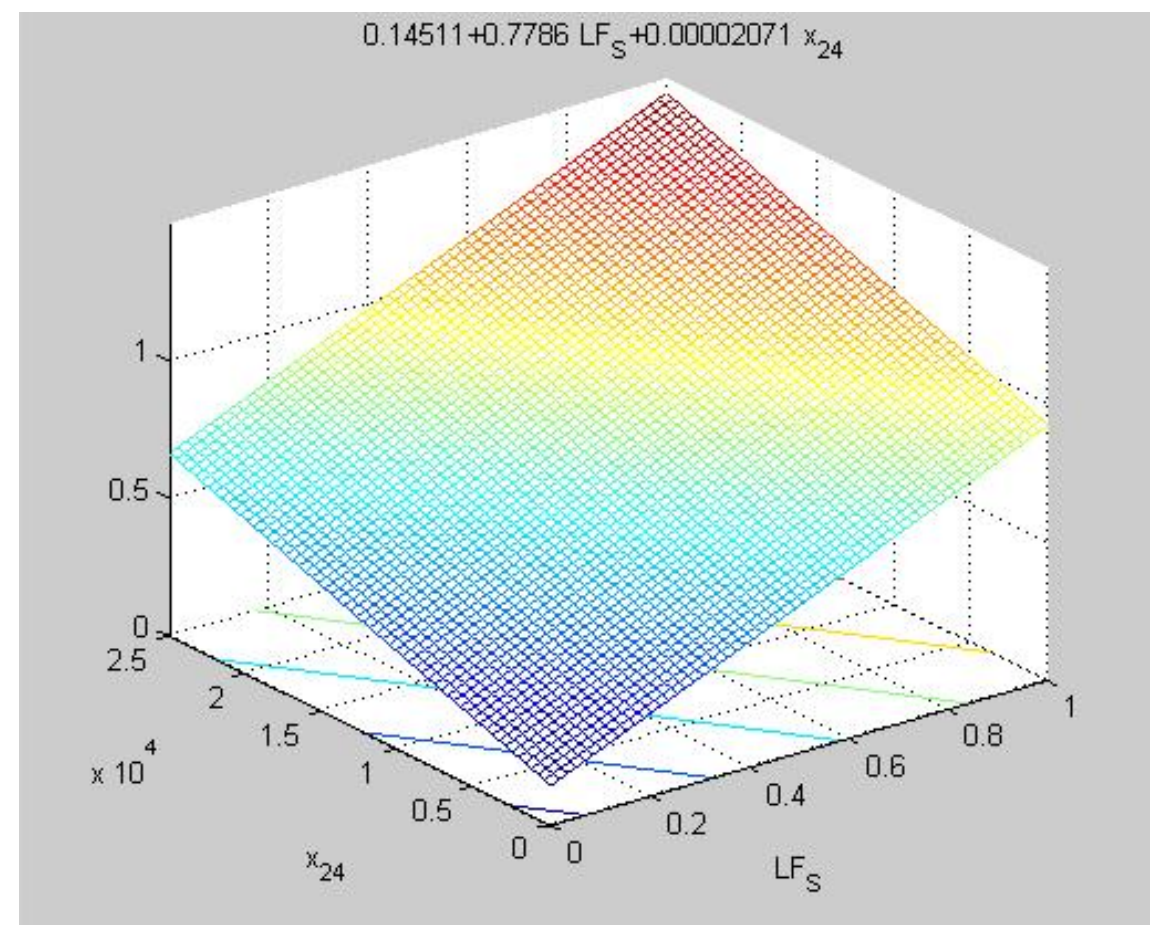

Figure 4.19 Response Surface for Model Fitted to Data

\subsection{Model Validation}

As discussed earlier the data was splitted into model building data set and validation data set or prediction data set, which was used to validate model. For 
validation of the model MSPR criteria has been used. 10 observations were available for validation of the model. By far the preferred method to validate a regression model is through collection of new data. Often, however, this is neither practical nor feasible [36]. Since entire data set is not very large here to make an equal split the model validation data split will need to be smaller than the model building data set. $80-20 \%$ split is considered here to maintain the strength of model building data. The more the data in the model building data set the better the model. When data are collected sequentially in time, it is often useful to pick a point in time to divide the data. Generally the earlier data is used for model building and later data for model validation. Use of time point to split data set provides the opportunity to test the generalizability of the model since conditions differ for the two data sets. The validation data set contains motors in the range of $30 \mathrm{hp}-$ $250 \mathrm{hp}$. The model building data set has motors in range of $20 \mathrm{hp}-250 \mathrm{hp} . \hat{Y}$ can be calculated using the model fitted. The sum of squares of difference between $\mathrm{Y}_{\mathrm{i}}$ and $\hat{Y}$ over number of validation observation will give us MSPR. Detailed calculations are shown in Table 4.25.

Table 4.25 Validation of Selected Model

\begin{tabular}{|c|c|c|c|c|c|c|c|}
\hline Sr. & HP & S & Volt & LF_S & LF_P (Yi) & Yhat & (Yi- Yhat)2 \\
\hline 40 & 125 & 21.8 & 460 & 0.872 & 1.054 & 1.031729 & 0.000496 \\
\hline 41 & 250 & 30.8 & 460 & 0.832 & 1.039 & 1.086324 & 0.00224 \\
\hline 42 & 100 & 10.1 & 460 & 0.673 & 0.789 & 0.765326 & 0.00056 \\
\hline 44 & 125 & 12.4 & 480 & 0.62 & 0.74 & 0.751108 & 0.000123 \\
\hline 46 & 150 & 2.9 & 460 & 0.121 & 0.421 & 0.266948 & 0.023732 \\
\hline 47 & 75 & 9.5 & 460 & 0.475 & 0.679 & 0.605448 & 0.00541 \\
\hline 49 & 30 & 20.1 & 460 & 0.502 & 0.587 & 0.727452 & 0.019727 \\
\hline 50 & 50 & 55 & 460 & 0.733 & 1.219 & 1.239787 & 0.000432 \\
\hline 51 & 60 & 3.4 & 480 & 0.995 & 1.126 & 0.953616 & 0.029716 \\
\hline 52 & 30 & 19.9 & 460 & 0.068 & 0.199 & 0.387634 & 0.035583 \\
\hline & & & & \multicolumn{5}{|c|}{ Total (Yi-Yhat) $^{2}=$} & 0.118019 \\
\hline
\end{tabular}

Mean square error of prediction $=\operatorname{MSPR}=\frac{\sum_{i=1}^{n^{*}}\left(Y_{i}-\hat{Y}\right)^{2}}{n^{*}}$ $\sum_{i=1}^{n^{*}}\left(Y_{i}-\hat{Y}\right)^{2}=0.118019$ 
$\mathrm{n}^{*}=10=$ observations available for model validation

MSPR $=0.0118019$

From Table 4.16, the mean square error of the model, $(\mathrm{MSE})_{\text {model }}=0.02372$. It can be seen that MSPR $<(\mathrm{MSE})_{\text {model }}$. Therefore, it can be concluded that the present model will produce adequate results for different set of observations. The model is validated. Since the MSPR is fairly close to MSE based on the regression fit to the model building data set, the MSE for the selected regression model is not seriously biased and gives an appropriate indication of the reasonable predictability of the model [36].

\subsection{Summary \& Conclusion}

This chapter focused on analyzing collected field data statistically in order to develop a meaningful model for prediction of power measurement load factor from slip load factor of motor. Mainly three types of models were investigated, viz. straight line, polynomial and multiple regression. The models are summarized in Table 4.24. The findings are summarized below:

- Multiple regression model was found to be the best because of highest coefficient of determination and adjusted $\mathrm{R}^{2}$ as indicated in Table 4.24.

- The residuals of this model were analyzed with hat matrix leverage values (hii), DFFITS and DFBETAS to remove outliers in the data to further refine the model.

- Breusch Pagan test conducted in section 4.4.3.6 proved constancy of error variance.

- Thus model was tested for heteroscedasticity (constancy of error variance) and normality of error terms.

- The model has no multicollinearity problems as has been check by variance inflation factors VIF in section 4.4.3.7.

- The model is validated in section 4.5, proves that model can predict input power measurement load factor from slip load with mean square prediction error (MSPR) less than mean square error (MSE) of the model. 


\section{Chapter 5}

\section{Load Factor Discrepancies and Other Considerations}

As mentioned in Chapter 1 it has been found that motors installed in the industry are largely under-loaded. In the study carried out by X-Energy in 1998, over the nation it was found that more than $40 \%$ of $5 \mathrm{hp}$ or larger motors were running below $40 \%$. Also, in the present study in which motors were monitored from 15 facilities, it was found as stated in Chapter 1 that $31 \%$ of motors were loaded below $40 \%$ and $15 \%$ were loaded $40-60 \%$. The reasons why are motors oversized are discussed in following section.

\subsection{Reasons for under-loaded motors}

There are several reasons for which oversized motors are such a commonplace in the industry. Some of them are discussed here:

\subsubsection{Application Need}

Many motors are oversized for their applications. Motors are installed in a facility for an atypical application which requires instantaneous high power but drops down below average for other time of the load cycle. In such cases motors with specific controls on them would be beneficial especially ASDs might help in this case. Premium efficiency motors may prove even worse for these kinds of applications than standard efficiency motors [40]. Thus uncertain loads might force plant personnel to install oversized motors.

\subsubsection{Purchasing practices}

In many plants a motor is replaced or repaired without engineering analysis and is often replaced with the same size, brand, and model number. Only in the case of large motors (over approximately $250 \mathrm{hp}$ ) with reasonably high operating costs does an engineering or economic analysis usually precede decisions concerning replacement of the motor.

End-users can obtain information on motors and related equipment from manufacturers' catalogs, trade publications, manufacturers' representatives, distributors, contractors, and professional organizations. It is common belief that motors under approximately $200 \mathrm{hp}$ 
and other drive power components are same though from different manufacturers and are interchangeable. This may be true from the functional perspective; it could not be further from the truth from an energy efficiency perspective [26]. For many customers, purchase decisions are made based primarily on reliability, price, and availability, not on efficiency. Consequently, energy cost saving is a factor in decisions, but not a primary concern. Some large companies and exceptionally a smaller one have formal motorpurchase policies that address motor efficiency; however, most do not.

\subsubsection{Aversion to Downtime}

In many businesses, particularly in industry, shutting down equipment for upgrading or replacement can mean losing thousands of dollars per hour in forgone production. Such penalties may induce an understandable aversion to downtime. Because of this, many facility managers shy away from new, unfamiliar technology that they fear might be less reliable than the equipment they are used to. Furthermore, if a highefficiency substitute for a failed motor is not stocked by the distributor, in order to save time the user is likely to buy a standard replacement or simply repair the old motor just to put production back in place as quickly as possible. Also, if a properly sized motors fails while in operation, the plant personnel tend to put spare motor available in shop to restore production. If a same sized motor is not available generally it will be replaced by a higher sized motor. Thus, availability of the motor also plays vital role.

\subsubsection{Maintenance Practices}

Motor maintenance practices are generally limited to what is needed to keep equipment running rather than attempting to optimize performance and save energy. Most industrial plants and large commercial firms have full-time maintenance staff that regularly lubricate (and often over-lubricate) motors, listen for bearing noise (a sign of wear or misalignment), and check and tighten belts as needed [26]. Few firms do some more sophisticated monitoring or maintenance work on motor systems. But motor loads are hardly monitored to figure out the actual capacity needed. No maintenance analysis is followed to analyze early life failure of motor. It is known that constant under-loaded running of motor can substantially deteriorate its life [26]. Motors are run with out even noticing that they are oversized. 


\subsubsection{Downsized Production}

In some cases, it might so happen that production volume is decreased because of loss of business or moving the production unit to other places. Original production requirements then are reduced, leaving a grossly oversized motor in place.

\subsubsection{Allowance for load growth}

Many motor design professionals figure that the increase in price for a larger motor is a small price to pay for the capability to handle higher loads if the use of the motor changes over time. Also, sometimes while designing certain design factor is applied to compensate for growth of production over the years of life of motor.

\subsubsection{Rounding up to the next size}

Sometimes, because of motors manufacturing in standard steps, the designers have to round up the size of motor to next size. If an application needs $160 \mathrm{hp}$ the motor of $200 \mathrm{hp}$ is selected at that place, leading to oversized motor.

Thus, there can be many reasons why motors are under loaded in the industry. While many oversized motors should be downsized, some should instead be equipped with controls that enable them to operate more efficiently at partial load. Most motors are fixed speed motors. However, adjusting the speed to match the requirements of the loads which generally vary over time can enhance efficiency of motor system. Speed controls can save the most energy in centrifugal machines, which include most pumps, fans and blowers and centrifugal air-compressors. Speed control is also effective in mills, such as the rolling mills that produce sheet metal in a steel plant, traction drives, conveyors, machine tools, and robotics.

Oversized motor causes low operating load factor for the motor. This reduces the efficiency of motor considerable if the motor is operating below $50 \%$ of load. Sometimes motor may not be undersized because of its application as discussed in section 5.1.1. In such cases speed control may give improved performance for the system. The available options for motor speed control include multi-speed and DC motors, hydraulic couplings, eddy current drives and electronic adjustable speed drives (ASD). Advantages, 
limitations, cost and applications of ASDs along with their types and operating principles are discussed here.

\subsection{Adjustable Speed Drives (ASD)}

The primary purpose of an adjustable speed drive is to let an AC-motor run slower. These drives allow the motor-driven machines to produce the same output as standard counterparts but with less electrical input, often improving manufacturing quality as well. Such drives can also enhance motor and machine life and reduce maintenance by allowing operation at lower temperatures and smoothing machine startup and shutdown [41]. Adjustable speed drives operate alternating current (AC) electric motors slower than constant speed. ASDs change the characteristics of the electricity (voltage and frequency) powering the motor so that the speed at which the motor rotates actually changes to meets the desired machine output level. Because throttling motor output wastes energy, ASDs can save a great deal on energy costs by increasing the overall machine operating efficiency.

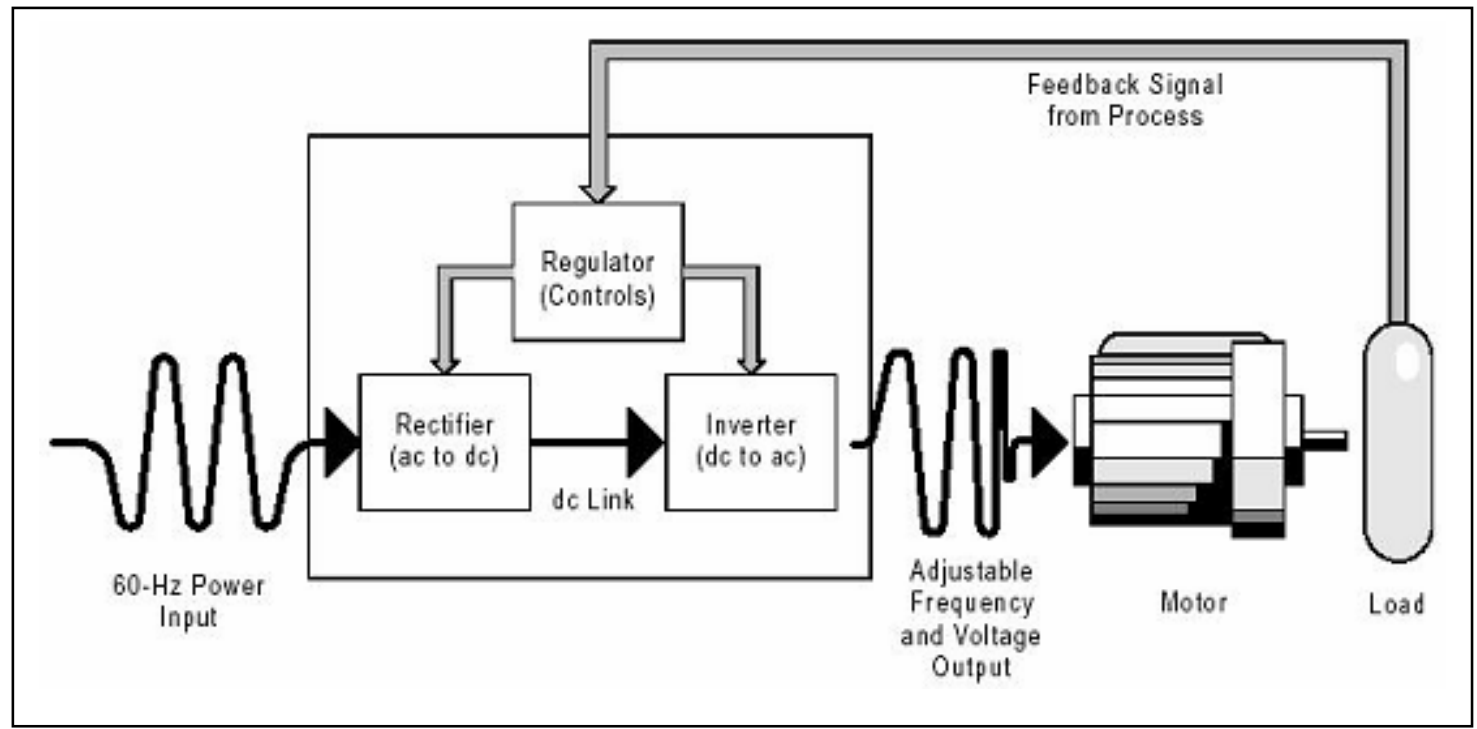

Figure 5.1 Schematic of Adjustable Speed Drive with Feedback Loop [41]

Figure 5.1 shows a typical schematic of ASD system, which has four basic components: rectifier, DC link, inverter, and regulator. The rectifier converts line frequency alternating current (AC) to direct current (DC). The DC link smoothes the output of the rectifier and, the inverter generates an adjustable frequency and voltage $\mathrm{AC}$ 
output to the motor. Some applications may require regulators, which help control system output to optimize the process requirements [42].

\subsubsection{Types of Adjustable Speed Drives}

ASDs are also commonly referred to as variable speed drives (VSDs), variable frequency drives (VFDs), and adjustable frequency drives (AFDs). Several types of ASDs are available; each with its own practical applications. All are similar in controlling motor speed by varying electrical voltage and frequency. They differ in how they accomplish AC-to-DC conversion and DC-to-AC inversion. The three most common rectifier/inverter types are discussed below; many hybrid forms combine characteristics of these basic types.

\subsubsection{Current Source Inverter (CSI)}

A CSI actually uses the inductive characteristic of the motor to stabilize DC as it reaches the inverter. Because the inductor has to be fairly large to keep the current source stable, this type of electronic ASD is generally used with 100-hp and larger drives. It is harder to tune in the field because it cannot operate without connection to the motor [41].

\subsubsection{Voltage Source Inverter (VSI)}

The VSI is sometimes called a variable voltage inverter (VVI) or six-step inverter. It uses a capacitor before the inverter to store energy from the rectifier and stabilize the voltage entering the inverter. It is used in low to medium power applications, generally up to a few hundred horsepower [42].

\subsubsection{Pulse-Width Modulated Inverter (PWM)}

The PWM inverter develops the voltage output by chopping pulses of varying widths to synthesize the desired waveform. PWM drives use complex software algorithms to determine timing, duration, and frequency of the voltage pulses delivered to the motor. Each manufacturer employs its own algorithms, causing significant differences in motor performance and life. This is presently the most common ASD type for up to 400-hp motor sizes. These drives are well suited for motors up to $100,000 \mathrm{hp}$, but above $1,000 \mathrm{hp}$, electronic components and inverter controls are more complex [42]. Discussed are the most common types of ASDs. Those not included in discussion are load commutated inverter, cycloconverter and vector control ASDs. 


\subsubsection{Benefits of Using ASDs}

- Energy savings can be very significant in many situations, depending on the existing system design, installed equipment and motor load requirements.

- Speed reduction may extend the life of a machine and motor due to reduced stresses and fewer revolutions.

- ASDs start motors gradually, reducing stress on drive components such as belts. This gradual start reduces maintenance on these components and the effect of fluctuating voltage due to the sudden start of a large motor.

- A single ASD can control several motors at once. All the motors connected to the drive will operate at the same speed.

- Some ASDs can operate motors at speeds greater than their original design speed.

- PWM ASDs can significantly improve power factor.

- Some ASDs provide power regeneration when the motor slows down.

- Speed control can be accomplished in many ways based on load requirements.

- Some speed control sensors include rpm, temperature, pressure, flow, and power.

\subsubsection{Drawbacks of ASDs}

- If the motor operates at or near full speed most of the time, adding an ASD will increase overall energy consumption, due to energy losses in the drive.

- ASDs may increase motor heating, especially at slower speed. Many motors rely on internal cooling fans attached to the motor shaft to remove internal heat. At slower speeds, the heat generated internally may not decrease in proportion to the fan's cooling capacity so additional cooling may be required.

- Some ASDs can produce electrical interference that harms other electronic equipment at the facility, so electrical isolation equipment may be required.

- The additional electronics associated with an ASD add to the maintenance and repair complexity of the drive system.

- An ASD may be less efficient than a two-speed motor in situations where speeds between high and low are not required.

- Each ASD application needs to be carefully considered and engineered for proper installation and compatibility. 


\subsubsection{Applications of ASDs}

ASDs are best suited for modifying the speed of centrifugal machines to provide the exact flow required by the system. Fan, pumps, blowers and compressors come under this category. In general following are good situations for variable speed flow control [42].

- The applications are fixed at a flow rate higher than that required by the load.

- The application is variable flow, where variation is provided by throttling and where the majority of operation is below design flow.

- The applications use flow diversion or bypassing via pressure reducing valve.

- The applications are greatly oversized for the flow required.

- The applications have long distribution networks.

- The applications are single stage rather than multiply staged pumps or fans.

A typical system efficiency curve having ASD installed is shown in Figure 5.2.

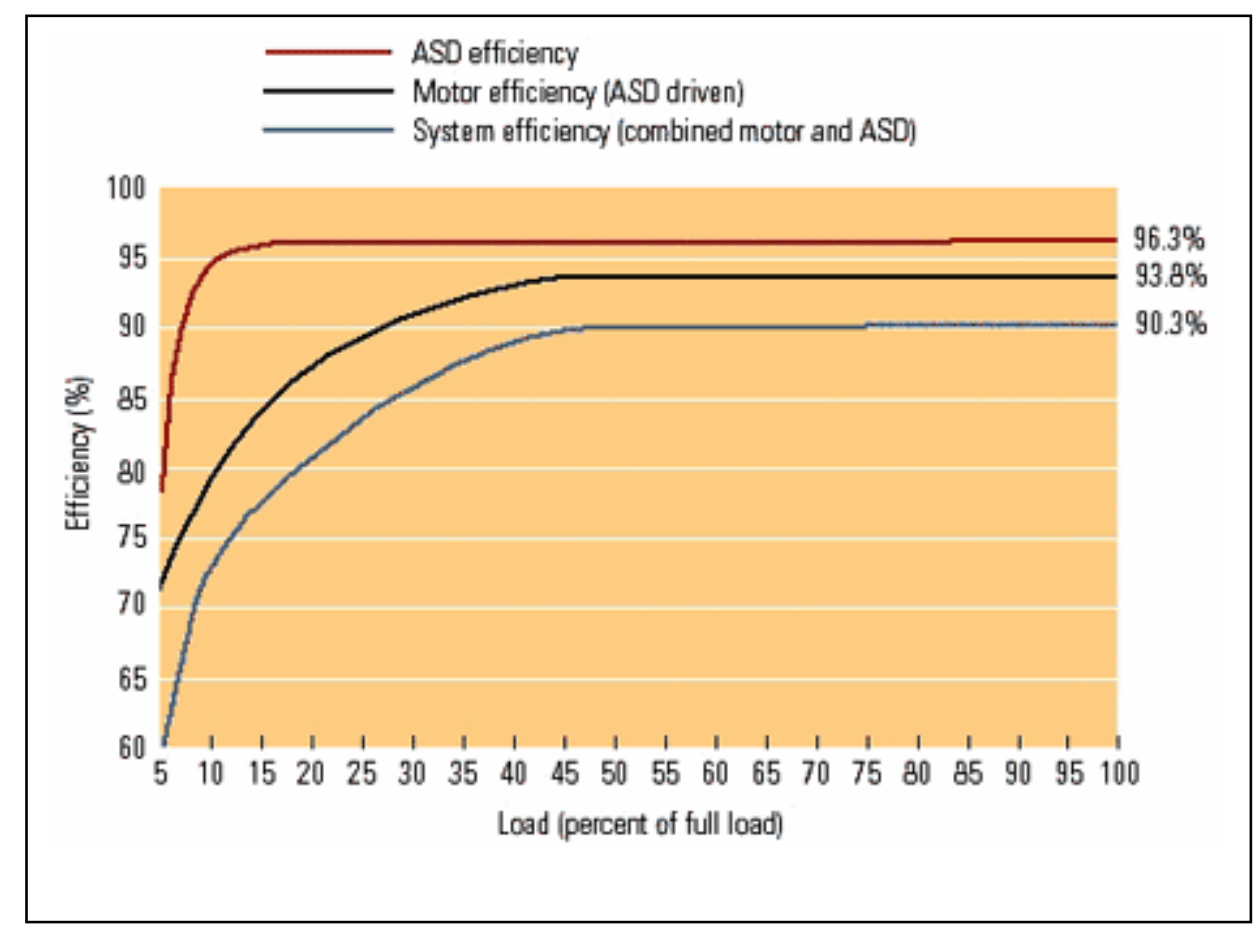

Figure 5.2 ASD, Motor and System Efficiency vs. Partial Load [42]

It can be seen that there will be always more energy consumption if the motor keeps on operating at rated load. However, if motor comes down below rated load even for small amount of time, the amount of savings that are produced justifies the installation of ASD. 


\subsection{Discrepancies in Load Factors}

As noted in Chapter 3, large discrepancies exist in the loads obtained by different methods of estimating load factor for recorded motors. Out of four methods used for estimation of load, the load obtained by input power measurement is compared with each of the method below.

\subsubsection{Slip Method}

The load comparison graph for slip method compared with load factors obtained with input power measurement is reproduced in Figure 5.2 below.

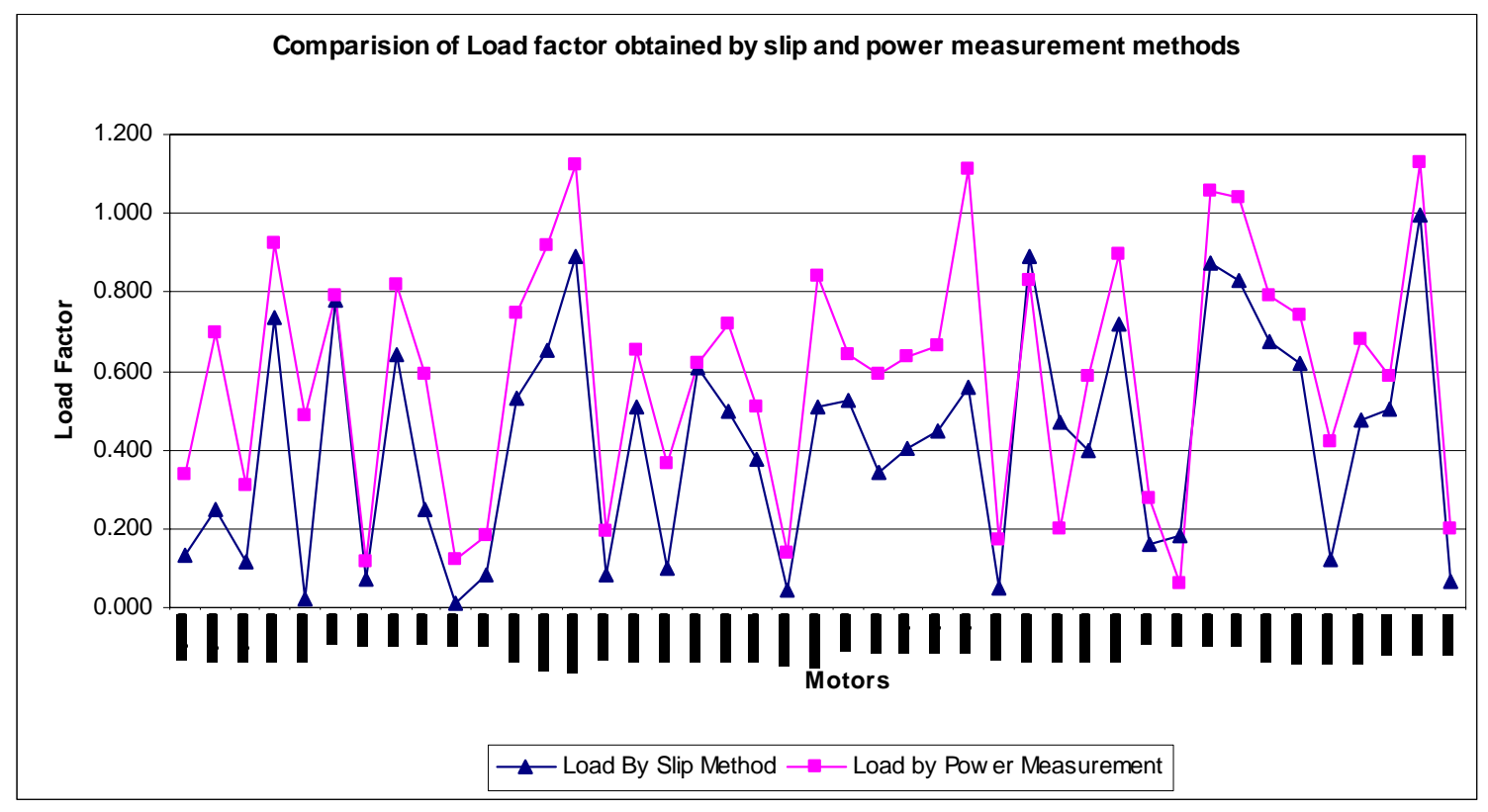

Figure 5.3 Discrepancy in Load Factors Obtained by Slip Method and I/P Power measurement Method

As can be seen in the graph, the load obtained by power measurement method is always on higher side as compared with the load factor obtained by slip method. This is true at all points except a few where the load obtained by power measurement is actually less than the load obtained by the simple slip method. A possible explanation of this is given in following sections. The average of load factor discrepancies obtained at each horsepower motor is plotted against horse power of motor in Figure 5.4. 


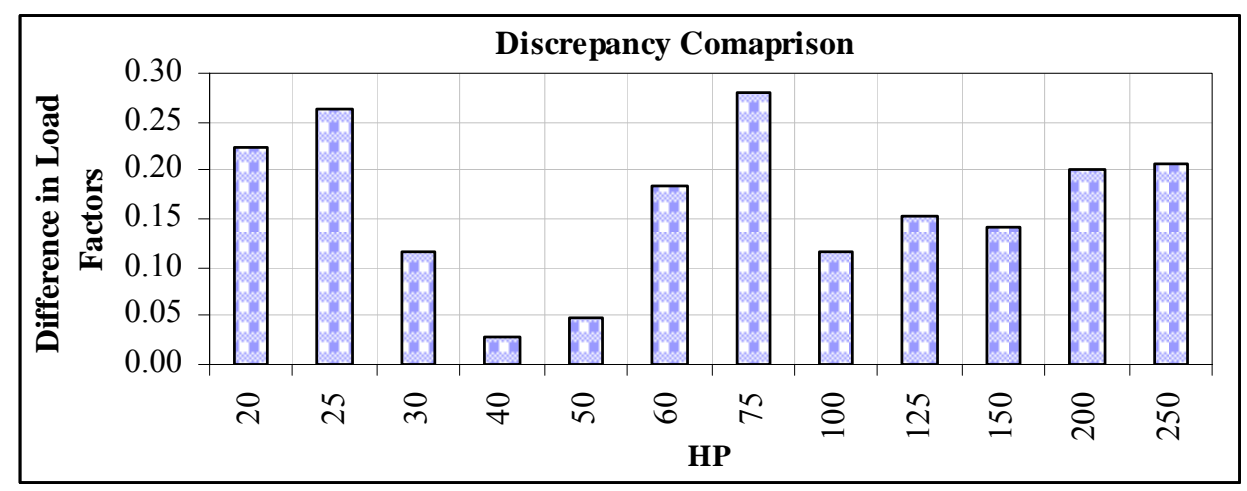

Figure 5.4 Load factor discrepancy for slip method vs. Motor HP

As we can see there is no specific pattern in the differences obtained with respect to horsepower. The differences reduce till the size increases to 40-50 hp but again start to increase once the size further starts increasing. This may be due to high losses associated with low and high horsepower motors as discussed later.

\subsubsection{Voltage Corrected Slip Method}

A graph showing comparison of load factors obtained by voltage corrected slip method with load factors calculated using input power measurement method is shown in Figure 5.5. This method is a modification of simple slip method in that, a correction of voltage is applied to the previous method in order to compensate for the slip because of voltage unbalance. This method shows more or less similar behavior as simple method itself.

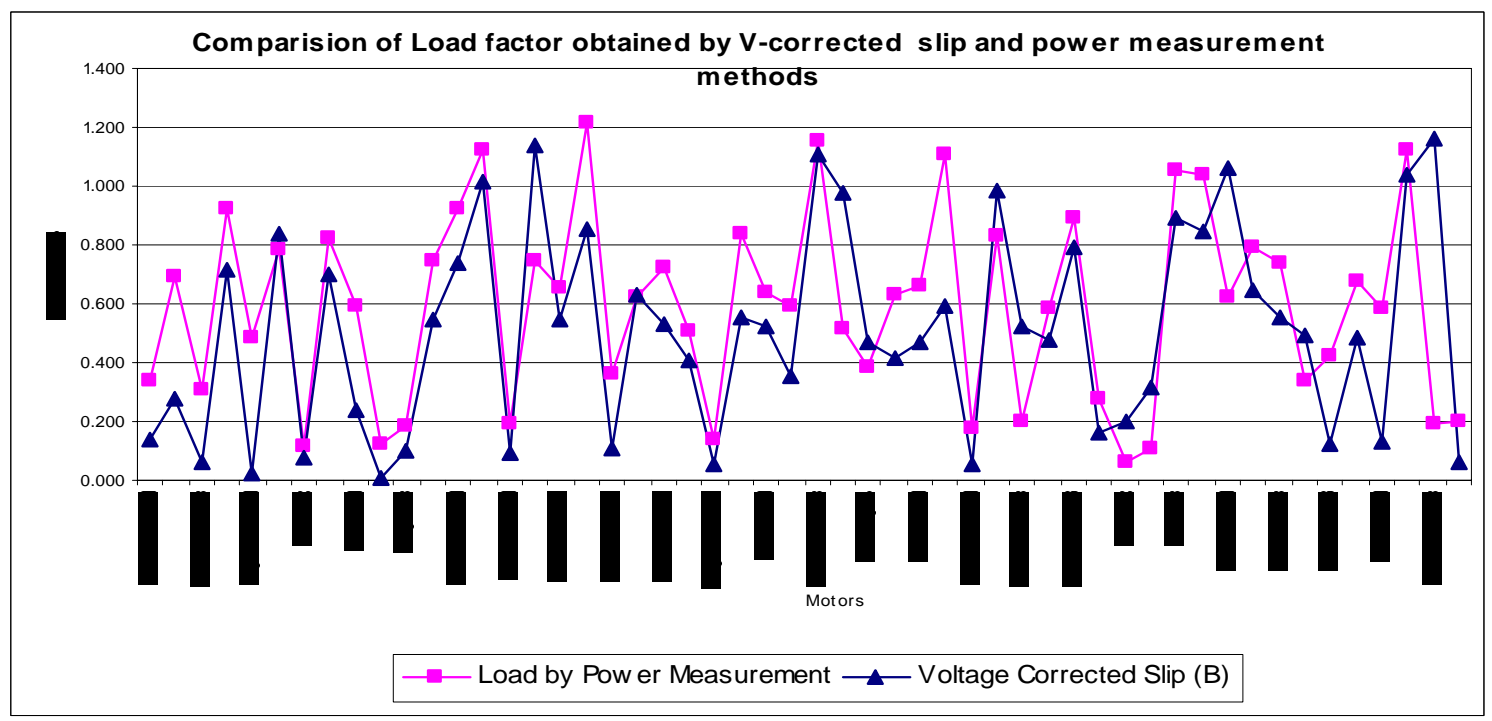

Figure 5.5 Discrepancies in Load Factors obtained by Power Measurement and Voltage Corrected Slip 
With this method also, the load factor obtained, most of the time, is less than the power measurement load factor as shown in Figure 5.6. The differences in load factor obtained when plotted against the horsepower of motor shows that load factor differences for the horsepower ranges $40-50 \mathrm{hp}$ is negative. The load factor differences for this category had lowest values in slip method.

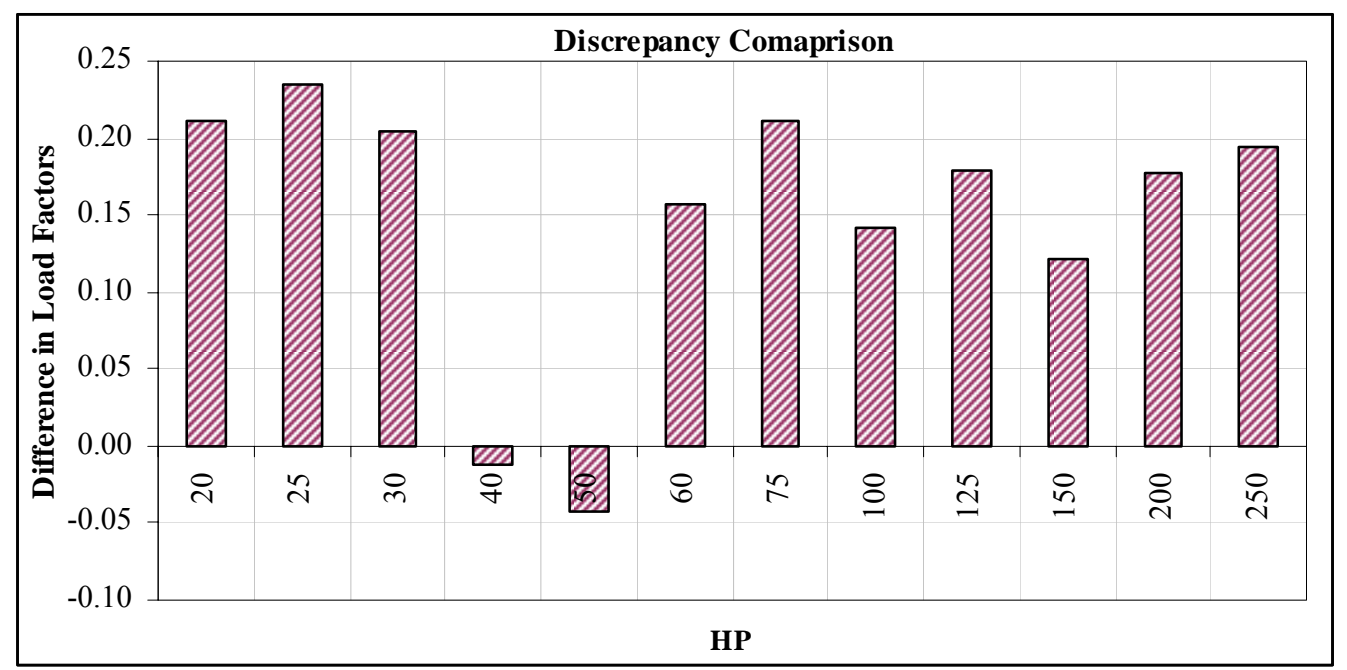

Figure 5.6 Load factor discrepancy for voltage corrected slip method vs. Motor HP

\subsubsection{Current Voltage Method}

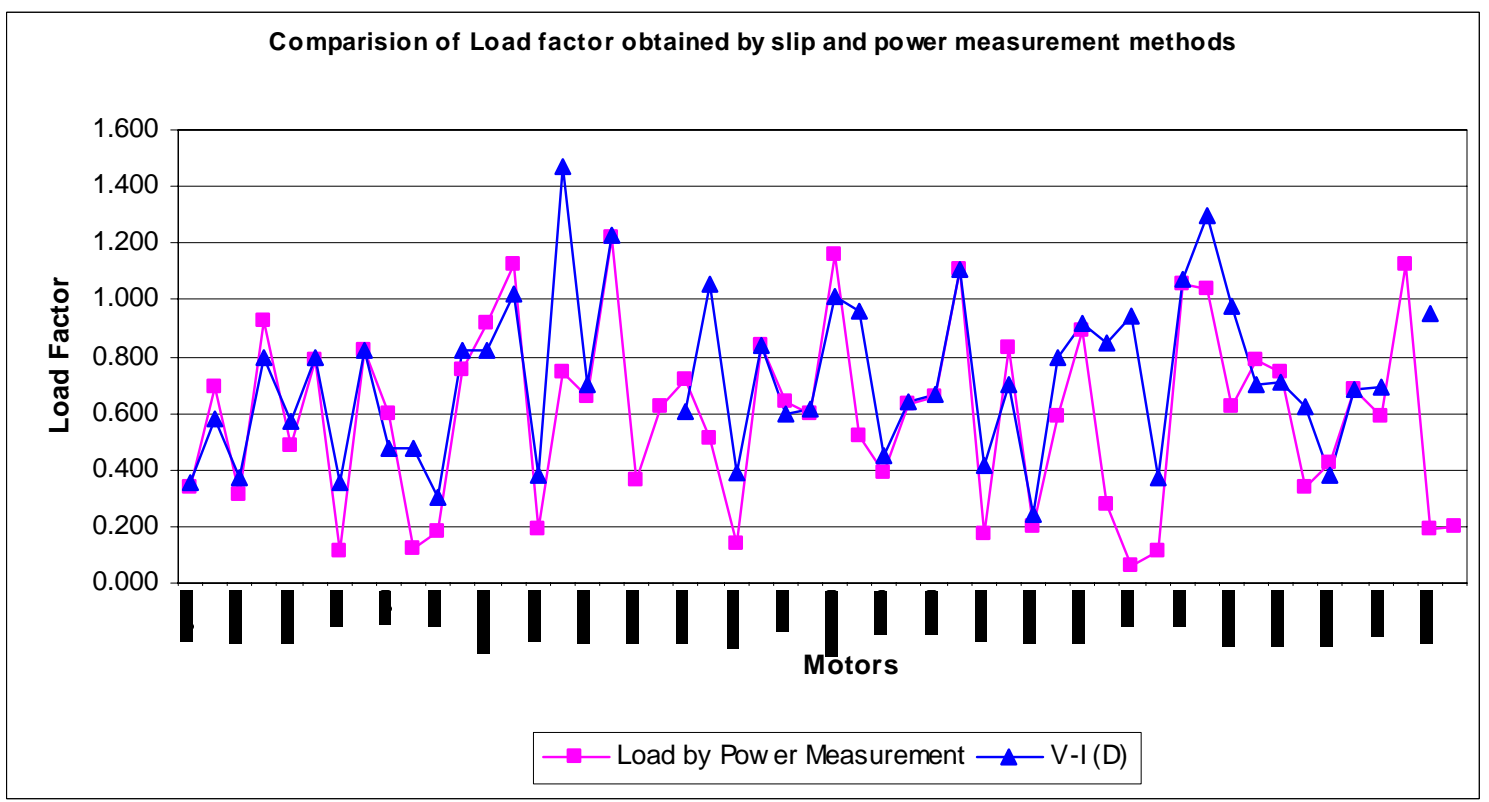

Figure 5.7 Discrepancies in Load Factors obtained by Power Measurement and Current Voltage Method 
The load factors obtained by this method exhibit different behavior than both methods discussed above. In this case the load factors are almost equally divided into higher or lower regions as compared to the input power measurement load factor. The graph shown in Figure 5.7 illustrates this fact.

Differences in the load factors obtained are plotted against horse power of motors in Figure 5.8. The graph shows that, the considered method obtains very low load factors for motors in horse power category 40-50 hp. Also, the differences are distributed in positive and negative regions and go on increasing as the horse power increases.

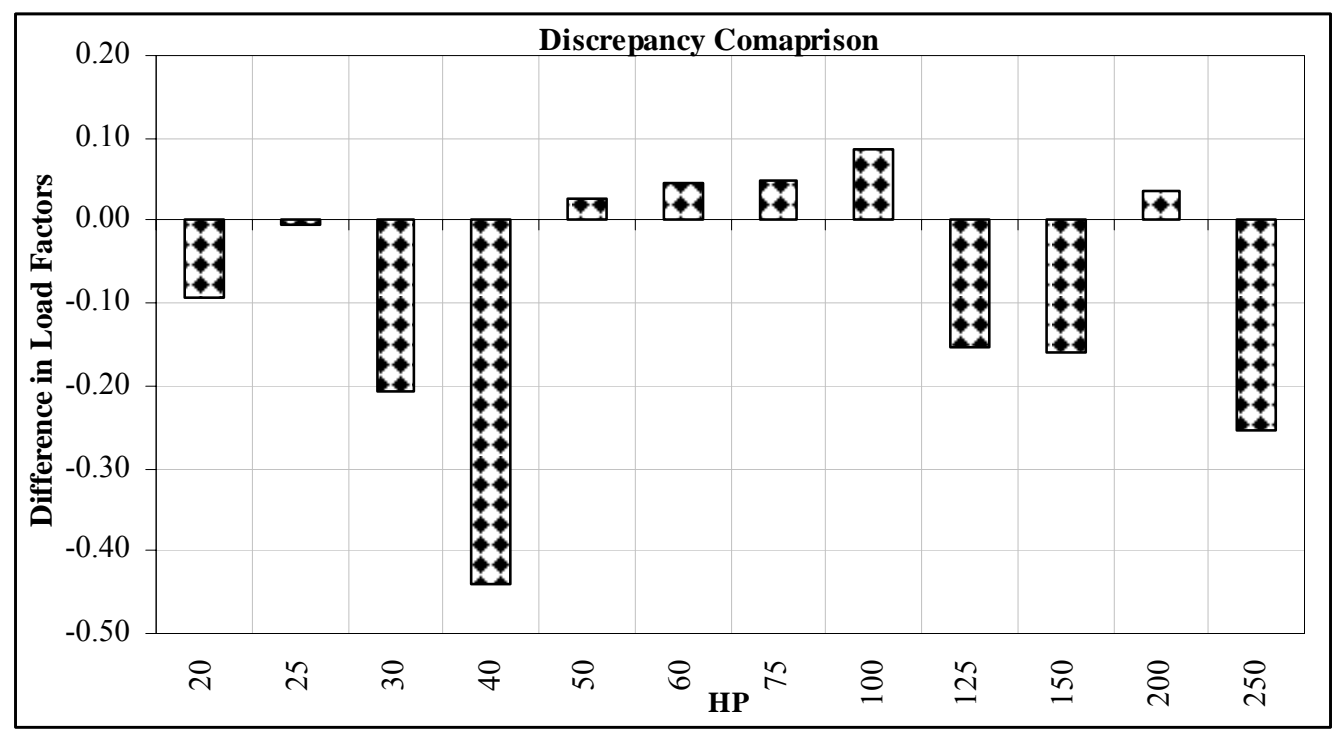

Figure 5.8 Load factor Discrepancy for Current Voltage Method vs. Motor HP

To get a good idea of how load factors differences behave with respect to horse power of motors a collective graph of Figures 5.4, 5.6, 5.8 would be helpful. Such a graph is shown in Figure 5.9. As we can see, except for some categories of HPs the voltage corrected slip method acts towards reducing the difference between load factors obtained by slip method and input power measurement method. For HPs 40 and 50 we get least differences by slip method and voltage corrected slip method while for current voltage method, the difference in this category is the highest. 


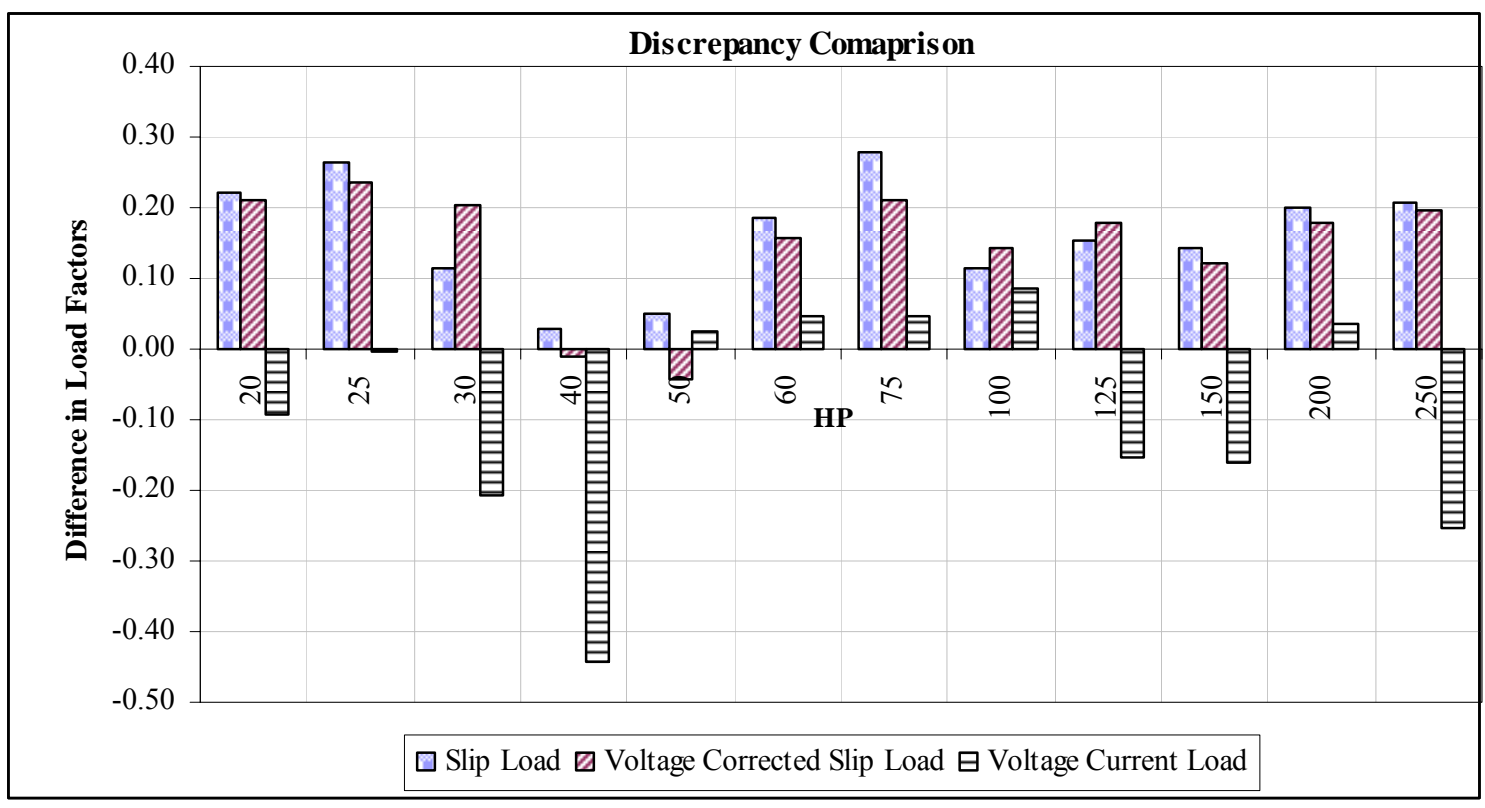

Figure 5.9 Load Factor Discrepancies vs. HP of Motors

\subsection{Reasons for Load Factor Discrepancies}

The load factors of recorded motors are evaluated to find that it is relatively very easy to evaluate load factor for a motor with slip method, as we just need to measure operating speed of that motor. However, the actual load varies from the slip load values because of following:

1. Rated speed on nameplate is rounded off to nearest multiple of 5

2. Motor is rewound number of times in its lifetime and its rated speed changes

3. Error in the measurement of operating speed

Also as specified in Table 2.3 in Chapter 2, NEMA has allowed certain tolerance limit for specification of the rated parameters of speed, voltage and current on the nameplate of motor. This may account for error in the loads calculated using these values. Fairly accurate load factor of motor can be found out using input power measurement method. Inaccuracies exist with this method also due to inaccuracy in estimating operating efficiency of motor. Nevertheless, it is pretty accurate method to estimate load factor of an in-situ motor. The limitations of the slip method are that it does not recognize actual current losses which vary at loaded and no-load conditions, and the calculations rely upon the value indicated on the motor nameplate for speed (rpm) at full load which is an average for groups of similar motors tested by the manufacturer. 
One more reason for slip load not matching with input power measurement load may be that, while estimating it is assumed that slip of motor is directly proportional to the load on the motor. This is because the load factor falls in a region near to the rated speed on the torque-speed curve. The torque-speed curve though not exactly is almost linear in this region. For low values of slip, this happens to be true but for larger values it may deviate slightly from the straight line assumption.

Developed torque is given by, Equation. 5.1

$$
T_{d}=\frac{V_{T h}{ }^{2}\left(\frac{R_{2}{ }^{\prime}}{s}\right)}{\omega_{s}\left[\left(R_{T h}+\frac{R_{2}{ }^{\prime}}{s}\right)^{2}+\left(X_{T h}+X_{2}{ }^{\prime}\right)^{2}\right]}
$$

Where,

$\mathrm{V}_{\mathrm{Th}}=$ Voltage of Thevenin's equivalent circuit, volts

$\mathrm{R}_{\mathrm{Th}}=$ Thevenin's equivalent circuit resistance, $\mathrm{Ohm}$

$\mathrm{X}_{\mathrm{Th}}=$ Thevenin's equivalent circuit reactance, Ohm

$\omega_{\mathrm{s}}=$ Synchronous angular speed of motor, $\mathrm{rad} / \mathrm{sec}$

$\mathrm{S}=\%$ Rated slip of motor, fraction

$\mathrm{R}_{2}{ }^{\prime}=$ Stator equivalent resistance, Ohm

$\mathrm{X}_{2}{ }^{\prime}=$ Stator equivalent reactance, $\mathrm{Ohm}$

For small slip values the curve can be assumed as straight line on torque vs. speed curve, $T_{d} \approx \frac{V_{T h}^{2} S}{\omega_{s} \cdot R_{2}{ }^{\prime}}$

If this underlying assumption is not satisfied, the load factor value will tend to be different than obtained by input power measurement method.

\subsection{MATLAB GUI for torque-speed curve generation}

To explain the discrepancy in the obtained slip load and load factor obtained by power measurement method a MATLAB graphical user interface (GUI) is developed. In the MATLAB program the parameters of the equivalent circuit of a motor can be entered on the circuit diagram. The program draws the Thevenin's equivalent circuit [32]. Performance characteristics are then obtained for the specified slip and the torque slip curve is plotted on the screen. The analysis can be repeated for different slips. The GUI 
can be used to estimate parameters for different motors and thus helpful in getting operating characteristics of a particular motor. The input screen for the graphical user interface is shown in Figure 5.10. User can input data on motor nameplate data in the frame motor nameplate data.

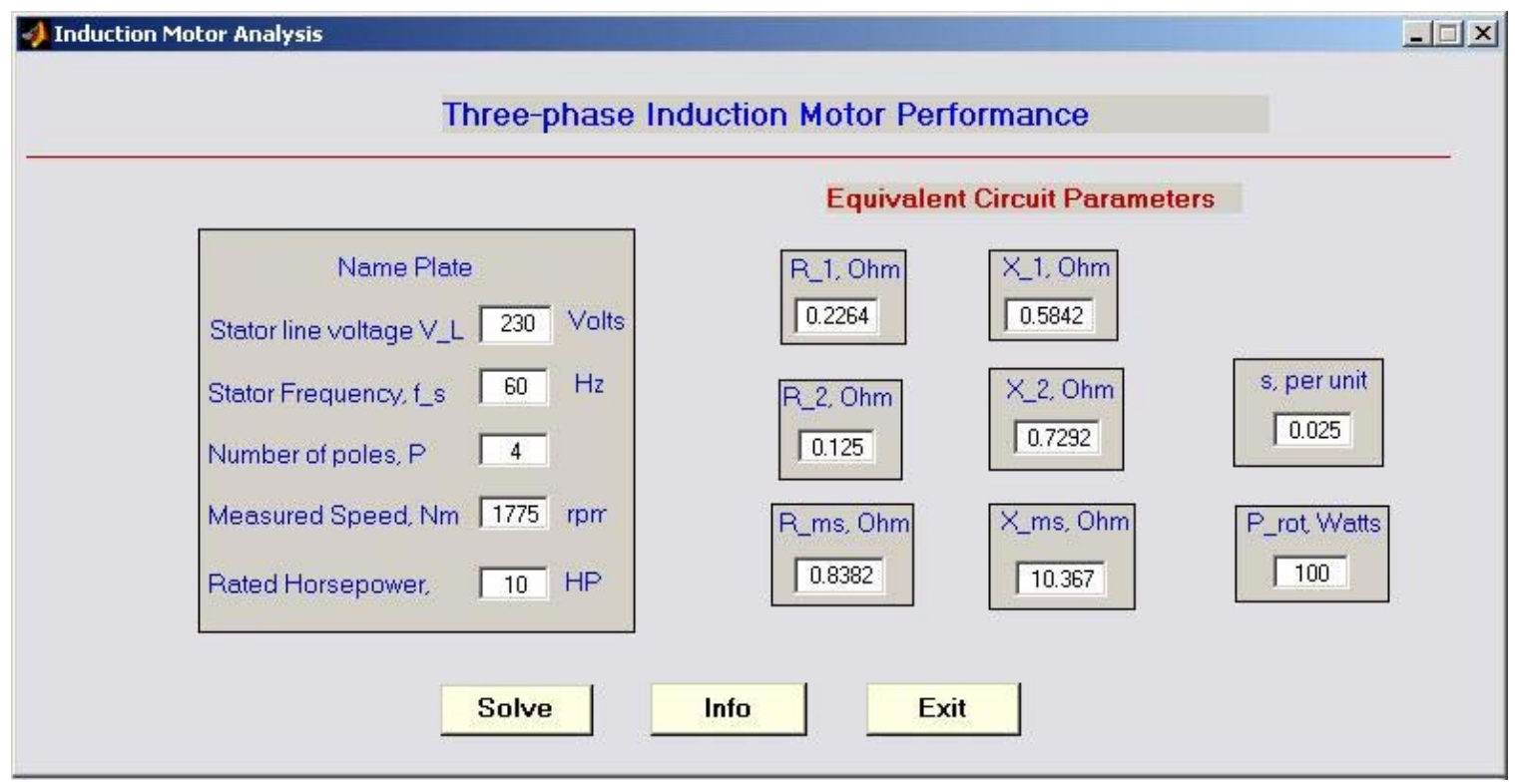

Figure 5.10 Input Screen for MATLAB GUI to Calculate Performance of Induction Motor

The equivalent circuit parameters can be entered into the edit boxes below equivalent circuit parameters. The program draws equivalent circuit as shown in Figure 5.11 with respective label.

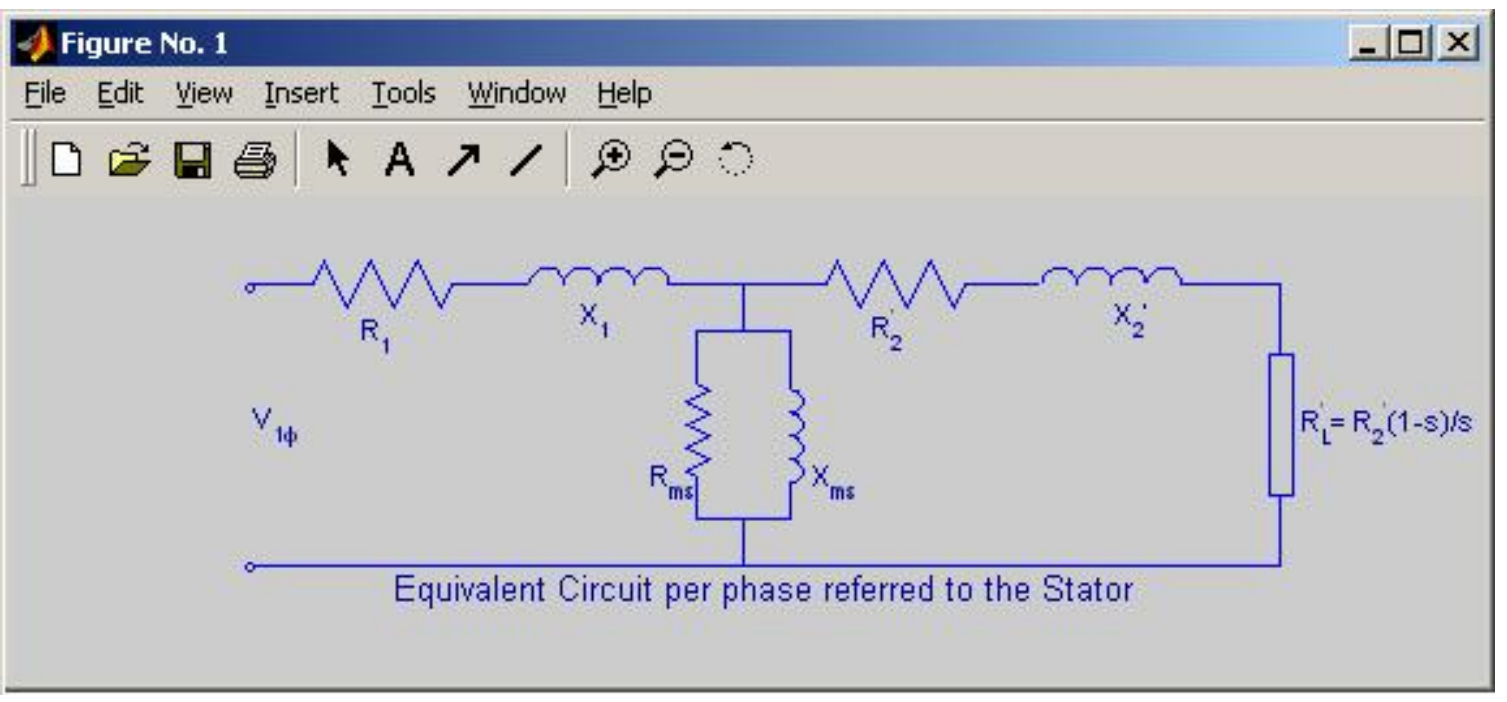

Figure 5.11 Equivalent Circuit Produced by MATLAB GUI 
Information about the program is given when 'Info' button is clicked on the GUI. It summarizes the formulae used in calculating the performance characteristics for motor being evaluated. The info screen is shown in Figure 5.12.

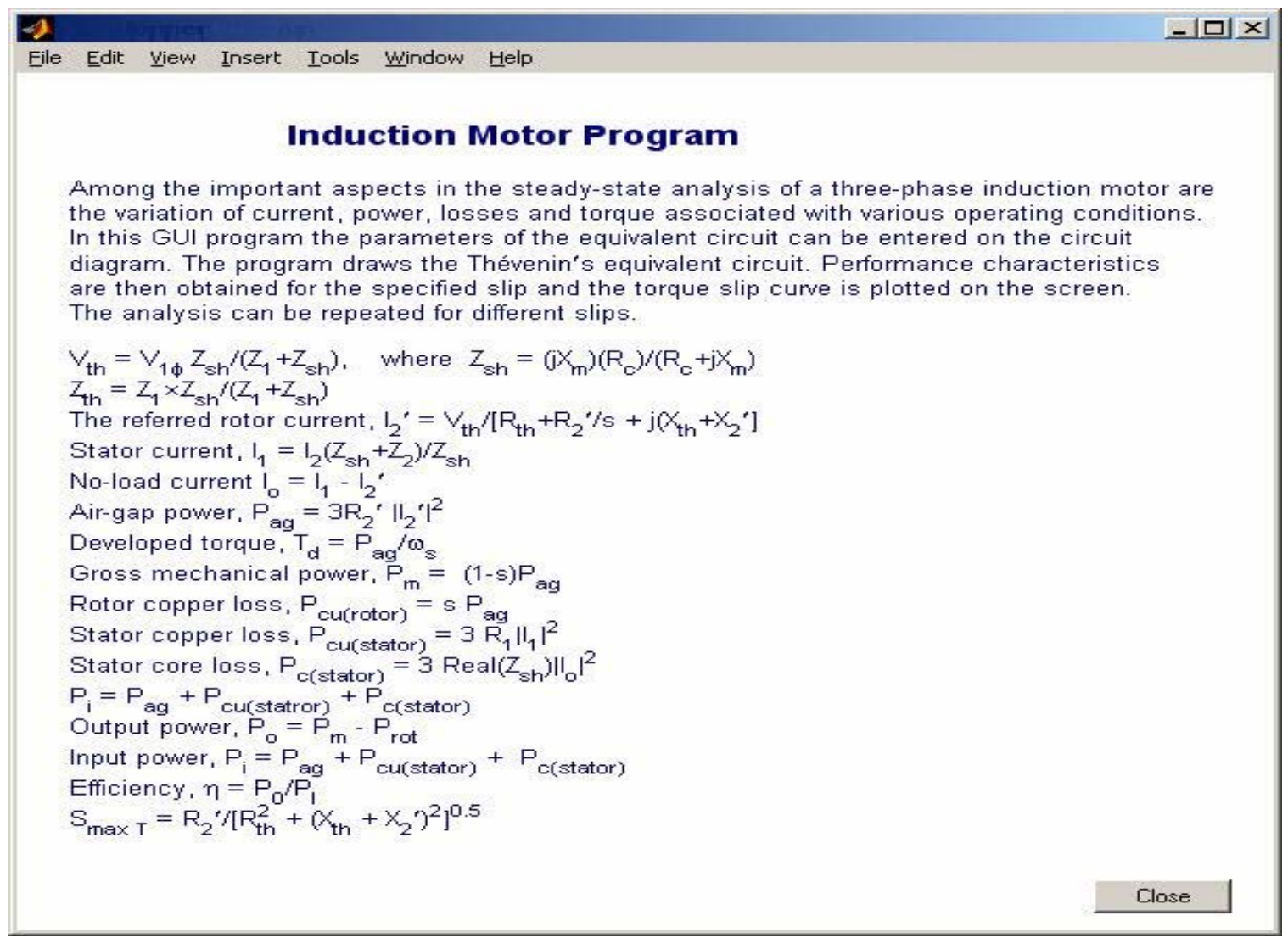

Figure 5.12 Information Screen - Formulae Used for Calculation of Performance for Motor

When 'Solve' button is hit the program analyzes the equivalent circuit of the motor with given parameters. It draws a Thevenin's equivalent circuit for motor at the specified slip in the input box. A torque vs. rotor speed curve also plotted as shown in output screen of the program in Figure 5.13. The program estimates the losses of the motor for given equivalent circuit parameters of motor. In the graph shown in Figure 5.13 the two vertical lines mark the operating and rated slip of motor. 


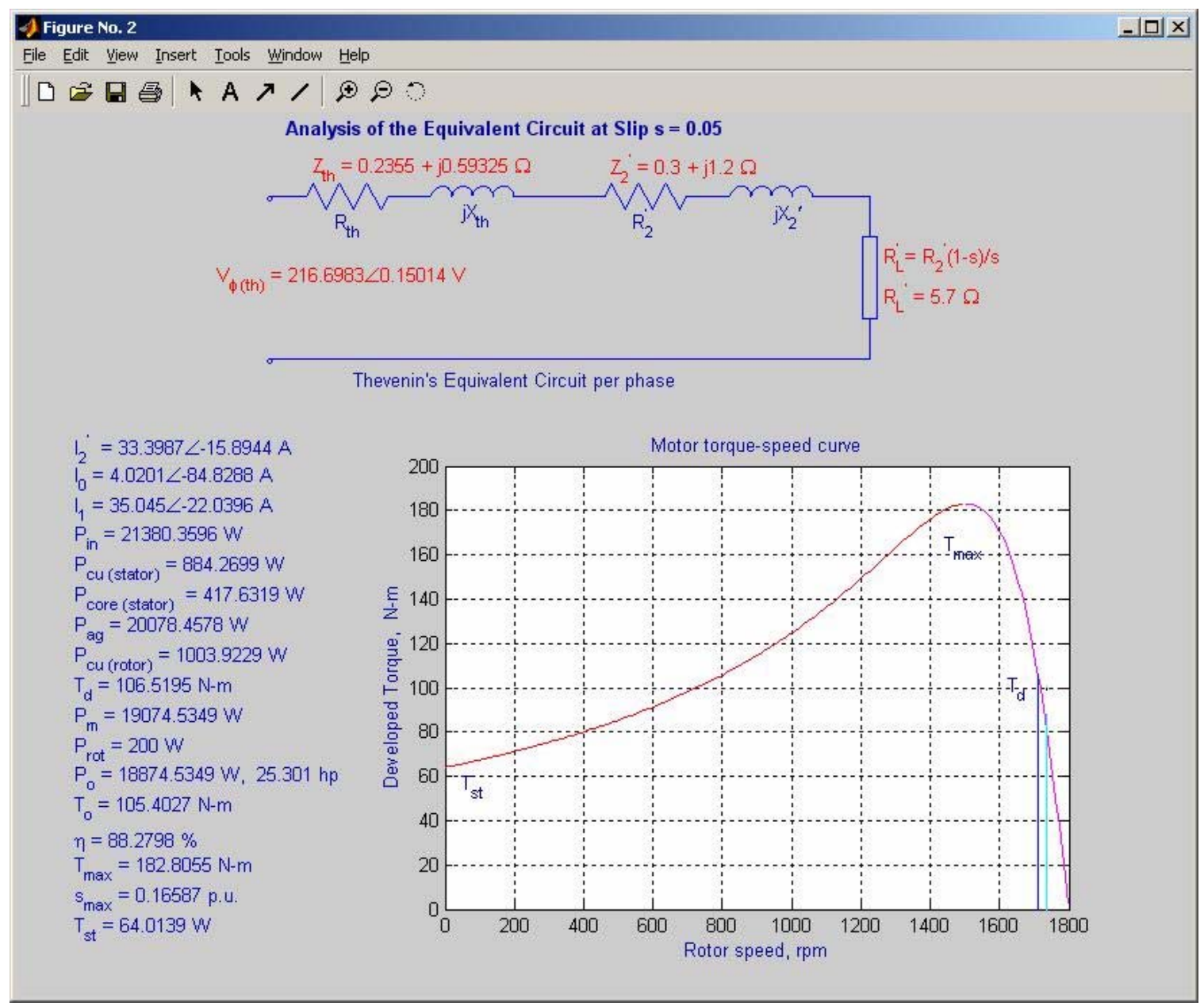

Figure 5.13 Output Generated by Designed GUI and Operating Characteristics of Motor

\subsection{Validation of Statistical Model Built Considering Losses in Motor}

The model built for prediction of power measurement load factor was validated statistically in Chapter 4. Efforts have been made here to validate the model based on electrical parameters, taking into consideration, the losses incurred in motor when it is operating. The losses that occur in motor include stator and rotor copper losses, core losses, rotational or friction and windage losses and stray losses. While copper losses and core losses can be calculated from the equivalent circuit parameters of motor friction and windage losses depend on system and stray load losses cannot be accounted for. Generally as a rule of thumb stray load losses are assumed to be $1.5 \%$ of motor input (as suggested by IEC standard) [51]. Following motor was considered for validation of model. Only one motor has been used here as it is very difficult to get data for equivalent 
circuit parameters of motors. Also, it is very time consuming and involve rigorous experimentation for calculation of the same. For this only one motor has been considered here.

\section{Nameplate Data}

Size $\quad 5 \mathrm{HP}$

Voltage 230 Volts

RPM 1740 RPM

Frequency $\quad 60 \mathrm{~Hz}$

s $\quad 0.033$

$\mathrm{S}$
60 RPM

\section{Equivalent circuit data}

$\mathrm{R}_{1} \quad 0.6 \mathrm{ohm}$

$\mathrm{X}_{1} \quad 0.8 \mathrm{ohm}$

$\mathrm{R}_{2} \quad 0.4 \mathrm{ohm}$

$\mathrm{X}_{2} \quad 0.5 \mathrm{ohm}$

$\mathrm{R}_{\mathrm{ms}} \quad 400 \mathrm{ohm}$

$\mathrm{X}_{\mathrm{ms}} \quad 20 \mathrm{ohm}$

From the statistical model proposed in equation 4.6,

LF_P $=0.14511+0.77860 *$ LF_S $+0.00002071 * S *$ Volt

At rated conditions,

LF_S $=1.00, S=60$, Volt $=230$,

LF_P $=1.20$

The equivalent circuit with parameters shown in Figure 5.14 is analyzed using conventional analysis approach.

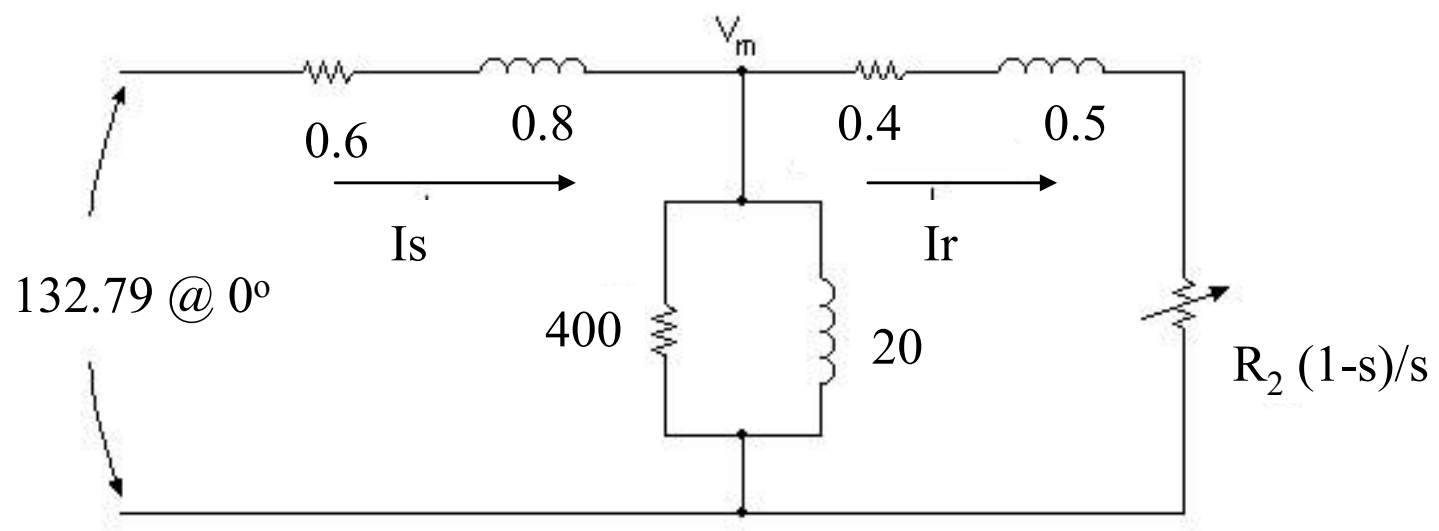

Figure 5.14 Per Phase Equivalent Circuit for the Motor

By nodal analysis,

$\mathrm{I}_{\mathrm{S}}=12.3 \mathrm{amps} L-33.9^{\circ}$

$\mathrm{I}_{\mathrm{R}}=10.1 \mathrm{amps} L-4.3^{\circ}$

$\mathrm{V}_{\mathrm{m}}=121.3 L-1.91^{\circ}$ 
The losses are calculated for all the 3-phases as,

Stator $\mathrm{Cu}$ Loss $=\mathrm{P}_{\mathrm{S}}=3 \mathrm{I}_{\mathrm{S}}{ }^{2} \mathrm{R}_{1}=3(12.3)^{2}(0.6)=271 \mathrm{~W}$

Rotor $\mathrm{Cu}$ Loss $=\mathrm{P}_{\mathrm{R}}=3 \mathrm{I}_{\mathrm{R}}{ }^{2} \mathrm{R}_{2}=3(10.1)^{2}(0.4)=122 \mathrm{~W}$

$\mathrm{P}_{\text {core }}=3 \mathrm{~V}_{\mathrm{m}}^{2} / \mathrm{R}_{\mathrm{ms}}=3(121.3)^{2} / 400=110 \mathrm{~W}$

Friction and windage losses depend on motor. It usually depends on the components like bearings and rotational components. A value of $210 \mathrm{~W}$ is reasonable to assume for the kind of motor under consideration.

To determine stray losses IEC standard graph was used which is shown in Figure 5.15.

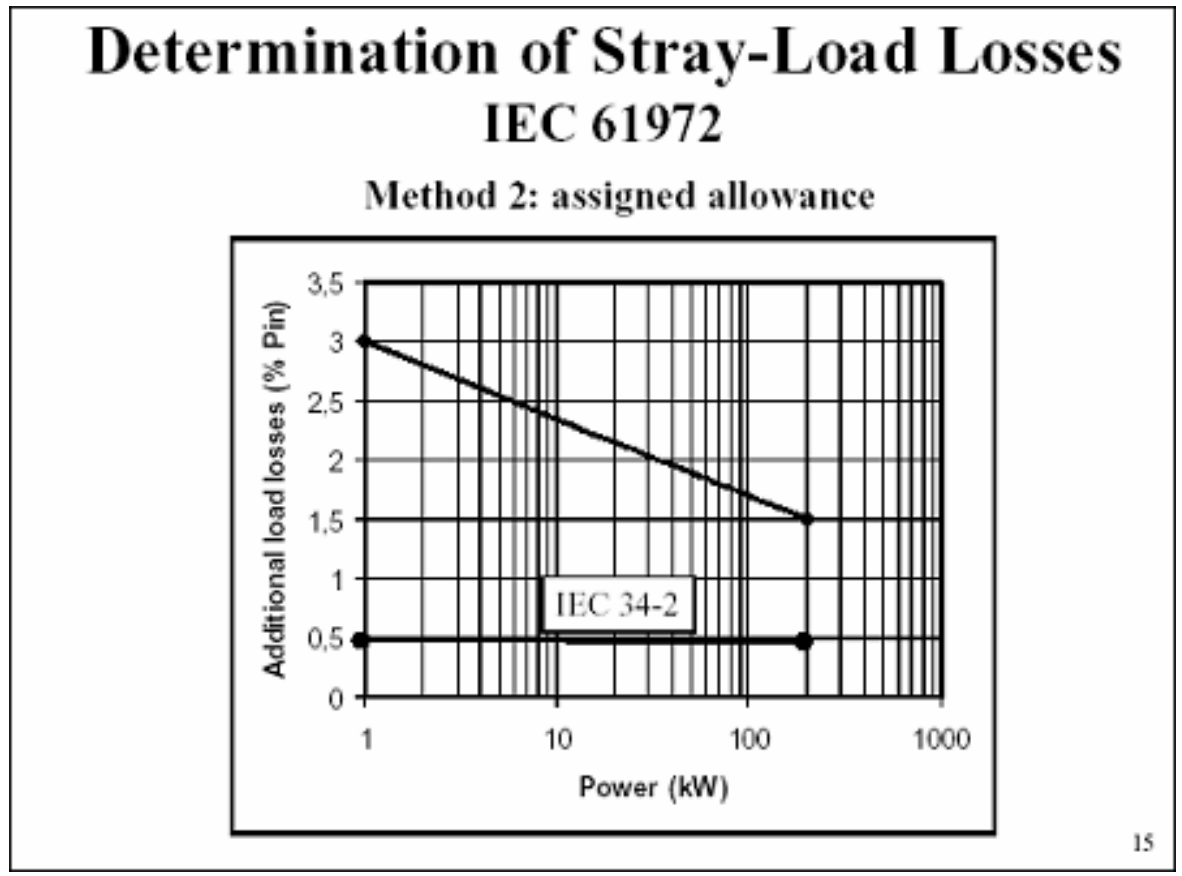

Figure 5.15 Determination of Stray Losses, IEC 61972 [51]

For $5 \mathrm{hp}(3.73 \mathrm{~kW})$, the graph shows stray load losses of $2.6 \%$ of input power $\mathrm{P}_{\text {in }}$. The mechanical output power of motor is the horsepower rating on nameplate. For $5 \mathrm{hp}$ motor, mechanical O/P Power $=5 \times 746=3,730 \mathrm{~W}$

The stray load losses are assumed to be $115 \mathrm{~W}$ for time being, later these are checked with input power calculated in order to check of they are within limits. The input power can be calculated as [32],

$\mathrm{P}_{\text {in }}=$ Mechanical Power $+\mathrm{P}_{\mathrm{s}}+\mathrm{P}_{\mathrm{R}}+\mathrm{P}_{\text {core }}+\mathrm{P}_{\mathrm{F} \& \mathrm{~W}}+\mathrm{P}_{\text {stray }}$

$\mathrm{P}_{\text {in }}=3,730+271+122+110+210+115$

$\mathrm{P}_{\text {in }}=4,558 \mathrm{~W}$

To check value of stray load losses, Pstray $=2.6 / 100 \times 4,558=118.5 \mathrm{~W}>115 \mathrm{~W}$. 
To estimate rated input power,

$\mathrm{P}_{\mathrm{ir}}=\frac{\text { Mech. O/P Power }}{\eta_{\text {motormaster }}}=\frac{3,370}{0.902}=4,135 \mathrm{~W}$

Load factor can be calculated as,

$\mathrm{LF}=\frac{4,558}{4,135}=1.103$

Comparing equation 5.3 and equation 5.4

$\%$ error $=\frac{\left|x_{0}-x\right|}{x}=\frac{1.20-1.103}{1.20}=8 \%$

$\therefore$ error $^{2}=0.0064<\mathrm{MSE}_{\text {model }}(0.02372)$ as given in Table 4.11 (a). It can be said that the model has acceptable behavior from electrical point of view as well from the above verification. Figure 5.16 shows output for $5 \mathrm{hp}$ motor from developed MATLAB ${ }^{\circledR}$ GUI.

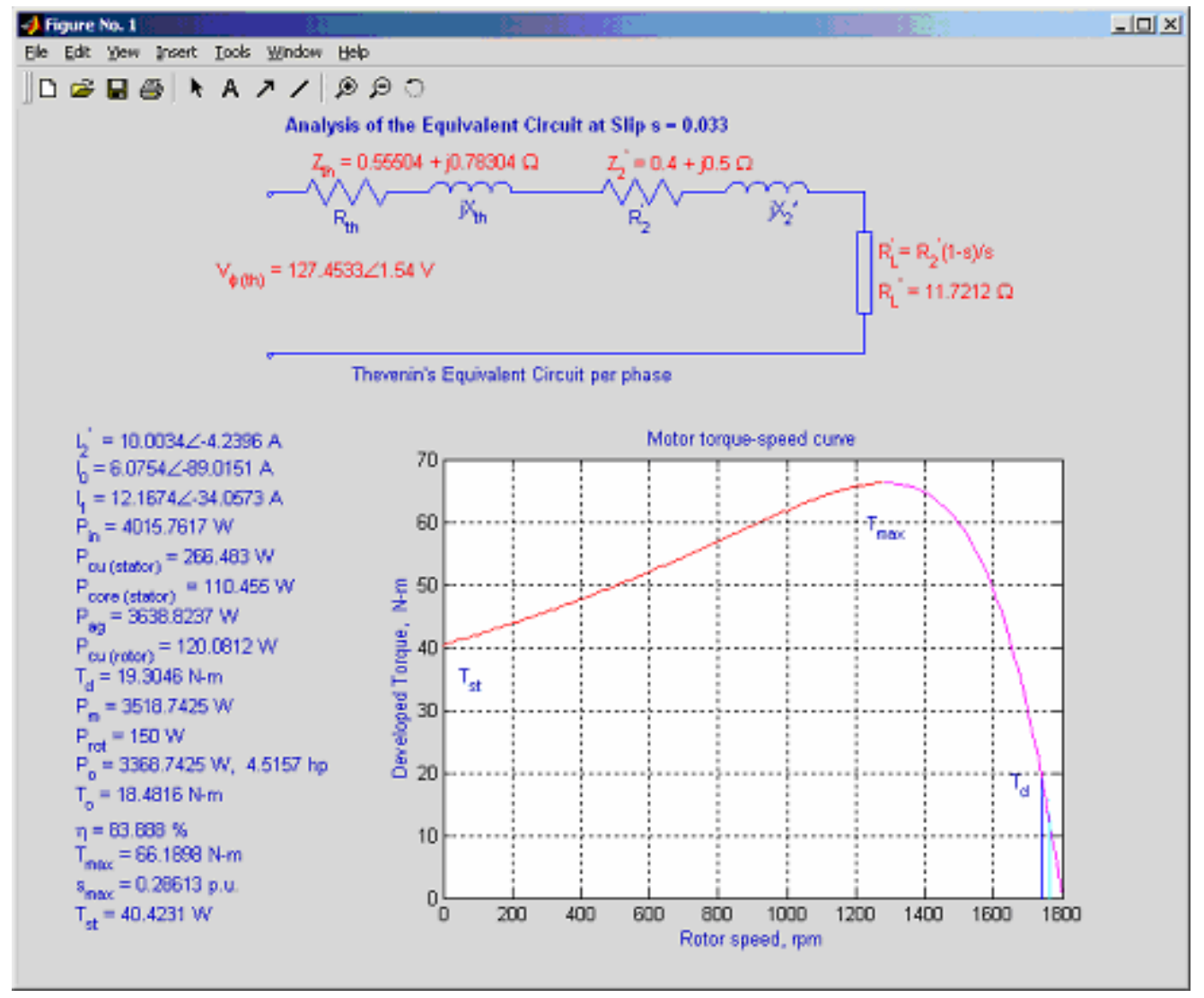

Figure 5.16 Operating Characteristics and Torque-Speed Curve for $\mathbf{5}$ hp motor

The output shows Thevenin's equivalent circuit drawn for the $5 \mathrm{hp}$ motor. Also it can be seen from output in Figure 5.16 that values of currents $I_{s}, I_{R}$ match with those 
obtained by calculation. The values for copper losses in stator and rotor and also the value of core losses match with those obtained by manual calculation.

\subsection{Summary \& Conclusion}

- Motors are under loaded for a number of reasons in industry as has been discussed in 5.1. One of major effective method to handle fluctuating loads on motor is ASD. It is discussed along with advantages and disadvantages in 5.2. If a motor is oversized because of application it is installed for, ASD can be helpful to improve system performance.

- The load factors obtained by slip method, voltage corrected slip method and current-voltage method are compared with load factor calculated by input power measurement method in section 5.3. The slip method and voltage corrected slip method most of the times produced load factor less than that by power measurement method. This was not true for current voltage method.

- The discrepancy for slip methods was least for motors ranging in 30-50 hp. For current-voltage method this discrepancy was negative most for this category of motor hp. Reasons for these discrepancies are discussed in section 5.4.

- Torque-speed curve can be generated for motor with known equivalent circuit parameters using MATLAB ${ }^{\circledR}$ graphical user interface in section 5.5. The GUI also helps in determining losses in the motor, which can be used to find actual load factor of motor.

- For example a $5 \mathrm{hp}$ motor is considered. Model developed in Chapter 4 gives input power measurement load factor at $100 \%$ slip as, 1.2. The load factor obtained from electrical principles is 1.103 which gives $8 \%$ deviation from the model result. The squared deviation is less than MSE of the model. In future more motors should be used to validate model from electrical principle using same approach. 


\section{Chapter 6}

\section{Conclusion and Future Work}

\subsection{Conclusion}

In this research motor data was collected from 15 facilities which were audited for energy assessment. This data was analyzed with the purpose of developing a model to obtain actual load factor of motor from load factor obtained by simple slip method. The author also performed an overview of relationships between two other methods of load factor measurement and actual load factor, viz. voltage corrected slip method and line current method. However, these relationships were not emphasized. The relationship obtained between voltage corrected load factor and input power measurement load factor is,

$\mathrm{LF}_{\mathrm{I} / \mathrm{P}}=0.8893 * \mathrm{LF}_{\text {slip-volt }}+0.2104$

Where,

$\mathrm{LF}_{\text {slip-volt }}=$ Load factor obtained by voltage corrected slip method

$\mathrm{LF}_{\mathrm{I} / \mathrm{P}}=$ Load factor obtained by input power measurement method

For load factors obtained by line current method and input power measurement method it was found that there existed no simple relationship. Investigation was not carried out further to analyze that data. The model of major interest was the relationship between load factor obtained by slip method and load factor obtained by input power measurement method. The model is presented by following equation,

$\mathrm{LF}_{\mathrm{I} / \mathrm{P}}=0.14511+0.7756 * \mathrm{LF}_{\text {slip }}+0.0002071 * \mathrm{~S} *$ Volt

Where,

$\mathrm{LF}_{\mathrm{I} / \mathrm{P}}=$ Load factor obtained by input power measurement method

$\mathrm{LF}_{\text {slip }}=$ Load factor obtained by slip method

$\mathrm{S}=$ Measure slip, RPM = Synchronous speed - Measured speed.

Volt $=$ Nameplate voltage rating of motor being investigated.

This model showed coefficient of determination, $\mathrm{R}^{2}$ as 0.7843 and adjusted $\mathrm{R}^{2}$ as 0.77 which is fairly high for this kind of model. The model was successfully validated with data from 10 motors. The value of mean square prediction error (MSPR) was fairly below MSE of the model which shows fair validity of the model. The model was also 
validated electrically with one motor for which equivalent circuit parameters were known. The losses were calculated and load factors obtained showed $8 \%$ error.

The model developed will be extremely helpful to the industrial end users who can not devote required time and cost that goes into power measurement and efficiency estimation. The model will also provide safe and easy way to measure load on three phase induction motors with which the load can be estimated fairly accurately and based on which certain important decisions such as how the motor should be optimally sized to achieve maximum energy efficiency can be based. The model developed clearly has following advantages:

- Easy technique for load estimation, one has to just use stroboscope to measure the operating speed.

- The load measurement will not have safety problem as no connections involved around high voltage areas.

- The load measurement will be extremely less time consuming.

- The cost of expensive equipment and the labor that goes for load estimation will be almost eliminated

- Lastly, with all the above advantages the load estimated will be in fairly accurate range on which responsible decisions could be based regarding motor sizes.

\subsection{Future Work}

When unequal phase voltages are applied to a 3-phase induction motor unbalanced currents in stator winding result. A small percentage of voltage unbalance will result in large unbalance of currents and consequently, the temperature of motor will rise at a particular operating load. This reduces performance of the motor. To take this into account the horsepower of motor should be multiplied by a factor that is obtained from graph given in Figure 6.1. Thus voltage unbalance wastes energy and leads to high losses in induction motor. A voltage unbalance of $2 \%$ may lead to $25 \%$ increase in losses [26]. It is desired that these derating factors should be taken into account when measurements are done for calculating load factors. This may be done in a future study if undertaken. 


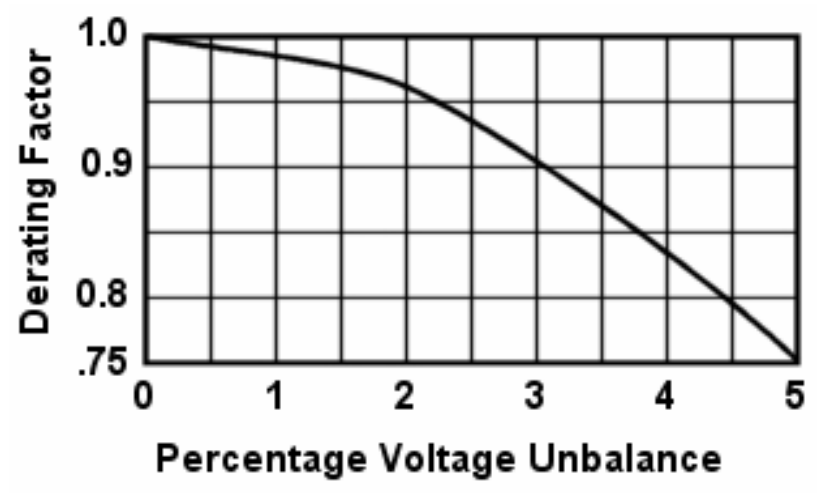

Figure 6.1 Derating Factor Due to Unbalance in Voltage

Also, it is important to find out losses that occur in the induction motor. This is possible for a motor if equivalent circuit parameters are known for that motor. In the future study observation for motors should be carried out for which equivalent circuit parameters are known.

If equivalent circuit parameters are known for the motors, it will enable us to determine operating efficiency of motor more accurately which can then be used in determination of input power measurement load factor. This will lead to increased accuracy of the model. To summarize following future work is suggested.

- Study and analyze effect of voltage unbalance on motor losses, efficiency and hence load factor of the motor. Appropriate amendments can be made in the model to accurately estimate the motor load.

- Motors for which equivalent circuit parameters are known can be tested to have a better accuracy in efficiency and load estimation for motor.

- More of the similar data can be collected to enhance model developed. Data can be grouped according to the category of their applications e.g. compressors or pumps. 


\section{References}

[1] Beaty H., Kirtley J. Jr., "Electric Motor Handbook", McGraw Hill Book Company, 1998.

[2 ] Brender, D., "Calculating motor system energy savings", Strategic Planning for Energy and the Environment Journal, Vol 16, no.2, p 72-78, Fall1996.

[ 3 ] Bush, D., Maestas, J., "Effective Load Management Planning - A Case Study", Energy Engineering, Vol. 99, No. 3, 2002.

[4] Cogdell, J., "Foundations of Electrical Engineering", Prentice Hall, Second Edition, 1996.

[ 5 ] Cole, R.; Thome, T., "Motors matched to load profiles lead to high-efficiency service”, Pulp \& Paper, Vol 69, no.8, 6pp., Aug 1995.

[6] Consulting- Specifying Engineer Magazine, "Weyerhaeuser Policy Calls for Premium-Efficiency Motors and Transformers", Reed Business Publications, Jan 2003.

[7] Cowern, E., "Effectively applying premium efficiency motors", Electrical construction and maintenance, v 94, no 3, 4pp, March 1995.

[8] EASA Reliable Solutions Today, "A Guide to AC Motor Repair and Replacement", http://easa.com/indus/ac_gd199.pdf, Electrical Apparatus Service Association, 1999.

[9] EASA Reliable Solutions Today, "Understanding Energy Efficient Motors", Electrical Apparatus Service Association, http://easa.com/indus/ee_399.pdf, 1999.

[10] Fairford Electronics, "The Fixed-Speed Induction Motor Energy OptimizerScience Or Snake Oil?", <Website>, www.ienergyideas.com/pdfs/SD00014x1Snakeoil.pdf, 2003.

[11] Grantham, C., Tabatabaei-Yazdi, H., "A Novel Power Electronic Machineless Dynamometer for Load Testing and Efficiency Measurement of Three-Phase Induction Motors", Proceedings of The Third International Power Electronics and Motion Control Conference, IPEMC2000; 15-18 Aug., 2000, Beijing, China, IEEE Catalogue No. 00EX435, Vol. 1, pp 564 - 569.

[12 ] Hardware User's Manual, DM II Pro Datalogger, Amprobe ${ }^{\mathrm{TM}}$. 
[13 ] Hirzel, J., "Impact of rewinding on motor efficiency", Annual Pulp and Paper Industry Technical Conference, available from IEEE service center c1985-, June 20-24, 1994.

[14] Jordan, H., "Energy Efficient Electric Motors and Their Application", Van Nostrand Reinhold Company, 1983.

[15 ] Lincoln Electric Motor Division, "How Accurate is AC Motor Energy Auditing", Lincoln Electric Company, http://www.lincolnmotors.com/pdf/D11T.pdf, June 1997.

[16] Lobdovsky, K., "Motor Efficiency Management", Energy Engineering, Vol. 91, No.2, 1994.

[17 ] Lung, R., et. al., "Industrial Motor System Optimization Projects in the US: An Impact Study", ACEEE, Proceedings of the ACEEE Summer Study on Energy Efficiency in Industry, Washington DC, 2003.

[18 ] Mate, A., "Energy Analysis and Diagnostics in Wood Manufacturing Industry" Master's Thesis, West Virginia University, 2002.

[19] McCoy, G.; Rooks, J.; Tutterow, V., "MotorMaster+: An energy-efficient motor selection and energy management tool for the pulp and paper industry”, Annual Pulp and Paper Industry Technical Conference, available from IEEE service center, c1985-, June 16-20,1997.

[20 ] Mecker, S., "How loads affect efficiency of motors", Electrical construction and maintenance, Vol 93, no.8, p33-35, Aug 1994.

[21 ] Mecker, S., “What makes a motor more efficient?" Electrical construction and maintenance, volume 93,no.5, 3p, May 1994.

[22] Pacific Energy Center Factsheet, "Efficiency Improvements of AC Electric Motors", Pacific Gas Electric Company, May 1997, <Website>, http://www.pge.com/003_save_energy/003c_edu_train/pec/info_resource/pdf/acm otors.pdf

[23 ] Sanchez, I.; Pillay, P, "Sensitivity analysis of induction motor parameters", Southeastcon '94: creative technology transfer : a global affair, p 50-54 Miami, FL, April 10-13,1994 
[24 ] Selvaraj, R., "Plant-Wide Energy Assessment using a Systems Approach" Master's Thesis, West Virginia University, 2003.

[25] Spee, R.; Wallace, A., "Comparative evaluation of power-factor improvement techniques for squirrel-cage induction motors”, IEEE Conference, p 12-17, Seattle, WA. Oct 7-12, 1990.

[26] Steven N., et al., "Energy-efficient motor systems: a handbook on technology, program, and policy opportunities", ACEEE Publications, 2002.

[27 ] United States Department of Energy, Motor Challenge Program, "Determining Electric Motor Load and Efficiency" (FACT SHEET), 2001.

[28 ] Vaughen, D., Kota, S., University of Michigan, website for course ME 350, $<$ Website>, http://www.engin.umich.edu/labs/csdl/ME350/motors/ac/induction/3phase/

[29] Wallace, A.; et. al., "Effects of voltage and winding abnormalities on the measured performance of induction motors”, IEEE Conference, p 196-200 New Orleans, LA, Oct 5-9 1997

[30 ] Wallace, A., et. al. "Measured effects of under-voltage, over-voltage and unbalanced voltage on the efficiency and power factor of induction motors over wide ranges of load", International Conference on Electrical Machines and Drives (proceedings), p 258-262, Cambridge, UK, Sep 1997.

[ 31 ] Website, "Energy Facts", Http://www.solarenergy.org, Solar Energy Internatinal, Renewable Energy and Sustainable Future.

[ 32 ] Wildi, T., "Electrical Power Technology", John Wiley \& Sons, 1981.

[ 33 ] Will, F. C., "Factors That Affect Your Plant Power Bill", Annual Paper and Pulp Conference, IEEE 1993 Annual Textile, Fiber and Film Industry Technical Conference, Crowne Plaza Ravinia, Atlanta, Georgia May 4-6, 1993.

[34 ] Scheihing, P., et. al. "United States Industrial Motor-Driven Systems Market Assessment: Charting a Roadmap to Energy Savings for Industry", Paper presented at the International Workshop on Industrial Energy Efficiency Policies: Understanding Success and Failure, Utrecht, The Netherlands, June 10-12, 1998.

[35] Ashram, H., 'Statistical data analysis: Prove it with data', Manchester Metropolitan University website, 1996, 
http://obelia.jde.aca.mmu.ac.uk/resdesgn/arsham/opre330.htm

[ 36 ] Neter, J., Kutner M., et. al. "Applied Linear Regression Models”, The McGraW Hills Companies, $3^{\text {rd }}$ edition, 1996.

[ 37 ] Neter, J., et. al. "Applied Linear Regression Models_Table of Percentiles of $\chi^{2}$ Distribution”, The McGraw Hills Companies, 1996, pp.688.

[ 38 ] Der, G., Everitt, B., “A Handbook of Statistical Analyses using SAS”, Chapman \& Hall CRC, $2^{\text {nd }}$ edition, 2002

[39] Delwiche, L., Slaughter, S., “The Little SAS Book: A Primer”, BBU Press, $3^{\text {rd }}$ edition, 2003.

[40] Jordan, H., "Energy Efficient Electric Motors and Their Application", Van Nostrand Reinhold Company, 1983.

[41] Application Note, "Efficiency Opportunities with Adjustable Speed Drives", Pacific Gas and Electric Company, May 1997, <Website>, http://www.pge.com/003_save_energy/003c_edu_train/pec/info_resource/pdf/SP EEDRIV.PDF

[ 42 ] Platts Research and Consulting, "Motors: Adjustable Speed Drives", a Division of The McGraw-Hill Companies, Inc., 2004.

[ 43 ] Hanselman, D., Littlefield, B., "Mastering MATLAB: A Comprehensive Tutorial and Reference", Prentice Hall, 1996.

[ 44 ] Floyd, T., "Electrical Circuits Fundamentals”, Prentice Hall, 3rd edition, 1995

[ 45 ] Taber, M., Silgalis, E., "Electric Circuit Analysis", Houghton Mifflin Company, Boston, 1980.

[46] Ong, C., "Dynamic Simulation of Electric Machinery: Using MATLAB/Simulink”, Prentice Hall, 1998

[ 47 ] Yoshino, H., Kurata, Y., "Energy Saving Induction Motors”, Mitsubishi Electric Advance, Technical Reports, 2000, <Website $>$, http://global.mitsubishielectric.com/pdf/advance/vol90/vol90_tr6.pdf

[ 48 ] Famouri, P., Wang, J., "Loss Minimization of a DC Motor Drive", Electric Machines and Power Systems, 25:525-537, 1997.

[ 49 ] Angelo, C., et. al. " Loss Minimization in DC Motor Drives”, IEEE International Electric Machines and Drives Conference, Seattle, Washington, May 9-12, 1999. 
[ 50 ] Famouri, P., Cathey, J., "Loss Minimization Control of an Induction Motor Drive”, IEEE Transactions on Industry Applications, Vol. 27 no.1, 1991

[51] IEC Std 61972:1998: Method for determining losses and efficiency of threephase, cage induction motors.

[52 ] Hsu, J., et.al. "Comparison of Induction Motor Field Efficiency Evaluation Methods", IEEE Transactions on Industry Applications, Vol 34, no.1, January/February, 1998.

[ 53 ] Power Systems Engineering P.S. website, http://www.powerstudies.com/content/resources/Diane\%20Power\%20Factor.pdf

[54] Hatanaka, T., "Supermizer- Energy Saving System for 3-phase AC Induction Motors", Proceedings of 1995 International Conference on Power Electronics and Drive Systems; Singapore, 21-24 February, 1995. 
APPENDICES 


\section{APPENDIX I}

\begin{tabular}{|c|c|c|c|c|c|c|c|c|c|c|}
\hline & & & & & Mo & $\operatorname{tor} \mathcal{D} a$ & ta Colle & tion She & & \\
\hline \multicolumn{11}{|c|}{ Facility, Location \& Application } \\
\hline \multirow{2}{*}{\multicolumn{11}{|c|}{ Annual Operation ( $\mathrm{Hrs}$ ) }} \\
\hline & & & & & & & & & & \\
\hline & & & & & & & & & & \\
\hline \multirow[b]{2}{*}{ Sr. } & & \multirow[b]{2}{*}{ Make } & \multirow[b]{2}{*}{$\begin{array}{l}\text { Size } \\
\text { (HP) }\end{array}$} & \multicolumn{2}{|c|}{ Speed } & \multirow[b]{2}{*}{ Voltage } & \multirow[b]{2}{*}{ Efficiency } & \multirow[b]{2}{*}{ Enclosure } & \multirow[b]{2}{*}{$\begin{array}{l}\text { Rated } \\
\text { Current }\end{array}$} & \multirow[b]{2}{*}{ Serial } \\
\hline & Name / Ref \# & & & Rated & Measured & & & & & \\
\hline 1 & & & & & & & & & & \\
\hline 2 & & & & & & & & & & \\
\hline 3 & & & & & & & & & & \\
\hline 4 & & & & & & & & & & \\
\hline 5 & & & & & & & & & & \\
\hline 6 & & & & & & & & & & \\
\hline 7 & & & & & & & & & & \\
\hline 8 & & & & & & & & & & \\
\hline 9 & & & & & & & & & & \\
\hline 10 & & & & & & & & & & \\
\hline
\end{tabular}

Figure A-1 Field Data Collection Template 


\section{APPENDIX II}

The data measured and recorded with Amprobe ${ }^{\mathrm{TM}}$ is presented in this Appendix. The average values of voltage and current are calculated from the RMS values of phase voltages and RMS values of line currents respectively. The values given for each motor are average values for the time period it was monitored. One observation for each of the values was logged each 5 seconds in Amprobe ${ }^{\mathrm{TM}}$ in the time period during which it was coupled with motor.

Table I-1 Summary of data obtained in energy audits using Amprobe ${ }^{\mathrm{TM}}$

\begin{tabular}{|c|c|c|c|c|c|c|c|c|c|c|c|c|c|c|}
\hline \multirow[b]{2}{*}{ No } & \multirow{2}{*}{$\begin{array}{c}\text { Size } \\
\text { (HP) }\end{array}$} & \multirow[b]{2}{*}{$\mathbf{k W}$} & \multicolumn{3}{|c|}{ Power } & \multirow[b]{2}{*}{$\mathbf{P F}$} & \multicolumn{2}{|c|}{ Average } & \multicolumn{3}{|c|}{ RMS Voltage } & \multicolumn{3}{|c|}{ RMS Current } \\
\hline & & & $(\mathbf{k W})$ & (kVAR) & (kVA) & & $\begin{array}{c}\text { V } \\
\text { (Volts) }\end{array}$ & I (Amp) & $\mathrm{V}_{\mathrm{AB}}(\mathrm{V})$ & $\mathrm{V}_{\mathrm{BC}}(\mathrm{V})$ & $\mathrm{V}_{\mathrm{CA}}(\mathrm{V})$ & $\mathrm{I}_{\mathrm{A}}(\mathrm{A})$ & $I_{B}(A)$ & $I_{c}(A)$ \\
\hline 1 & 60 & 44.76 & 19 & 12 & 22 & 0.84 & 449 & 24.9 & 449 & 449 & 449 & 25 & 25 & 25 \\
\hline 2 & 25 & 18.65 & 17 & 3 & 17 & 0.98 & 466 & 18.2 & 466 & 466 & 466 & 18 & 18 & 18 \\
\hline 3 & 125 & 93.25 & 15 & 13 & 20 & 0.74 & 330 & 73.6 & 266 & 265 & 460 & 74 & 74 & 73 \\
\hline$* 4$ & 75 & 55.95 & 35 & -71 & 79 & 0.45 & 456 & 87.0 & 456 & 455 & 456 & 87 & 88 & 86 \\
\hline 5 & 200 & 149.2 & 88 & -11 & 88 & 0.99 & 454 & 187.0 & 453 & 454 & 454 & 188 & 188 & 184 \\
\hline 6 & 200 & 149.2 & 88 & -11 & 88 & 0.99 & 454 & 187.0 & 452 & 452 & 453 & 209 & 226 & 219 \\
\hline$* 7$ & 200 & 149.2 & 28 & 155 & 157 & 0.18 & 452 & 218.0 & 452 & 453 & 453 & 134 & 121 & 137 \\
\hline 8 & 200 & 149.2 & 121 & -60 & 139 & 0.91 & 477 & 171 & 477 & 476 & 478 & 167 & 176 & 170 \\
\hline 9 & 150 & 111.9 & 14 & 45 & 47 & 0.29 & 488 & 56 & 487 & 489 & 489 & 56 & 55 & 59 \\
\hline 10 & 40 & 29.84 & 27 & 17 & 32 & 0.85 & 481 & 38 & 481 & 482 & 481 & 38 & 39 & 38 \\
\hline 11 & 20 & 14.92 & 7 & 8 & 11 & 0.62 & 469 & 12.9 & 469 & 467 & 471 & 14 & 12 & 13 \\
\hline 12 & 150 & 111.9 & 17 & 71 & 73 & 0.23 & 470 & 86.4 & 471 & 468 & 470 & 91 & 88 & 80 \\
\hline 13 & 150 & 111.9 & 23 & 66 & 44 & 0.51 & 473 & 54.0 & 474 & 473 & 471 & 54 & 56 & 52 \\
\hline 14 & 25 & 18.65 & 15 & 16 & 22 & 0.70 & 466 & 28 & - & 465 & 468 & 28 & 27 & 28 \\
\hline 15 & 75 & 55.95 & 68 & -37 & 78 & 0.88 & 492 & 91 & 491 & 492 & 493 & 92 & 93 & 90 \\
\hline 16 & 75 & 55.95 & 71 & -32 & 77 & 0.91 & 494 & 91 & 494 & 494 & 493 & 90 & 90 & 92 \\
\hline
\end{tabular}




\begin{tabular}{|c|c|c|c|c|c|c|c|c|c|c|c|c|c|c|}
\hline \multirow[b]{2}{*}{ No } & \multirow{2}{*}{$\begin{array}{l}\text { Size } \\
\text { (HP) }\end{array}$} & \multirow[b]{2}{*}{$\mathbf{k W}$} & \multicolumn{3}{|c|}{ Power } & \multirow[b]{2}{*}{$\mathbf{P F}$} & \multicolumn{2}{|c|}{ Average } & \multicolumn{3}{|c|}{ RMS Voltage } & \multicolumn{3}{|c|}{ RMS Current } \\
\hline & & & $(\mathbf{k W})$ & (kVAR) & (kVA) & & $\begin{array}{c}\mathrm{V} \\
\text { (Volts) }\end{array}$ & I (Amp) & $\mathrm{V}_{\mathrm{AB}}(\mathrm{V})$ & $V_{B C}(V)$ & $\mathrm{V}_{\mathrm{CA}}(\mathrm{V})$ & $I_{A}(A)$ & $\mathrm{I}_{B}(A)$ & $\mathrm{I}_{C}(\mathrm{~A})$ \\
\hline 17 & 200 & 149.2 & 64 & 6 & 64 & 1.00 & 489 & 171 & 490 & 488 & 489 & 149 & 182 & 183 \\
\hline 18 & 150 & 111.9 & 23 & 47 & 53 & 0.44 & 478 & 63 & 479 & 477 & 477 & 65 & 60 & 63 \\
\hline 19 & 150 & 111.9 & 80 & 53 & 96 & 0.82 & 475 & 114 & 477 & 474 & 475 & 118 & 110 & 116 \\
\hline 20 & 200 & 149.2 & 31 & -16 & 38 & 0.90 & 473 & 78 & 473 & 472 & 475 & 78 & 77 & 78 \\
\hline 21 & 200 & 149.2 & 57 & -95 & 111 & 0.52 & 468 & 231 & 467 & 467 & 469 & 227 & 230 & 236 \\
\hline 22 & 60 & 44.76 & 34 & -7 & 35 & 0.96 & 474 & 43 & 473 & 474 & 475 & 44 & 42 & 43 \\
\hline 23 & 30 & 22.38 & 7 & 17 & 19 & 0.39 & 476 & 39 & 477 & 477 & 476 & 39 & 38 & 0 \\
\hline 24 & 20 & 14.92 & 2 & 7 & 7 & 0.30 & 481 & 9.0 & 483 & 482 & 479 & 9 & 9 & 8 \\
\hline 25 & 20 & 14.92 & 14 & 9 & 16 & 0.85 & 479 & 19.6 & 482 & 479 & 476 & 19 & 21 & 19 \\
\hline 26 & 30 & 22.38 & 15 & 12 & 19 & 0.76 & 233 & 48 & - & 234 & 233 & 52 & 50 & 42 \\
\hline 27 & 30 & 22.38 & 16 & 6 & 17 & 0.92 & 229 & 43.1 & 231 & 225 & 231 & 45 & 43 & 41 \\
\hline 28 & 25 & 18.65 & 12 & 11 & 16 & 0.75 & 234 & 40.4 & 232 & 234 & 235 & 41 & 39 & 41 \\
\hline 29 & 25 & 18.65 & 13 & 11 & 17 & 0.77 & 234 & 42.1 & 232 & 235 & 234 & 40 & 43 & 43 \\
\hline 30 & 75 & 55.95 & 39 & 28 & 48 & 0.81 & 472 & 59.6 & 471 & 471 & 475 & 59 & 57 & 62 \\
\hline 31 & 75 & 55.95 & 67 & 45 & 81 & 0.83 & 473 & 97.3 & 471 & 476 & 471 & 96 & 92 & 104 \\
\hline$* 32$ & 100 & 74.6 & 30 & 29 & 42 & 0.71 & 474 & 52.1 & 477 & 473 & 473 & 50 & 55 & 51 \\
\hline$* 33$ & 40 & 29.84 & 24 & 14 & 28 & 0.87 & 232 & 68.2 & 233 & 233 & 231 & 71 & 69 & 65 \\
\hline 34 & 20 & 14.92 & 2 & 6 & 7 & 0.35 & 487 & 10 & 487 & 488 & 487 & 7 & 11 & 11 \\
\hline 35 & 50 & 37.3 & 34 & 18 & 38 & 0.88 & 484 & 46 & 484 & 485 & 484 & 47 & 44 & 48 \\
\hline 36 & 50 & 37.3 & 8 & 10 & 13 & 0.61 & 485 & 16 & 485 & 486 & 485 & 16 & 14 & 17 \\
\hline 37 & 150 & 111.9 & 2 & -2 & 3 & 0.60 & 481 & 147 & 481 & 482 & 481 & 148 & 146 & 146 \\
\hline 38 & 25 & 18.65 & 19 & 15 & 24 & 0.78 & 483 & 28 & 484 & 483 & 483 & 28 & 29 & 29 \\
\hline 39 & 125 & 93.25 & 29 & 91 & 98 & 0.28 & 457 & 124.5 & 456 & 455 & 460 & 127 & 121 & 126 \\
\hline
\end{tabular}




\begin{tabular}{|c|c|c|c|c|c|c|c|c|c|c|c|c|c|c|}
\hline \multirow[b]{2}{*}{ No } & \multirow{2}{*}{$\begin{array}{c}\text { Size } \\
\text { (HP) }\end{array}$} & \multirow[b]{2}{*}{$\mathbf{k W}$} & \multicolumn{3}{|c|}{ Power } & \multirow[b]{2}{*}{$\mathbf{P F}$} & \multicolumn{2}{|c|}{ Average } & \multicolumn{3}{|c|}{ RMS Voltage } & \multicolumn{3}{|c|}{ RMS Current } \\
\hline & & & $(\mathbf{k W})$ & (kVAR) & (kVA) & & $\begin{array}{c}\text { V } \\
\text { (Volts) }\end{array}$ & I (Amp) & $V_{A B}(V)$ & $\mathrm{V}_{\mathrm{BC}}(\mathrm{V})$ & $\mathrm{V}_{\mathrm{CA}}(\mathrm{V})$ & $\mathrm{I}_{\mathrm{A}}(\mathrm{A})$ & $I_{B}(A)$ & $I_{c}(A)$ \\
\hline 40 & 40 & 29.84 & 2 & 1 & 2 & 0.79 & 231 & 156.2 & 232 & 232 & 229 & 156 & 161 & 151 \\
\hline 41 & 125 & 93.25 & 107 & 63 & 124 & 0.86 & 465 & 154.2 & 468 & 464 & 464 & 159 & 153 & 151 \\
\hline 42 & 250 & 186.5 & 216 & 66 & 226 & 0.96 & 463 & 273.4 & 466 & 462 & 462 & 263 & 278 & 279 \\
\hline 43 & 100 & 74.6 & 62 & -24 & 68 & 0.93 & 451 & 87.5 & 451 & 452 & 450 & 89 & 88 & 86 \\
\hline$* 44$ & 200 & 149.2 & 61 & -114 & 130 & 0.47 & 469 & 139.7 & 470 & 469 & 468 & 137 & 143 & 139 \\
\hline 45 & 125 & 93.25 & 74 & 45 & 87 & 0.86 & 455 & 110.5 & 455 & 453 & 456 & 112 & 109 & 110 \\
\hline$* 46$ & 150 & 111.9 & 86 & 131 & 157 & 0.55 & 458 & 170.7 & 459 & 459 & 456 & 171 & 169 & 172 \\
\hline 47 & 150 & 111.9 & 31 & 8 & 32 & 0.97 & 466 & 63.3 & 464 & 467 & 468 & 68 & 60 & 61 \\
\hline 48 & 75 & 55.95 & 43 & -28 & 51 & 0.84 & 466 & 59.9 & 468 & 467 & 464 & 64 & 50 & 65 \\
\hline$* 49$ & 150 & 111.9 & 2 & 13 & 13 & 0.17 & 465 & 95 & 465 & 465 & 466 & 86 & 100 & 98 \\
\hline 50 & 50 & 37.3 & 49 & 34 & 60 & 0.82 & 497 & 69.5 & 498 & 494 & 500 & 71 & 67 & 71 \\
\hline 51 & 30 & 22.38 & 5 & 12 & 13 & 0.37 & 468 & 16.1 & 472 & 466 & 467 & 17 & 16 & 15 \\
\hline 52 & 60 & 44.76 & 3 & -1 & 3 & 0.98 & 470 & 67.5 & 470 & 474 & 467 & 69 & 71 & 62 \\
\hline
\end{tabular}




\section{APPENDIX III}

The data collected in the field from the motors that were monitored is presented here. Empty spaces represent where the data could not be recorded due to difficulties in obtaining data. This data was collected in the data sheet that has been presented in the Appendix I. The speed was measured using a digital stroboscope. Other observations were obtained from the nameplate of the motor or with discussion with plant personnel.

Table III-1 Data collected from 15 facilities in data sheet

\begin{tabular}{|c|c|c|c|c|c|c|c|c|c|c|c|}
\hline $\mathrm{Sr}$ & Application & Make & $\begin{array}{c}\text { Size } \\
\text { (HP) }\end{array}$ & $\begin{array}{l}\text { Rated } \\
\text { Speed }\end{array}$ & $\begin{array}{c}\text { Speed } \\
\text { Measured }\end{array}$ & Voltage & $\begin{array}{c}\text { Rated } \\
\text { Current }\end{array}$ & Sr. No & Frame & Eff & Enclosure \\
\hline 1 & \#1 Coal Conv & - & 60 & 1180 & 1197.3 & 440 & 71 & - & - & - & - \\
\hline 2 & $\begin{array}{c}\text { \#3 Coal } \\
\text { Conveyor belt }\end{array}$ & - & 25 & 1760 & 1790 & 440 & 30 & - & - & - & - \\
\hline 3 & $\begin{array}{c}\text { \#3 A Flyash } \\
\text { Vacuum Pump }\end{array}$ & - & 125 & 1780 & 1797.7 & 460 & 143 & - & - & - & - \\
\hline$* 4$ & $\begin{array}{l}\text { \#3 Hotwell } \\
\text { Pump }\end{array}$ & US Electric & 75 & 1770 & 1770 & $230 / 460$ & $180 / 90$ & $\mathrm{H} 07552 \mathrm{~B} 2 \mathrm{~S}$ & S321 & & DP \\
\hline 5 & $\begin{array}{l}\text { \#2 Coldwell } \\
\text { Pump }\end{array}$ & US Electric & 150 & 1775 & 1772.3 & 460 & 170 & 6502-Z07Z128R133M & & & \\
\hline 6 & $\begin{array}{c}\text { Coldwell Pump } \\
\text { \#3 }\end{array}$ & US Electric & 200 & 1775 & 1781.6 & 460 & 233 & B02-97011399-GT & & 93.6 & DP \\
\hline$* 7$ & $\begin{array}{c}\text { Fermenter } \\
\text { Agitator F20 }\end{array}$ & & 200 & 1785 & 1782 & 460 & 225 & & & & \\
\hline 8 & Hogg & Lincoln & 200 & 1780 & 1784.4 & 460 & 223 & TV-3025A1 & 1194460 & & - \\
\hline
\end{tabular}




\begin{tabular}{|c|c|c|c|c|c|c|c|c|c|c|c|}
\hline Sr & Application & Make & $\begin{array}{l}\text { Size } \\
\text { (HP) }\end{array}$ & $\begin{array}{l}\text { Rated } \\
\text { Speed }\end{array}$ & $\begin{array}{c}\text { Speed } \\
\text { Measured }\end{array}$ & Voltage & $\begin{array}{c}\text { Rated } \\
\text { Current }\end{array}$ & Sr. No & Frame & Eff & Enclosure \\
\hline 9 & Chipper & Lincoln & 150 & 1780 & 1798.6 & 460 & 169 & TM-6T08A & 2772114 & 93.5 & - \\
\hline 10 & Blower & Lincoln & 40 & 1765 & 1777.6 & $230 / 460$ & $98 / 49$ & $\mathrm{~T}-4163$ & 2759440 & 90.2 & - \\
\hline 11 & Air Compressor & Tatung Co. & 20 & 1745 & 1786.4 & $\begin{array}{c}203- \\
230 / 480\end{array}$ & $\begin{array}{c}57- \\
53 / 26.5\end{array}$ & $\begin{array}{c}\mathrm{U} 34205044 \\
\text { (TB0204DBA) }\end{array}$ & & & \\
\hline 12 & $\begin{array}{c}2 \text { Speed } 60 " \\
\text { Mill }\end{array}$ & $\begin{array}{c}\text { Continental } \\
\text { Electric }\end{array}$ & $\begin{array}{c}150- \\
75\end{array}$ & $\begin{array}{l}710- \\
355\end{array}$ & 719.4 & 440 & $195-160$ & - & NF806S & & \\
\hline 13 & $\begin{array}{c}1 \text { Speed 60" } \\
\text { Mill }\end{array}$ & $\begin{array}{l}\text { GE (HE } \\
\text { Wilson) }\end{array}$ & 150 & 720 & 717.9 & 440 & 190 & 259 (Job \#W2849) & & & \\
\hline 14 & Air Compressor & $\begin{array}{c}\text { Lincoln } \\
\text { Ultimate E1 }\end{array}$ & 25 & 1775 & 1786.7 & $230 / 460$ & $68 / 34$ & U3980702821 & & 90.2 & ODP \\
\hline 15 & $\begin{array}{l}\text { Refrigeration } \\
\text { Compressor }\end{array}$ & Lincoln & 75 & 1775 & 1777.8 & $230 / 460$ & $192 / 96$ & 3912251 & & 91.7 & - \\
\hline 16 & $\begin{array}{c}\text { Refrigeration } \\
\text { Compressor }\end{array}$ & Lincoln & 75 & 1775 & 1761.5 & $230 / 461$ & $192 / 96$ & 3780055 & & 91.7 & - \\
\hline 17 & Tannery Blower & - & 200 & 1775 & 1783.7 & $230 / 460$ & $444 / 222$ & $9404802 \mathrm{~A}$ & & 95 & - \\
\hline 18 & Chipper & Lincoln & 150 & 1780 & 1798.3 & 460 & 169 & 13811926 & $3023 \mathrm{~A}-1$ & & \\
\hline 19 & Chipper & Lincoln & 150 & 1780 & 1789.8 & 460 & 169 & 13811926 & $3023 \mathrm{~A}-2$ & & \\
\hline 20 & Head Saw & WEQ & 200 & 1780 & 1798 & 460 & - & - & & & \\
\hline
\end{tabular}




\begin{tabular}{|c|c|c|c|c|c|c|c|c|c|c|c|}
\hline Sr & Application & Make & $\begin{array}{c}\text { Size } \\
\text { (HP) }\end{array}$ & $\begin{array}{l}\text { Rated } \\
\text { Speed }\end{array}$ & $\begin{array}{c}\text { Speed } \\
\text { Measured }\end{array}$ & Voltage & $\begin{array}{c}\text { Rated } \\
\text { Current }\end{array}$ & Sr. No & Frame & Eff & Enclosure \\
\hline 21 & Head Saw & WEQ & 200 & 1780 & 1787.8 & 460 & - & - & & & \\
\hline 22 & Resaw & Lincoln & 60 & 1780 & & $230 / 460$ & $146 / 73$ & 013203409J-R & & 92.4 & \\
\hline 23 & Aircompressor & $\begin{array}{l}\text { Marathon } \\
\text { Electric }\end{array}$ & 30 & 1755 & 1783 & $230 / 460$ & $76 / 38$ & - & & 89.5 & \\
\hline 24 & Compressor \#1 & Delco & 20 & 1755 & 1797.9 & 460 & 24.3 & $\begin{array}{l}\text { GM7EQEMINPEM- } \\
200\end{array}$ & & 91 & \\
\hline 25 & Compressor\#2 & Delco & 20 & 1755 & 1777 & 460 & 24.3 & $\begin{array}{l}\text { GM7EQEMINPEM- } \\
201\end{array}$ & & 91 & \\
\hline 26 & Shinwa & $\begin{array}{l}\text { Yaskawa } \\
\text { Electric Co }\end{array}$ & $\begin{array}{c}30(22 \\
\mathrm{kW})\end{array}$ & 1760 & 1779.9 & $230 / 460$ & $70 / 35$ & 344446103 & & - & - \\
\hline 27 & $\begin{array}{l}\text { Hot Water } \\
\text { Heater }\end{array}$ & US Electric & 30 & 3520 & 3558 & $230 / 460$ & $71.6 / 35.8$ & B564AV10V253R337F & & & TEFC \\
\hline 28 & Vacuum Pump 1 & Toshiba & 25 & 1165 & 1188 & $230 / 460$ & $66.4 / 33.2$ & $\mathrm{AB} 03117-46$ & & & TEFC \\
\hline 29 & Vacuum Pump 2 & Toshiba & 25 & 1165 & 1185.8 & $230 / 461$ & $66.4 / 33.3$ & AB11913-5 & & & TEFC \\
\hline 30 & $\begin{array}{c}\mathrm{NH} 3 \\
\text { Compressor } 1\end{array}$ & Reliance & 75 & 1765 & 1784.4 & $230 / 460$ & $184 / 92$ & P360248 & & & \\
\hline 31 & $\begin{array}{c}\mathrm{NH} 3 \\
\text { Compressor } 2\end{array}$ & Reliance & 75 & 1765 & 1780.4 & $230 / 460$ & $180 / 90$ & $\begin{array}{c}\text { P36G0029F- } \\
\text { G4PM/MN1436 }\end{array}$ & & & \\
\hline$* 32$ & $\begin{array}{c}\mathrm{NH} 3 \\
\text { Compressor } 3\end{array}$ & Relaince & 100 & 1770 & 1786.7 & $230 / 460$ & $240 / 120$ & $\begin{array}{l}\text { P40G21H-G2- } \\
\text { NM/MN1268 }\end{array}$ & & & IP \\
\hline
\end{tabular}




\begin{tabular}{|c|c|c|c|c|c|c|c|c|c|c|c|}
\hline Sr & Application & Make & $\begin{array}{l}\text { Size } \\
\text { (HP) }\end{array}$ & $\begin{array}{l}\text { Rated } \\
\text { Speed }\end{array}$ & $\begin{array}{c}\text { Speed } \\
\text { Measured }\end{array}$ & Voltage & $\begin{array}{l}\text { Rated } \\
\text { Current }\end{array}$ & Sr. No & Frame & Eff & Enclosure \\
\hline$* 33$ & $\begin{array}{c}\text { NH3 } \\
\text { Compressor } 4\end{array}$ & US Electric & 40 & 1800 & 1851.9 & $208 / 416$ & $52 / 104$ & 1100101 & & & \\
\hline 34 & $\begin{array}{l}\text { High Pressure } \\
\text { \#2 Pump }\end{array}$ & Leeson & 20 & 1755 & 1797.7 & 460 & 24.1 & $\mathrm{n} 256 \mathrm{t} 17 \mathrm{fk} 48$ & - & 91 & TEFC \\
\hline 35 & $\begin{array}{l}\text { \# } 17 \text { Injection } \\
\text { Mold }\end{array}$ & - & 50 & 1175 & 1177.7 & 460 & 70 & TV4688A1C & - & - & - \\
\hline 36 & $\begin{array}{l}\text { \# } 17 \text { Injection } \\
\text { Mold }\end{array}$ & - & 50 & 1175 & 1188.2 & 460 & 70 & TV4688A1C & - & - & - \\
\hline 37 & GrayMill & GE & 150 & 595 & 594.7 & 440 & 202 & 5K6335FBA2 & - & - & - \\
\hline 38 & $\begin{array}{c}\text { Den. Gard. } \\
\text { Recip Air Comp }\end{array}$ & Baldor & 25 & 1760 & 1771.2 & 460 & 32.5 & M25311CW & - & - & - \\
\hline 39 & boltmaker duty & Delco & 125 & 855 & 884.6 & 460 & 187.5 & $4 \mathrm{~A} 75$ & & & \\
\hline 40 & & Reliance ele & 40 & 565 & 593.6 & $220 / 440$ & $174 / 87$ & X-115677-A1 & N7800Y4R & & \\
\hline 41 & guard & Linconln & 125 & 1775 & 1778.2 & $230 / 460$ & 146 & 1298248 & & & \\
\hline 42 & & Lincoln & 250 & 1775 & 1769.2 & 460 & 213 & 3524847 & & & - \\
\hline 43 & \#2Hyd Pump & WEQ & 100 & 1185 & 1189.9 & 460 & 122 & AF72609 & - & - & TEFC \\
\hline$* 44$ & Air Comp & WAUSAU & 200 & 1770 & 1785.7 & 460 & 228 & FF93504613-5 & - & - & - \\
\hline
\end{tabular}




\begin{tabular}{|c|c|c|c|c|c|c|c|c|c|c|c|}
\hline Sr & Application & Make & $\begin{array}{l}\text { Size } \\
\text { (HP) }\end{array}$ & $\begin{array}{l}\text { Rated } \\
\text { Speed }\end{array}$ & $\begin{array}{c}\text { Speed } \\
\text { Measured }\end{array}$ & Voltage & $\begin{array}{c}\text { Rated } \\
\text { Current }\end{array}$ & Sr. No & Frame & Eff & Enclosure \\
\hline 45 & $\begin{array}{l}\text { A Air Comp } \\
\text { West }\end{array}$ & Marathon & 125 & 1780 & 1787.6 & 480 & 147 & - & - & - & - \\
\hline$* 46$ & Air Comp & GE & 150 & 1785 & 1784 & 460 & 174 & VC321029 & - & - & - \\
\hline 47 & \#1 comb. Air fan & MAXSE & 150 & 1776 & 1797.1 & 460 & 168 & CMC13037-1 & - & 95 & TEFC \\
\hline 48 & $\begin{array}{c}\text { furnace ejector } \\
\text { airfan }\end{array}$ & - & 75 & 1780 & 1790.5 & $230 / 460$ & $178 / 89$ & 6212-2ZJC3 & - & 93.6 & - \\
\hline$* 49$ & $\begin{array}{l}8 \text { Unit Press } \\
\text { Motor } 1\end{array}$ & GE & 150 & 1750 & 1781.6 & 460 & 238 & SCD204SAO46A810 & & - & - \\
\hline 50 & & Baldor & 50 & 3525 & 3545 & $230 / 460$ & $122 / 61$ & $12 / 466000509803$ & & & \\
\hline 51 & & Baldor & 30 & 1750 & 1796.6 & 480 & & c0205300072 & & & \\
\hline 52 & cold water pump & US Electric & 60 & 1780 & 1780.1 & $230 / 460$ & & F216-A06A120R083M & & & \\
\hline
\end{tabular}




\section{APPENDIX IV SAS Codes}

\section{Code for Scatter Matrix}

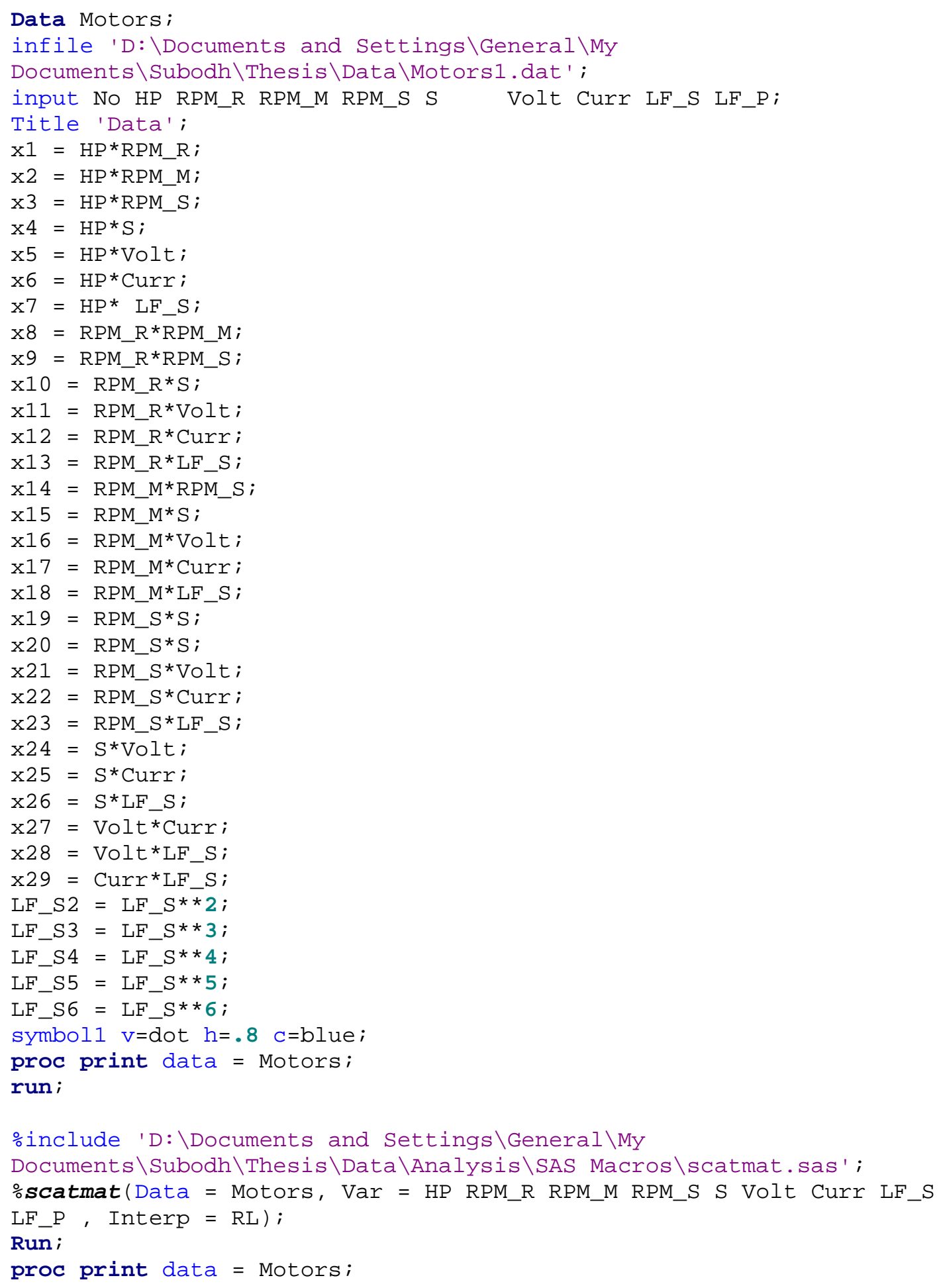




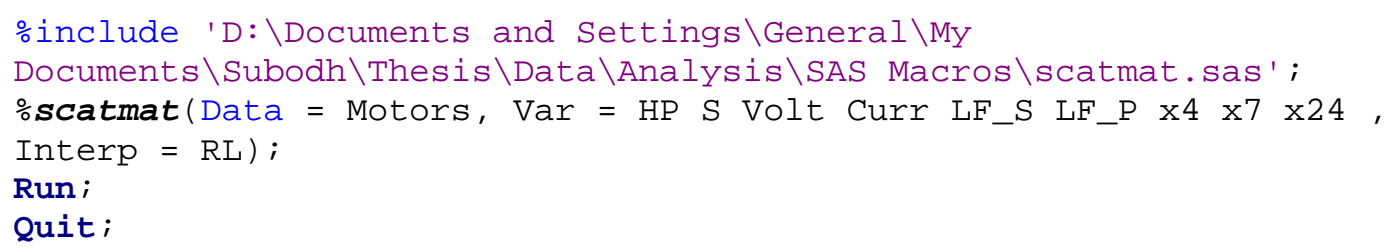

\section{Code for Straight Line Model}

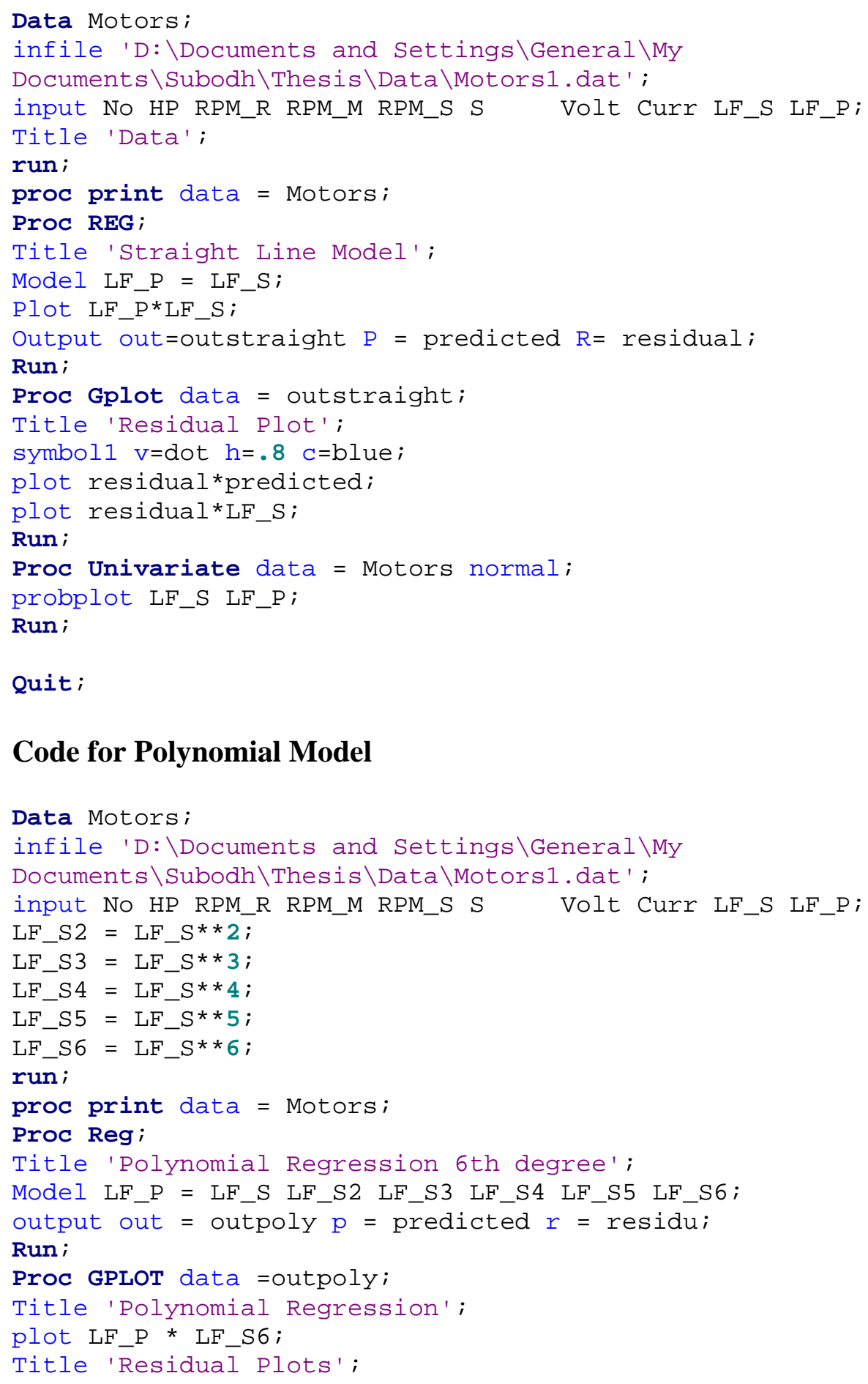


plot residu*predicted;

Plot residu*LF_S6;

Run;

Proc univariate data = outpoly noprint ;

Title 'QQ Plot';

qqplot residu/normal;

run;

Quit；

\section{Code for Multiple Regression Model}

Data Motors;

infile 'D: \Documents and Settings \General\My

Documents $\backslash$ Subodh $\backslash$ Thesis $\backslash$ Data $\backslash$ Motors1. dat ' ;

input No HP RPM_R RPM_M RPM_S S Volt Curr LF_S LF_P;

/*All 2 factor interactions*/

$\mathrm{X} 1=\mathrm{HP}{ }^{*} \mathrm{RPM} \_\mathrm{R}$;

$\mathrm{X} 2=\mathrm{HP}{ }^{*} \mathrm{RPM} \_\mathrm{M}$;

$\mathrm{X3}=$ HP*RPM_S;

$\mathrm{X} 4=\mathrm{HP}^{*} \mathrm{~S}$;

$\mathrm{x} 5=\mathrm{HP}^{*}$ Volt;

$\mathrm{x}^{6}=\mathrm{HP}^{*}$ Curr;

$x 7=H^{*}$ LF_S;

$\times 8=$ RPM_R ${ }^{*}$ RPM $\_$M;

$x 9=$ RPM_R ${ }^{*}$ RPM_S;

$X 10=$ RPM $\_R^{\star} S$;

$\mathrm{x} 11=$ RPM_R $\mathrm{R}^{\star}$ Volt ;

$\times 12=$ RPM_R ${ }^{*}$ Curr ;

$\mathrm{X13}=$ RPM_R*LF_S;

$\times 14=$ RPM $M^{*}$ RPM $\_$;

$X 15=$ RPM_M*S;

$\mathrm{x} 16=$ RPM_M*Volt;

$\mathrm{X} 17=$ RPM_M*Curr;

$X 18=$ RPM_M*LF_S;

$\times 19=$ RPM_S*S;

$\times 20=$ RPM_S*S;

X21 = RPM_S*Volt;

X22 = RPM_S*Curr;

$\times 23=$ RPM_S*LF_S;

$\mathrm{x} 24=\mathrm{S}^{*}$ Volt;

$\times 25=S^{*}$ Curr;

$\times 26=S^{*}$ LF_S;

$\times 27=$ Volt ${ }^{*}$ Curr;

$\times 28=$ Volt ${ }^{*}$ LF_S;

x29 = Curr *LF_S;

symbol1 $\mathrm{v}=\operatorname{dot} \mathrm{h}=.8 \mathrm{c}=\mathrm{blue}$;

Title 'DATA';

run;

proc print data $=$ Motors;

Proc REG;

Title 'Full Model';

Model LF_P = HP RPM_R RPM_M RPM_S S Volt Curr LF_S / Selection = None ;

Run;

Proc REG; 


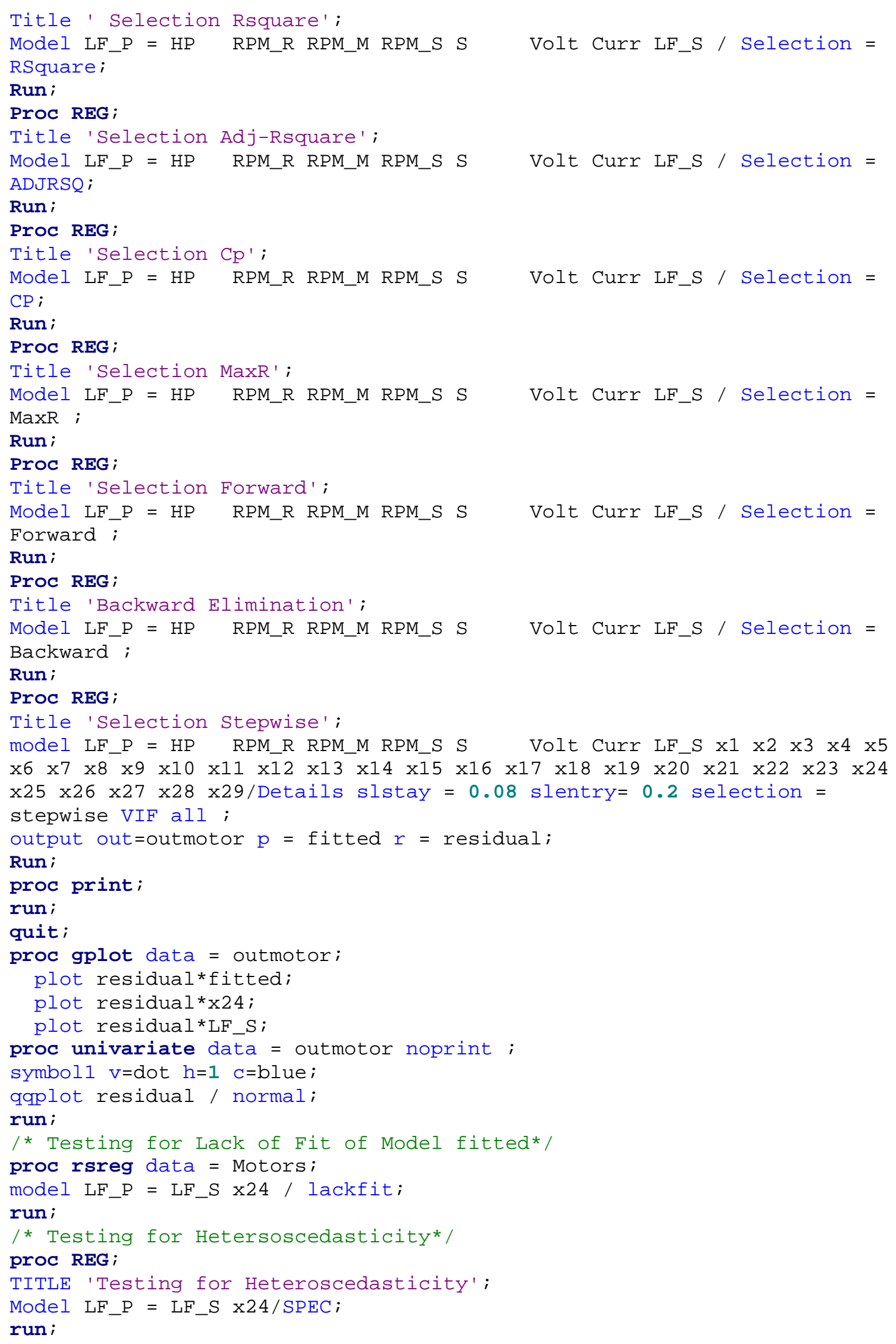




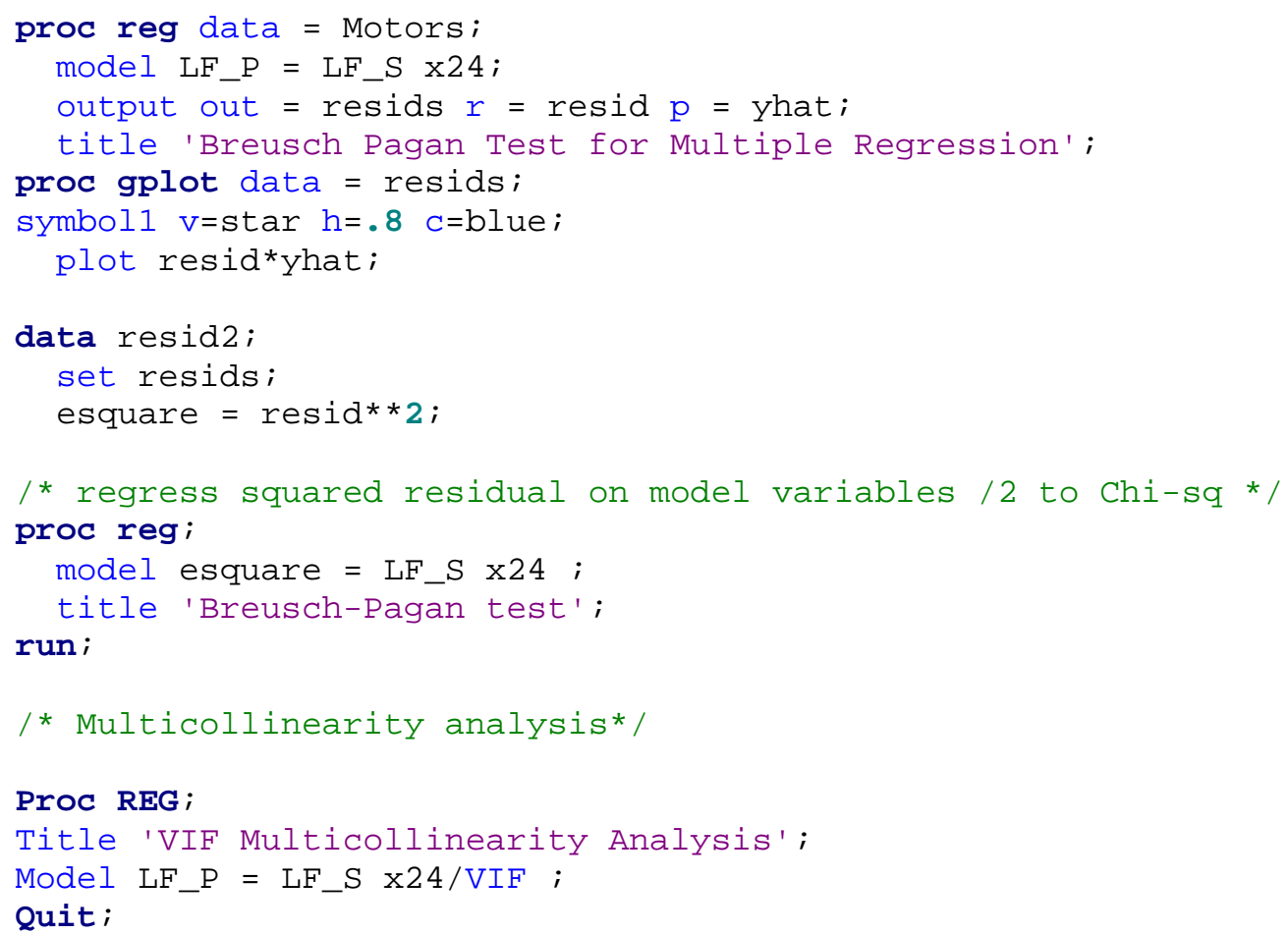




\section{APPENDIX V}

This appendix gives the MATLAB graphical user interface code that was developed.

function varargout $=$ ind_motor(varargin)

$\%$ IND_MOTOR Application M-file for ind_motor.fig

$\% \quad$ FIG $=$ IND MOTOR launch ind motor GUI.

$\% \quad$ IND MOTOR('callback name', ...) invoke the named callback.

\% Last Modified by GUIDE v2.0 08-Sep-2004 10:48:21

if nargin $==0 \%$ LAUNCH GUI

fig $=$ openfig $($ mfilename,'reuse' $)$;

$\%$ Generate a structure of handles to pass to callbacks, and store it. handles = guihandles(fig); guidata(fig, handles);

$\%$ This program draws the induction motor equivalent circuit

ths $=0: .0025: \mathrm{pi}$;

$\mathrm{xs} 1=1.45+0.075^{*} \cos (\mathrm{ths})$;

ys $1=1.2+0.075 * \sin ($ ths $)$;

$\mathrm{xs} 2=1.6+0.075 * \cos (\mathrm{ths})$;

$\mathrm{xs} 3=1.75+0.075^{*} \cos ($ ths $)$;

xs4 $=1.9+0.075 * \cos ($ ths $)$;

$\mathrm{x} 5=\left[\begin{array}{ll}0.75 & 0.75 .8\end{array}\right]$;

y5 $=\left[\begin{array}{llll}1.2 & 1.0 & 1.0\end{array}\right]$;

$\mathrm{x} 6=\left[\begin{array}{lll}1.1 & 1.3 & 1.3\end{array}\right]$;

$\mathrm{y} 6=\left[\begin{array}{lll}1.0 & 1.0 & 0\end{array}\right] ;$

$\mathrm{xW}=\left[\begin{array}{lllll}0.65 & 0.65 & 1.4 & 1.4 & 0.65\end{array}\right] ;$

$\mathrm{yw}=\left[\begin{array}{lllll}0.95 & 1.35 & 1.35 & 0.95 & 0.95\end{array}\right]$;

$\% \mathrm{R} \mathrm{ms}$

$\mathrm{xr}=\left[\begin{array}{llllllllllllllll}.5 & .5 & .3 & .3 & .35 & .25 & .35 & .25 & .35 & .25 & .35 & .25 & .3 & .3 & .5 & .5\end{array}\right]$;

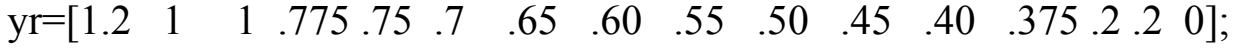

$\% \mathrm{X} \mathrm{ms}$

thm $=-$ pi/2:.0025:pi/2;

$\mathrm{xm}=0.7+0.05 * \cos ($ thm $)$;

$\mathrm{ym}=.05 * \sin (\mathrm{thm})$

$\mathrm{xxm}=\left[\begin{array}{llll}\mathrm{xm} & \mathrm{xm} & \mathrm{xm} & \mathrm{xm}\end{array}\right]$;

$\mathrm{yxm}=[.4+\mathrm{ym} 0.5+\mathrm{ym} 0.6+\mathrm{ym} 0.7+\mathrm{ym}]$;

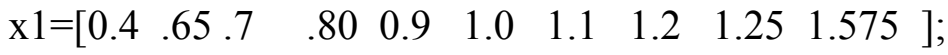

$\mathrm{y} 1=\left[\begin{array}{llllllllll}1.2 & 1.2 & 1.3 & 1.1 & 1.3 & 1.1 & 1.3 & 1.1 & 1.2 & 1.2\end{array}\right]$;

plot(x1-1.2, y1,'b', 'erasemode','none')

hold on 


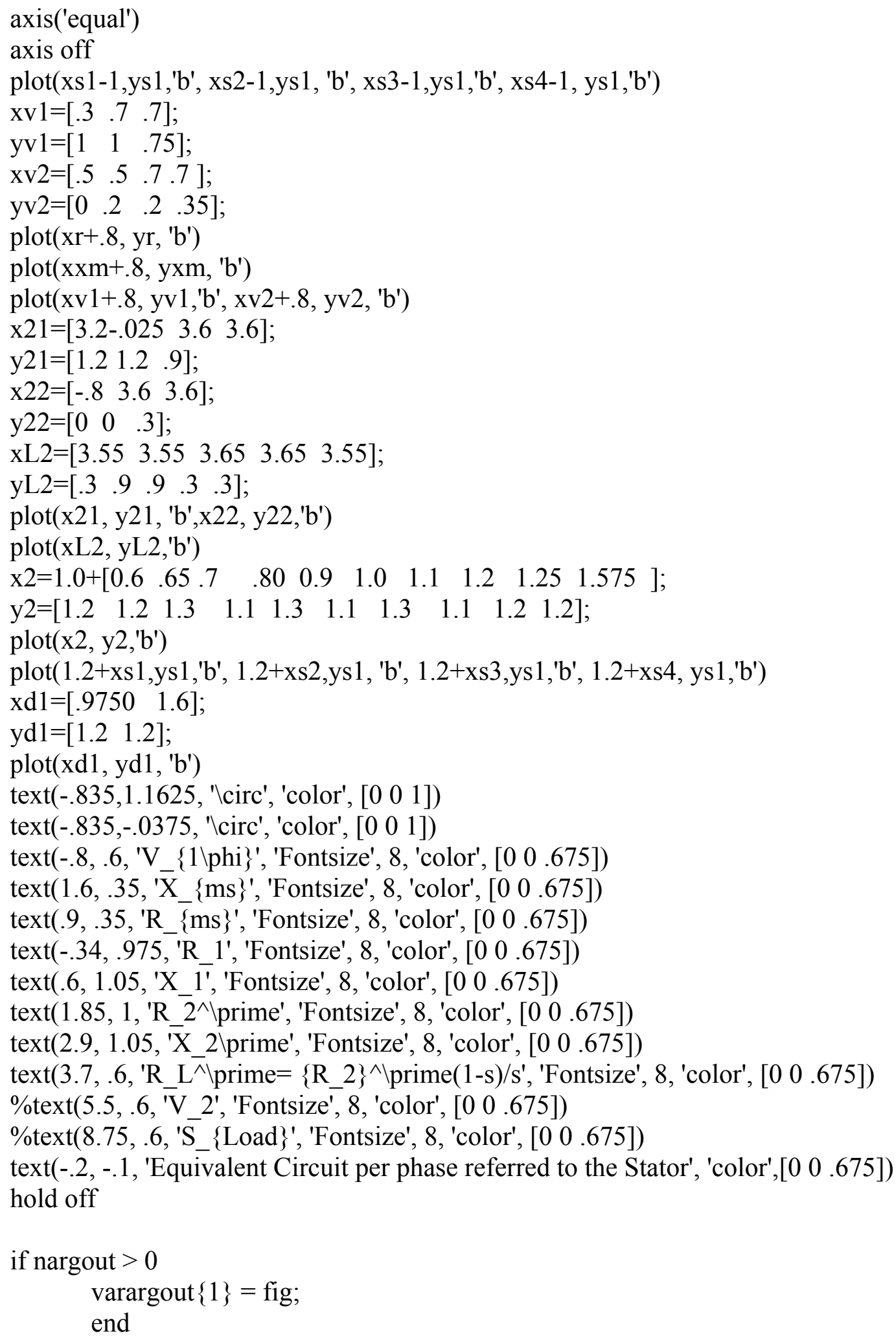


try

if (nargout)

[varargout $\{1:$ nargout $\}]=$ feval $(\operatorname{varargin}\{:\}) ; \%$ FEVAL

switchyard

else

feval(varargin $\{:\}) ; \%$ FEVAL switchyard

end

catch

disp(lasterr);

end

end

$\%$ ABOUT CALLBACKS:

$\%$ GUIDE automatically appends subfunction prototypes to this file, and

$\%$ sets objects' callback properties to call them through the FEVAL

$\%$ switchyard above. This comment describes that mechanism.

$\%$

$\%$ Each callback subfunction declaration has the following form:

$\% \mid<$ SUBFUNCTION_NAME $>(H$, EVENTDATA, HANDLES, VARARGIN)

$\%$

$\%$ The subfunction name is composed using the object's Tag and the

$\%$ callback type separated by '_,', e.g. 'slider2_Callback',

$\%$ |'figure1_CloseRequestFcn', 'axis1_ButtondownFcn'.

$\%$

$\% \mid \mathrm{H}$ is the callback object's handle (obtained using GCBO).

$\%$

$\%$ EVENTDATA is empty, but reserved for future use.

$\%$

$\%$ HANDLES is a structure containing handles of components in GUI using

$\%$ tags as fieldnames, e.g. handles.figure1, handles.slider2. This

$\%$ structure is created at GUI startup using GUIHANDLES and stored in

$\%$ the figure's application data using GUIDATA. A copy of the structure

$\%$ is passed to each callback. You can store additional information in

$\%$ this structure at GUI startup, and you can change the structure

$\%$ during callbacks. Call guidata(h, handles) after changing your

$\%$ | copy to replace the stored original so that subsequent callbacks see

$\%$ the updates. Type "help guihandles" and "help guidata" for more

$\%$ information.

$\%$

$\%$ | VARARGIN contains any extra arguments you have passed to the

$\%$ callback. Specify the extra arguments by editing the callback

$\%$ property in the inspector. By default, GUIDE sets the property to:

$\% \mid<$ MFILENAME $>('<$ SUBFUNCTION_NAME $>$ ', gcbo, [], guidata(gcbo))

$\%$ Add any extra arguments after the last argument, before the final 


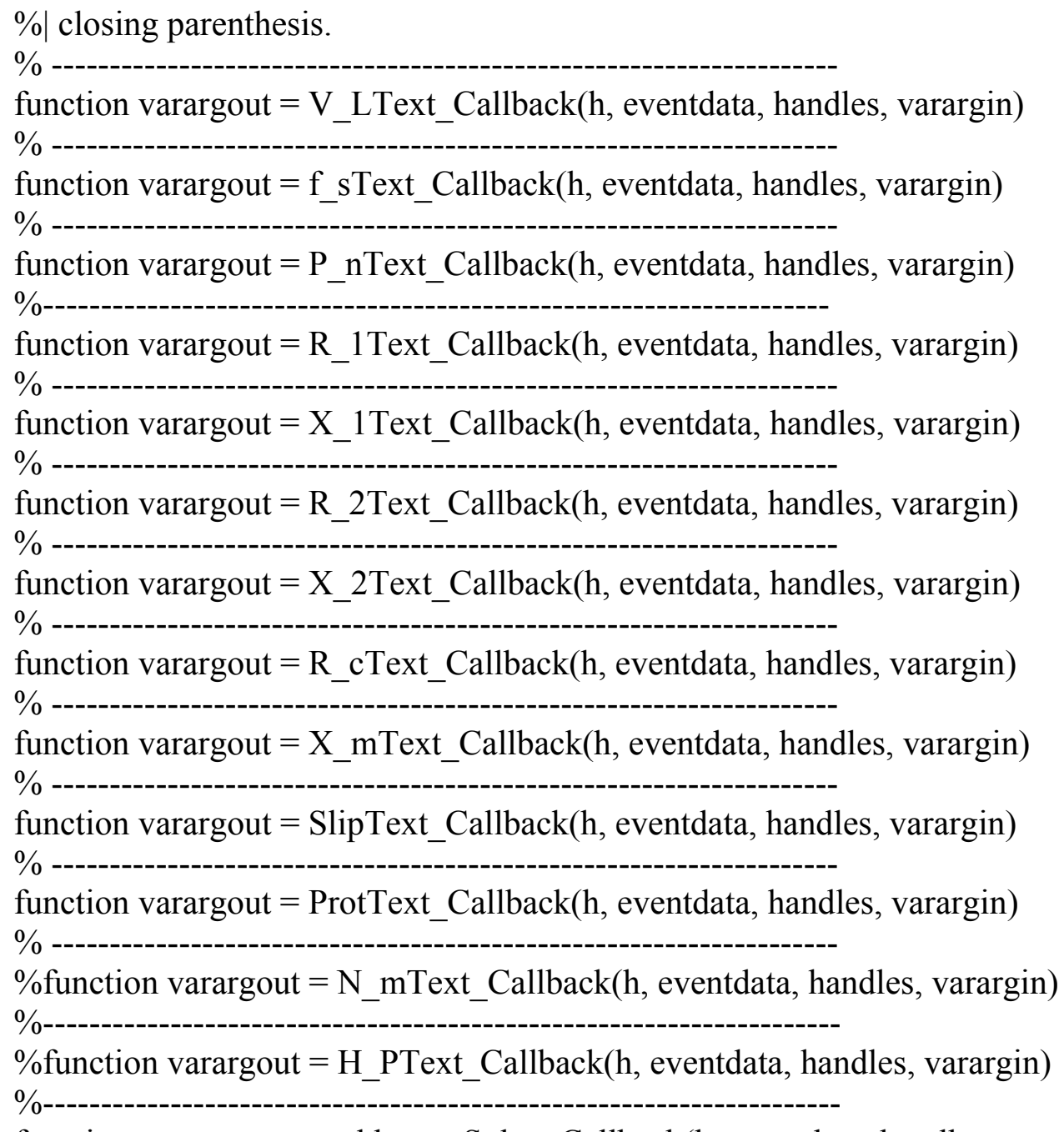

\%function [Rclv, Xmlv, Rchv, Xmhv, Zelv, Zehv, Ic, Io, Re, Zemag, Error] = OcScTest; Error $=0$; 


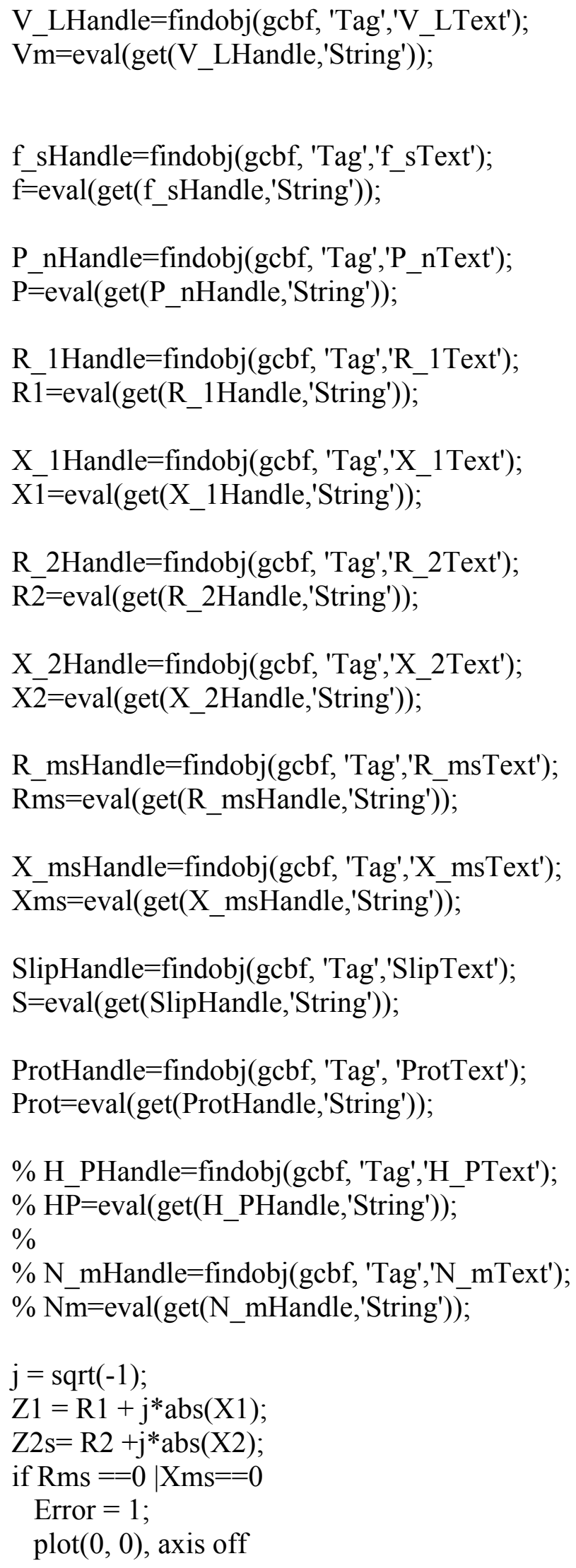


text(-1, .6,'Data error: R_c an R_m cannot be zero, $0<\mathrm{R} \_\mathrm{c} \backslash$ leq inf $\& 0<\mathrm{X} \_\mathrm{m} \backslash$ leq inf', 'color', [lllll, 100 , 'erasemode','xor')

text(-1, .25, 'Enter the correct value for R_c or X_m and try again. If neglected enter

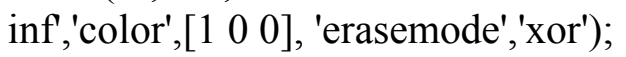

return, end

if $\mathrm{S}>1 \mid \mathrm{S}<=0$

Error $=2$;

$\operatorname{plot}(0,0)$, axis off

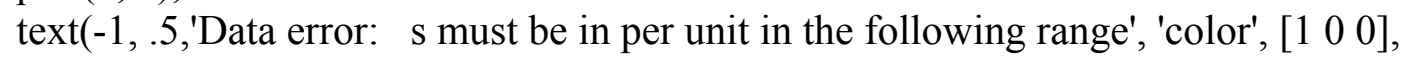
'erasemode','xor')

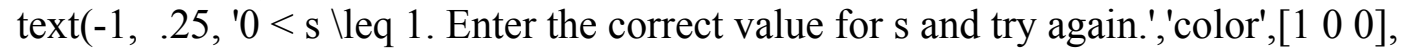

'erasemode','xor');

return, end

if $\mathrm{R} 2==0$

Error $=3$;

$\operatorname{plot}(0,0)$, axis off

text(-.6, .4,'Data error: $\mathrm{R} \_2$ cannot be zeo, enter the correct value and try again', 'color',

[1 100$]$, 'erasemode','xor')

return, end

$\% \% \% \% \% \%$

$\mathrm{Vmp}=\mathrm{Vm} / \mathrm{sqrt}(3)$

$\mathrm{V}=\mathrm{Vmp}+\mathrm{j} * 0$;

$\mathrm{Ns}=120 . * \mathrm{f} / \mathrm{P}$

$\mathrm{Nr}=(1 .-\mathrm{S}) * \mathrm{Ns}$

$\mathrm{Ws}=2 . * \mathrm{pi}^{*} \mathrm{Ns} / 60$;

$\mathrm{Wr}=(1 .-\mathrm{S}) * \mathrm{Ws}$;

$\mathrm{Zrd}=\mathrm{R} 2+\mathrm{j} * \mathrm{abs}(\mathrm{X} 2)$;

$\% \mathrm{KW}=0.746 * \mathrm{HP}$

$\% \mathrm{Sm}=(\mathrm{Ns}-\mathrm{Nm}) / \mathrm{Ns}$;

if $\mathrm{S} \sim=0$

$\mathrm{RLd}=\mathrm{R} 2 *(1-\mathrm{S}) / \mathrm{S}$;

$\mathrm{R} 2 \mathrm{ds}=\mathrm{R} 2 / \mathrm{S}$;

else $\mathrm{RLd}=\mathrm{inf} ; \mathrm{R} 2 \mathrm{ds}=\mathrm{inf}$; end

$\mathrm{Z} 2=\mathrm{R} 2 \mathrm{ds}+\mathrm{j}^{*} \mathrm{abs}(\mathrm{X} 2)$;

if $\mathrm{Rms}==\inf \mid \mathrm{Rms}==0, \mathrm{Gc}=0$; else $\mathrm{Gc}=1 / \mathrm{Rms}$; end

if $\mathrm{Xms}==\inf \mid \mathrm{Xms}==0, \mathrm{Bm}=0$; else $\mathrm{Bm}=1 / \mathrm{abs}(\mathrm{Xms})$; end

$\mathrm{Y} 2=1 / \mathrm{Z} 2$;

$\mathrm{Ye}=\mathrm{Gc}-\mathrm{j} * \mathrm{Bm}$;

if $(\mathrm{Gc}==0 \& \mathrm{Bm}==0) \mathrm{Ze}=\mathrm{inf}+\mathrm{j} *$ inf; else $\mathrm{Ze}=1 / \mathrm{Ye}$; end

$\mathrm{Yf}=\mathrm{Y} 2+\mathrm{Ye}$;

$\mathrm{Zf}=1 / Y f ; R f=\operatorname{real}(Z f) ; X f=\operatorname{imag}(Z f)$;

Zin $=Z 1+Z f ;$ Rin $=\operatorname{real}(Z i n) ; X i n=\operatorname{imag}(Z i n)$;

if $(\mathrm{Gc} \sim=0 \mid \mathrm{Bm}) \sim=0$

$\mathrm{Zth}=\mathrm{Z1} * \mathrm{Ze} /(\mathrm{Zl}+\mathrm{Ze})$; 


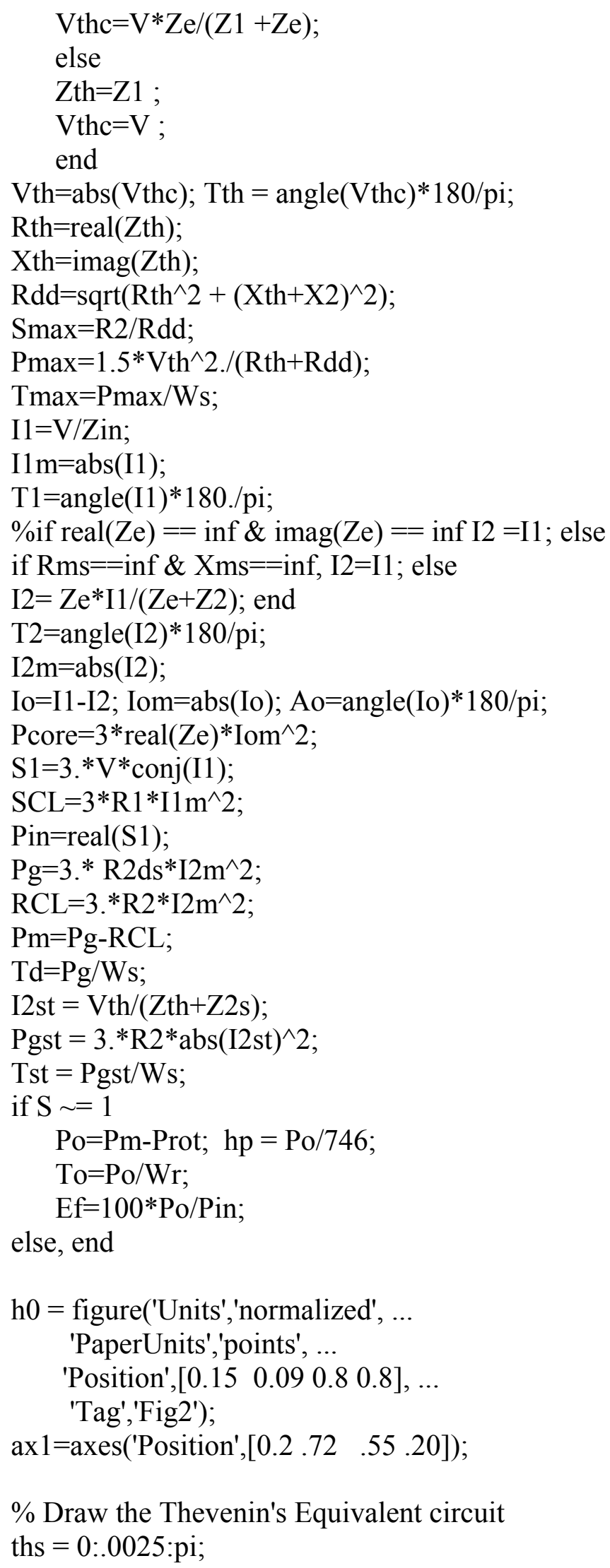




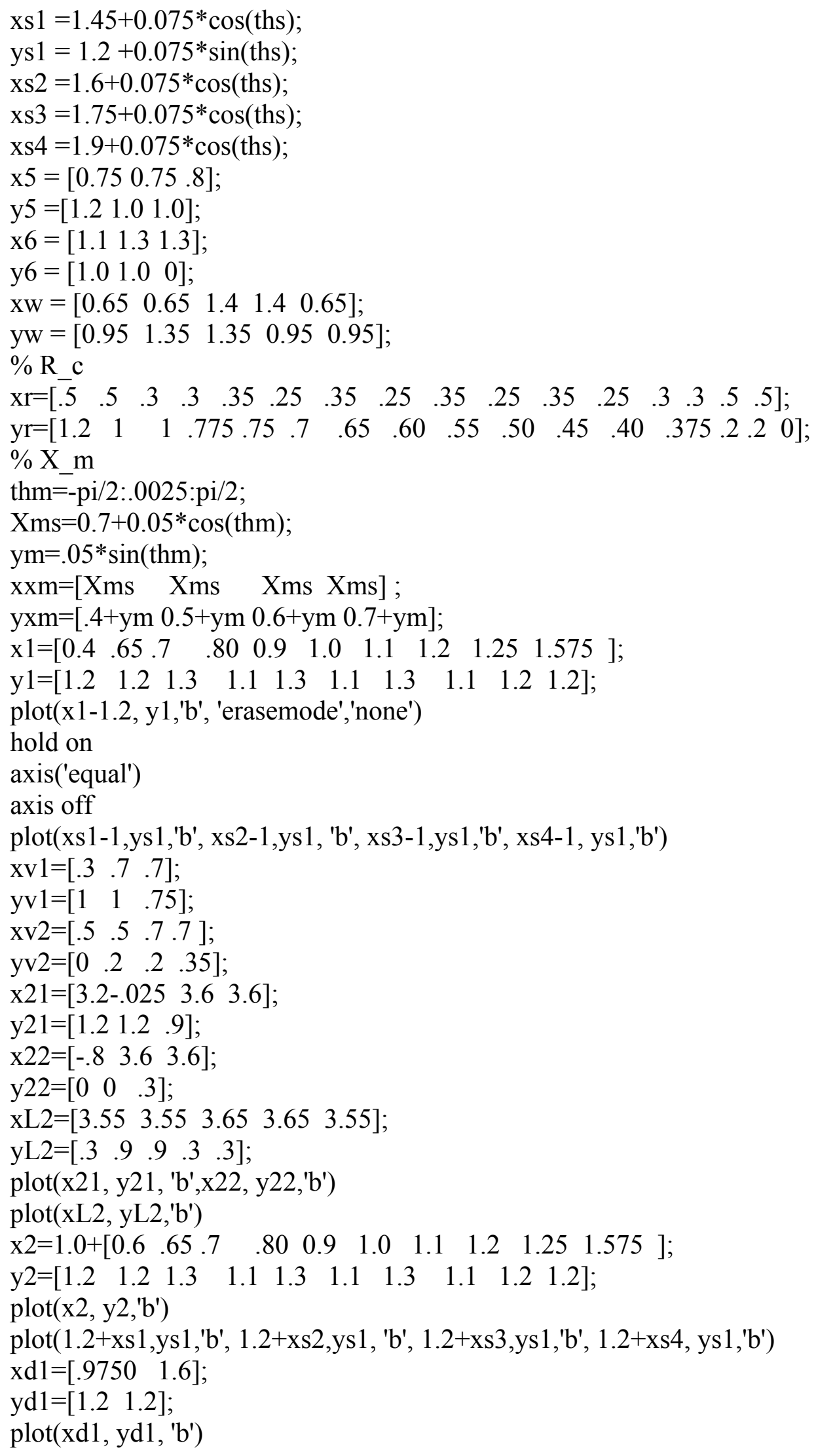


text(-.835,1.1625, 'lcirc', 'color', [0 001$])$

text(-.835,-.0375, '\circ', 'color', [0 01 1])

$\%$ text(1.6, .35, 'jX_\{m\}', 'Fontsize', 10, 'color', [0 00.675$])$

$\%$ text(.9, .35, 'R_\{c $\}$ ', 'Fontsize', 10, 'color', [0 0 .675])

text(-.34, .975, 'R_\{th $\}$ ', 'Fontsize', 10, 'color', [0 0 .675])

text(.6, 1.05, 'jX_\{th\}', 'Fontsize', 10, 'color', [0 0.675$])$

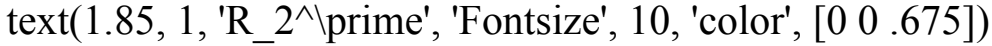

text(2.9, 1.05, 'jX_2\prime', 'Fontsize', 10, 'color', [0 0 .675])

$\%$ text $(5.5, .6$, 'V_ 2 ', 'Fontsize', 10, 'color', [0 00.675$])$

$\%$ text $\left(8.75, .6, \bar{S}_{-}\{\operatorname{Load}\}\right.$ ', 'Fontsize', 10, 'color', [0 0 .675])

text(-.2, -.15, 'Thevenin"s Equivalent Circuit per phase', 'color',[0 0.675$]$ )

text(-.5, 1.4, ['Z_\{th $\}=$ ', num2str(Rth),' + j', num2str(Xth), ' 'Omega'], 'Fontsize', 10, 'color', [ $\left.\left[\begin{array}{lll}1 & 0 & 0\end{array}\right]\right)$

$\operatorname{text}\left(1.7,1.4,\left[{ }^{\prime} Z 2\right\}^{\wedge} \backslash\right.$ prime $=$ ', num2str(R2) ' + j', num2str(abs(X2)), ' $\backslash$ Omega'],

'Fontsize', 10, 'color', [lllll)

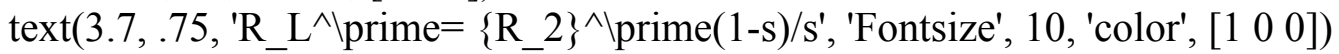

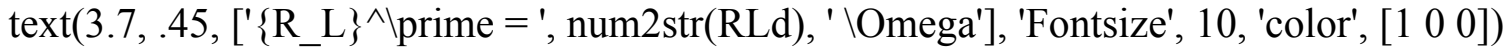

$\operatorname{text}(-1.2, .6,[$ 'V_ $\{$ phi (th) $\}=$ ', num2str(Vth), '\angle', num2str(Tth) ' V'], 'Fontsize', 10, 'color', [ $\left.\left[\begin{array}{lll}1 & 0 & 0\end{array}\right]\right)$

$\% \operatorname{text}\left(2.8,1.4,\left[{ }^{\prime}\left\{\mathrm{I} \_2\right\}^{\wedge} \backslash\right.\right.$ prime = ', num2str(I2), '\angle', num2str(T2), ' A'], 'Fontsize', 10, 'color', [1 100$])$

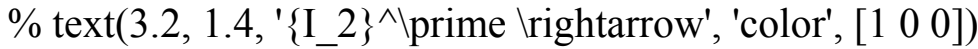

text(-.7, 1.7,['ไbfAnalysis of the Equivalent Circuit at Slip s = ',num2str(S)], 'color', [0 0 $.675])$

hold off

$\%$ Display the results of theequivalent circuit analysis

ax2=axes('Position',[0.05

axis off

hold on

$\%$ uncomment down///

$\% \operatorname{text}\left(0,1.125,\left[\right.\right.$ 'V_ $\{1(\mathrm{LL})\}=$ ', num $2 \mathrm{str}(\mathrm{Vm}), \mathrm{I}^{\mathrm{V}}$ ', 'R_1 = ', num2str(R1), ' $\backslash$ Omega ', 'X_1 = ', num2str(X1), ' 'Omega ',...

$\% \quad$ 'R $2=$ ', num2str(R2), ' $\backslash$ Omega ', 'X_2 = ', num2str(X2), ' $\backslash$ Omega ', 'R_c = ', num2str(Rms), ' \Omega ', ...

$\% \quad$ 'X_m = ', num2str(Xms),' \Omega '], 'Fontsize', 10, 'color', [ $\left.\left.\begin{array}{lll}0 & 0 & 0.77\end{array}\right]\right)$

$\%$ uncomment up ${ }^{\wedge \wedge \wedge \wedge}$

$\operatorname{text}\left(0,1.0,\left[{ }^{\prime}\{\mathrm{I} 2\}^{\wedge} \backslash\right.\right.$ prime $=$ ', num2str(I2m), '\angle', num2str(T2), 'A'], 'Fontsize', 10,'color', [ [ [ 00.77 ); 


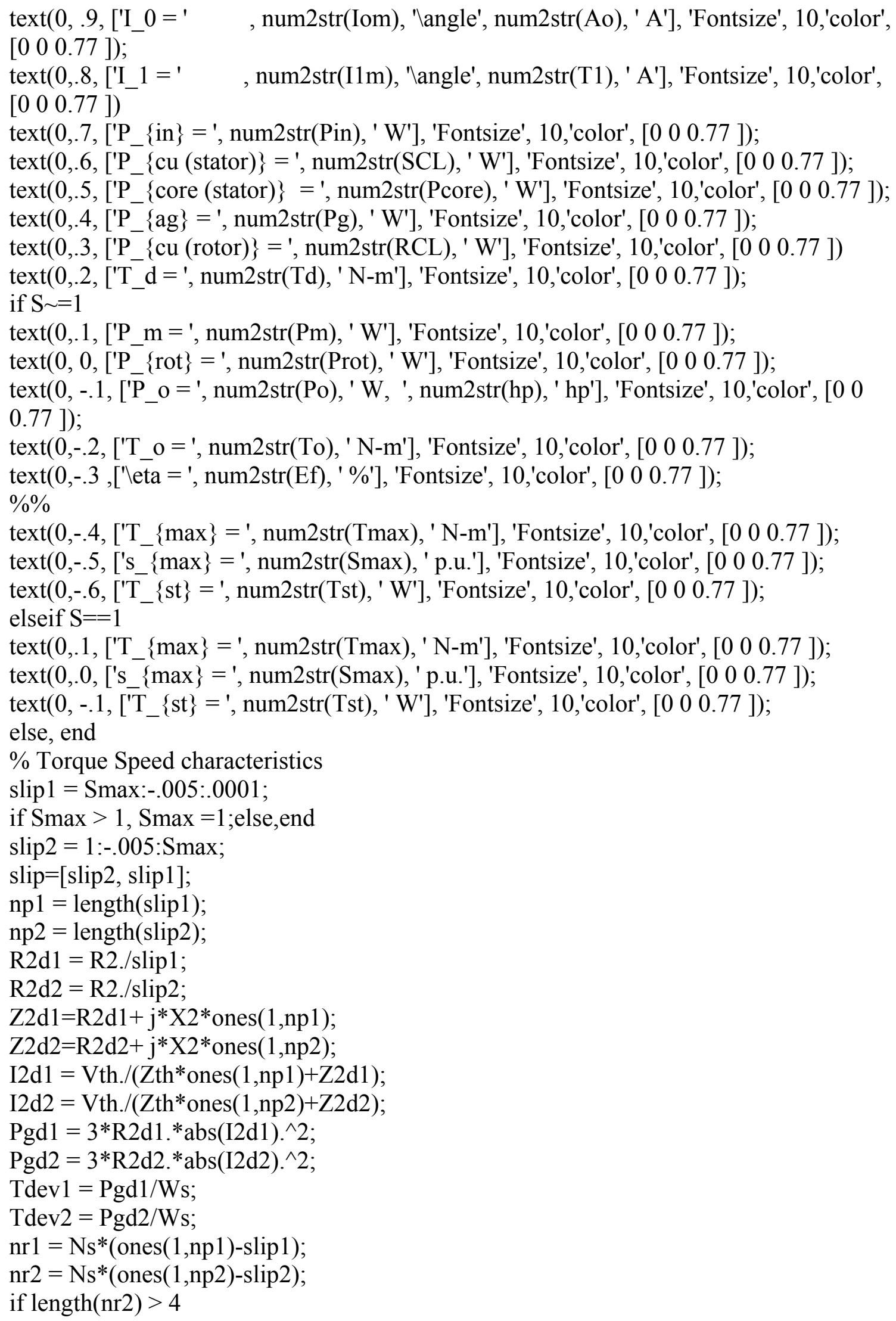




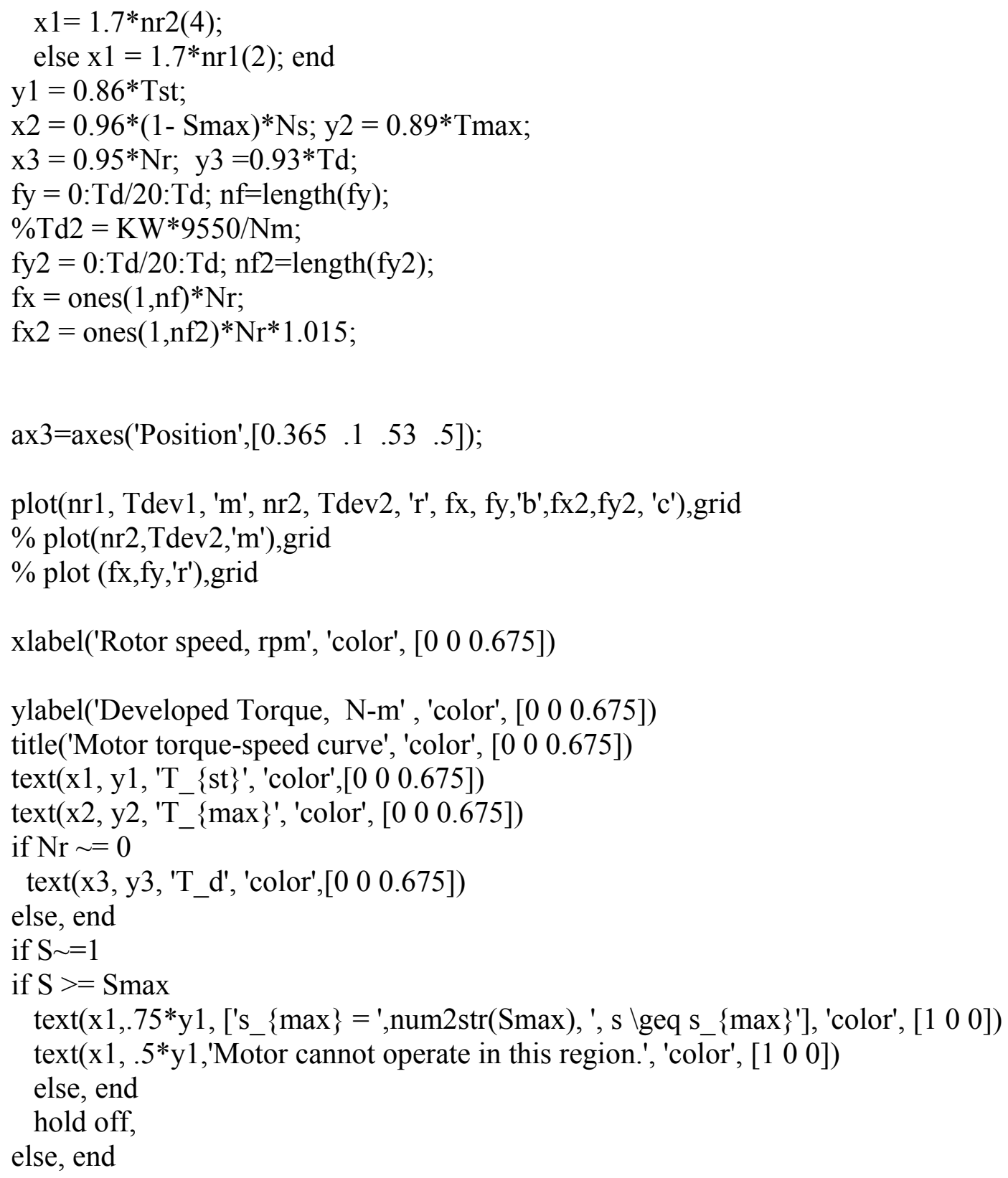

